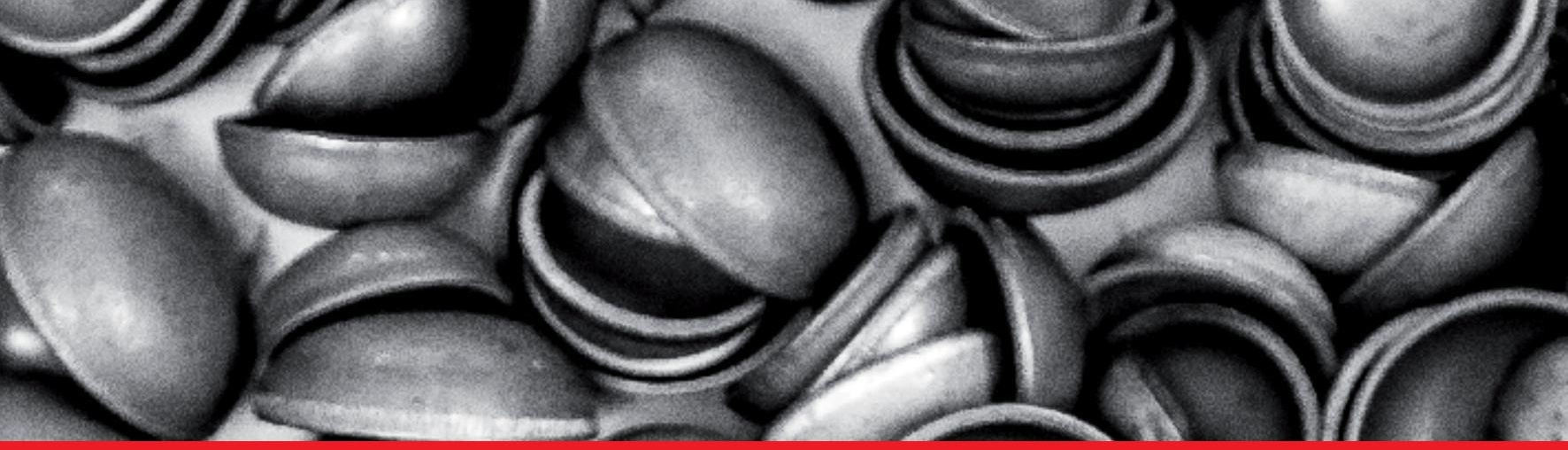

\author{
IntechOpen
}

\title{
Harnessing Knowledge, Innovation and Competence in Engineering of Mission Critical Systems
}

Edited by Ali G. Hessami

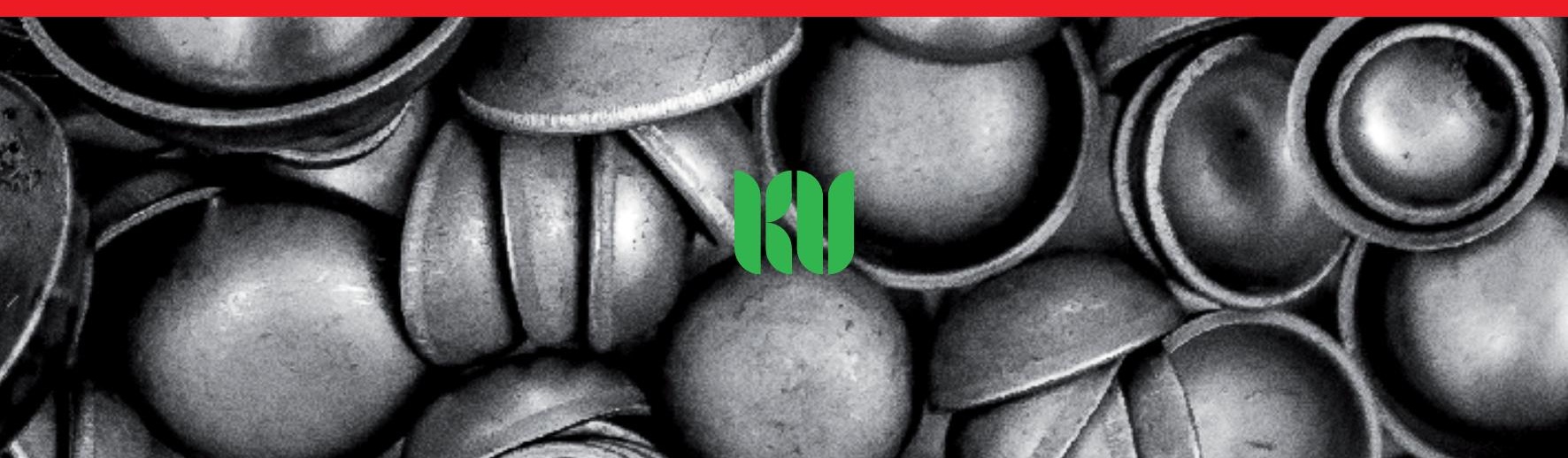



Harnessing Knowledge,

Innovation and

Competence in

Engineering of Mission

Critical Systems

Edited by Ali G. Hessami 

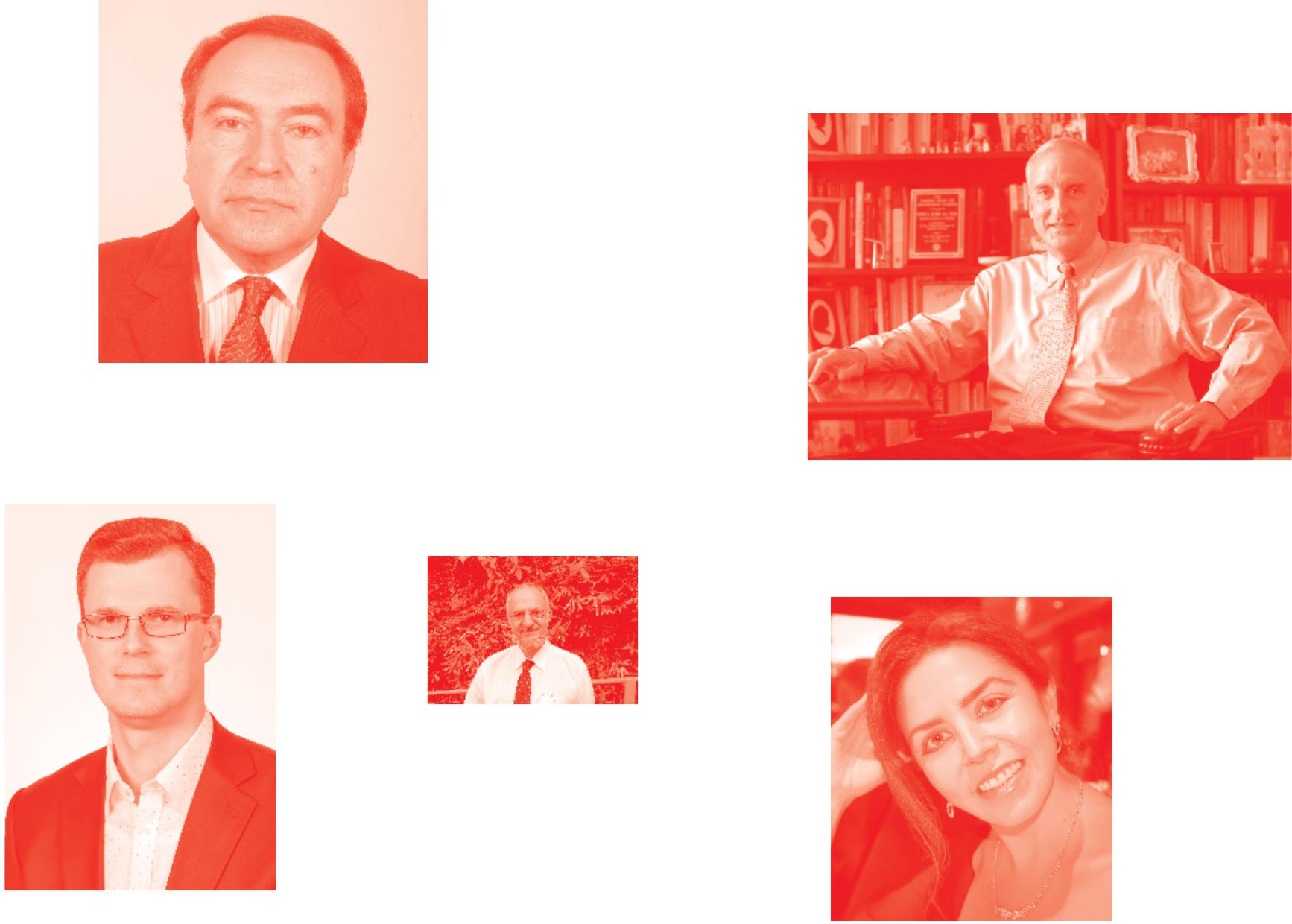

Supporting open minds since 2005
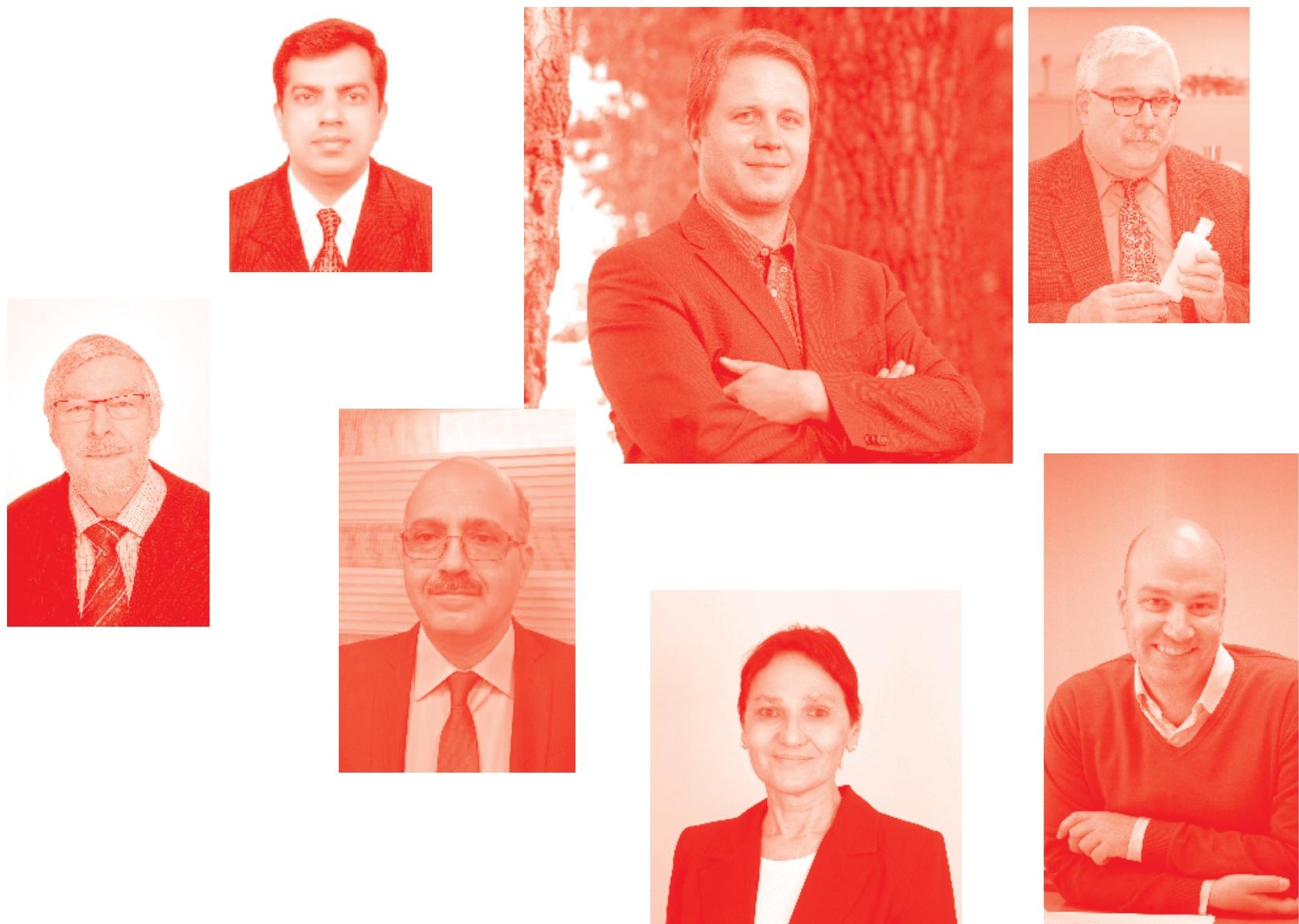
Harnessing Knowledge, Innovation and Competence in Engineering of Mission Critical Systems http : //dx. doi.org/10.5772/intechopen. 81421

Edited by Ali G. Hessami

\section{Contributors}

Stefan Kambiz Behfar, Nikola Vukašinović, Roman Žavbi, Janez Benedičič, Subashini Suresh, Suresh Renukappa, Saeed Al Nabt, Khaled Algahtani, Redouane Sarrakh, Y.P. Tsang, Joseph S. M. Yuen, K. L. Choy, H.Y. Lam, Maurizio Magarini, Giacomo Verticale, Davide Scazzoli, Michael Reiss, Darrell Mann, Farhad Fassihi, Reza Ghaffari, Michael Henshaw, Sofia Ahlberg Pilfold, Ali G. Hessami

( ) The Editor(s) and the Author(s) 2020

The rights of the editor(s) and the author(s) have been asserted in accordance with the Copyright, Designs and Patents Act 1988. All rights to the book as a whole are reserved by INTECHOPEN LIMITED. The book as a whole (compilation) cannot be reproduced, distributed or used for commercial or non-commercial purposes without INTECHOPEN LIMITED's written permission. Enquiries concerning the use of the book should be directed to INTECHOPEN LIMITED rights and permissions department (permissions@intechopen.com).

Violations are liable to prosecution under the governing Copyright Law .

\section{(c)) BY-NC}

Individual chapters of this publication are distributed under the terms of the Creative Commons Attribution - NonCommercial 4.0 International which permits use, distribution and reproduction of the individual chapters for non-commercial purposes, provided the original author(s) and source publication are appropriately acknowledged. More details and guidelines concerning content reuse and adaptation can be found at http : //www . intechopen . com/copyright-policy . html .

\section{Notice}

Statements and opinions expressed in the chapters are these of the individual contributors and not necessarily those of the editors or publisher. No responsibility is accepted for the accuracy of information contained in the published chapters. The publisher assumes no responsibility for any damage or injury to persons or property arising out of the use of any materials, instructions, methods or ideas contained in the book.

First published in London, United Kingdom, 2020 by IntechOpen

IntechOpen is the global imprint of INTECHOPEN LIMITED, registered in England and Wales, registration number: 11086078,7 th floor, 10 Lower Thames Street, London,

EC3R 6AF, United Kingdom

Printed in Croatia

British Library Cataloguing-in-Publication Data

A catalogue record for this book is available from the British Library

Additional hard and PDF copies can be obtained from orders@intechopen.com

Harnessing Knowledge, Innovation and Competence in Engineering of Mission Critical Systems

Edited by Ali G. Hessami

p. cm.

Print ISBN 978-1-78984-109-1

Online ISBN 978-1-78984-110-7

eBook (PDF) ISBN 978-1-78984-467-2

An electronic version of this book is freely available, thanks to the support of libraries working with Knowledge Unlatched. KU is a collaborative initiative designed to make high quality books Open Access for the public good. More information about the initiative and links to the Open Access version can be found at www. knowledgeunlatched. org 


\section{We are IntechOpen, \\ the world's leading publisher of Open Access books}

\section{Built by scientists, for scientists}

\section{$4,600+$}

Open access books available

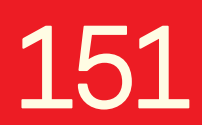

Countries delivered to

\section{$120,000+$}

International authors and editors

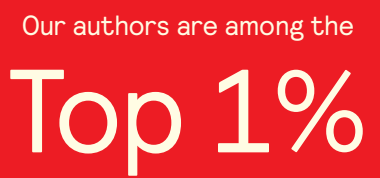

most cited scientists

Contributors from top 500 universities
$135 \mathrm{M}+$

Downloads
1200

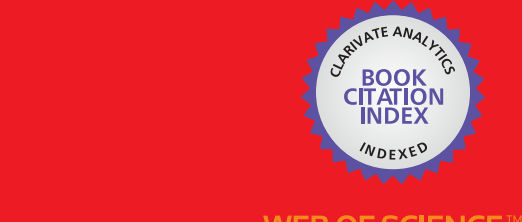

Selection of our books indexed in the Book Citation Index in Web of Science ${ }^{\mathrm{TM}}$ Core Collection (BKCI)

\section{Interested in publishing with us? \\ Contact book.department@intechopen.com}





\section{Meet the editor}

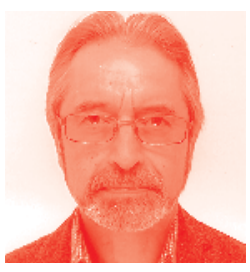

Prof. Ali G. Hessami is the Director of Research and Development and Innovation at Vega Systems, UK. He is an expert in the systems assurance and safety, security, sustainability and knowledge assessment/management methodologies and has a background in design and development of advanced control systems for business and safety critical industrial applications. He is a UK expert at systems safety and security standardization in CENELEC and IEC, chairs the IEEE P7000 Ethics in Technology standard and is the VC of the Ethics Certification Programme at IEEE. Prof. Hessami is a Visiting Professor at London City University's Centre for Systems and Control and at the Beijing Jiaotong University School of Electronics \& Information Engineering. He is also a Fellow of the Royal Society of Arts (FRSA), a Fellow of the UK Institution of Engineering \& Technology (IET), and a Senior Member of IEEE. 



\section{Contents}

Preface

Section 1

Knowledge and Competence Fundamentals

Chapter 1

Introductory Chapter: KM in Mission Critical Environments -

Process vs. People!

by Ali G. Hessami

Chapter 2

Intelligent Systemic/Systematic Innovation and Its Role in Delivering Improvement and Change in the Design of Mission Critical Systems by Farhad Fassihi and Reza Ghaffari

Chapter 3

Evolution of Communication Skills in Virtual Product Development Process: Experience From EGPR

by Nikola Vukašinović, Janez Benedičič and Roman Žavbi

\section{Section 2}

KM a Key Success Driver

Chapter 4

Systems Engineering as an Essential Organizational Competence for Knowing and Innovating

by Michael Henshaw and Sofia Ahlberg Pilfold

Chapter 5

An ISM Approach to Evaluate Critical Success Factors for Knowledge Management in the Kingdom of Saudi Arabia

by Suresh Renukappa, Subashini Suresh, Saeed Al Nabt, Redouane Sarrakh and Khaled Algahtani

Chapter 6

Importance of Social Networks for Knowledge Sharing and the Impact of Collaboration on Network Innovation in Online Communities by Stefan K. Behfar 
Section 3

KM, Mission Critical Applications

Chapter 7

Knowledge Redundancy Cycles in Complex Mission-Critical Systems by Darrell Mann

Chapter 8

Simplexity: A Hybrid Framework for Managing System Complexity by Michael Reiss

Chapter 9

Redundancy and Synchronisation Management in Mission- and

Time-Critical Wireless Sensor Networks

by Davide Scazzoli, Maurizio Magarini and Giacomo Verticale

Chapter 10

Harnessing IoT Data and Knowledge in Smart Manufacturing

by Joseph Shun Ming Yuen, King Lun Choy, Yung Po Tsang and Hoi Yan Lam 


\section{Preface}

This book was conceived to inform the decision makers and practitioners about the best practice in KM pertinent to many disciplines and sectors. It explores the critical role of acquisition, formalisation, application, reuse/enhancement, and management of knowledge and human competence in the context of the largely data/information dominated modern world. Whilst humanity owes much of its achievements to the distinct capability to learn from observation, analyse data, gain insights, and perceive beyond original realities, the systematic treatment of knowledge as a core capability and driver of success has largely remained the forte of pedagogy.

The chapters fall into three categories to guide the readers to gain insight from generic fundamentals to discipline-specific case studies and the latest practices in knowledge and competence management. The three broad categories comprise:

1. Knowledge and Competence Fundamentals;

2. KM a Key Success Driver;

3. KM, Mission Critical Applications.

In an increasingly intertwined global community faced with existential challenges and risks, the significance of knowledge creation, innovation, and systematic understanding and treatment of human competence is likely to be humanity's greatest weapon against the formidable adversity.

For sharing their knowledge, their rofessional stance, hard efforts, and diligence in reviewing and implementing the proposed enhancements to their manuscript, I would like to thank all authors who have contributed to this book. We have also incorporated reviewer's recommendations and the book is much improved as a consequence.

Special thanks goes to Marijana Francetic (Author Service Manager) for her dedicated support in the submission and reviewing process and her suggestions for further improvement. Finally, all thanks to IntechOpen for publishing this book.

Ali G. Hessami

Professor, Innovation Director,

Vega Systems, London, UK 

Section 1

\section{Knowledge and Competence Fundamentals}





\title{
Introductory Chapter: KM in Mission Critical Environments - Process vs. People!
}

\author{
Ali G. Hessami
}

\section{Introduction}

\subsection{Safety}

Safety is regarded as freedom from unacceptable risk of harm to humans and is the focus of much regulation and standardisation. Prevention of harm to people is therefore a moral as well as a legal issue; however, increasing complexity in modern products and systems poses a major challenge to the assurance of safety in mission critical systems.

\subsection{Security}

Unlike safety that is purely human focused, security is regarded as freedom from unacceptable risk of harm to people, loss to business and property or the natural environment. Unlike safety, security is characterised by malicious intent within the cyber, physical and organisational context and as yet not generally regulated. However, in the same manner as safety, assurance of security of complex products and services is another major challenge in mission critical systems.

\subsection{Environmental conformity}

Since the dawn of industrial revolution, the scale of mankind's influence on the natural habitat has increased significantly. The assurance of environment in complex products, systems and services is now regulated and under the protection of laws and government agencies. Respect for life and environment now constitutes another dimension of concern in any mission critical endeavour.

\subsection{Synergies}

The systemic and systematic identification, assessment and mitigation of safety, security, environmental and business risk issues under an integrated framework render enhanced integrity whilst posing significant savings in costs and time. In this setting, we explore the significant roles of the human agents and the application of pertinent knowledge to underpin success in a mission critical environment. 


\section{The human impact}

Given the role of the human agents and the pervasive interconnectedness and complexity of most modern products, processes and systems, we propose a radical shift of emphasis from hardware, software, products, systems and process/testing to the human attributes and operations that conceive, design, develop and deploy complex products and services.

The foremost contemporary management visionaries have labelled today's global economy as one in transition towards a "knowledge economy". During and post transition, knowledge resources such as know-how, expertise and innovation will increasingly be regarded as critical economic resources.

We refer to the totality of the abilities, know-how and attributes that empower people to successfully and consistently perform duties assigned under a role as competence. Competence is defined by the European Commission as the capacity to use effectively experience, knowledge and qualifications. A competent person would achieve the desired outcomes consistently, efficiently, every time or more often than not, satisfying or exceeding the expectations of the clients over varying circumstances. In this spirit, competency is the overall ability to generate success, satisfaction, value and excellence from the application of knowledge.

The systematic acquisition, assessment, development and management of competence pose a challenge beyond the traditional education, training appraisals and curriculum vitae. This is particularly pertinent in safety and mission critical roles where much rests on the performance of those tasked with specifying, developing, managing, deploying, operating or supervising an entire project, operation or mission. To this end, some new industry standards have emphasised the assurance of people competence, an emerging sensitivity that is bound to spread to many other facets of technological and service sectors.

There's a need for a new systemic vision in this arena. This paper develops and proposes a systems framework for ensuring the right entities are tasked with the critical roles in the overall life cycle of a complex system to enhance confidence and trust in the desirable properties such as safety and security. It describes the emerging competence requirements in European standards on software and hardware/ system safety and provides a framework for compliance principally aimed at safety and integrity assurance.

\section{Competence}

The European Guide to Good Practice in Knowledge Management [1] defines competence as an appropriate blend of knowledge, experience and motivational factors that enable a person to perform a task successfully. In this context, competence is the ability to perform a task correctly, efficiently and consistently to a high quality, under varying conditions, to the satisfaction of the end client. This is a much more demanding portfolio of talents and capabilities than successful application of knowledge. So a competent person is much more than a knowledge worker. Competency may also be attributed to a group or a team when a task is performed by more than one person in view of the multi-disciplinary nature, complexity or the scale. A competent person or team require a number of requisite qualities and capabilities as follows:

1. The domain knowledge empirical, scientific or a blend of both.

2. The experience of application (knowing what works) in different contexts and the requisite skills. 
3. The drive, motivation to achieve the goals and strive for betterment/excellence as well as appropriate behaviours such as teamwork, leadership, compliance with professional codes, etc.

4. The ability to adapt to changing circumstances and demands by creating new know-how.

5. The ability to perform the requisite tasks efficiently and minimise wastage of physical and virtual resources.

6. The ability to sense what is desired and consistently deliver a high quality to the satisfaction of the end client(s).

The right blend of these abilities renders a person or group of people (a team) competent in that they would achieve the desired outcomes consistently, efficiently, every time or more often than not, satisfying or exceeding the expectations of the clients over varying circumstances. Such persons/groups will be recognised for their mastery of the discipline and not just considered a fount of relevant knowledge often characterised by qualifications. In this spirit, competence is the ability to generate success, satisfaction, value and excellence from the application of knowledge and know-how.

The Business Dictionary [2] defines competence as a cluster of related abilities, commitments, knowledge and skills that enable a person (or an organisation) to act effectively in a job or situation. It further states that competence indicates sufficiency of knowledge and skills that enable someone to act in a wide variety of situations. Because each level of responsibility has its own requirements, competence can occur in any period of a person's life or at any stage of his or her career. With reference to the legal profession, the dictionary defines competence as the capacity of a person to understand a situation and to act reasonably. The disputes regarding the competence of an individual are settled by a judge and not by a professional (such as a doctor or a psychiatrist) although the judge may seek expert opinion before delivering at a judgment.

In the context of UK's Managing Health and Safety in Construction (CDM Regulations) [3], the Health and Safety Executive (HSE) elaborates on the necessity for competence as follows:

To be competent an organisation or individual must have:

\section{Sufficient knowledge of the tasks to be undertaken and the risks involved}

2. The experience and ability to carry out their duties in relation to the project, to recognise their limitations and take appropriate action to prevent harm to those carrying out construction work or those affected by the work

The HSE further maintains that competence develops over time. Individuals develop their competence through a mix of initial training, on-the-job learning, instruction, assessment and formal qualification. In the early stages of training and experience, individuals should be closely supervised. As competence develops, the need for direct supervision should be reduced. If you are engaging a person or organisation to carry out construction work for you, then you need to make a reasonable judgement of their competence based on evidence. The evidence will usually be supplied to you by the person or organisation quoting or bidding for the work. There are many industry card schemes which can help in judging competence. However, the possession of a card by an individual is only 
one indication of competence. You are expected to make efforts to establish what qualifications and experience the cardholder has.

\section{Recent developments}

Given the six facets of competence elaborated earlier, the acquisition, assessment, development and management of competence poses a challenge beyond the traditional education and curriculum vitae. Whilst a blend of all six facets is a prerequisite for competency and mastery in a given discipline, the significance of each is highly dependent on the context and requirements of a given domain. Whilst theoretical knowledge plays a more significant role in abstract scenarios such as research, experience of application, adaptability and creativity may become more prominent in other domains. Whichever the domain however, a systems framework for the understanding, characterisation, evaluation, development and enhancement of competence is called for. This by necessity comprises two interdependent frameworks [4], one focused on characterisation, evaluation and assessment and the other on the management of competence in a given context.

The matters of competence and relevance of the deployed human resource to the requirements of mission and safety critical tasks have always been recognised but not been explicitly formalised until recently. The European Standard for Safety Critical Software $[5,11,12]$ in the rail sector is potentially the first to recognise and formalise human competence requirements in the context of high-integrity software development for railway applications. The tables in Annex B of the standard have 10 normative role specifications in the development of high-integrity software for safety applications as follows:

\section{B.1: Software Requirements Manager}

B.2: Software Designer

B.3: Software Implementer

B.4: Software Tester

B.5: Software Verifier

B.6: Software Integrator

B.7: Software Validator

B.8: Software Assessor

B.9: Software Project Manager

\section{B.10: Software Configuration Manager}

For each one of the above roles, a template based on the UML class for the role is developed to describe the minimum competence requirements in terms of attributes (qualities) and operations (key activities and responsibilities) in the development and deployment of safety critical software. Whilst these appear simplistic and potentially inadequate, the significance of recognising and incorporating human characteristics in a traditionally process only standard $[5,11]$ cannot be over-stated. In this respect, the competence requirements in the safety critical software standard are just a start and a foundation for more elaborations!

In principle, many of the normative software roles are generic and can be modified and applied to hardware, subsystem and system aspects. In a complex and safety critical project, it is beneficial if not necessary to adopt a systematic approach 
to characterising, assessing and managing competence in the key roles since, as a minimum, these will be required for subsystem- and system-level software developers where a fair proportion of the change will originate from. To this end, a Competence Assessment and Management System (CAMS) is an essential aspect of a credible strategy within the context of a safety critical programme.

\section{Compliance versus competence: balance}

What counts as competence can vary between organisations because of the balance required between the need for competence and the observation of, and compliance to, the rules/standards or processes. If the supplier's competence management system (CMS) differs to that of the client's, then delays in demonstrating acceptability of the supplier's CMS can occur. It is pertinent to note that the delivery organisation and client's individual competencies may differ due to differences in the tasks to be performed.

No two projects are the same, and where it is important to use the company's standard governance, safety management system (SMS) $[13,14,16]$ and associated CMS, it is vital that each is reviewed and potentially adapted/tailored for each new project. The project documentation will declare which aspects of the governance systems are to be used (smaller projects do not necessarily require all aspects-some skill sets may need to be enhanced to meet specific requirements of a project).

The delivery scope of supply of the new ventures must be mapped in detail for the lifecycle of a project. The project organisation needs to align with the project hierarchical structure to ensure that the project can be delivered through all phases. The project competence management plan should also be reviewed to take account of any new contractual requirements (client standards, local legislation, task-based and/or functional environment, etc.) that can impact on competency requirements.

Roles and responsibilities for each post within a project organisation have to be defined (iterative process based on tasks to be performed) with defined departmental boundaries.

The competency desired proficiency level matrix (technical, time-related experience, behavioural and task-based) skills per role needs to be reviewed for each project to ensure suitability. The delivery scope of supply of a new venture must be mapped in detail for the lifecycle of the project.

The project competency management plan should be developed/reviewed to take account of any new contractual requirements (client standards, local legislation, task-based and/or functional environment, etc.); any can impact on competency requirements. Roles and responsibilities for each post within the project organisation have to be defined (iterative process based on tasks to be performed) with defined departmental boundaries. The competency desired proficiency level matrix (technical, time-related experience, behavioural and task-based) skills per role needs to be reviewed for each project to ensure suitability and best fit.

\section{Competence assessment and management: a systems approach}

Given the six facets of competence elaborated earlier, the acquisition, assessment, development and management of competence pose a challenge beyond the traditional education and curriculum vitae. Whilst a blend of all six facets is a prerequisite for competency and mastery in a given discipline, the significance of each is highly dependent on the context and requirements of a given domain. Whilst 
theoretical knowledge plays a more significant role in abstract scenarios, experience of application, adaptability and creativity may become more prominent in other domains. Whatever the domain however, a systems framework for the evaluation, development and enhancement of competence is called for. This by necessity comprises two interdependent frameworks, one focused on evaluation and assessment and the other on the management of competence.

\subsection{Assessment of competence}

The competence assessment framework provides an integrated perspective on competence in a given context whilst additionally empowering the duty holders or the organisation to benchmark each aspect, measure, assess and where necessary take actions to enhance various elements in the framework. This is illustrated in the Weighted Factors Analysis [6] (WeFA) schema of Figure 1. The latter aspects of benchmarking, evaluating, assessing and potentially enhancing competence are inherent in the underpinning WeFA methodology [7] and not elaborated here. The schema details are omitted and elaborated in the subsequent section.

The determination, benchmarking, evaluation and quantified performance assessment of six drivers and three inhibitor goals in the above WeFA schema is carried out as follows.

\subsubsection{Driver goals}

The requisite "domain knowledge and understanding" in a given context as depicted in the driver Goal 1 (G1) is broadly supported by relevant industry's skill/ competence frameworks. There are a number of such frameworks in use largely within various engineering disciplines in the United Kingdom, for example, OSCEng [8], IRSE [9] and IET [10]. Given the poor state of attention to competence and systematic approaches to its recognition, evaluation and assessment internationally, United Kingdom appears amongst the leading proponents globally.

The composition and extent of "skill and relevant experience" in a given context as depicted in the driver Goal 2 (G2) in the assessment framework is supported by subsequent decomposition of G2 into lower-level WeFA structures, the so-called level 2 and level 3 goals. This principally helps determine the driver and inhibitor goals for the higher-level goal, the domain experience.

The requisite "psychophysical factors and behaviours" in a given context as depicted in the driver Goal 3 (G3) in the framework is supported by subsequent decomposition of G3 into lower-level WeFA structures in WeFA. This principally

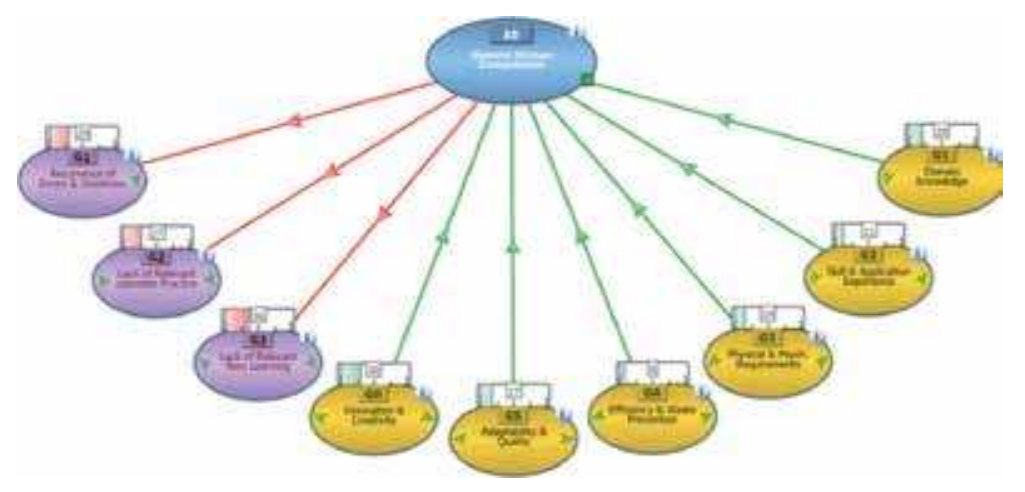

Figure 1.

The systemic competence assessment framework. 
helps determine the driver and inhibitor goals for motivational, behavioural and drive aspects.

The essential determinants of "efficiency and waste minimisation" in carrying out tasks in a given context as depicted in the driver Goal 4 (G4) in the framework is supported by subsequent decomposition of G4 into lower-level WeFA structures that drive or inhibit this goal.

The key determinants of "quality, excellence and consistency" in carrying out tasks in a given context as depicted in the driver Goal 5 (G5) in the framework is supported by subsequent decomposition of G5 into lower-level WeFA structures, drivers and inhibitors, respectively.

Finally, the degree of "adaptability, innovation and creativity" in a given context as depicted in the driver Goal 6 (G6) in the framework is supported by subsequent decomposition of G5 into lower-level factors relevant to this focus.

Given the hierarchical nature of WeFA schema, the so-called level 1 goals in the proposed individual competence assurance system are generic and universal. The decomposition of these goals into appropriate drivers and inhibitors in levels 2 and beyond will help tailor the generic model towards specific requirements of a given role in a given context. The driver and inhibitor goals in levels 2 and below in a competence role schema denote the specific measurable predictors for generic level 1 goals such as knowledge, experience, etc.

Once a role is completely characterised through decomposition of the generic model (level 1) into a number of predictors (levels 2 and below), the schema is subsequently weighted by the same expert panel that have helped with the development of the schema. This assigns relative significance to the factors in the schema, thus rendering it compatible with the values, preferences and possibly culturally driven norms within the application environment. A calibrated schema is then reviewed, enhanced and validated for general application within the context of use. In an automated environment, a validated/authorised schema can be assigned to every member of staff in a given role, enabling them to evaluate themselves against the criteria and develop a competence profile to establish the areas in need of further development.

\subsubsection{Inhibitor goals}

The key aspects and the extent of "lack or inadequacy of relevant new learning" in a given context of application as depicted in the inhibitor Goal 1 (G1) in the proposed framework are supported by subsequent decomposition of G1 into lower-level WeFA structures, the so-called level 2 and level 3 drivers and inhibitors in WeFA.

The key predictors and the extent of the "absence or inadequacy of relevant practice" in a given context as depicted in the inhibitor Goal 2 (G2) in the framework are supported by subsequent decomposition of G2 into lower-level WeFA structures.

Finally, the degree of "recurrent errors and violations" in a given context as depicted in the inhibitor Goal 3 (G3) in the framework is supported by subsequent decomposition of G3 into specific predictors of these behaviours and outcomes in the schema.

A suitably developed and validated WeFA schema for competence assessment in a given role, context and/or domain additionally requires a measurement scale for each goal (driver or inhibitor) as well the weights, i.e. the strengths of influence(s) from each goal on higher-level goals. Once established, the weighted framework lends itself to application for assessment and management of individual's or groups' competence in fulfilling tasks in the particular context as depicted by 
the framework. This would render a number of advanced features and benefits, namely:

- Up to five levels of competence typically comprising apprentice, technician, practitioner, expert and leader in a given role/domain

- Identification of the gaps and training/experience/mentoring requirements

- A consistent and systematic regime for continual assessment and enhancement

It should be noted that assessment here is devised and intended as a tool in the service of systematic approach to staff capability/talent development and should not be misconstrued as an adversarial instrument for classification of people in an organisation.

\subsection{Management of competence}

The deliverables of the engineering process applied to the creation and realisation of parts, products, systems or processes often follow a life cycle from concept to decommissioning as popularised by engineering standards typically comprising as follows:

1. Concept and feasibility

2. Specification and design

3. Development

4. Commissioning

5. Deployment and operation

\section{Maintenance and retrofit}

\section{Decommissioning}

In this spirit, the human resource involvement/employment within an engineering environment, organisation or project likewise follows a life cycle comprising seven key phases essential to the systematic and focused management of knowledge, namely:

1. Proactivity: comprises corporate policy, leadership, mission, objectives, planning, quality assurance and commitments to competency and service delivery for the whole organisation;

2. Architecting and profiling: comprises specification and development of a corporate structure aligned with the strategy and policy objectives together with the definition of roles and capabilities to fulfil these;

3. Placement: essentially involves advertising and attracting candidates matching the role profiles/requirements involving search, selection and induction. Selection relates to deriving role-focused criteria and relevant tests to assist with the systematic assessment, scoring and appointment tasks. Induction involves 
a period of briefing, familiarisation and possibly training, the extent of which is determined by the familiarity and competence of the individual concerned and the complexity and novelty of the role;

4. Deployment and empowerment: involves a holistic description depicting the scope of the responsibility, accountability and technical/managerial tasks associated with a specific role and empowering the individual to fulfil the demands of the role. This would include training, supervision, coaching, resourcing, delineation of requisite authority and accountabilities, mentoring and potential certification as means to empowerment for achievement and development.

5. Appraisal: involves the planning and setting performance objectives and identification of the performance indicators/predictors synergistic to the demands of a role and the individual's domain knowledge, aimed at ensuring all relevant and periphery aspects of the role are adequately addressed and the necessary provisions are made for learning where a need is identified. The evaluation and appraisal provide the necessary feedback on compliance with individual and organisational objectives and achievement, enabling the organisation to identify and reward good performance and develop remedial solutions where necessary.

6. Organisation and culture: involves clarification of role relationships and communications, support, reward and motivational aspects for competency development including requisite resources and learning processes for attaining the policy objectives. This is intended to develop and foster a caring and sensitive approach/culture nurturing talents and paving the way towards an innovating organisation.

7. Continual development and progression: this comprises identifying the synergistic aspects which may serve as a complementary and rewarding extension to individuals'/teams' specific roles. Development may involve managerial, technical and support functions or an appropriate blend of duties at the whole life cycle level or extensions to the role-specific activities and vision/ career paths above an existing role into other parts of an organisation and even beyond. The review and assessment of success in all the principles inherent in the framework also fall within the continual development principle.

The seven focal areas/principles constitute a systematic competency management framework. It is worth noting however that employment and project/product

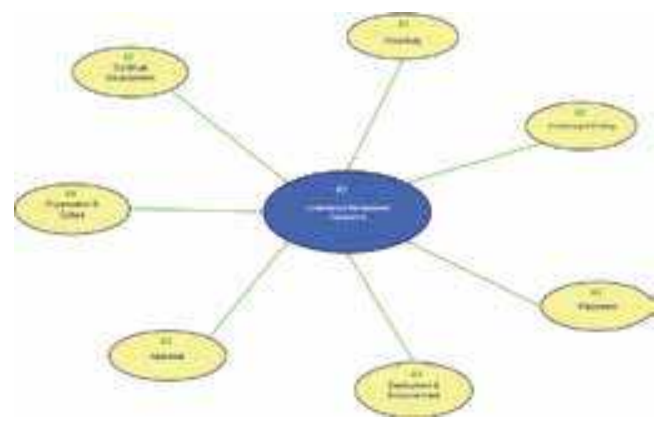

Figure 2.

The systemic competence management framework. 
life cycles are orthogonal in that securing the requisite human resource and competence for any phase of an engineering production activity would potentially involve all the seven phases of the competence management.

The systematic framework for management of competence is depicted in the WeFA schema of Figure 2. Note that the two frameworks for assessment and management of competence are interrelated and complementary. Whilst assessment focuses on the individual and/or the team in terms of performance, the management framework addresses broader issues relating to the corporate's policy and a nurturing environment to foster competency development, [15] talent and innovation as an embedded culture, thus creating a sustainable business/service provision.

\section{Competence: the way forward}

The traditional process-based prescriptive rules and standards [5] have served the industry over a century where product and system complexities were generally low permitting good design and sufficient testing to ensure integrity of products, processes and systems. The pervasive complexities arising from adoption of new ICT technologies have necessitated a continuous approach to assurance throughout the life cycle as advocated by modern standards. This is now the accepted norm in most safety and mission critical applications and industries.

Alas, the significance and role of the human agent has been largely ignored so far on the unfounded assumption that a recipe given to any capable and qualified person will ensure quality and integrity of the outcomes. With the ever-increasing embedded knowledge contents in most products, processes and systems, the necessity to focus on the source of such knowledge creation, the humans, and their fitness for the task in hand is now gaining momentum. In the face of such realisation and demands, our capacity to understand, characterise and evaluate human capabilities and latent potential has lagged significantly behind other technological advances.

We posit that human competence should be regarded as an integral facet of assuring designs, products and services especially those with safety, security, sustainability or mission critical profile $[17,18]$. The continual assurance processes advocated by modern standards need to complemented with focus on human competence to face the modern challenges of high risks and ever-increasing complexity. The framework offered uses systems thinking to address assessment and management of competence within a coherent solution for enhancing quality, safety and reliability and assuring integrity.

\section{Acknowledgements}

Contributions from Andy Mallendar in the discussions and some facets of this introductory chapter are hereby gratefully acknowledged. 
Introductory Chapter: KM in Mission Critical Environments - Process vs. People! DOI: http://dx.doi.org/10.5772/intechopen.90260

\section{Author details}

Ali G. Hessami

Innovation Director, Vega Systems, London, UK

*Address all correspondence to: hessami@vegaglobalsystems.com

\section{IntechOpen}

(C) 2020 The Author(s). Licensee IntechOpen. Distributed under the terms of the Creative Commons Attribution - NonCommercial 4.0 License (https://creativecommons.org/ licenses/by-nc/4.0/), which permits use, distribution and reproduction for non-commercial purposes, provided the original is properly cited. (cc) BY-NC 


\section{References}

[1] European Guide to Good Practice in Knowledge Management, Work Item 5: Culture Working Draft 6.0, CEN-ISSS; 2003. Available from: https://ec.europa. eu/digital-single-market/en/news/ cen-workshop-knowledge-management

[2] Available from: http://www. businessdictionary.com/definition/ competence.html

[3] Managing Health and Safety in Construction, Construction (Design and Management) Regulations. Guidance on Regulations. HSE Books. 2015. ISBN: 978071766626 3. Available from: http://www.hse.gov.uk/pubns/ priced/1153.pdf

[4] +Safe Version 1.2, A Safety Extension to CMMi-DEV Version 1.2, TECHNICAL NOTE CMU/SEI-2007-TN-006

Defence Materials Organisation, Australian Department of Defence; Mar 2007. Available from: https:// resources.sei.cmu.edu/asset_files/ TechnicalNote/2007_004_001_14816.pdf

[5] BS EN 50128:2011, Railway applications. Communications, signalling and processing systems. Software for railway control and protection systems. ISBN: 978-0-580-62768-2

[6] Hessami A. Safety assurance, a systems paradigm, hazard prevention. Journal of System Safety Society. 1999;35(3):8-13

[7] Hessami A, Gray R. Creativity, the Final Frontier? In: The 3rd. European Conference on Knowledge Management ECKM 2002, Trinity College Dublin; 2002

[8] OSCEng. The Occupational Standards Council for Engineering Publishes Occupational Standards for Engineering and Manufacturing. 2006. Available from: www.osceng.co.uk
[9] IRSE. Institution of Railway Signal Engineers Licensing Scheme. 2007.

Available from: www.irselicences.co.uk

[10] IET. Competence FrameworkAssessing Competence. UK: The Institution of Engineering and Technology; 2007. Available from: www.theiet.org/careers/cpd/ competences

[11] BS EN 50128:2001, Railway applications. Communications, signalling and processing systems. Software for railway control and protection systems. BSI. ISBN: 978-0-580-86207-6

[12] BS ISO/IEC/IEEE 15288:2015, Systems and software engineering System life cycle processes ISO/IEC. IEEE; 2015. Available from: https:// www.iso.org/obp/ui/\#iso:std:iso-iecieee:15288:ed-1:v1:en

\section{[13] BS EN 50129:2018, Railway} applications. Communication, signalling and processing systems. Safety related electronic systems for signalling. BSI Standards. ISBN: 978-0-580-93810-8

[14] Hessami AG. A systems framework for safety \& securityThe holistic paradigm. Systems Engineering Journal USA. 2004;7(2):105-107

[15] Guedes Soares C, editor. Safety and Reliability of Industrial Products, Systems and Structures. CRC Press; 2010. pp. 21-31. ISBN: 978-0-415-66392-2. Available from: https://www.crcpress. com/

[16] Managing competence for safetyrelated systems, Part 1: Key guidance. Health and Safety Executive; 2007. Available from: http://www.hse.gov.uk/ humanfactors/topics/mancomppt1.pdf 
Introductory Chapter: KM in Mission Critical Environments - Process vs. People! DOI: http://dx.doi.org/10.5772/intechopen.90260

[17] Railway Safety Principles and Guidance: Part 3 Section A, Developing and Maintaining Staff Competence HSG197 HSE Books; 2002. ISBN: 0-7176-1732-7.3

[18] ORR. Developing and maintaining staff competence Railway Safety Publication; 1 Nov 2016. Available from: https://orr.gov.uk/_data/assets/ pdf_file/0016/4264/developing-andmaintaining-staff-competence-rsp1.pdf 



\title{
Intelligent Systemic/Systematic Innovation and Its Role in Delivering Improvement and Change in the Design of Mission Critical Systems
}

\author{
Farhad Fassihi and Reza Ghaffari
}

\begin{abstract}
Mission critical systems (MCS) are complex nested hierarchies of systems, subsystems and components with defined purpose, characteristics, boundaries and interfaces, working in harmony to deliver vital organisational functionalities. Upgrading MCS performance is inevitable when capability enhancement is required or new technologies emerge. Improving MCS however is considered with certain degrees of reluctance due to their sensitive role in organisations and the potential disruptive impact of unexpected consequences of change. Innovation in MCS often appears in small steps that affect the entire system due to their highly interdependent structures. Effective management of innovation introduction in complex systems require systemic/systematic processes that involve process management and collective analysis, scoping, decision-making and R\&D which relies on effective information sharing. This approach should run throughout the system and must include all aspects and stakeholders, utilising the skills and knowledge of all involved. This chapter describes the basic concepts and potential approaches that could be utilised to build intelligent systemic/systematic and collaborative environments for MCS innovation. Advances in ICT technologies provide an opportunity to access the wider sphere of knowledge and support the systemic innovation processes. Adopting systemic approaches increases process efficacy, leading to more reliable solutions, shorter development lead times and reduced costs.
\end{abstract}

Keywords: innovation, systems, ICT, collaboration, machine learning

\section{Introduction}

Mission critical systems (MCS) are systems whose performance is fundamental to continued operation or even survival of businesses or organisations. Failure of MCS can have catastrophic consequences for the businesses/organisations and their clients. Examples of MCS can be taken from a wide spectrum of systems: from sensitive defence systems, public services such as utilities to those supporting banking infrastructure and financial transactions. Even systems that facilitate smooth operation of many small businesses such as taxi companies are MCS where their 
integrity affects the livelihood of business owners and employees and is instrumental in providing satisfactory service to their clients.

A significant characteristic of MCS is their reliability and resilience which is necessary due to their critical role in operational integrity. Other attributes considered in the design of MCS is modularity and redundancy. Hazard/crisis/disaster mitigation and recovery are also common in MCS. Another important factor is cost. By nature, such systems tend to be complicated interrelated structures where time, effort and money have to be spent in the validation of their compliance which can introduce heavy burdens during their development and testing.

Advances in technology present new opportunities to upgrade and modernise every system and solution including MCS. Whilst innovation tends to find its way into every man-made system, the penetration rate of new technology and new innovation is much lower when it comes to MCS. This is primarily due to the time and effort required for their validation and assurance of operational reliability. The common wisdom seems to be in favour of relying on older proven technology than taking on new developments and its associated costs and risk of unexpected failure that may arise when introducing new systems. Almost all existing MCS solutions utilise computers, both hardware and software, where complete validation of response in all circumstances is extremely difficult if not impossible. This is not just a theoretical concern but borne from realities with many examples to prove the case.

The Royal Bank of Scotland's (RBS) systems failure in 2012 which resulted from upgrading the payment processing software and the more recent failure of Visa card processing in 2018 which resulted from the partial hardware failure in one of the switches in their data centre are clear examples of why there is a reluctance in upgrading MCS. This problem is not limited to banks and is applicable to many other areas. The recent report in 2017 that the HMS Queen Elizabeth, Britain's largest ever warship, relied on Windows XP for some of its functionalities highlights the same underlying concerns that has led to a situation where nearly two decades after the retirement of the XP platform by Microsoft, it is still operationally utilised in a highly sensitive defence platform.

The occurrence of such failures, although may be used by some as the reason to prolong reliance on older technology, is a clear example as why it is necessary to address this issue. The fact that RBS and Visa (and many other examples like it) found it necessary to introduce new innovative upgrades to their system is a proof that upgrading and introduction of new technology is inevitable. By the same token, the outcome highlights the potential consequences of getting it wrong. In the case of the HMS Queen Elizabeth, cyber security threats and the vulnerabilities of the Microsoft Windows XP system have already raised concerns about the wisdom of its continued utilisation. It is likely that this situation is subjected to reviews which could result in its retirement (if it has not already happened).

This clearly demonstrates that it is not the change that is problematic but the approach to change. Decisions about change to any system especially the MCS should not be taken lightly for the reasons highlighted above. This is a management decision that must determine the time and process for introduction of new innovation.

Different organisations have different strategies to deal with this problem whether they are active in the development of MCS or not. These strategies are influenced by two important factors of criticality of the system and the significance of innovation in the organisation's prevalent culture.

At the lowest level, when system performance begins to lag, it is usually the indication of the need to change and time to consider new innovative elements/ solutions to maintain the system's relevance. This often means that change is becoming inevitable and has to be seriously considered. Delays in facing such issues could have serious consequences for the organisation. 
Another possible indicator of the need for change is the technology backdrop and emergence of new technologies. For example, when smartphone manufacturers start releasing 5G mobile technology, it is no longer viable for service providers to drag their heels and rely on satisfactorily performing $4 \mathrm{G}$ platforms. Customer demands will eventually make its impact and customers vote with their feet, if the new solution is not introduced.

Progressive innovating companies often have innovation departments who are actively involved in developing new innovative technologies relevant to their business whilst scanning the horizon for any new development that can be applied to their business. Some even afford their staff free time to pursue their innovative ideas that may not even be related to their sphere of work.

It is important to highlight the importance of being proactive in search for and introduction of new innovation in all systems including MCS applications. This is likely to reduce cost and maintain control well before systems become obsolete.

Once the time for change has been established, capability upgrades and application of innovation in its realisation must be handled with great care and with consideration of the likely impact, consequence and costs of potential changes. Consideration should be given to all areas, especially technology capability and maturity, and applicable to all changes from small steps (localised improvements) or overall system capability enhancements through system overhaul.

Organisations' management philosophy and strategy is usually set according to vision of its founders. At the same time, this philosophy has a direct relationship with the application area and the market place for its products and services.

\section{MCS design and development}

Design and development of MCS require much more stringent levels of project management compared to their noncritical applications. Key considerations in MCS design, development and innovation have the following characteristics:

\subsection{Leadership}

Strong process control through effective leadership is a necessity when it comes to development and successful delivery of MCS.

\subsection{Objectives}

Clear definition of objectives is key in developments of MCS applications. This should define every aspect of the project from scoping, requirement planning, capability provision as well as business objectives that includes budgeting and delivery schedules.

\subsection{System architecture/construction plan}

Suitable system architecture that considers modularity in design is particularly important in MCS as it allows small step/localised innovation. This is because most innovations in critical infrastructure are introduced in small steps.

\subsection{Availability and redundancy}

MCS applications by definition need to be available and, in many cases, need to have $100 \%$ uptime. When criticality levels demand, systems must be designed 
with redundant elements to ensure uninterrupted service availability. Firms are constantly trying to improve the availability of their critical services, with many targeting 'five nines' uptime (i.e. 5.26 minutes downtime per year).

\subsection{Resilience}

MCS application must safeguard its users against failure. Failure may be due to system design/performance, changes in operation, human error and information integrity or malicious interventions. A detailed assessment of all potential pitfalls to ensure resilience must be covered at the earliest possible stage in the design process. Highly resilient systems are usually designed without any single point of failures (SPOFs). In MCSs with no SPOFs, a failure of a module, system component or site will not halt the entire operational function. Achieving such levels of resiliency often requires a relatively large investment of time and effort in the design phase of the project.

\subsection{Disaster mitigation/recovery planning}

Despite all the hard work put into design and development of MCS, on rare occasions system failure can occur. Clear investigation of risks and structured planning ensures a clear vision about potential risks and their mitigation. Consideration and implementation of disaster response, either automatic or manual, through clear procedures for dealing with unexpected circumstances is a key requirement. Such considerations must be catered for during the design stage.

\subsection{Transition state}

Another factor that must be carefully considered and managed, especially when upgrading systems through innovation, is management of the implementation process and its likely impact on system availability and performance. This may be the main barrier that affects some of the more frequently utilised approaches to system improvements and upgrades.

With this brief introduction, it is not difficult to conclude that intelligent systemic/systematic innovation in MCS is essentially a management problem with technical dimensions. This process consists of two key constituent strategic elements: a specific process for introduction of innovation and change including identification of the right components for change and a mechanism for choosing the right time for its introduction. Such strategies are often based on balancing clients/market needs, demands, expectations and/or trends with the technology horizon from one hand and commercial priorities for the business on the other. No doubt, the same level of scrutiny required in design and development of MCS is also applicable to its upgrade and initiation of new innovation.

\section{Intelligent systemic/systematic innovation in MCSs}

At this stage it is necessary to mention that although the scope of this review is expressed as a general guide to field practitioners, the increased frequency and widespread application of computers in modern MCS solutions has skewed this bias. Reliance on computer hardware and software in critical management and control has shifted the focus onto MCS solutions that rely on computers as a key element of their design and composition. This covers almost all contemporary MCS systems that control and manage present-day critical application areas. 
Furthermore, the proposed process is not suggested as a replacement for the current knowledge, expertise and practice in design of the mission critical systems but an extra supplement to be utilised by field practitioners to support early introduction of new technology innovation in the existing MCS applications.

It was demonstrated that when considering introduction of changes and upgrades, especially concerning MCS solutions, what is not in question is the inevitability of system enhancement/innovation but the timing and the approach to it. The answers to questions of 'When is it time to heed to demands for improved services?' or 'Until when will the existing arrangements remain viable?' or 'When is the current system no longer viable or serve their intended purpose?' are at the heart of decision-making process about the timing of introduction of innovation and therefore essential to be answered. Furthermore, even when the need to change is established, there remains another question as to how this improvement should be best conducted.

One of the most relevant tools created that can answer such questions and help achieve objectives of MCS system designers is the systems theory and its branches of systems' thinking and engineering. Systemic and systematic approaches to development of innovative solutions have been utilised in many areas, providing structured paths for creation of new solutions especially when the objectives relate to large and complex multidisciplinary projects. Systematic approach demands a disciplined process and introduces organised development roadmaps. It primarily focuses attention onto key objectives and considers their delivery through an assured path. Systemic approach however guides the process through detailed and exhaustive strategies that ensure all eventualities and circumstances are covered to enhance confidence in delivering reliability in performance and operational resilience. Whilst most if not all developments follow the systematic path, all MCS should adopt the systemic approach due to their sensitive nature.

The thesis followed in the presentation of the arguments of this chapter is to address the above two critical questions and propose new approaches that could be utilised in innovation and functionality enhancement in MCS.

Systems approach to new development is well established and covers every aspect of projects, ranging from prospecting, scoping, planning, design, testing, evaluation, etc. What has not been sufficiently considered in the relevant literature is establishment of a mechanism to signal the potential opportunity or time for change based on market (demand) and technology trends. Decisions about potential directions/choice of new emerging technologies for implementation, target system elements as well as appropriate timing are amongst important questions whose answer could put an end to overreliance on old technologies and deprive users of MCS from reliable and up-to-date service.

Another management dilemma is the approach required to embed innovation within the systematic and systemic MCS design process. Creating a framework that carves a separate track for systemic innovation as part of the design process should create a vehicle for delivering much needed progress.

The hypothesis and the proposed solution explained in this chapter is about developing new systemic methods that can help in a more regular development and adoption of system enhancements leading to continued performance of MCS solutions in line with new technology advances. The proposed approach has two key aspects: first, a collaborative development environment built on systemic innovation principles and next, deployment of artificial intelligence (AI) in the process and creation of intelligent agents that can support users' and developers' objectives. 


\section{Artificial intelligence: a systemic support tool}

In view of the proposed inclusion of AI in this approach as a supporting tool, it is necessary to highlight few points for clarity.

Whilst application of $\mathrm{AI}$ and its capabilities is a proven reality, $\mathrm{AI}$ is somewhat controversial. A recent report broadcast by BBC [1] that reported a machine capable of accurately predicting the decisions of the European Court of Justice $79 \%$ of the time leaves little doubt about the potential capabilities of intelligent machines.

The capabilities of applying AI in utilising available data-generated social networks in political manipulation have already been established and roundly condemned for its potential abuse. Whilst no one yet suggests that judges in European court should be replaced by computers anytime soon, the ability of AI and machine learning in support of making quick decisions in times of crisis is well established. The possibility of analysing data and literature to locate hard-to-find information and intelligent systems' potential in analysing multiple scenarios, predicting the likely outcomes and the degree of confidence in predicted results, are capabilities that can be taken advantage of, as part of the MCS development and its life cycle.

\subsection{AI in MCSs}

MCSs by nature are complex systems with multiple internal and external dependencies. Different parts of the system (both primaries and secondaries) are often designed and developed by multiple external vendors. In general, the focus of MCS designers is not on cost but often on preserving life, nature or the business [2, 3]. Rigorous recovery requirements are imposed on the system as future existence may be at stake in case of delayed or incomplete recovery.

Geographically dispersed teams often contribute to the MCS project. Documentation and user manuals can be in multiple languages and styles. Many legacy MCSs often lack proper documentation and disaster recovery plans. They might use obsolete product/software with limited or no third-party support and maintenance. Managing all these complexities in any noncritical system is proven to be challenging to say the least. The challenge, however, would be even greater when dealing with multiple MCSs.

In MCS, agility in response and service uptime are the key constraints [4]. The system has a very concise and clear set of requirements [5]. The system should always act in deterministic fashion based on the requirements and nothing more. The problem occurs when stochastic bottlenecks disturb the normal operation of the system. This introduction of chaos into an orderly operation of the system requires immediate attention and response. Similar to an open-heart surgery, one would not be able to shut down the entire system (the patient's heart in this case) in order to fix a problem. Instead, the system needs to be maintained, fixed or replaced with minimum downtime ( $\sim 5$ minutes a year in $99.999 \%$ SLAs) or sometime without any downtime at all.

During the past 60 years, many frameworks [6-8], procedures $[4,9]$ and systems [10] were created to support designing [11] and managing the complexities of the MCSs. These efforts have had major effects on improving the three aspects of MCSs: reliability, resiliency and recovery. In the next section, the authors explore three aspects of MCSs which can benefit from AI and machine learning algorithms which have previously gained less attention in the literature.

\subsection{AI for MCSs rapid adaptation to risk and immediate response}

Assume that an MCS system, SystemX, is responsible for orchestrating a series of autonomous delivery vehicles and road infrastructure. A major failure occurs in 
the system on Monday morning around 02:00 AM. The monitoring systems failed to alert the shift staff in the control centre. Calls were made to the customer facing team with reports of autonomous vehicle failures. The customer facing team aggregated the data and once a certain threshold was met escalated the call to the technical team. The technical team congregated the extra information by checking the logs and sending out a field engineer to the geographical locations with the reports of failure. The team managed to revive the system by 9:30 AM on Monday morning. By 10:30 AM, official press release was published on the company's website and social network platforms with minimal information about the actual root causes of the problem. The latter, simply because such information was not available at the time. Social media, however, started an online outrage with scandalous reports. This has resulted in decline of the company's share prices when the stock markets opened later on that afternoon. There is also evidence of damage to the company's reputation/brand. The company has managed to deal with the technical problem and reinstate the services based on their well-structured disaster recovery plans. The technical team addressed the issue in the most efficient and effective manner. After a few days, it emerged that the failure was due to a planned software upgrade of a noncritical component of the MCS. The senior managers dealt with the public side of the issue making sure that the end-user's expectations were managed properly and any potential consequences were mitigated. Two important questions come to mind: (1) What are the unexpected consequences of the failure? (2) Could the company have prevented the nontechnical consequences of the failure or at least responded to them more appropriately to reduce the overall damage?

The current disaster recovery plans are mostly designed to deal with the problem at hand in the shortest amount of time. This makes sense as during the time of disaster, the highest priority should be dedicated to save lives/nature, minimise the damage and restore the operation completely. However, service interruptions often come with a series of expected and unexpected consequences. The real consequences of an event are hard to predict as there are many socioeconomic factors involved. They will often manifest in the form of loss of customers, reputation, share prices or general trust in the brand/services. In the worst-case scenarios, the failure may be detrimental to public safety in the years to come (e.g. the BP Gulf of Mexico oil spill in 2010). Rebuilding trust in the service/system and rectifying secondary issues, although possible, is a costly exercise and can potentially take months/years. AI and machine learning can be utilised in such scenarios to minimise the consequences.

Most of the well-designed MCSs come with an extensive set of monitoring and alert systems [12]. They are designed to gather data from a series of sources such as physical sensors, software/application activities, public resources and user feedback. The data is gathered, aggregated and presented to the technical teams. They will then act on the presented data reactively. This is useful to make sure that the disaster/failure is captured and fixed as soon as possible. This is sufficient to deal with the problem at hand and will also extend to rectifying any expected chain of consequences (i.e. taking care of external connected services, compensation and recovery, etc.). It is evident that the process is very much reactive.

The real value of the MCS related data can be unleashed using machine learning algorithms $[13,14]$. Prediction and anomaly detection algorithms can run silently in the background going through millions of lines of sensory data. They can also go through the public information/census on the MCS of the interest [15]. The algorithms are capable of predicting how markets or the public would react to a specific event/disaster related to the target MCS. They can also outline the potential unexpected consequences of a certain event by looking at historical data. Such algorithms will be able to provide timely recommendations on what needs 
to happen next in the very early/crucial period of incident also known as golden minutes. During this time all efforts are focused on resolving the problem at hand. Going back to our earlier scenario, SystemX, an intelligent system would be able to conduct the following tasks while the technical team are busy fixing the problem:

1. Predict the time that it would take for an event to trend on social media and publish proactive notifications.

2. Predict the changes in the stock market value of the company so precautions can be made to minimise damage.

3. Predict the public reaction based on similar types of failures in the past.

4. Predict the potential chain of events based on previous evidence so they can be prevented earlier.

This intelligent tool would be an extension to the existing processes to enable rapid response to failures and early mitigation of the future risks.

\subsection{AI, MCSs and critical regions (CR)}

There are certain components/areas in the MCS that are categorised as a critical region. A CR is the beating heart of the MCS. Similar to SPOFs, its failure is highly likely to result in a major disruption in the whole system. A single MCS is comprised of multiple CRs. The CRs are often indicated and documented during the design phase. They are closely monitored at all times by sensors or human/software examination. They are maintained carefully and replaced on regular basis. As the system evolves, it becomes harder to identify or track new CRs. Every system in its life cycle goes through extensions, replacements and overhauls. During such processes new/ undetected CR may occur. Machine learning algorithms can analyse historical logs to identify minor failures in the system and investigate the overall impact of the failure on the entire system. The AI-enabled tool can eventually recommend new CRs in the system that might have been unnoticed in the past. Referring to our SystemX example, the incident may have been preventable if the system upgrade had already been identified and flagged as a CR.

\subsection{AI, MCS and lessons learned}

Once failures are dealt with and resolved, teams often document what, where and when things went wrong, the underlying causes and the lessons learned. Learning from failure is the key factor in making sure that similar issues will not occur in the future. Many industries work with the policy of transparency and noblame culture to make sure that entities share their failures so that others can learn from their experiences. One example is the aviation industry in which airlines are obliged to report failures and incidents to prevent them from happening again.

Extracting knowledge from previous incidents is a convoluted process and often touches only the surface of the issues. In our SystemX scenario, the incident may have been preventable if previous upgrade-related issues were flagged and described in fine detail to the technical teams. Online communities and forums are overwhelmed by description of member experiences of various problems, issues or system failures and mitigating advice based on member expertise and experience. It is hard to find an issue which has not been experienced by someone else in another related or unrelated field. It is, however, an impossible job for a human to aggregate 
the available public information before conducting a task. Machine learning algorithms such as deep learning can help. Deep learning is a machine learning technique that does what comes naturally to humans: learn by example. They can find relationships between independent information trying to find patterns of interest. Deep learning algorithms can go through the private and public incident reports to reveal valuable information which is hidden from unsuspecting human eyes. In some cases, it can even exceed expert-level performance. Let us revisit our SystemX example; the intelligent tool could have been consulted prior to the software upgrade to identify if any failures occurred during performing a structurally similar task, albeit in a different industrial domain, sometimes in the past, highlighting the underlying causes and consequences of its occurrence. This could have surely been of value to the management and technical teams in charge of planning modifications or upgrades.

\section{Conclusion}

What worries scholars and the public is the prospect of machines making decisions that are usually taken by humans which requires application of morality and ethical standards. It is this aspect that creates ethical dilemmas and the moral conundrums, to the extent that leading philosophers and thinkers, no less than the late Stephen Hawking, have raised concerns and recommended caution.

The intelligent algorithms do not need to replace humans but can in fact go hand in hand with them to extend human capabilities. This is particularly valuable in the case of MCS. The AI-enabled tools do not need to take control, but they can surely utilise the available data to provide and present the bigger picture to help decisionmakers. This allows humans to focus their efforts on what matters in MCSs: reliability, resilience and recovery. Preventions and dealing with consequences can be delegated to the AI-enabled tools.

What is suggested here in this context is not placing machines at the centre of decision-making process and replacing humans but using them to provide decision support networks that inform system designers. What is covered in the course of this chapter is a new approach to disrupt the development of MCS and to harness knowledge, competence and capabilities in augmenting the performance of MCS and assist in their continued development and modernisation. What has also been acknowledged and recommended is mindfulness about the ethical and moral standards that should be applied in decision-making process during the various stages of design, development and operational phases whilst considering exploitation of such technologies. 


\section{Author details}

Farhad Fassihi ${ }^{1 *}$ and Reza Ghaffari ${ }^{2}$

1 GEP TEC Ltd., Loughborough, UK

2 Deloitte, Welwyn Garden City, UK

*Address all correspondence to: farhad@geptec.co.uk

\section{IntechOpen}

(C) 2020 The Author(s). Licensee IntechOpen. Distributed under the terms of the Creative Commons Attribution - NonCommercial 4.0 License (https://creativecommons.org/ licenses/by-nc/4.0/), which permits use, distribution and reproduction for non-commercial purposes, provided the original is properly cited. (cc) BY-NC 
Intelligent Systemic/Systematic Innovation and Its Role in Delivering Improvement and Change... DOI: $h$ ttp://dx.doi.org/10.5772/intechopen.89840

\section{References}

[1] BBC. Could AI replace judges and lawyers? 2016 October 24. Available from: https://www.bbc.co.uk/news/ av/technology-37749697/could-aireplace-judges-and-lawyers [Accessed: 24/10/2016]

[2] Fowler K. Mission-critical and safety-critical development. IEEE Instrumentation and Measurement Magazine. 2004;7(4):52-59

[3] Bozzano M, Villafiorita A. Design and Safety Assessment of Critical Systems. New York: Auerbach Publications; 2010. DOI: 10.1201/ b10094

[4] Perraju TS, Rana SP, Sarkar SP. Specifying fault tolerance in mission critical systems. In: Proceedings. IEEE High-Assurance Systems Engineering Workshop (Cat. No.96TB100076). Canada: Niagara on the Lake, Ontario; 1996. pp. 24-31. DOI: $10.1109 /$ HASE.1996.618557

[5] Ponsard C et al. Early verification and validation of mission critical systems. Formal Methods in System Design. 2007;30(3):233

[6] Houliotis K, Oikonomidis P, Charchalakis P, Stipidis E. Missioncritical systems design framework. Advances in Science, Technology and Engineering Systems Journal. 2018;3:128-137. DOI: 10.25046/aj030215

[7] Carrozza G, Pietrantuono R, Russo S. A software quality framework for large-scale Mission-critical systems engineering. Information and Software Technology. 2018;102:100-116. DOI: 10.1016/j.infsof.2018.05.009

[8] Dasarathy B et al. Network QoS assurance in a multi-layer adaptive resource management scheme for mission-critical applications using the
CORBA middleware framework. In: 11th IEEE Real Time and Embedded Technology and Applications Symposium. San Francisco, CA: USA; 2005. pp. 246-255

[9] Banerjee A, Venkatasubramanian KK, Mukherjee T, Gupta SKS. Ensuring safety, security, and sustainability of Mission-critical cyber-physical systems. Proceedings of the IEEE. 2011;100(1):283-299. DOI: 10.1109/ JPROC.2011.2165689

[10] Liu J, Chou PH, Bagherzadeh N, Kurdahi F. Power-aware scheduling under timing constraints for missioncritical embedded systems. In: Proceedings of the 38th Annual Design Automation Conference. ACM; 2001. pp. $840-845$

[11] Ponsard C, Massonet $P$, Rifaut A, Molderez JF, van Lamsweerde A, Van HT. Early verification and validation of mission critical systems. Electronic Notes in Theoretical Computer Science. 2005;133:237-254

[12] Gill CD et al. Applying adaptive real-time middleware to address grand challenges of COTS-based mission-critical real-time systems. In: Proceedings of the 1st IEEE International Workshop on Real-Time Mission-Critical Systems: Grand Challenge Problems. 1999

[13] Challagulla VUB et al. Empirical assessment of machine learning based software defect prediction techniques. International Journal on Artificial Intelligence Tools. 2008;17(02):389-400

[14] Weinand A et al. Application of machine learning for channel-based message authentication in mission critical machine type communication. In: European Wireless 2017; 23rd 
European Wireless Conference. VDE;

2017

[15] Stolfo SJ et al. Data mining-based intrusion detectors: An overview of the Columbia IDS project. SIGMOD Record. 2001;30(4):5-14 


\title{
Evolution of Communication Skills in Virtual Product Development Process: Experience From EGPR
}

\author{
Nikola Vukašinović, Janez Benedičič and Roman Žavbi
}

\begin{abstract}
More than a decade of continuous international collaboration of several European universities in teaching new product development in virtual environment gives unique opportunity to investigate evolution and development of communication techniques for NPD collaboration in virtual environment. This chapter provides theoretical and practical view on different aspects: technical evolution of ICT tools, development and fostering of communication flow, personal aspects of IT communication, with important emphasis on building of trust within virtual teams. The reader can extract from this chapter guidelines for work in collaborative virtual environment, to run effectively either small projects, meetings and lectures or even more complex projects, distributed among several dislocated teams. The chronological overview of the continuous virtual communication in the last 15 years gives also fair suggestions about future evolution for the next decade.
\end{abstract}

Keywords: virtual development, new product development, IT communication, virtual team, collaborative virtual environment, project

\section{Introduction}

New product development (NPD) is a demanding and complex activity as it is, and its level of difficulty is additionally increased by the ever-changing business environment, primarily by functional association of geographically dispersed multicultural human resources [1-5].

A virtual team is an organisational unit potentially capable to perform NPD within actual business environment [6]. A virtual team is a group of geographically dispersed people who interact through interdependent tasks guided by a common purpose with the support of information and communication technology $[7,8]$. They showed several advantages compared to centralised local teams, e.g., easier recruitment of best professionals globally, without the need for their physical relocation, better organisational flexibility or the ability to perform relay product development process by distributing and handing over the tasks to teams in different time zones [9-11].

In a virtual development team (but also in collocated teams), good communication is needed for trust building [12], since trust is a prerequisite of the knowledge 
exchange, creativity and performance of virtual teams. Faulty or inadequate verbal and non-verbal information exchange hampers team creativity, leads to frustration, misunderstanding and even to conflicts among team members [13]. Therefore, one of the key challenges of virtual teams is effective communication [14].

Sivasubramaniam et al. [15] found that internal communication, external communication, group cohesiveness and goal clarity (as team process variables) are paramount for the success of NPD team. Internal communication refers to frequency and openness of information exchange among team members, while external communication refers to the degree of information exchange with people outside the team and taking advantage of external resources. Group cohesiveness refers to level of interpersonal bonds. Group cohesiveness is more influential in case of intense and interconnected activities, as is the case of NPD. Goal clarity refers to the goal consensus within NPD team. It has been shown that specific and challenging goals are superior to ambiguous and easy goals [6].

In this chapter we will give the overview on evolution of ICT tools and protocols that were used from the very beginning of EGPR course in 2001 when videoconferencing systems were only scarcely used in academic environment, particularly and even less commonly for regular lectures and courses that take place in virtual world until the year 2015, when the era of MOOCs, open access video lectures and ubiquity of information dominate the academic world.

EGPR teams are hybrid teams, since their sub-teams are sometimes colocated and have even common history from other projects during study period. Nevertheless, all the EGPR teams are taken into consideration as they were completely virtual.

\section{Theoretical underpinnings}

Verbal communication delivers only a part of meaning, while the rest is conveyed as, e.g., posture, facial expressions (i.e. body language), voice intonation, pauses etc. These factors make communication a complex social process [13].

In general, communication involves a feedback loop between the sender of a message and its recipient (Figure 1) $[12,16]$. Non-verbal communication, such as

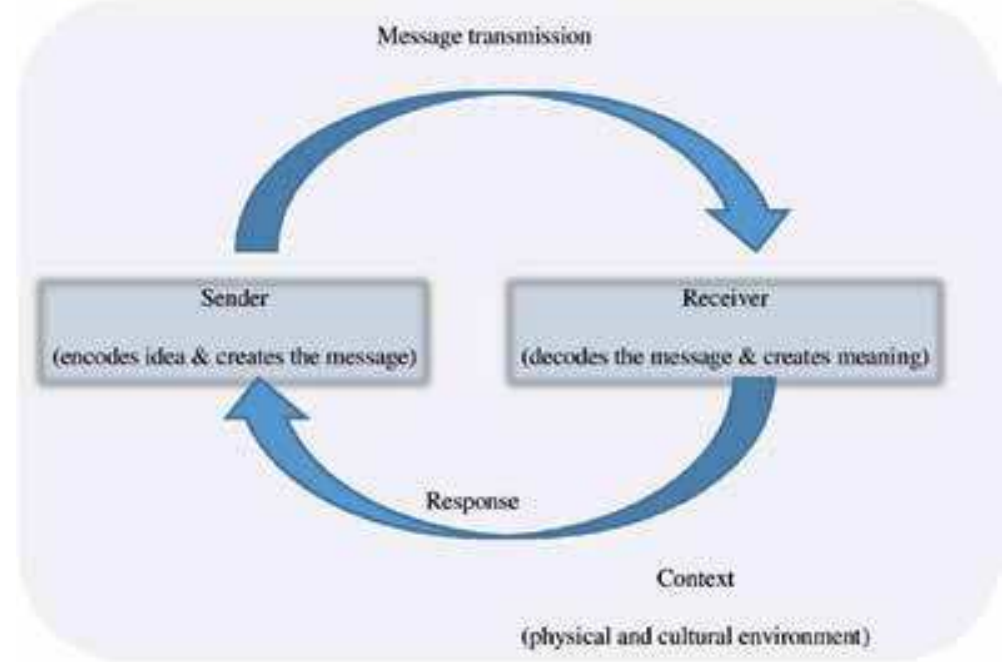

Figure 1.

Transactional model of communication (adapted from [12, 16]). 
mimics, plays important role in every physical communication and has to be somehow compensated in virtual environment to keep communication effective. This is even more important, when recipients are from different cultural backgrounds or share different types of expertise. Then a clear, modified explanation is required. To achieve that, as many communication channels as possible (audio, video and textual, etc.) have to be used concurrently and without hesitation [12]. Thus, it is recommended to respond to each message that is distributed among team member in order to know that the message was delivered and that the intent of the message was achieved.

Due to the virtual nature of development teams, most of the work process requires various means of electronic communication [17] and virtual team members have to learn communication skills in order to facilitate virtual NPD. Virtual team members also need to find out ways to express what in a "real" environment is expressed non-verbally [13]. Key challenges in acquiring these skills are geographical dispersion of virtual team members, operation in different time zones, various levels of their technological proficiency, and differences in work-process habits, levels of expertise and cultural differences [14].

Time and place, social presence, and information richness are four dimensions that distinguish different kinds of internet communication tools [14]. The first dimension-time, defines if there are delays between the moments when the information is sent and received, or there is synchronous communication without any delays. The second dimension-place defines the geographic distance between the participants of the communication. Co-located participants communicate at the same place, while dispersed communication is running across different places. The third dimension is social presence and describes the level of possible social sensitivity and personal inter-connections of participants, e.g., allowing nonverbal cues to be communicated along with the verbal message. Information richness is defined as "the potential information-carrying capacity of data", consequently facilitating personal and immediate feedback. Due to the high level of interactivity, information rich communication tools reduce misunderstanding [14, 18]. Some of the most commonly used internet communication tools are analysed in Table 1, according to the above-mentioned four dimensions.

The asynchronous type of communication requires longer period of time to close the message-response loop (Figure 1) potentially causing communication noise, delays in process and misunderstandings. For that reason, synchronous types of communication are fostered to facilitate social presence and personal engagement, which are important because they increase personal commitment and ease interpersonal dialogue [14]. Technical improvements of internet communication tools processing and high-speed internet have enabled an effective transition of synchronous types of communication also into the virtual environment [17].

Some researchers claim [20] that humans are not well adapted to asynchronous communication tools regardless to fast technological development of digital communication tools. Kock claims that synchronicity is one of the key elements of media naturalness, especially when communication of knowledge is the goal.

However, despite the rapid development and facilitation of various synchronous internet communication technologies we do not discourage the use of standard face-to-face interaction. On the opposite, number of cases showed that face-to-face meetings, particularly in the early stages of the course or product development process can be useful for team formations, assigning team roles, specifying goals and building initial trust [14]. This was important, as one of the necessary conditions to achieve and maintain a high level of team creativity is the trust among all team members. Research has shown that in uncertain and complex conditions requiring mutual adjustment (which is characteristic for NPD), effective and sustained action is only 


\begin{tabular}{|c|c|c|c|c|}
\hline & Dimensions & & & \\
\hline Types of communication (tool) & Time & Space & $\begin{array}{l}\text { Social } \\
\text { presence }\end{array}$ & $\begin{array}{l}\text { Information } \\
\text { richness }\end{array}$ \\
\hline Face-to-face & Same (synchronous) & $\begin{array}{l}\text { Same } \\
\text { (co-located) }\end{array}$ & Highest & Richest \\
\hline $\begin{array}{l}\text { Videoconferencing (e.g., Skype- } \\
\text { audio-video, etc.) }\end{array}$ & Same (synchronous) & $\begin{array}{l}\text { Different } \\
\text { (dispersed) }\end{array}$ & High & Rich \\
\hline $\begin{array}{l}\text { Audio conferencing (e.g., } \\
\text { Skype-audio, conference phone } \\
\text { calls, etc.) }\end{array}$ & Same (synchronous) & $\begin{array}{l}\text { Different } \\
\text { (dispersed) }\end{array}$ & Moderate & Moderate \\
\hline $\begin{array}{l}\text { Instant messaging (e.g., Skype } \\
\text { chat, Windows live messenger, } \\
\text { Yahoo messenger, etc.) }\end{array}$ & Same (synchronous) & $\begin{array}{l}\text { Different } \\
\text { (dispersed) }\end{array}$ & Moderate & Low \\
\hline $\begin{array}{l}\text { Video recorded standup } \\
\text { meeting [19] }\end{array}$ & $\begin{array}{l}\text { Different } \\
\text { (asynchronous) }\end{array}$ & $\begin{array}{l}\text { Different } \\
\text { (dispersed) }\end{array}$ & Moderate & Rich \\
\hline Shared workspace (e.g., BSCW) & $\begin{array}{l}\text { Different } \\
\text { (asynchronous) }\end{array}$ & $\begin{array}{l}\text { Different } \\
\text { (dispersed) }\end{array}$ & Low & Moderate \\
\hline E-mail & $\begin{array}{l}\text { Different } \\
\text { (asynchronous) }\end{array}$ & $\begin{array}{l}\text { Different } \\
\text { (dispersed) }\end{array}$ & Low & Low \\
\hline Voice mail & $\begin{array}{l}\text { Different } \\
\text { (asynchronous) }\end{array}$ & $\begin{array}{l}\text { Different } \\
\text { (dispersed) }\end{array}$ & Low & Moderate \\
\hline
\end{tabular}

Table 1.

Types of ICT tools according to four dimensions [17].

possible where there is mutual trust [2, 21, 22]. Similarly, Ijsedoorf (2002, personal communication) found out that personal acquaintances before the beginning of collaboration are regarded as stimulative for virtual teams in industrial environments.

The communication methods and information contents to be shared within teams are in a strong correlation to the phase of the product development process and each of the tasks requires an appropriate ICT infrastructure [23]. However, the results of some studies have shown that the mere availability of ICTs does not necessarily lead to their use and effective/efficient work of the NPD team [24].

Therefore, the certain norms and protocols have to be carefully defined prior to the project start to avoid misunderstandings, unnecessary delays and conflict situations. Norms describe communication behaviour (e.g., availability of team members, acknowledgement of reception of messages, check and response time intervals, frequency of messaging, recipients of various types of information, etc.) [14]. Protocols are more specific and are of operative character on how to use particular ICT tools, who are participants of various sessions and initiators of sessions etc.

According to [14], appropriate balance between structured (i.e. guided by rules) and unstructured (i.e. spontaneous) communication is necessary. Unstructured communication in virtual teams serves as a kind of electronic socialising and is important for, e.g., trust building [4].

Of course, norms, protocols, tools and processes have to be adopted and adapted by the NPD team members to facilitate cooperative work. The almost 15-year history of EGPR course offers us a great opportunity to analyse the evolution of communication tools, norms and protocols used in international virtual teams.

The establishment of communication protocols, which would serve all aspects of NPD process needs, is usually a complex and delicate task, while the final result is usually a multi-layered structure of communication rules serving specific needs of information types, importance and relevance. 


\section{Evolution of ICT tools for virtual NPD collaboration}

The ideas for NPD collaboration in virtual environment, between various partners all over the continent and globe emerged soon after IT communication channels became fast and reliable enough, to support live communication of all project stakeholders and ensure safe and reliable exchange and access to project documents. The EGPR course thus was initiated when all partner organisations had available technical resources to support necessary communication.

The minimum threshold of required resources is rising every year together with development of IT technology and with increase of IP communication channels, but in any case, needs to satisfy these basic communication functions:

1. recorded multipoint professional videoconference system (room) for lectures and presentations;

2. non-recorded multipoint professional videoconference system (room) for project and team meetings;

\section{IT tool for real-time slideshow exchange;}

4. file exchange system and depository.

All these services have been provided by EGPR partners through all years of the project, as it can be identified from the Table 2 .

The table shows the constant growth of available internet speed for videoconferences which resulted in more reliable communication, fewer voice and image delays, more frequent use of the VC equipment for communication and increased number of concurrent access points to the conference channels. Namely, in 2009 the project faced initial attempts of joining Videoconferences from personal computers, using H.323 and SIP software to access MCU videoconferencing channels (e.g., ConferenceMe and Ekiga).

After struggling initial attempts and facing a number of technical issues, as connection problems, slow bandwidth, voice echoes, which caused this technology only partially usable, in the last few years the technology allows flawless HD communication from personal computers and mobile devices. This allowed participants to join videoconferences from almost any location. However, although there are no technological obstacles anymore, our experience showed, that the output efficiency of VC meetings declines, when there are too many dispersed participants. The maximal optimal number of different locations concurrently joining the VC is still around 4-5, while there can be several participants at one location. In cases when this number is exceeded, it is obligatory to select skillful moderator who will lead the meeting and maintain strong communication discipline.

In the first 2 years of the project, when only three academic partners were involved in the project, the videoconferencing was hosted at one of the universities (usually at TU Delft) which had equipment, capable of sharing the calls. The larger number of videoconference participants in later years required use of special videoconferencing service and equipment called MCU (Multipoint Control Unit), allowing more participants to join the conference independently-i.e. there is no need for one partner to be available (online) just to host the conference. At first this service was organised by TU Delft, later, since 2009, this service has been provided by ARNES (The Academic and Research Network of Slovenia) (See Figure 2). In 2016, the number of concurrent participants was limited to 9 ( 1 of which is reserved for recording of communication)-see Figure 3. Since many of participants tried 


\begin{tabular}{|c|c|c|c|c|c|c|c|c|}
\hline Year & $\begin{array}{l}\text { No. of } \\
\text { partners }\end{array}$ & $\begin{array}{l}\text { VC Bandwidth } \\
(\mathbf{L} \mathbf{j})\end{array}$ & vC & Presentation sharing & $\begin{array}{l}\text { Virtual } \\
\text { classroom }\end{array}$ & Team meetings & Informal communication & File sharing \\
\hline 2002 & 3 & $\begin{array}{l}4 \times 64 \text { kbit ISDN } \\
(256 \mathrm{kbit})\end{array}$ & $\begin{array}{l}\text { Polycom in } \\
\text { Delft }\end{array}$ & $\begin{array}{l}\text { MS NetMeeting, } \\
\text { separate PC from VC }\end{array}$ & $\begin{array}{l}\text { TU Delft } \\
\text { blackboard }\end{array}$ & VC & Email, ICQ, MSN & TU Delft blackboard \\
\hline 2003 & 3 & $\begin{array}{l}4 \times 64 \mathrm{kbit} \text { ISDN } \\
(256 \mathrm{kbit})\end{array}$ & $\begin{array}{l}\text { Polycom in } \\
\text { Delft }\end{array}$ & $\begin{array}{l}\text { MS NetMeeting, } \\
\text { separate PC from VC }\end{array}$ & $\begin{array}{l}\text { TU Delft } \\
\text { blackboard }\end{array}$ & VC & Email, MSN & TU Delft blackboard \\
\hline $\begin{array}{l}2004- \\
2006\end{array}$ & 4 & $\begin{array}{l}100 \text { Mbit } \\
\text { ethernet }\end{array}$ & $\begin{array}{l}\mathrm{MCU} \text { in } \\
\mathrm{NL}\end{array}$ & $\begin{array}{l}\text { MS NetMeeting, } \\
\text { separate PC from VC }\end{array}$ & $\begin{array}{l}\text { TU Delft } \\
\text { blackboard }\end{array}$ & VC & Email, MSN & TU Delft blackboard \\
\hline 2007 & 5 & 1 Gbit ethernet & $\begin{array}{l}2 \times \mathrm{MCU} \\
\text { Arnes }\end{array}$ & $\begin{array}{l}\text { MS NetMeeting, } \\
\text { separate PC from VC }\end{array}$ & $\begin{array}{l}\text { TU Delft } \\
\text { blackboard }\end{array}$ & VC & Email, MSN, Google chat & TU Delft blackboard \\
\hline 2008 & 5 & 1 Gbit ethernet & $\begin{array}{l}2 \times \mathrm{MCU} \\
\text { Arnes }\end{array}$ & $\begin{array}{l}\text { MS NetMeeting, } \\
\text { separate PC from VC }\end{array}$ & $\begin{array}{l}\text { TU Delft } \\
\text { blackboard }\end{array}$ & VC & Email, Google chat & TU Delft blackboard \\
\hline 2009 & 6 & 1 Gbit ethernet & $\begin{array}{l}2 \times \mathrm{MCU} \\
\text { Arnes }\end{array}$ & $\begin{array}{l}\text { MS NetMeeting, } \\
\text { separate PC from VC }\end{array}$ & $\begin{array}{l}\text { TU Delft } \\
\text { blackboard }\end{array}$ & $\begin{array}{l}\text { VC-MCU, } \\
\text { Skype }\end{array}$ & Email, Google chat & TU Delft blackboard \\
\hline 2010 & 5 & 1 Gbit ethernet & $\begin{array}{l}2 \times \mathrm{MCU} \\
\text { Arnes }\end{array}$ & $\begin{array}{l}\text { Adobe connect (by } \\
\text { FSB) }\end{array}$ & Huddle.com & $\begin{array}{l}\text { VC-MCU, } \\
\text { Skype }\end{array}$ & $\begin{array}{l}\text { Email, Google chat, Google } \\
\text { groups, Facebook }\end{array}$ & $\begin{array}{l}\text { Huddle.com, FTP } \\
\text { server (by BME) }\end{array}$ \\
\hline $\begin{array}{l}2011 \text { and } \\
2012\end{array}$ & 5 & 1 Gbit ethernet & $\begin{array}{l}2 \times \mathrm{MCU} \\
\text { Arnes }\end{array}$ & $\begin{array}{l}\text { Adobe connect (by } \\
\text { FSB) }\end{array}$ & - & $\begin{array}{l}\text { VC-MCU, } \\
\text { Skype }\end{array}$ & $\begin{array}{l}\text { Email, Google chat, Google } \\
\text { groups, Facebook }\end{array}$ & $\begin{array}{l}\text { FTP server (by } \\
\text { BME) }\end{array}$ \\
\hline 2013 & 4 & 1 Gbit ethernet & $\begin{array}{l}2 \times \mathrm{MCU} \\
\text { Arnes }\end{array}$ & $\begin{array}{l}\text { Adobe connect (by } \\
\text { FSB) }\end{array}$ & - & $\begin{array}{l}\text { VC-MCU, } \\
\text { Skype }\end{array}$ & $\begin{array}{l}\text { Email, Facebook, Google } \\
\text { chat and groups }\end{array}$ & $\begin{array}{l}\text { BSCW server } \\
\text { (UL-FME) }\end{array}$ \\
\hline 2014 & 4 & 1 Gbit ethernet & $\begin{array}{l}2 \times \mathrm{MCU} \\
\text { Arnes }\end{array}$ & $\begin{array}{l}\text { Adobe connect (by } \\
\text { FSB) }\end{array}$ & - & $\begin{array}{l}\text { VC-MCU, } \\
\text { Skype }\end{array}$ & $\begin{array}{l}\text { Facebook, WhatsApp, } \\
\text { Google, etc. }\end{array}$ & $\begin{array}{l}\text { BSCW server } \\
\text { (UL-FME) }\end{array}$ \\
\hline 2015 & 4 & 1 Gbit ethernet & $\begin{array}{l}2 \times \mathrm{MCU} \\
\text { Arnes }\end{array}$ & $\begin{array}{l}\text { Adobe connect (by } \\
\text { FSB) }\end{array}$ & $\begin{array}{l}\text { Conceptboard. } \\
\text { com }\end{array}$ & $\begin{array}{l}\text { VC-,PC-MCU, } \\
\text { Skype, }\end{array}$ & $\begin{array}{l}\text { Facebook, WhatsApp, } \\
\text { Google, etc. }\end{array}$ & $\begin{array}{l}\text { BSCW server } \\
\text { (UL-FME) }\end{array}$ \\
\hline 2016 & 5 & 10 Gbit ethernet & $\begin{array}{l}2 \times \mathrm{MCU} \\
\text { Arnes }\end{array}$ & $\begin{array}{l}\text { Adobe connect (by } \\
\text { FSB) }\end{array}$ & $\begin{array}{l}\text { Adobe VOX (by } \\
\text { Arnes) }\end{array}$ & $\begin{array}{l}\text { VC-,PC-MCU, } \\
\text { VOX, Skype }\end{array}$ & $\begin{array}{l}\text { Facebook, WhatsApp, } \\
\text { Google, etc. }\end{array}$ & $\begin{array}{l}\text { BSCW server } \\
\text { (UL-FME) }\end{array}$ \\
\hline
\end{tabular}

Table 2.

Evolution of IT communication tools and infrastructure used for EGPR course. 


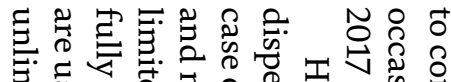

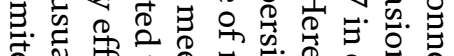

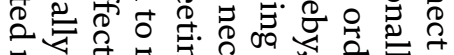

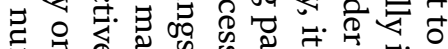

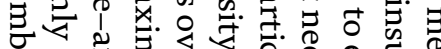

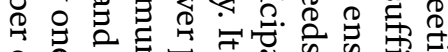
우의 प 究. 它

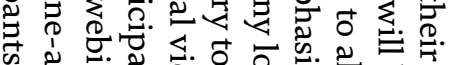

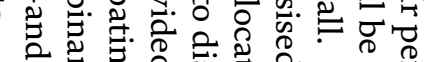

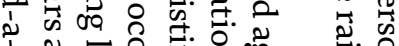

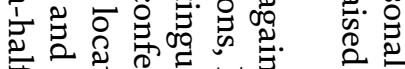

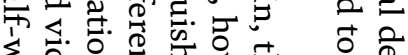

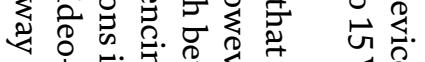

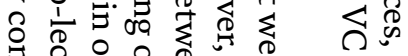



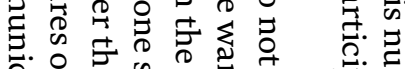

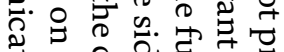

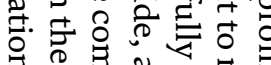

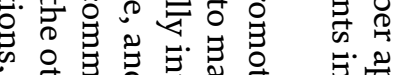
政 웅 E. 灵

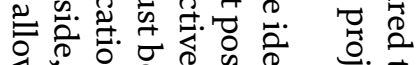

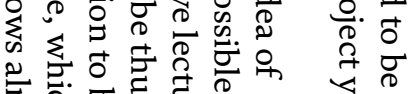

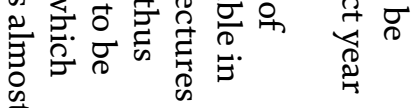
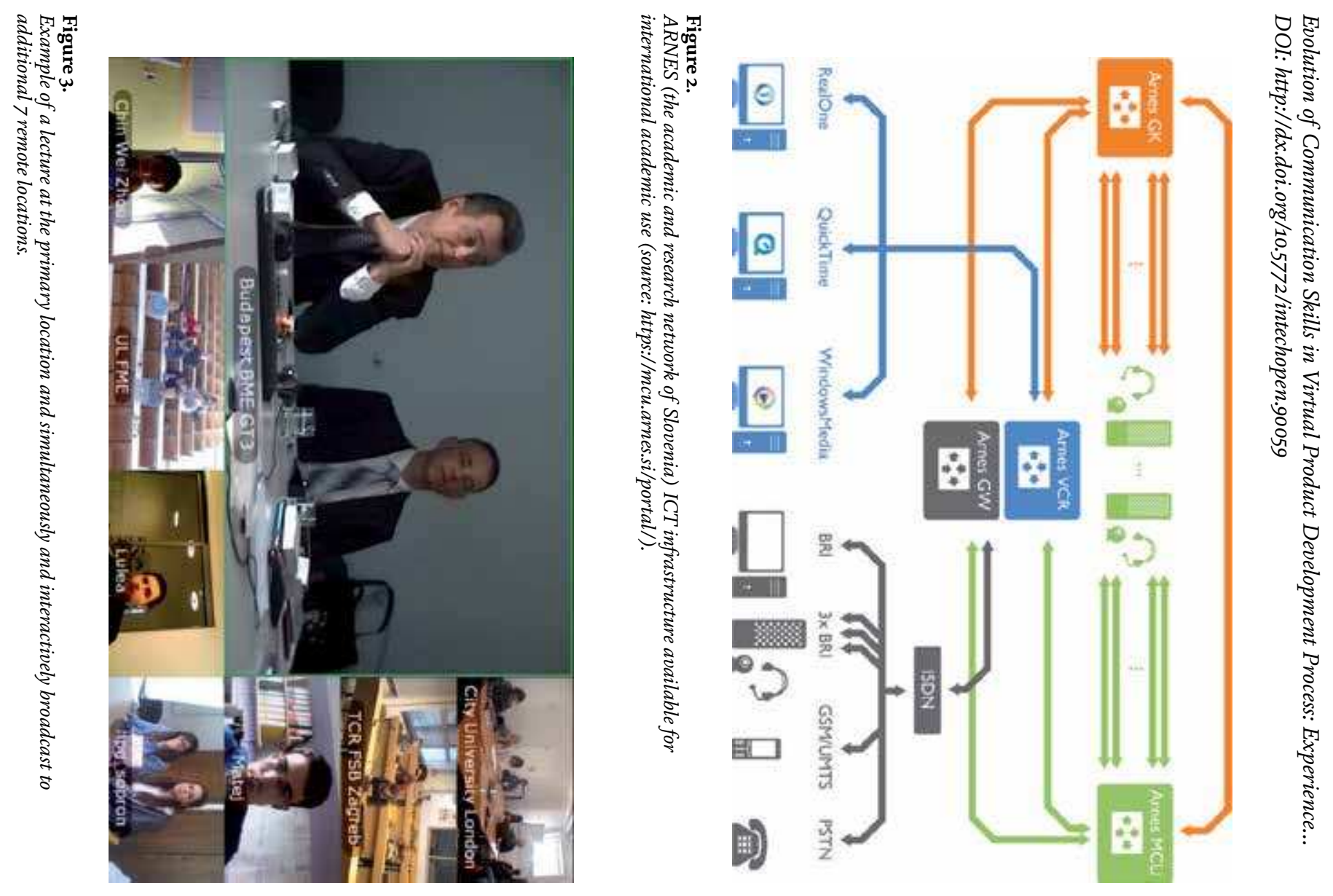
Besides multipoint transmission of live camera picture and voice, it is often required to share computer screen or presentations. EGPR partners tried various solutions for that, including H.239 videoconferencing protocol that enables sharing of the second screen over video professional videoconferencing equipment. However, several problems emerged, when using this standard: most of the professional VC equipment supports receiving the second image, however, only more expensive devices allow also sharing the second screen; the second screen required also broader bandwidth, which was particularly limited in the initial years of the project; H.239 protocol is often not supported in desktop clients, which would limit their usability in case presentations would be shared over H.239 protocol. The H.239 protocol also requires some experienced IT support which was not always available for all project partners. For all that reasons the project partners always used webbased services for presentation sharing. In the first few years of the project, the presentations were successfully shared using Microsoft NetMeeting software, but when Microsoft suspended NetMeeting technical support and upgrades, the EGPR migrated to Adobe Connect service, provided by University of Zagreb, Faculty of Mechanical Engineering and Naval Infrastructure, and has been used so far.

Videoconferences are used daily not only for the lectures, but also for formal and informal team meetings. Weekly formal meetings took place almost as a rule on the professional videoconference channels and equipment. However, in recent years they are also shifting to other services, such as Skype or Adobe VOX (Figure 4) as the availability and reliability of these services increased.

On the other side, the informal communication has always been following the most flexible channels available and changed yearly and even within some teams during the same project. Informal communication always acts as a pioneer for exploration of new available technologies and services and often dictates the evolution of formal virtual communication in the future. For that reason, we recommend researchers to carefully observe informal communication also as an indicator of

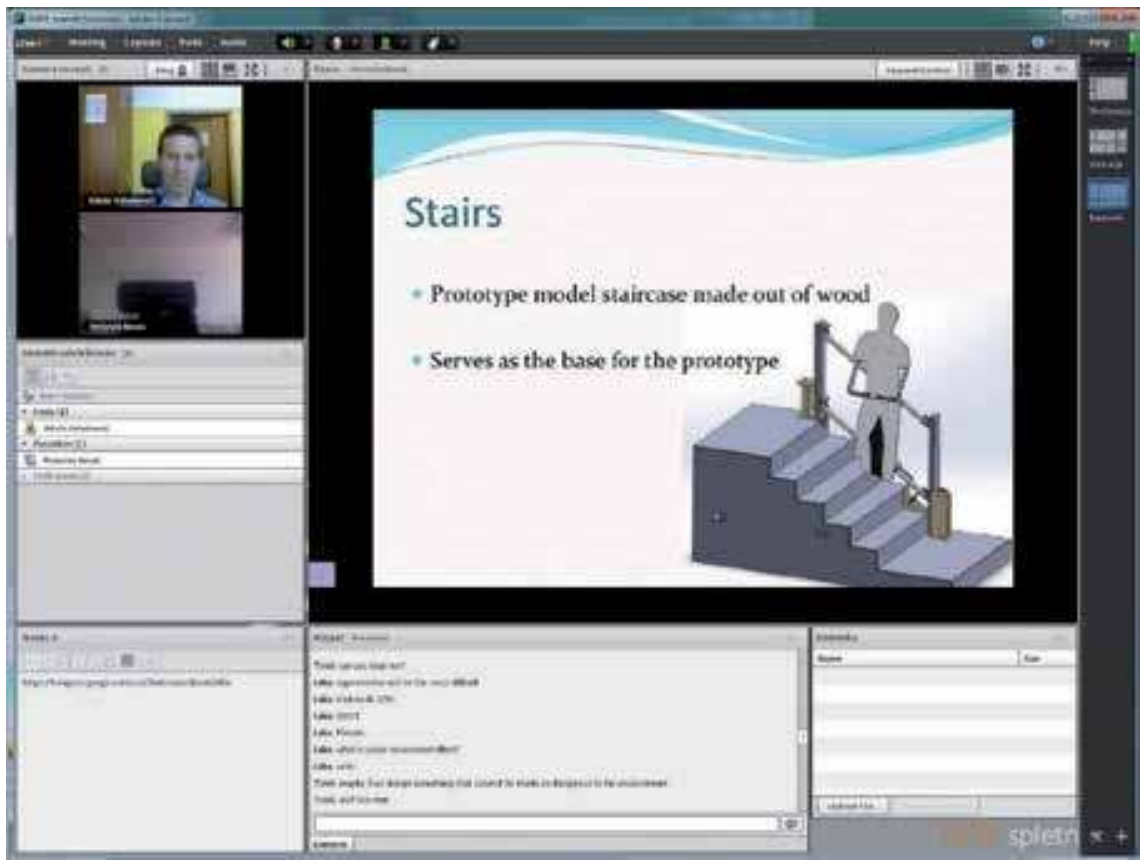

Figure 4.

Adobe VOX system is frequently used for team meetings and presentation sharing. 
Evolution of Communication Skills in Virtual Product Development Process: Experience... DOI: http://dx.doi.org/10.5772/intechopen.90059
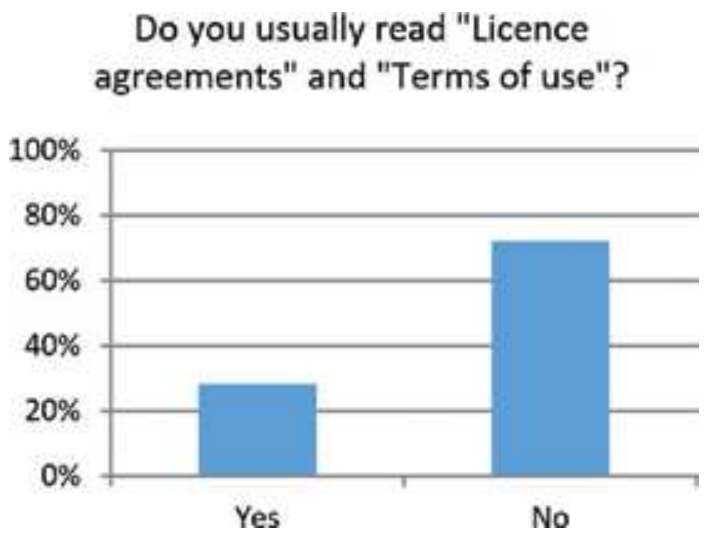

Figure 5.

Most of the participants do not read Licence agreements and terms of use, when using internet services.

\begin{tabular}{|c|c|c|c|c|c|c|c|}
\hline \multicolumn{8}{|c|}{ Eagrave } \\
\hline \multirow{2}{*}{\multicolumn{8}{|c|}{ 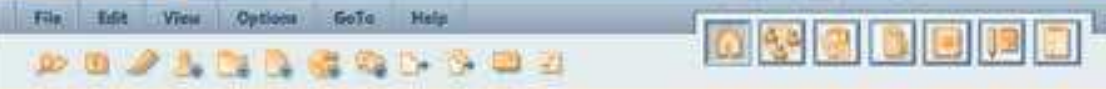 }} \\
\hline & & & & & & & \\
\hline \multicolumn{5}{|c|}{ 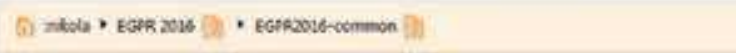 } & \multicolumn{2}{|l|}{ Seenen } & 9 \\
\hline \multirow{2}{*}{\multicolumn{5}{|c|}{ 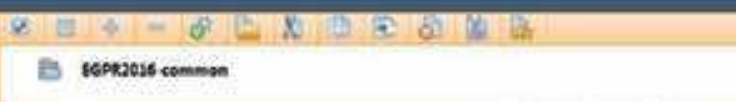 }} & \multirow{2}{*}{\multicolumn{3}{|c|}{ A. No filter }} \\
\hline & & & & & & & \\
\hline - & wanes: & neter: & sat: & onest & & 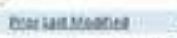 & tume \\
\hline in a & Ist phase & . & is & now & & 201603-41:24 & $\Delta=$ \\
\hline an & 7 and plase & - & 3 & natol & & 20300000 tode & $A \alpha$ \\
\hline BD & Ind phave & $*$ & 4 & nalo & & $2016-05001396$ & $\dot{x}=$ \\
\hline$\pm \cong$ & Eltu phase & 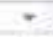 & 6 & kocarisieha & & $202005: 172206$ & $d x$ \\
\hline 100 & Sts phase - Budapeat Workahop & $*$ & 10 & bianlitefis & & $204-0622020$ & $\therefore=$ \\
\hline 10 & 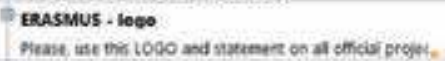 & 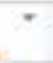 & 4 & natole & & 2016020112:6 & 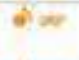 \\
\hline क든 & 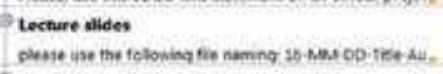 & * & 23 & salda & & $2000042725 \times 60$ & $8=$ \\
\hline en: & 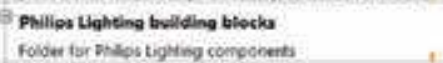 & * & 4 & endeneten & & $203603 / 251210$ & is $=0$ \\
\hline 150 & Team 1 & $*$ & 2 & bonarivictia & & $2040-02-161000$ & ol $=0$ \\
\hline 10 & Team 2 & $*$ & 3 & becarizsebs & & $2016.03-002340$ & $\therefore=$ \\
\hline 100 & Team 3 & 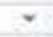 & 2 & Eouviasiofa & & $2010-01-171055$ & $d x$ \\
\hline D包 & Team 4 & $*$ & - & bourizseka & & $201602-120011$ & Fit \\
\hline$\square \square$ & Toam 5 & $*$ & 0 & tovarisiofs & & $201002-161004$ & R $N$ \\
\hline$\square=$ & Teams, Students IGPR 2016.pat & - & $476 x$ & verarizena & & $\rightarrow 201603 \times 101000$ & $18=$ \\
\hline EC & IGSE $2016 \mathrm{Ir}$ quide.pat & $*$ & $\cos x$ & atods & & $+2016-2-151352$ & 20 \\
\hline $0 *$ & Temm 3 Preventation Phase 1.pptex & $\cdot$ & $21 \mathrm{M}$ & sethsiar & & $\rightarrow 201603 \cdot 00019$ & $\mathrm{~B} \approx$ \\
\hline$\Delta \approx$ & City personal dasa theet xisx & * & $435 \mathrm{~K}$ & Dhandent & & $\rightarrow-2 m e-021015.15$ & $\infty$ \\
\hline 10 락 & tGPR 2016 Course schodule vioxdsx & $*$ & $30 x$ & bovarisesta & & $\rightarrow 2010041721: 15$ & $*$ \\
\hline a w & ISPR,2016,Courne schedule Vexisx & - & $325 x$ & toverizsefs & & $+29002-231516$ & $\approx$ \\
\hline DE & Philipa project assignement - 2016 - dratt vs corre & $\cdot$ & $1.1 \mathrm{M}$ & touarinotha & & $+209602-80,1610$ & $\approx$ \\
\hline a日 & Research Phave Repert - Team 3.pat & * & $2 \mathrm{M}$ & cotesas & & $\rightarrow 2020.03-0004-45$ & in $\alpha$ \\
\hline a & Team 3 Presentation Phase L padt & . & $14 \mathrm{M}$ & setsid & & $\rightarrow 2020.03 \cdot 5003 \times$ & $B=$ \\
\hline
\end{tabular}

Figure 6.

User interface of the BSCW server used for file exchange in EGPR since 2013.

future trends. For the same reason, we also recommend it to keep it deregulated as much as possible; However, it is necessary for all project participants (students and staff) to be constantly aware about intellectual property rights when sharing delicate information over new services. According to one of our surveys [25], more 
than $70 \%$ of EGPR participants do not usually read Licence agreements and terms of use, when applying for new internet services (Figure 5).

Experience showed that the need for regulation of informal communication emerges also when several teams are working on different modules of the same product/prototype. In such cases it is crucial to organise the communication channels and hierarchy (e.g., team leaders, cross-team communication representatives, official document types and versions) for effective communication.

Any NPD project requires also safe storage for deposition and exchange of various sorts of computer documents, e.g., text and graphical documents, spreadsheets, CAD drawings and models, etc. Besides that, it is often required to track versions, changes and to set different access and edit permissions for different users and documents. Through the history of EGPR, these needs were served in various different ways. In the years, when TU Delft was involved in the course, they provided partnership with TU Delft Blackboard system, which included simple file depository and exchange system.

The replacement was needed when TU Delft left the course, so various other systems were tested. At first, remaining partners tried to use a combination of FTP file deposit provided by BME and commercial online collaborative service called Huddle.com. The latter was abandoned next year, as the service showed several limitations of use and high operative costs. Therefore, the partners used only FTP server from BME for all official file exchange and deposition for the next several years until 2013 when consortium started to use BSCW server, provided by UL-FME (Figure 6), which completely superseded the needs for the FTP server.

\section{Communication in virtual NPD}

Our experience from elaborating, organising as well as from running EGPR courses during several consecutive years showed and confirmed that high-quality communication is essential for undisturbed, continuous and successful work in virtual teams. To achieve that communication has to serve as a reliable transfer of clear and meaningful information.

Using technical drawings and equations according to standards and nomenclature are crucial elements to minimise misunderstanding and lack of clarity in communication related to product development process. For example, contemporary CAD modellers provide tools to develop, design, visualise and verify complex $3 \mathrm{D}$ parts and assemblies in collaboration (and communication) with other team members. However, focusing too early on too many details, can inhibit the creativity and flexibility that is required to be successful in early stages of the development process or to apply necessary design changes.

The quality of information transfer is another crucial parameter, and requires appropriate local and global IT infrastructure and communication equipment, as well as skilled users or operators. Any kind of interruption, slow or mis-performance or equipment problems (or mishandling) divert attention from communication, and thus having a negative impact on both the quality of discussions and on decision-making [26].

Our experiences from previous courses in virtual collaborative environment have showed that video-conferences are one of the most important tools in the concept generation and concept evaluation phases of new product development process. Based on our experience video-conferences proved to be the best alternative to face-to-face communication for use in virtual teams. This is in line with The 
Media Naturalness Theory which sees face-to-face communication as most natural to humans; the theory states that a decrease in the degree of media naturalness of a communication leads to increased cognitive effort and increased level of ambiguity $[26,27]$. In the concept generation phase the team members are creating, elaborating and evaluating new ideas. This process is known to require vivid and intensive interpersonal communication, which can only be achieved with co-located faceto-face communication or alternatively with an equivalent virtual communication tool. Some researchers even claim that there is no significant difference between the two of them $[14,28,29]$.

In embodiment design or prototyping stage, that is the later stage of product development process, the exchanged information consists mostly of technical facts, resulting in a smaller need for negotiation, argumentation and potential misunderstanding, therefore e-mails can be a main communication channel, while video-conferencing serves mainly for taking final decisions. This is in agreement with other projects carried out by authors [17], where up to $60-70 \%$ of all communication was done by face-to-face and Skype (cumulative of both types of communication).

\subsection{Trust and the role of informal communication}

Trust is defined as an expectation that a partner will act in a way to achieve a positive outcome without the need for control [30]. Additionally, trust encompasses not only people's expectations about others, but also their willingness to use that knowledge as the basis for action $[22,31]$. By trust team members can expect their team colleagues will also act cooperatively when they are cooperating [32].

Trust is one of the key ingredients of teamwork, due to its effects on efficiency of an individual team member and a team as a whole. It facilitates collaboration, knowledge exchange and team learning. In short, it affects team performance [32, 33]. Among trusted team members there are no difficulties in idea sharing, no embarrassment in case of "crazy" ideas or even mistakes in work process [22, 34, 35]. Besides, trust also reduces the need for control and supervision, thus lowering the operating costs $[22,36]$.

Regarding EGPR, product development requires close cooperation between team members; this in turn requires trust. Good communication and creativity also require trust.

Research on trust suggests that trust is a dynamic process with three distinct stages [37]:

1. trust formation: the stage in which team members develop trust over time and start with an initial level of trust,

2. trust dissolution: it occurs when trust erodes as a result of other team members failing to meet a team member's expectations,

3. trust restoration: it can occur when trust stops declining after violation and eventually reaches a relatively stable state.

Al-Ani et al. [32] also observed a fourth stage-a trust adjustment, which occurs when team members adjust their expectations so that they can be met by other team members and it consequently enables trust restoration.

Fulmer and Gelfand [37] defined 6 common and 2 less common dynamic trust patterns (or trust trajectories). The patterns indicate magnitude of changes in trust levels across the formation, dissolution and restoration stages (Table 3, Figures 7 and 8). 


\begin{tabular}{|c|c|c|c|c|}
\hline Trust pattern & $\begin{array}{l}\text { Formation } \\
\text { stage }\end{array}$ & $\begin{array}{l}\text { Dissolution } \\
\text { stage }\end{array}$ & $\begin{array}{l}\text { Restoration } \\
\text { stage }\end{array}$ & Influential factors \\
\hline High trust & Fast & Slow & Fast & $\begin{array}{l}\text { Individual: high self-esteem, secure } \\
\text { attachment, locomotion. } \\
\text { Social contextual: relationship } \\
\text { history, third party and reputation, } \\
\text { collectivism within group. }\end{array}$ \\
\hline High distrust & Slow & Fast & Slow & $\begin{array}{l}\text { Individual: low self-esteem, } \\
\text { anxious attachment, cynicism, } \\
\text { betrayal aversion. } \\
\text { Social contextual: surveillance } \\
\text { and monitoring, honour logics, } \\
\text { collectivism with outgroup. }\end{array}$ \\
\hline Tit-for-tat trust & Fast & Fast & Fast & $\begin{array}{l}\text { Individual: tit-for-tat, equity } \\
\text { sensitivity. } \\
\text { Social contextual: exchange } \\
\text { relationship, dignity logics. }\end{array}$ \\
\hline $\begin{array}{l}\text { Sizing and } \\
\text { freezing trust }\end{array}$ & Fast & Slow & Slow & $\begin{array}{l}\text { Individual: need for closure. } \\
\text { Social contextual: time pressure, } \\
\text { power distance with authority. }\end{array}$ \\
\hline Assessment trust & Slow & Slow & Slow & $\begin{array}{l}\text { Individual: assessment, need to } \\
\text { avoid closure. } \\
\text { Social contextual: public situation. }\end{array}$ \\
\hline Grim trigger trust & Fast & Fast & Slow & $\begin{array}{l}\text { Individual: grim strategy, } \\
\text { interpersonal orientation. } \\
\text { Social contextual: performance } \\
\text { orientation. }\end{array}$ \\
\hline
\end{tabular}

Table 3.

Basic characteristics of 6 common dynamic trust patterns (adapted from [37]).

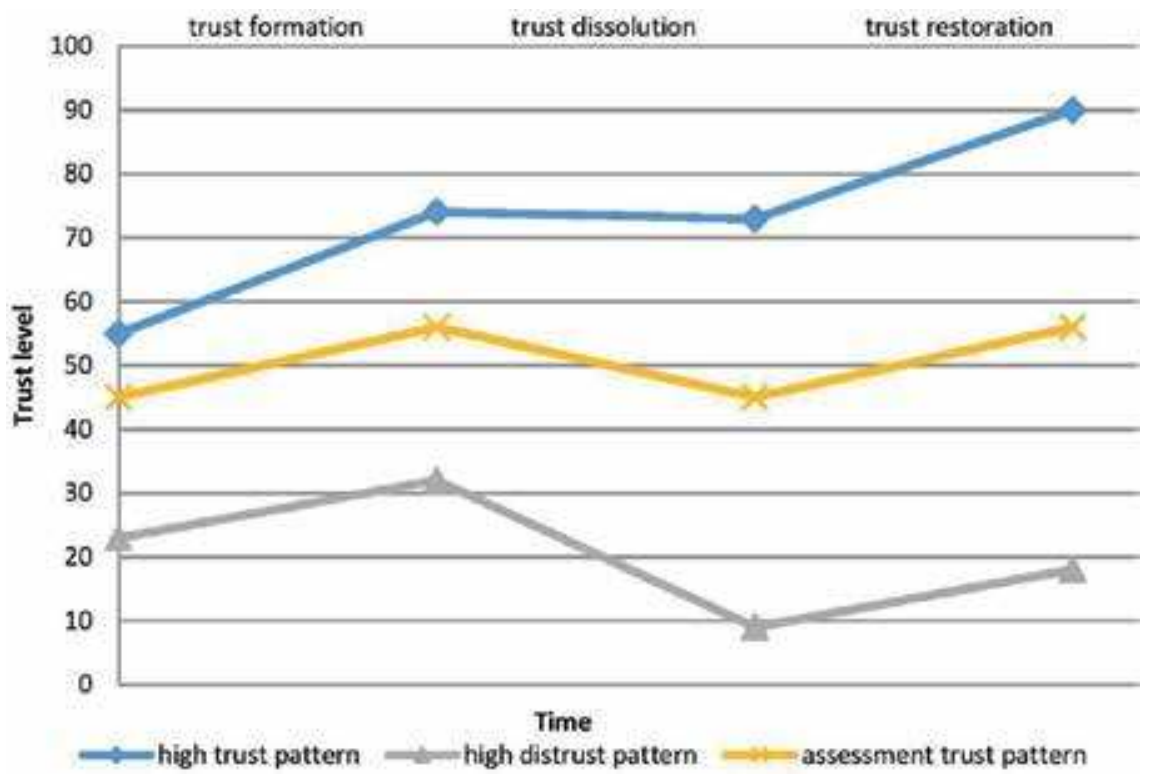

Figure 7 .

Trust patterns (adapted from [37]). 
Evolution of Communication Skills in Virtual Product Development Process: Experience... DOI: http://dx.doi.org/10.5772/intechopen.90059

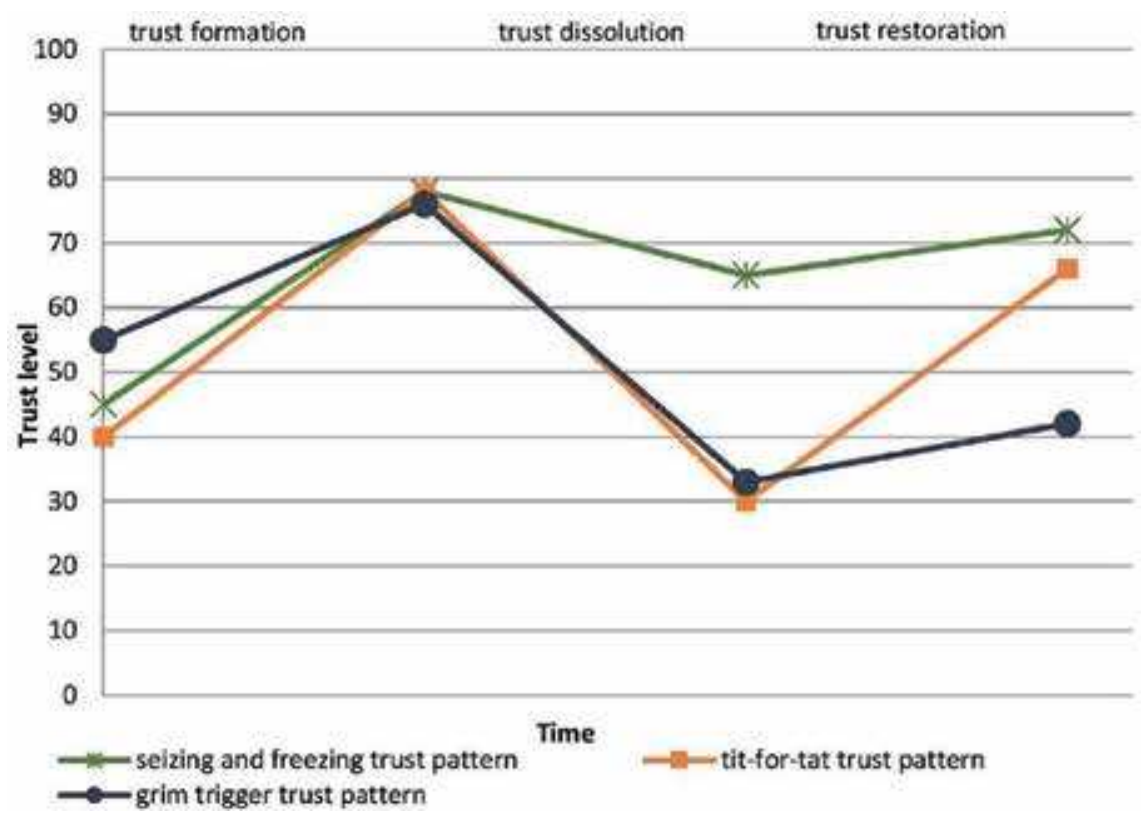

Figure 8.

Trust patterns (adapted from [37]).

They further identified and explained individual and social contextual factors characteristic to trust patterns, and focused also on the important role of cultural dimensions, such as [37]:

honour: trust restoration following trust violations in honour cultures is expected to be very slow and difficult. Trust formation is also expected to be slow, because members of honour cultures are strongly concerned in the competences and benevolence of the trustee than other cultures;

dignity: members of dignity cultures generally form trust fast, because they believe that dignity is inherent in all human beings. However, they are also sensitive to trust violations, which leads to fast trust dissolution;

collectivism: collectivists tend to perceive their ingroup members to be trustworthy, which should lead to fast trust formation. On the other hand, due to distrust of outgroup members, trust formation can be slow;

power distance: members of high power distance cultures expect the authority members are competent and benevolent, therefore trust formation is expected to be fast. In case of trust violation of authority member, trust restoration would be slow and difficult, especially when subordinates were highly committed;

performance orientation: members of performance-oriented cultures should be fast in trust formation, due to sense of urgency created by performance orientation. The members are also responsive to trust violation, meaning that trust dissolution is fast and restoration slow.

Cultural dimensions of trust process are of high relevance for global virtual teams.

For trust to develop, it is necessary for team members to share a common history and have personal contacts; this is what trust within development teams at a single location (i.e. collocated teams) is built on. However, in the case of EGPR project teams and often in professional product development teams this is not possible, because projects have to be finished in a limited time frame. In such circumstances, virtual teams have no time to build interpersonal relationship. Additionally, EGPR team members will very unlikely work together in the future. 
Therefore, it is necessary to start with initial, swift trust and build on it. Swift trust is trust that is formed around a common task with a short time span (e.g., product development projects within EGPR) [38]. It is based on team members' background, competences and affiliations, and not on past experience (i.e. common history); swift trust provides necessary initial confidence for team members to interact $[38,39]$. In their research Jarvenpaa and Leidner [38] categorised major characteristics of studied virtual teams regarding communication behaviours that facilitated trust early in a virtual team's life:

Social communication: initial communication among team members beginning with high trust was mainly social. Similarly, in Ref. $[19,40]$ found high number of social talk/cheap talk messages at the beginning of a virtual team lifecycle. Teams with low initial trust exchanged only few social messages. Team members of successful teams were careful not to use social communication as a substitute for task progress;

Communication of enthusiasm: for the teams with high initial trust high content of enthusiasm was characteristic for their messages, while teams with low initial trust communicated low contents of enthusiasm.

This portion of trust, which is built initially and serves as the basis for further consolidation of trust via appropriate communication, is what team members can rely upon most $[12,38]$.

Later, trust can and needs to be consolidated through predictable communication, quick responses and individual initiative, because the swift trust is fragile and temporal. Communication behaviours that helped maintain trust later in a virtual team's life are [38]:

Predictable communication: irregular and unpredictable communication patterns hindered trust. Announcing communication absences additionally contributed to confidence in team members' commitment. Regularity in communication was very important. Frequency of communication alone is of lesser importance [33, 41];

Substantive and timely responses: thorough evaluation of contents and prompt responses to messages were the key factors of trust maintenance. The senders were confident that their contributions to project tasks were appreciated, elaborated and reflected upon. Superficial evaluation or even lack of any response signalled low commitment and consequently erosion of trust.

Similar characteristics of initial trust and trust maintenance were also found by e.g., [36, 42]. Al-Ani et al. [32] found that richer communication media (i.e. video conferencing) are better for trust development than leaner (i.e. e-mails).

Regarding research of trust building and its maintenance, researchers have used various perspectives. For example, Ref. [40] used a novel cost-benefit perspective, rather than a social relationship one. They found that the team members that engaged in their internal communication in so called cheap talk (i.e. non-work related conversation behaviour), generally have higher trust. This is interesting since some economics literature claim that such non-work related communication is meaningless and a waste of time [40].

Due to key importance of communication regarding virtual team work appropriate norms that describe communication behaviour (e.g., availability of team members, acknowledgement of reception of messages, check and response time intervals, frequency of messaging, recipients of various types of information, etc.) were defined and disseminated to virtual teams prior to each year's EGPR project start. Norms promote adaptive and effective behaviour by providing guidelines for acceptable and unacceptable behaviour [33, 43]. For example, [33, 44] found that externally induced communication rules boost trust in a virtual team. Similarly, Saunders and Ahuja [45] cited in [33] believed that normative actions related to technology and communication facilitate goal achievement and increase the overall productivity of the team. 
Evolution of Communication Skills in Virtual Product Development Process: Experience... DOI: http://dx.doi.org/10.5772/intechopen.90059

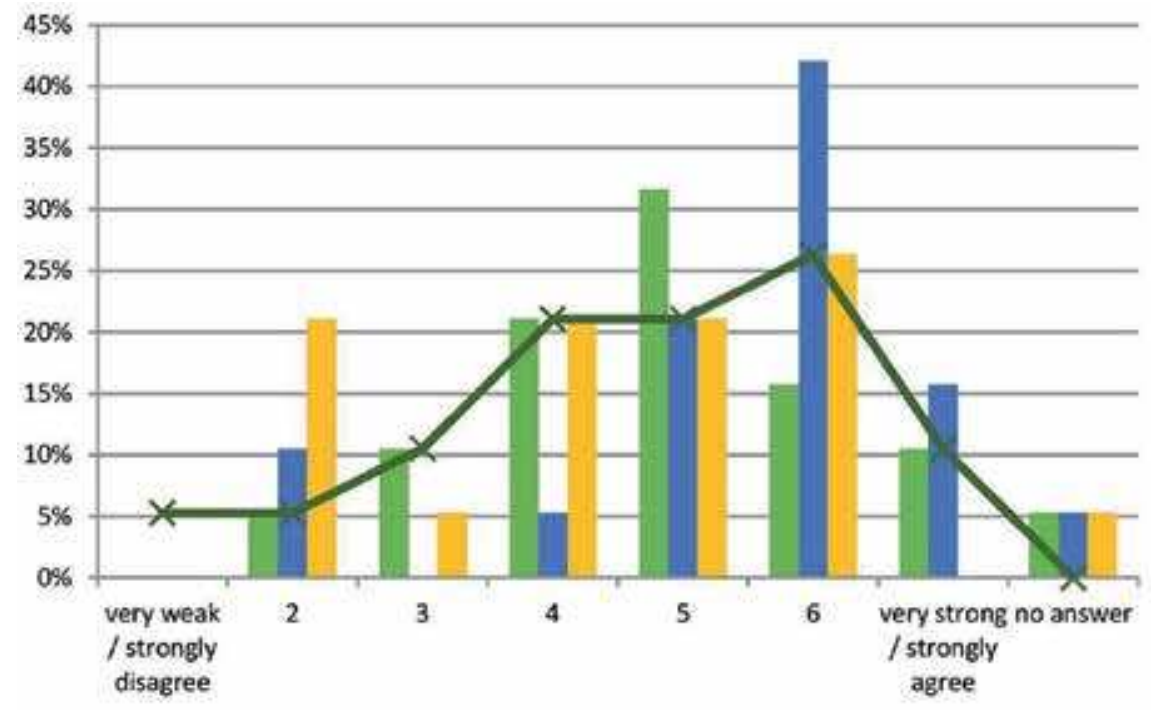

Members took the time to share things of interest with one another
Members shared humorous stories and were playful with one another
Members shared personal issues and crisis with others
$=$ the level of trust

Figure 9.

Chart showing the level of trust among team members and the activities necessary to build personal bonds between team members [5].

For example, Figure 9 shows the rate and structure of informal information shared among EGPR team members (columns) as well as among them. Comparing the results, one notices their congruity. The trust among the members was relatively strong, although some people did not want to share private details (personal issues, crises or things of interest). However, there was still a lot of impersonal, non-task related communication among the participants, which also served for socialising and trust building.

Socialising in virtual teams facilitates creation of trusting relationships between EGPR team members. It is very important and complicated to perform as there is no personal contact between team members, which means that greater efforts are required for the development of interpersonal relationships within the team, which consequentially increases the need for communication-electronic socialising. This is done mostly by exchange of personal or non-professional information, such as hobbies, movies they watch, music they like, sports they practice, exchange of personal photographs, travelling preferences, concern for others etc. [4, 19, 32, 35, 40, 46-48].

\section{Communication trends (future) in virtual NPD teams}

Collaboration in virtual teams has been established in many industries such as software development, electronics, etc. but also in science and research. It is a modern and flexible organisational form, which allows cooperation of various geographically dispersed experts, who can join the teams at the beginning of the project, or only when their knowledge and expertise is needed and leave afterwards. This form of collaboration became possible with the development and availability of adequate computer and IT technology, but requires also some knowledge and experience from the users. This form of organisation was implemented also in many 
engineering courses. One of the earliest such courses is European Global Product Realisation, which aims to teach students of real industrial experience of new product development in virtual environment already since study year 2001/2002.

EGPR can be seen as a unique example of continuous evolution, development and increasing availability of IT infrastructure and software for communication, sharing of documents, organisation of work and cooperation. At the same time the knowledge about work in such organisational entities increased and matured. Hereby EGPR provided good opportunity to implement new practices, obtain our own experience and to test other's results.

Good communication flow is crucial factor for NPD process to be successful and well timed. This chapter has covered various aspects of communication in virtual environment, and given insight into the evolution of 15 years long project and provided generalised directions to make collaboration in virtual environment successful. Communication, however, is not only dull exchange of professional information, but a complex interaction between numbers of individuals with unique personal characteristics. Therefore, it is crucial to develop sufficient level of trust among all project participants. One can say, trust is along with team members' technical competences basically a fundament, which ensure efficient work and successful completion of the project.

Interpersonal communication basically consists of verbal exchange of messages, intonation, facial expressions and body language. There has been a lot of research to evaluate the importance of each component of personal communication, e.g., $[49,50]$ or $[51]$, however all researchers agree, that words represent only a fraction of interpersonal communication. Communication in virtual teams using various sources of information transmitters therefore filter some components of interpersonal communication. E-mails facilitate exchange of words only, telephone and Skype calls facilitate exchange of words, voice and intonation, while video calls support exchange words, voice, intonation, facial expressions, but majority of body language remains concealed even when communicating over best video conferencing systems. As the team members being geographically dispersed, often also with different cultural background and field of expertise, makes the process of information exchange even more difficult and delicate.

Due to all these limitation of communication in virtual environment we recommend to follow some basic rules for effective NPD in virtual environment. These rules were developed based on our research, practical experience from organising EGPR course, personal testimonies of students, coaches and industrial representatives and analysis of various questionnaires:

If possible, organise kick-off face-to-face meeting at the beginning of the project, for all team members;

It is necessary to introduce all ICT tools which will be used for the project and test/improve knowledge and competences of user's/team members for uninterrupted use during the project. It is also crucial to facilitate compatible infrastructure and maintain its service and support at all project locations during the whole project's lifetime;

Set the communication rules and protocols before the official project start;

All team members must be well aware of cultural and personal differences and of the importance of trust building;

Leaders of virtual teams must be aware of and allow and encourage informal communication (i.e. cheap-talk). It is recommended to allocate and dedicate particular time and meetings for that in order to keep working meetings effective;

Informal communication should not be limited to formally defined communication protocols and ICT tools. It should stimulate the use of new and alternative ICT tools. 
Evolution of Communication Skills in Virtual Product Development Process: Experience... DOI: http://dx.doi.org/10.5772/intechopen.90059

All these rules are derived from our 15 year long experience from organising EGPR academic-industrial courses which we believe to be a good analogy to real industrial virtual team cases.

\section{Author details}

Nikola Vukašinović, Janez Benedičič* and Roman Žavbi

Faculty of Mechanical Engineering, LECAD Laboratory, University of Ljubljana, Ljubljana, Slovenia

*Address all correspondence to: janez.benedicic@lecad.fs.uni-lj.si

\section{IntechOpen}

(C) 2020 The Author(s). Licensee IntechOpen. Distributed under the terms of the Creative Commons Attribution - NonCommercial 4.0 License (https://creativecommons.org/ licenses/by-nc/4.0/), which permits use, distribution and reproduction for non-commercial purposes, provided the original is properly cited. (cc) BY-NC 


\section{References}

[1] Ball AG, Zaugg H, Davies R, Tateishi I, Parkinson AR, Jensen CG, et al. Identification and validation of a set of global competencies for engineering students. International Journal of Engineering Education. 2012;28(1):156-168

[2] Dayan M, Di Benedetto CA. The impact of structural and contextual factors on trust formation in product development teams. Industrial Marketing Management. 2010;39(4):691-703

[3] Jansen DE. Developing the intercultural competence of engineering students: A proposal for the method and contents of a seminar', world transactions on engineering and technology. Education. 2004;3(1):23-28

[4] Žavbi R, Tavčar J. Preparing undergraduate students for work in virtual product development teams. Computers \& Education. 2005;44:357-376

[5] Žavbi R, Vukašinović N. A concept of academia-industry collaboration to facilitate the building of technical and professional competencies in new product development. International Journal of Engineering Education. 2014;30(6):1562-1578

[6] Fain N, Žavbi R, Vukašinović N. The influence of product complexity on team performance within NPD. In: Proceedings of a Conference DESIGN 2016. Zagreb/Glasgow: Faculty of Mechanical Engineering and Naval Architecture/Design Society; 2016, 2069-2080

[7] Boudreau MC, Loch KD, Robey D, Straub D. Going global: Using information technology to advance the competitiveness of the virtual transnational organization. Academy of Management Executive. 1998;12(4):120-128
[8] Montoya MM, Massey AP, Lockwood NS. 3D collaborative virtual environments: Exploring the link between collaborative behaviours and team performance. Decision Sciences. 2011;42(2):451-476

[9] Biggs M. Assessing risks today will leave corporate leaders well-prepared for the future of work. InfoWorld. 2000;22(39):100-100

[10] Lipnack J, Stamps J. Virtual Teams: People Working across Boundaries with Technology. 2nd ed. New York: Wiley; 2000

[11] Paul S, Seetharaman P, Samarah I, Mykytyna PP. Impact of heterogeneity and collaborative conflict management style on the performance of synchronous global virtual teams. Information and Management. 2004;41(3):303-321

[12] Tavčar J, Žavbi R, Verlinden J, Duhovnik J. Skills for effective communication and work in global product development teams. Journal of Engineering Design. 2005;16(6):557-576

[13] Stasi C. Effective Communications in a Virtual Team. 2013. Available from: http://www.open.ac.uk/business-school/ sites/www.open.ac.uk.business-school/ files/files/Virtual\%20Teams\%20\%20Carlo_S.pdf [Accessed: 4 August 2016]

[14] Nemiro JE. Creativity in Virtual Teams. San Francisco: Pfeiffer; 2004

[15] Sivasubramaniam N, Liebowitz SJ, Lackman CL. Determinants of new product development team performance: A meta-analytic review. Journal of Product Innovation Management. 2012;29(5):803-820

[16] Spence WR. Innovation, The Communication of Change in Ideas, 
Practices and Products. London: Chapman \& Hall; 1994

[17] Benedičič J, Krek J, Leben V, Velez Vörös G, Beravs T, Potočnik S, et al. Development of an automatic marketplace using virtual collaboration. Technical Gazette. 2012;19(2):201-208

[18] Daft RL, Lengel RH. Organizational information requirements, media richness and structural design. Management Science. 1986;32(5):554-571

[19] Giuffrida R, Dittrich Y. How social software supports cooperative practices in a globally distributed software project. In: Proceedings of a Conference CHASE 2014. Association for Computing Machinery; 2014. pp. 24-31

[20] Kock N. Designing E-collaboration technologies to facilitate compensatory adaption. Information Systems Management. 2008;25(1):14-19

[21] Thompson JD. Organizations in Action. New York: McGraw-Hill; 1967

[22] McAllister DJ. Affect- and cognition-based trust as foundations for interpersonal cooperation in organizations. Academy of Management Journal. 1995;38(1):24-59

[23] Christophersen E, Coupe PS, Lenschow RJ, Townson J. Evaluation of Civil and Construction Engineering Education in Denmark. Available from: Centre for Quality Assurance and Evaluation of Higher Education in Denmark, Copenhagen. 1994. [Accessed: 1 October 2012]

[24] Montoya MM, Massey AP, Caisy Hung Y-T, Crisp CB. Can you hear me now? Communication in virtual product development teams. The Journal of Product Innovation Management. 2009;26(2):139-155

[25] Vukašinović N, Duhovnik J. Design2go-how, yes, no? In: Proceedings of a Conference ICoRD'13. New Delhi: Springer; 2013. pp. 1243-1252

[26] Žavbi R, Kolšek T, Duhovnik J. Virtual product development study courses-Evolution and reflections. In: Proceedings of a Conference ICED 2009. Glasgow: Stanford Center for Design Research, Stanford University and Design Society; 2009. pp. 113-124

[27] DeRosa DM, Hantula DA, Kock N, D'Arcy J. Trust and leadership in virtual teamwork: A media naturalness perspective. Human Resource Management. 2004;43(2-3):219-232

[28] Graetz KA, Boyle ES, Kimble CE, Thompson P, Garloch JL. Information sharing in face-to-face, teleconferencing, and electronic chat groups. Small Group Research. 1998;29(6):714-743

[29] Harvey CM, Koubek RJ. Toward a model of distributed engineering collaboration. Computers \& Industrial Engineering. 1998;35(1-2):173-176

[30] Mayer RC, Davis JH, Schoorman FD. An integrative model of organizational trust. Academy of Management. 1995;20(3):709-734

[31] Luhman N. Trust and Power. Chichester: Wiley; 1979

[32] Al-Ani B, Bietz MJ, Wang Y, Trainer E, Koehne B, Marczak S, et al. Globally distributed system developers: Their trust expectations and processes. In: Proceedings of a Conference CSCW 2013. Association for Computing Machinery; 2013. pp. 563-573

[33] Crisp CB, Jarvenpaa SL. Swift trust in global virtual teams. Journal of Personnel Psychology. 2013;12(1):45-56

[34] Edmondson A. Psychological safety and learning behavior and learning in work teams. Administrative Science Quarterly. 1999;44(2):350-383 
[35] Peñarroja V, Orengo V, Zornoza A, Sánchez J, Ripoll P. How team feedback and team trust influence information processing and learning in virtual teams: A moderated mediation model. Computers in Human Behaviour. 2015;48:9-19

[36] Kanawattanachaia P, Yoo Y. Dynamic nature of trust in virtual teams. Journal of Strategic Information Systems. 2002;11(3-4):187-213

[37] Fulmer CA, Gelfand MJ. How do I trust thee? Dynamic trust patterns and their individual and social contextual determinants. In: Sycara K, editor. Models for Intercultural Collaboration and Negotiation. Dordrecht: Springer Science+Media; 2013. pp. 97-131

[38] Jarvenpaa SL, Leidner DE. Communication and trust in global virtual teams. Journal of ComputerMediated Communication. 1998;3(4). DOI:10.1111/j.1083-6101.1998.tb00080.x

[39] Meyerson D, Weick KE, Kramer RM. Swift trust and temporary groups. In: Kramer RM, Tyler TR, editors. Trust in Organizations: Frontiers of Theory and Research. Thousand Oaks, CA: Sage Publications; 1996. pp. 166-195

[40] Wang Y, Redmiles D. Cheap talk, cooperation, and trust in global software engineering. In: Empirical Software Engineering. 2016;21(6): 2233-2267. DOI: $10.1007 / s 10664-$ 015-9407-3. (https://redmiles.ics.uci. edu/publication/)

[41] Jarvenpaa SL, Shaw TR, Staples DS. Toward contextualized theories of trust: The role of trust in global virtual teams. Information Systems Research. 2004;15(3):250-267

[42] Iacono CS, Weisband S. Developing trust in virtual teams. In: Proceedings of the 30th Hawaii International Conference on System Sciences. IEEE; 1997. pp. $412-420$
[43] Cialdini RB, Trost MR. Social influence: Social norms, conformity, and compliance. In: Gilbert DT, Fiske ST, Lindzey G, editors. The Handbook of Social Psychology. Vol. 2. New York: McGraw-Hill; 1998. pp. 151-192

[44] Walther JB, Bunz U. The rules of virtual groups: Trust, liking, and performance in computer mediated communication. Journal of Communication. 2005;55(4):828-846

[45] Saunders CS, Ahuja MK. Are all distributed teams the same? Small Group Research. 2006;37(6):662-700

[46] Ahuja MK, Galvin JE. Socialization in virtual groups. Journal of Management. 2003;29(2):161-185

[47] Lin C, Standing C, Liu Y-C. A model to develop effective virtual teams. Decision Support Systems. 2008;45(4):1031-1045

[48] Zigurs I. Leadership in virtual teams: Oxymoron or opportunity? Organizational Dynamics. 2003;31(4):339-351

[49] Mehrabian A. Nonverbal Communication. Chicago, Illinois: Aldine-Atherton; 1972

[50] Trimboli A, Walker M. Nonverbal dominance in the communication of affect: A myth? Journal of Nonverbal Behavior. 1987;11(3):180-190

[51] Beattie G. Visible Thoughts: The New Psychology of Body Language. Routledge; 2004. (https://psycnet.apa. org/record/2004-14259-000) 
Section 2

KM a Key Success Driver 



\title{
Systems Engineering as an Essential Organizational Competence for Knowing and Innovating
}

\author{
Michael Henshaw and Sofia Ahlberg Pilfold
}

\begin{abstract}
Systems Engineering is described as a transdisciplinary approach that integrates all disciplines and specialty groups into a team effort, developing an innovation from concept to fully operational system. However, its procedural nature has been viewed by some as inhibiting innovation. By considering the whole of the innovation cycle, we demonstrate that Systems Engineering is actually essential to overcome the so-called valley of death in terms of technology readiness. Drawing on two case studies of knowledge management in large organizations (one government and one private industry), we show the benefits of a perspective in which the organization is viewed as a system through which dispersed explicit and tacit knowledge may be integrated to support innovation. However, this relies on appreciations of the full range of different knowledge types and the importance of organizational culture in the knowing and action cycle. The importance of organizations and the individuals within them adopting systemic thinking and systematic effectiveness are essential attributes of innovation: these are embodied in the discipline of Systems Engineering.
\end{abstract}

Keywords: innovation, Systems Engineering, knowledge management, systematic, systemic

\section{Introduction}

Innovation concerns the development of an initial idea through to its realization as a viable product, service, or infrastructure. The meaning of viability depends on the circumstances; for example, commercially viable, public service system viability, etc. it is a widely held view that many potentially viable ideas fail to be realized during the mid-development phase, which has been referred to as the 'valley of death' for innovation [1]. In this chapter, we shall argue that this phase of development concerns integration and, as such, the risk of failure can be reduced by adopting a Systems Engineering approach. We are essentially concerned with technological innovation in this chapter, which begins with some general considerations to explain our interpretation of the concept of innovation. We then describe Technology Readiness Levels [2] as a construct for measuring the maturity of an innovation. The role of Systems Engineering is explained, and the skills and 
mindset of a Systems Engineer is described so that their importance can be appreciated as beneficial to the process of technological innovation. We close the chapter by recognizing the significance of knowledge management in innovative organizations, which we illustrate with two briefly described case studies.

\section{Innovation: process or culture?}

Some years ago, I was asked to write a chapter on the 'innovation process' in aeronautics [3], meaning the procedural nature of innovation. I concluded that, from an organizational perspective, environment and culture were of much more significance than process, noting the view of Steve Jobs (then chairman and CEO of Apple Computers) when asked 'How do you systemize innovation?', he replied: 'You don't. You hire good people who will challenge each other every day to make the best products possible... ... Our corporate culture is simple' [4]. However, I noted that in domains such as aerospace, the future challenges are highly complex and should address not just technology, but legal, social, environmental, financial, etc. aspects as well. Indeed, a (whole) systems approach is needed.

If we set aside the notion of 'systematic innovation' meaning a step by step process for innovation and turn our attention to the process of technology development, then the meticulous process of development using Systems Engineering could be seen as an enabler of innovation, as will be discussed below.

Jobs's comment above indicates that innovation is linked to both the quality of the staff and the quality of their interactions; in the discussion below, we shall consider the value an organization places on knowledge management and some of the features that make this an effective enabler of innovation.

The discipline of Systems Engineering is concerned with both the systemic (behaviour of a system as a whole and its interaction with its environment) and the systematic (concerned with the detail of how a system's parts interact and are put together). In general, innovation requires consideration of both the systemic and the systematic and one without the other makes innovation less likely. It is an oft quoted example but consider the F117 (Nighthawk) as a highly complex, innovative capability. This was the first stealth aircraft, developed by Lockheed Martin Skunk Works in 1970s/1980s. Lockheed analyst Denys Overholser came across a paper by Russian mathematician, Pyotr Ufimtsev [5], concerned with radar detection and realized that he could use this to design an aircraft with very low radar signature. Thus the systemic nature of the F117 is that it is almost undetectable by radar, but the systematic aspect is that there are electromagnetics, aerodynamics, structures, propulsion, control, and many more individual challenges that must be overcome with appropriate technologies and integrated together to achieve this capability.

There is a tendency to think of innovation as being synonymous with invention [6], but it is really about taking an idea through to commercial success or societal benefit. It may be radical but is more usually incremental [7] and may occur at either the component or system level. Whilst it is appreciated that innovation is not solely the domain of technologists, the discussion herein will focus on technology development, the maturity of which is often described in terms of TRLs (Technology Readiness Levels).

\section{Technology readiness levels}

TRLs were introduced by NASA to track the maturity of technology projects

[2] and have become the de facto measure of maturity in many organizations, as 
Systems Engineering as an Essential Organizational Competence for Knowing and Innovating DOI: http://dx.doi.org/10.5772/intechopen.90070

\begin{tabular}{cl}
\hline TRL 1 & Basic principles observed and reported \\
\hline TRL 2 & Technology concept and/or application formulated \\
\hline TRL 3 & Analytical and experimental critical function and/or characteristic proof-of-concept \\
\hline TRL 4 & Component and/or breadboard validation in laboratory experiment \\
\hline TRL 5 & Component and/or breadboard validation in relevant environment \\
\hline TRL 6 & System/subsystem model or prototype demonstration in a relevant environment \\
\hline TRL 7 & System prototype demonstration in an operational environment \\
\hline TRL 8 & Actual system completed and qualified through test and demonstration \\
\hline TRL 9 & Actual system proven through successful mission operations. \\
\hline
\end{tabular}

Table 1.

Technology readiness levels summary [8].

generalized in [8]. Strictly they are concerned with technology projects, rather than technology per se, and indicate readiness for commercial deployment. TRLs range from 1 to 9 (Table 1) and represent the phases of research and invention (1-3), innovation (4-7), and commercial market (8-9). It is a generally held belief that many projects are terminated in the TRL 4-7 range [9], although precise figures are hard to find and it is also unclear what a reasonable level of failure at this level of maturity would be [10]. The costs associated with development increase substantially in this range, compared to TRL $1-3$, and so a proportion of project termination is to be expected. The causes may be manifold, but it is noted that from TRL 6 every level involves integration in some form. If Systems Engineering has been applied from the outset of the project, then the likelihood of success is increased [11], and certainly Systems Engineering is an essential part of integration.

\section{Systems Engineering}

Rechtin defines a system as 'A set of different elements so connected or related as to perform a unique function not performable by the elements alone' [12] and one could describe Systems Engineering as the discipline that chooses the elements and designs, plans, and implements the connections to realize the desired function in a reliable way, i.e. it is the discipline of integration. Systems Engineers must, therefore, adopt both a systemic and systematic perspective and employ systems thinking approaches and execute disciplined engineering processes.

The Systems and Software Lifecycle Standard [13] describes 30 processes needed to manage development and operationalization of a system; the processes of many systems organizations are based on this standard, though the manner in which they are procedurised may vary according to sector and internal factors. Application of these processes, with appropriate tools, should ensure good technical governance of system development. Systems Engineering is concerned with the whole life cycle of a system (from concept through to decommissioning or disposal) and provides a formal structure in which decisions relating to trade-offs between competing factors are addressed in order to manage cost, performance, and risk. Innovation can occur at any place in the life cycle, but we focus here on the development phase. As an example, we use the well-known V-model of the development life cycle (Figure 1).

Figure 1 is a model of a development cycle that shows the relationship of the various life cycle activities to each other: it is not a life cycle per se. The model indicates that a user has requirements (or needs); these may be very abstract and 


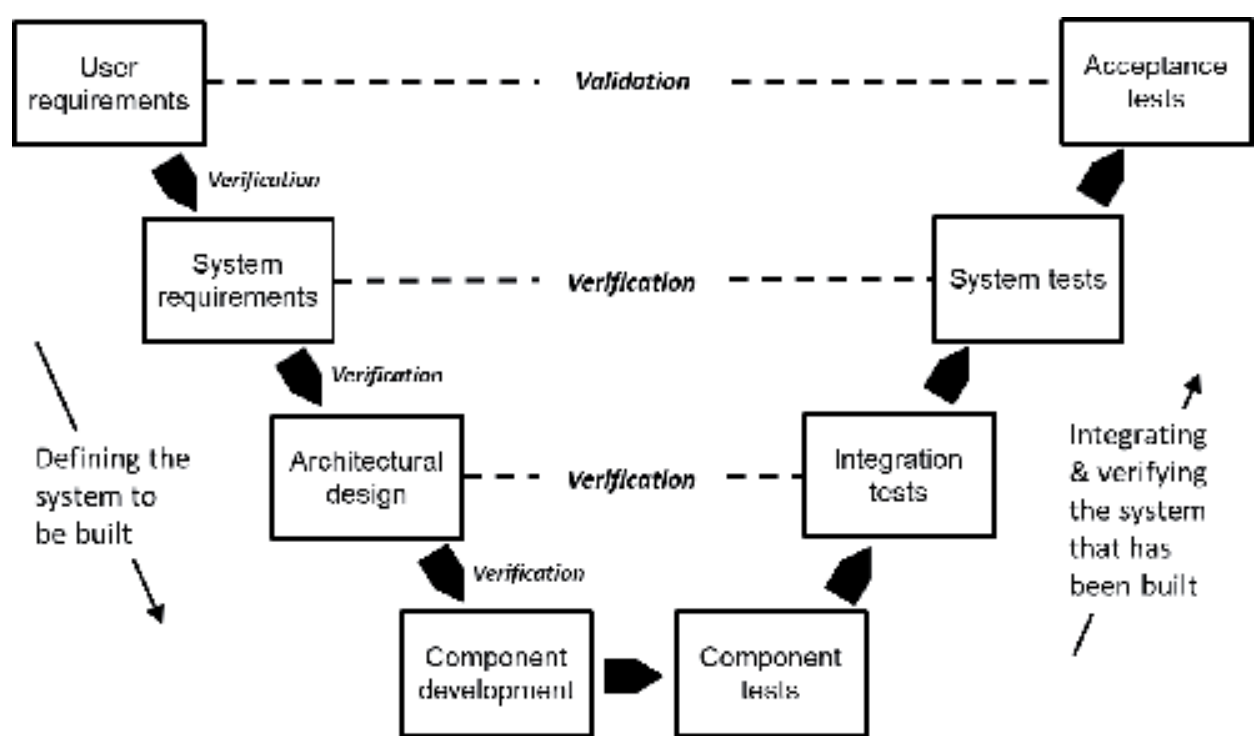

Figure 1.

The V-model of a system development lifecycle (after [14]).

may (often do) change as the user (or customer) learns more about the possibilities. At some point, these must be translated into systems requirements that provide sufficient detail to design a solution. The step of architectural design includes a raft of activities, including the inventiveness associated with creating a concept solution to meet the requirements. That concept must be expressed in architectural form that organizes a set of components that must be either created or acquired. These are broadly the processes through which the system is defined (left-hand side of the V). At every step verification takes place to ensure consistency between the steps and these are frequently iterations through which changes are agreed (e.g. to requirements). The right-hand side of the $\mathrm{V}$ concerns various stages of integration (i.e. build the system) with verification taking place to ensure that what has been built (assembled) is consistent with the design (i.e. that the system is built correctly). Finally, the system may be deployed and tested against the user's requirements (i.e. that the correct system has been designed and built). Checking that the user's requirements have been met is validation of the system. Verification is continually taking place to ensure correctness throughout the development. A more detailed discussion of the various stages may be found in references such as $[14,15]$.

One might justifiably assert that 'surely such tight control must stifle innovation'. But in fact, innovation can occur at all stages; the Systems Engineering processes are designed to ensure that the risk of errors and faults is reduced through the development and that the purpose is kept in mind throughout. Referring to Table 1, the so-called valley of death (for technology projects) is TRLs 5-7, which is the assembly of the system and its testing in appropriate environments. It has been asserted by UK Government that managing the risk through these stages is a major need for technological innovation [1], and we argue that Systems Engineering is the approach to do this.

\section{Systems, systems of systems, and standards}

Useful systems rarely comprise a unitary system acting in isolation, but are frequently combinations of interacting systems, referred to as 'Systems of Systems' 
(SoS). Brook has provided a general definition of SoS as '....a system (systemic statement) which results from the coupling of a number of constituent systems at some point in their life cycles (systematic statement)' [16]. Thus, systems that may, or may not, have been originally designed to work together may have to interoperate to deliver capabilities to a user; the constituent systems can operate outside the context of the SoS, or perhaps be constituent systems within several independent SoS. Their development histories (e.g. updates) and commitments to the SoS may be the responsibility of different organizations. The properties of operational or managerial independence are frequently defining characteristics of SoS [17] and certainly present many complex challenges for operation and control of SoS. Because of the massive increase in connectivity of systems since about 2008, Dahmann and Henshaw have suggested that all systems should now be considered to be SoS [18].

Recognizing that engineering of SoS concerns the connecting together of systems with different lifecycles, a popular development model (especially for defense systems) is the Wave Model [19], see Figure 2. This model suggests that planned introduction of new systems and retirement of old offer greater opportunities for agile innovations in the overall SoS, whilst maintaining rigorous integration of constituent systems. The process suggested by the wave model is one of identifying capability gaps with current SoS with reference to the (changing) external environment and seeking solutions that address the gap through changes to the SoS by introducing new systems, changing existing systems, or reconfiguration of the SoS.

Reconfiguration of SoS is an important component in some forms of innovation, whereby users are able to create new (or enhanced) capabilities by rapidly assembling interoperable systems to meet their needs. Some have argued that standards may stifle innovation [20], but in the case of this case, clearly innovation is only possible because of interoperability standards that enable reconfiguration.

Tidd et al. [7] mapped types of innovation to a six-box framework, depending on whether the innovation was at the component or system level and the extent to which it was incremental or radical. Based on the foregoing discussion, we can consider innovation in the context of Systems Engineering (Figure 3). The V-model includes innovation at either (or both) the system level and the component level; of particular note is the role of Systems Engineering in maturing the technology project through TRLs, 4-8 as integration proceeds within increasingly representative environments. Typically, this will of an incremental nature. For Systems of Systems, the wave model represents the inclusion of either new components, or

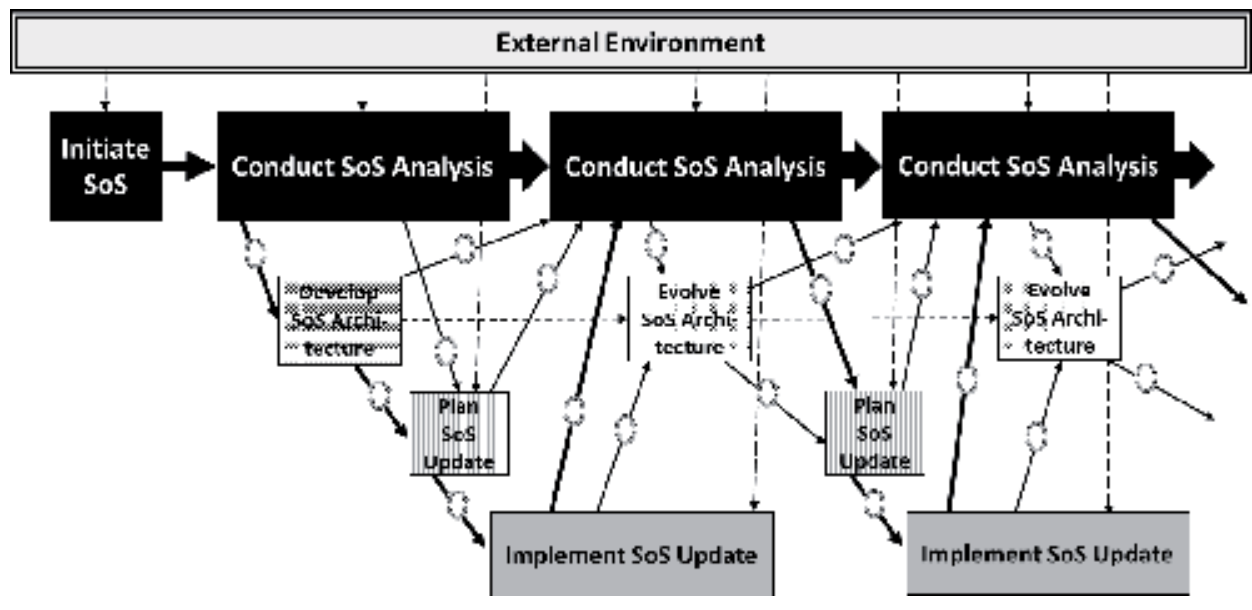

Figure 2.

Wave model for SoS development [19]. 


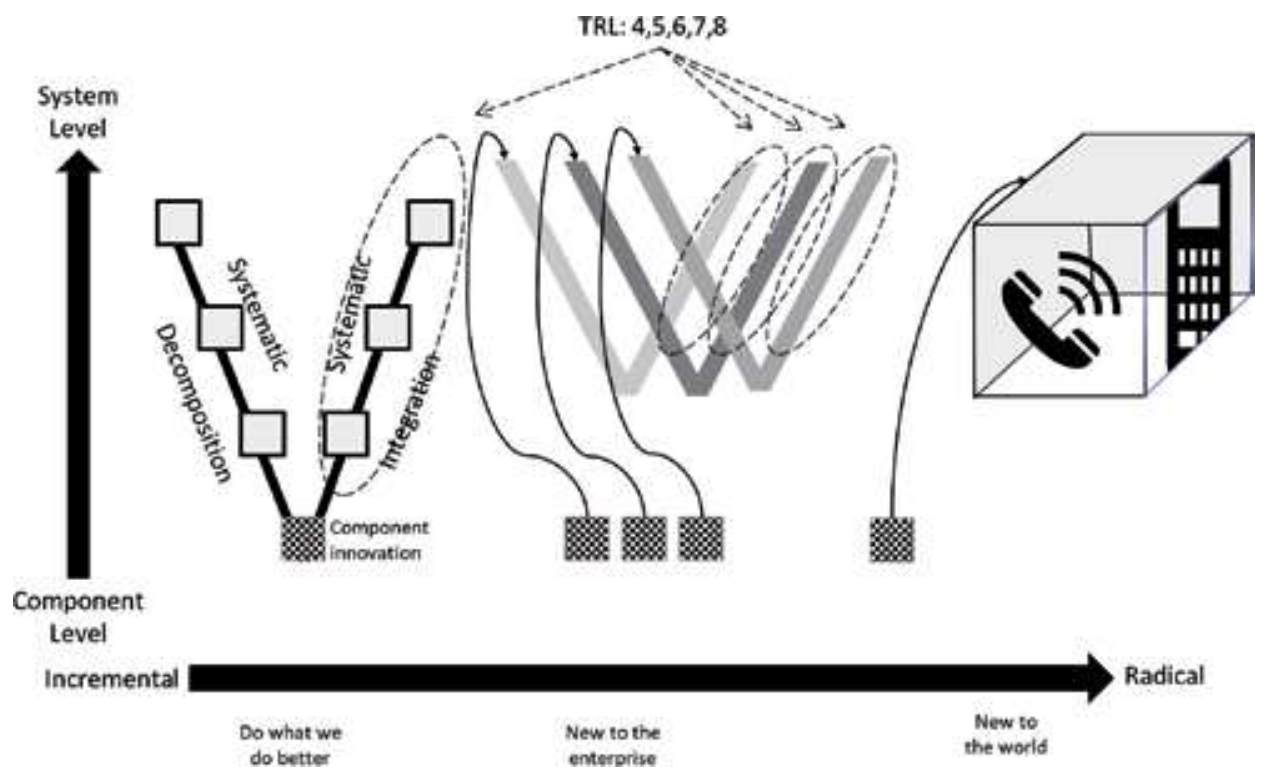

Figure 3.

Types of innovation based on framework of [7].

new configurations of components, so that the technology may be at a higher level of maturity at the decision point for inclusion. Systems Engineering provides the integration capability that once more matures the project through the TRLs 4-8. In fact, for the wave model, it may operate in a purely incremental level, or include some level of radical innovation. At the radical end of the scale, the innovations have more in common with disruptive technology, which may include completely new uses of already matured technologies, or game changer technologies that may be introduced through various mechanisms, depending on the type of application and the industries involved. It may be remarked that 'disruptive technologies' is perhaps a misnomer, as in general they refer to 'disruptive applications'.

To some extent, one might argue that the inventiveness aspect of innovation is due to systemic thinking (holistic viewpoint, consideration of problems from all angles), and the transformation of the idea to real world application is due to systematic thinking and work, that ensures orderliness of the development process. Certainly, this is true for innovation that is somewhat incremental. Inventiveness may be manifest at any point of the development lifecycles indicated schematically in Figure 3. Of course, it is the quality of the Systems Engineering in terms of choice of methods and tools, expertise in their application, and management of information that determines the effectiveness of maturing the technology project through TRLs 4-8. It is, then, appropriate to consider the attributes of good Systems Engineers in terms the innovation process.

\section{The qualities of innovators and systems engineers}

One important factor in innovation success is meeting customer or user expectations, and effective requirements management is the cornerstone of good Systems Engineering. A corollary of this is that technical 'inventiveness' at the component level may not translate into innovation success, because usually the customer is concerned with what the system (or device) can do, rather than how it does it. In his excellent book, 'The Myths of Innovation', Berkun draws attention to the fact 
that innovation does not just rely on technical prowess, but also on commercial proficiency [21]. He disagrees with the notion of the Eureka moment, arguing instead that the creative moment is not the sudden emergence of an idea, but rather the fitting of the last piece of a jigsaw that shows the inventor how a change may be achieved. This is very well illustrated by an example that I often give to undergraduate engineers, entitled: 'How the Wright Brothers Exemplified Systems Engineering', which I base on the biography of the brothers by Jakab [22]. These are the attributes they displayed:

- Conducted a thorough critical analysis of previous work: the brothers contacted the Smithsonian and the aviation pioneer Octave Chanute to request all the papers they could assemble, from which they learned what worked, but equally importantly what did not work.

- Critical thinking: the brothers challenged conventional wisdom; for example, the Smeaton coefficient had long been accepted as 0.005 , but the Wright's tested the theory of force due to flow and corrected the value to 0.0033 .

- Re-used appropriate data: satisfied of the reliability of data, they used Leilenthal's data sheets for aerofoil forces, rather than duplicating work.

- Employed an effective decision-making process: Orville and Wilbur Wright had many arguments, some very intense. They used a novel process to resolve these by holding a court of family members, with their father as judge, to hear their arguments and to resolve the disputes. Effective teams should have disagreements but should have mechanisms for resolving them in a positive manner.

- Holistic thinking: for any system to work, then all the individual components must work in a complementary fashion; for an heavier-than-air vehicle to fly, then the four aspects of control/stability, aerodynamics, propulsion, and structural strength must all be successfully addressed in the integrated design [23]. The Wright brothers were the first to conceive the aeroplane as a whole and complete system.

- Thoroughly understand the problem: the Wrights were the first to recognize the control/stability problem properly. Whereas others had relied on human control to restore a stable flight condition (e.g. when disrupted by a gust), they used a foreplane with a different angle of attack.

- Include humans/users in the system design: the brothers took good account of human factors; in particular, they realized that once airborne expertise in flying would be required. Thus they learned to fly and practiced using gliders prior to attempting powered flight.

- Technical knowledge: they knew the relevant laws of physics to make appropriate mathematical modeling, e.g. for sizing the vehicle.

- Visual thinking/analysis ability: Jakab [22] makes much of the brothers' visual thinking abilities, arguing that it is an essential element of engineering genius to be able to picture a design object and how it will work physically, incorporating new features and how they will perform in the minds-eye. An example would be their appreciation of the nature of drag and decision to use a prone 
pilot to reduce it. I once worked with a brilliant configuration designer in aeronautics, Ian Chisholm, who without calculation cured a strange acoustic effect with the introduction of a bump on a wing, because he could somehow visualize how it would work. It is a form of non-verbal reasoning and holistic thinking [24] but, whilst the value of visual thinking is appreciated, its precise nature and origin is less-well established.

- Synergistic thinking: The Wrights were bicycle manufacturers and used their knowledge of balance and user interaction to assist their understanding with respect to the development of the aeroplane. A well-known example of their synergistic thinking was the introduction of wing warping for control. Wilbur Wright apparently devised the mechanism for wing warping after absentmindedly playing with a cardboard box and realizing that even when applying considerable torsion (twisting) it retained its lateral stiffness. Synergistic thinking is the ability to apply principles learned in one context to the solution in another.

- They had practical ability: their understanding of bicycle building enabled them to be good at making machines to appropriate quality.

- Experimentation: The Wright brothers were not the first to use wind tunnels, but their practical abilities enabled them to make precision instruments for measuring forces and through hundreds of hours of wind tunnel experiments, they determined the most efficient aerofoil.

- Manufacturability: design for manufacture is a key competence within engineering, though not one that is always given sufficient priority. It is a part of lifecycle planning that should be valued; the Wrights built their vehicles in modular parts for easy construction onsite (also appreciating the logistics challenges of moving the vehicle to the test site).

- Prototyping: they used kites to understand forces and behaviours and, indeed, when they were struggling to achieve the control behaviours they desired, experimented with different foreplane angles using kites.

- Documentation: the brothers kept log books and recorded detailed information, although it would appear that some was recorded afterwards and not all the records are clear to others [22].

These iconic innovators used both systemic and systematic thinking, which is the quality of good systems engineers. The extent to which the qualities listed above are due to nature or nurture may be the subject of another analysis, and we express no view on that here; they provide a sketch of the abilities and behaviours that one would wish to see in a practicing Systems Engineer and appear to represent the qualities of innovators. Having focused on the behaviours of individual innovators, we now turn our attention to organizations in which innovation will thrive.

\section{Knowledge management in innovative enterprises}

The foregoing discussion on Systems Engineering has indicated that it is an essential discipline for complex systems projects; it probably offers less benefit for simple projects, where a systems approach, rather than the full weight of 
Systems Engineering is sufficient. Complex projects generally involve many people and it is often the case that contributions must be integrated across an enterprise of many collaborating organizations. One can legitimately ask how innovation can thrive in a complex enterprise. It may be stretching the simile a bit far, but Berkun's notion of inventiveness being the last piece of the jigsaw [21] implies that one must know all the other pieces and, most importantly, how they all fit together. Within the enterprise there must be an understanding of all the parts and how they interact, which is the task of systems engineers. We consider now the role of knowledge management in the context of complex systems and enterprises.

Blackler introduced a notion of knowledge belonging to one of five categories [25]:

- Embrained-abstract knowledge that is reliant on cognitive competence and conceptual abilities

- Embodied-knowledge that is oriented toward action, 'know how', skill. 'Practical thinking' that depends on understanding of the situation rather than abstract rules.

- Encultured-socially constructed knowledge that is manifested in a shared understanding. This knowledge is closely connected with language.

- Embedded-knowledge that is set in general routines, technologies, roles and procedures.

- Encoded-knowledge that communicated through symbols in paper and electronic formats such as books, manuals, handbooks, drawings, etc.

These clearly divide into knowledge that is mostly explicit (embedded and encoded) or mostly tacit (embrained, embodied, and encultured), and it is argued that all forms are important in effective organizational knowledge management. To these five, Ahlberg Pilfold [26] has added a sixth category, that of knowing where to find information or knowledge. This is an organizational knowledge skill. Put simply, the ability of an enterprise to put an idea into practice relies on the ability to assemble all the necessary knowledge effectively. The distinction between information and knowledge is important, here, as a contrast between 'know what' and 'know how'.

Cilliers has considered knowledge in the context of complexity [27] and argued that whereas fundamentalists believe that formal knowledge (facts, formulae, etc.) can be used to describe systems, in the case of complex systems they cannot be separated from their context and that it is not possible to know all aspects objectively and it is only possible to know about the complex system from a cultural or personal perspective: hence the knowledge is relative. He goes on to consider the problem of boundaries: that a complex system is made up of nonlinear relationships that cannot be reliably reduced, in terms of its complexity so that 'there is no accurate representation of the system, which is simpler than the system itself' [27]. Nevertheless, Cilliers criticizes relativism as an unsustainable position, and concludes that 'the notion of scientific knowledge should be developed beyond abstract objectivity without falling prey to relativism'. This suggests that the knowledge to create and develop complex systems should include the dynamics of the relationships within those complex system that may (for instance) include emotional, non-deterministic, or changeable interactions between system elements. 
We have argued above that innovation requires both systematic and systemic thinking. The knowledge of systematic thinking is objective, but it may be that systemic thinking may include relativistic knowledge, in which the individual parts and their interactions are not completely known, but the overall behaviour of the system is appreciated. Thus the five knowledge Es of Blackler [25] should all be appreciated in effective innovative enterprises and the sixth knowledge category of knowing where to find the required knowledge within the enterprise (or indeed outside it) provides the knowledge resources needed for collective innovation.

Ahlberg Pilfold [27] studied two large organizations, one in the private sector and the other a part of government, considering their ability to manage knowledge for the purposes of maintaining capability. The private company, 'ServiceCo' employs nearly 90,000 people worldwide, divided into six business units, and has private, corporate and government customers. ServiceCo relies on the products and services provided by a large number of suppliers, partners and external technical experts.

ServiceCo operates in a field where technology has a lifecycle ranging from 5 to 30 years, with infrastructure dating back to the 1970s. There is a risk that ServiceCo is unable to support the legacy systems because many employees who had worked with the implementation, design, operation and maintenance of the existing infrastructure were retired and/or chose voluntary redundancy.

At the time of the study, the government organization had approximately 3900 fulltime employees, of which around 2900 were professional and technical staff who manage and deliver a Science and Technology Programme. Whenever possible, work was placed with external providers such as academia and the private sector.

In both cases, management of knowledge is challenging because many of the complex systems that must be maintained and operated include substantial levels of legacy components (tangible and intangible), and the organizations rely strongly on expertise outside of their organization to deliver the capabilities for which they are contracted and responsible. Data was collected on knowledge management through organization documents and interviews with employees. The enquiry did not focus on innovation explicitly, but in both cases, the organization had to adapt and introduce new systems to meet the changing circumstances in which their capabilities must remain effective. Hence, the level of innovation directly impacts the competence of the organization. In both cases, the organizations are concerned with the development of new complex systems and apply Systems Engineering to achieve this.

Ahlberg Pilfold identified the following six matters for effective knowledge management (either because the organizations practiced them, or because they did not):

- Succession planning-management of complex systems requires knowledge to be passed on effectively as people retire.

- Maintaining state of the art knowledge (usually through research)

- Corporate values should include recognition that knowledge is a key attribute of the organization

- The need for slack - this means that there needs to be time for learning and consolidating knowledge

- Co-location: her findings indicated that knowledge was better managed with participants in the enterprise are co-located 
- Trust and openness across the enterprise is required to achieve effective interoperability of either organizations in the enterprise or the systems they produce.

- Use models as receptacles for knowledge. This speaks strongly to the Systems Engineering agenda and its current move toward model-based Systems Engineering (MBSE) [28].

These areas of good practice include management of the knowledge in heads (human aspects) and the explicit knowledge captured in models [26].

\section{Conclusions}

We have considered innovation in the context of complex systems and argued that Systems Engineering is an essential organizational skillset of an innovative organization. We identified a number of abilities and behaviours of exemplar innovators (the Wright brothers) and argued that these are the abilities and behaviours that Systems Engineers should practice. We further argued that for complex systems, the development and operation of which are necessarily the endeavour of enterprises rather than individuals, knowledge management is crucial to success. We adopted the five knowledge categories of Blackler [25], but also added the knowledge of where to find knowledge [26] as an attribute of innovative organizations. The knowledge categories include both explicit and tacit knowledge.

Innovation comprises the creativity to invent new ways of doing things, or to identify new opportunities for existing systems, but crucially, the ability to operationalize those ideas. Many technology projects flounder at the range of technology readiness levels between 4 and 7; this is sometimes referred to as the valley of death [1]. These levels are associated with integration, which is the realm of Systems Engineering. We agree with the assertion of Bessant [6], that 'Successful innovation management is not about doing one thing well, but rather organizing and managing a variety of different elements in an integrated and strategically coherent fashion'. To achieve this a systemic view must be retained throughout, but a systematic approach is needed for delivery. Thus, innovation requires individuals and organizations that can adopt systemic thinking and systematic effectiveness: Systems Engineering in terms of both the skills of an organization's employees, and the quality of its procedures, is an essential organizational competence for knowing and innovating.

\section{Acknowledgements}

The case studies referenced in this chapter were carried out in a CASE studentship supported by EPSRC, Dstl, and Loughborough University.

\section{Conflict of interest}

The authors declare no conflict of interest. 


\section{Author details}

Michael Henshaw* and Sofia Ahlberg Pilfold

Loughborough University, UK

*Address all correspondence to: m.j.d.henshaw@lboro.ac.uk

\section{IntechOpen}

(C) 2020 The Author(s). Licensee IntechOpen. Distributed under the terms of the Creative Commons Attribution - NonCommercial 4.0 License (https://creativecommons.org/ licenses/by-nc/4.0/), which permits use, distribution and reproduction for non-commercial purposes, provided the original is properly cited. (cc) BY-NC 


\section{References}

[1] House of Commons Science and Technology Committee, Bridging the Valley of Death: Improving the Commercialisation of Research. In: Eighth Report of Session 2012-13. London: The Stationery Office; 2013. DOI: $10.1049 /$ et.2013.0910

[2] Mankins JC. Technology Readiness Levels: A White Paper. NASA, Office of Space Access and Technology, Advanced Concepts Office; 1995

[3] Henshaw M. The process of innovation in aeronautics. In:

Young TM, Hirst M, editors. Innovation in Aeronautics. Cambridge: Woodhead Publishing; 2012. pp. 199-213. DOI: 10.1533/9780857096098.2.199

[4] Jobs S. Voices of Innovation. Businessweek; 2004. Available from: https://www.bloomberg.com/ news/articles/2004-10-10/voicesofinnovation-steve-jobs [Accessed: October 26, 2019]

[5] Ufimtsev PY. Method of edge waves in the physical theory of diffraction. Moscow Institute of Radio Engineering. 1962. pp. 1-243. DOI: $10.1080 / 02726349108908270$

[6] Bessant J. Challenges in innovation management. In: Shavinina L, editor. Interntional Handbook on Innovation, New York: Elsevier; 2003:761-773. DOI: 10.1016/B978-008044198-6/50052-8

[7] Tidd J, Bessant J, Pavitt K. Managing Innovation. 3rd ed. Chichester: Wiley; 2005

[8] DoD. Mandatory Procedures for Major Defense Acquisition Programs (MDAPS) \& Major Automated Information System (MAIS) Acquisition Programs. 5000.02. Washington DC: US DoD; 2002. Available from: https://ssilrc.army. mil/wpcontent/ uploads/2018/06/
DoD-5000-2-R-Mandatory-Proceduresfor-Major-Defense-Acquisi.pdf [Accessed: October25, 2019]

[9] European commission. A European Strategy for Key Enabling Technologies-A Bridge to Growth and Jobs. Brussels. EC COM, 341 final; 2012. Available from: https:// eur-lex.europa.eu/LexUriServ/ LexUriServ.do?uri=COM:2012:0341: FIN:EN:PDF [Accessed: October 25, 2019]

[10] Héder M. From NASA to EU: The evolution of the TRL scale in public sector innovation. The Innovation Journal. 2017;22(2):1-23

[11] Honour EC. Systems Engineering Return on Investment. Adelaide: University of South Australia; 2013

[12] Rechtin E. Systems Architecting, Creating and Building Complex Systems. Englewood Cliffs, NJ: Prentice Hall; 1991

[13] ISO/IEC/IEEE, ISO 15288. Systems and Software Engineering-System Life Cycle Processes. Version 15288:2015. Geneva: ISO, IEC, IEEE, 2015

[14] Stevens R, Brook P, Jackson K, Arnold S. Systems Engineering-Coping with Complexity. Prentice Hall, Europe: Harlow, Essex; 1998

[15] Blanchard BS, Fabrycky WJ. Systems Engineering and Analysis. 5th ed.

Harlow, Essex: Pearson Education; 2013

[16] Brook P. On the nature of systems of systems. In: INCOSE International Symposium. 18-21 July 2016; Edinburgh, Scotland. INCOSE; 2016

[17] Maier MW. Architecting principles for systems-of-systems. Systems Engineering. 1998;1(4):267-284. DOI: 10.1002/j.2334-5837.1996.tb02054.x 
[18] Dahmann JS, de Henshaw MJC. Introduction to Systems of Systems Engineering. Insight. 2016;19(3):12-16. Available from: https://onlinelibrary. wiley.com/doi/abs/10.1002/inst.12100 [Accessed: October 25, 2019]

[19] Dahmann J, Rebovich G, Lane JA, Lowry R, Baldwin K. An implementers' view of systems engineering for systems of systems. IEEE Aerospace and Electronic Systems Magazine, IEEE. 2011;27(5):212-217. DOI: 10.1109/ SYSCON.2011.5929039

[20] Vincent CJ, Niezen G, O’Kane AA, Stawarz K. Can standards and regulations keep up with health technology? JMIR mHealth and uHealth. 2015;3(2):e64. DOI: $10.2196 /$ mhealth.3918

[21] Berkun S. The Myths of Innovation. O’Reilly Media, Inc.; 2010

[22] Jakub PL. Visions of a Flying Machine: The Wright Brothers and the Process of Invention. Washington DC: Smithsonian Books; 1990

[23] Anderson JD. Aircraft Performance and Design. USA: WCB/McGraw-Hill; 1999

[24] Zhukovskiy VI, Pivovarov DV. The nature of visual thinking. Journal of Siberian Federal University. Humanities and Social Sciences. 2008;1:149-158

[25] Blackler F. Knowledge, knowledge work and organizations: An overview and interpretation. Organization Studies. 1995;16(6):1021-1046. DOI: 10.1177/017084069501600605

[26] Ahlberg-Pilfold S. Managing Knowledge for through Life Capability. UK: Loughborough University; 2016. Available from: https://dspace.lboro. ac.uk/2134/21802 [Accessed: October 25, 2019]

[27] Cilliers P. Knowledge, limits and boundaries. Futures.
2005;37(7):605-613. DOI: 10.1016/j. futures.2004.11.001

[28] Dickerson CE, Mavris D. A brief history of models and model based systems engineering and the case for relational orientation. IEEE Systems Journal. 2013;7(4):581-592. DOI: 10.1109/JSYST.2013.2253034 


\title{
An ISM Approach to Evaluate Critical Success Factors for Knowledge Management in the Kingdom of Saudi Arabia
}

\author{
Suresh Renukappa, Subashini Suresh, Saeed Al Nabt, \\ Redouane Sarrakh and Khaled Algahtani
}

\begin{abstract}
The Kingdom of Saudi Arabia (KSA) government aims to reduce fiscal deficit by improving efficiency, reducing costs, as well as its subsidies. This often calls for the creation, use and exploitation of new knowledge. Therefore, knowledge assets must be properly managed to provide an environment for well-informed decisions. The aim of this chapter is to investigate the critical success factors (CSFs) for effective implementation of Knowledge Management (KM) strategies in the KSA public sector organisations. Semi-structured interviews with 42 public sector directors and managers were conducted. Nine key CSFs were revealed. The association between the identified factors is established by employing an interpretive structural modelling methodology. The Matrix of Cross-Impact Multiplications Applied to Classification analysis is carried out for identifying the factors having high influential power. The results indicated that 'leadership' and 'organisational culture' are the most significant critical success factors having highest driving power. The chapter concludes that leadership plays a key role in implementing KM strategies in the KSA. Leadership is about preparing organisation with a KM vision and values. The findings of this research provide valuable insight and guidance which will help the public sector decision makers to accomplish KM strategies effectively.
\end{abstract}

Keywords: interpretive structural modelling, public sector, multi-criteria decision-making, knowledge management strategies

\section{Introduction}

Today, public sector organisations are also known as knowledge-based organisations and knowledge is as critical a resource to public sector organisations as it is to private sector firms [1]. Knowledge is one of the building blocks for an organisation's success and acts as a survival strategy in this knowledge era [2]. Therefore, knowledge resource resides in employees' minds and organisations must utilise this valuable resource for their competitive advantage [3].

Ragsdell et al. [4] noted that knowledge and know-how cannot simply and freely be flowed and shared among colleagues in organisations. Knowledge is the act of 
knowing or being aware or familiar by learning from experience or association. Knowledge has been defined as the factor that enhances an individual's capabilities for taking effective actions [5]. The two dimensions of knowledge according to Nonaka and Takeuchi [6]. The explicit knowledge is organised and well-structured; hence, it is easily communicated. The second dimension is the tacit knowledge which is hard to be explained and interpreted. It is not easily communicated and is based on the individuals' experience, emotions, values and the ideals which they espouse. Madhoushi and Sadati [7] state that KM is a planned and well-structured process that includes managing the construction, designing, disposal and transfer of explicit as well as tacit knowledge in order to gain competitive advantage and encourage innovative ideas.

Jashapara [8] highlights that knowledge is considered as a critical and important factor in organisations for competitiveness and economic growth underlying innovation. Wiig [9] argued that knowledge will be the key to success in the twenty-first century, due to knowledge generating a value for the organisation when it is employed. Egbu [10] noted that knowledge management is the interrelated cyclical and iterative processes by which knowledge is identified, captured, codified, stored and disseminated for the benefit of the organisation. Chase [11] noted that knowledge management is a discipline that some industries and people adopt in order to encourage people to share knowledge or any ideas with the purpose of creating value-added products and services. Alavi and Leidner [12], in their seminal work, concluded that KM involves distinct but interdependent processes of knowledge creation, knowledge storage and retrieval, knowledge transfer and knowledge application. Thus, KM is a natural solution for improving operations and enhancing citizen's satisfaction. The management of both explicit and tacit knowledge is a crucial aspect of the public sector in developing their competencies.

Yahya [13] stated that, in the Middle East and North Africa region, over two-thirds of organisations are evaluating the need for KM, but less than a third have or are currently setting up a KM programme. Milner [14] suggests that the lack of enthusiasm to adopt KM in the public sector is directly linked to the required achievement of innovative and creative outcomes through the sharing of tacit knowledge, "knowledge rich open and creative operating cultures". The Kingdom of Saudi Arabia (KSA) aims to reduce fiscal deficit by improving state efficiency, reducing costs as well as its state subsidies. Consequently, the KSA Government has announced an ambitious new strategy: Vision 2030 [15]. It is tending towards knowledge economy. Therefore, this chapter explores the critical success factors (CSFs) for effective implementation of KM strategies in the KSA public sector organisations. The KSA organisations have been implementing KM solutions, but they face several issues and challenges, such as organisational culture, technology barriers and weaknesses in leadership's lack of learning activities [16].

Digman [17] defined CSFs as the areas where things must go right in order for the business to flourish. Critical success factors are defined as the handful of key areas where an organisation must perform well on a consistent basis so as to achieve its mission [18]. Alazmi and Zairi [19] noted that CSFs are aimed at creating a KM environment that provides organisations with some sustainable competitive advantage through the continued creation of knowledge, maintenance of current knowledge assets and creating an environment in which the KM function can survive and grow. In the context of the implementation of KM strategies, CSFs represent the essential ingredients without which a project stands little chance of success. 


\section{Research methodology}

The aim of this study is to investigate the CSFs and to structure the relationship between these CSFs for effective implementation of KM strategies in the KSA public sector organisations en-route to organisational competitiveness. Therefore, the choice of research methodology is a crucial and difficult step in the research process.

To explore the in-depth understanding of the current study research problem, the research focuses on the perceptions of individuals relating to the CSFs for implementing KM strategies in the KSA public sector organisations. Therefore, to gain an understanding of employees' perceptions, it is necessary to use a methodology that elicits interviewees' inner thoughts and feelings. Kvale [20] stated that an interview's purpose is to gather descriptions of the lifeworld of the interviewee with respect to interpretation of the meaning of the described phenomena. Ribbens and Edwards [21] noted that the suitable number of experts for qualitative research may range from five to 50. Murry and Hammons [22] suggested that, for the qualitative decision-making process, the number of experts may be in the range of 10-30. To ensure greater dependability and transferability [23], a total of 42 professionals were interviewed in the KSA public sector organisations.

The sampling method used is purposive or non-probability sampling, whereby the subjective judgements of the researcher are used in selecting the sample [24]. In purposive sampling, participants are selected to meet a specific set of criteria. The study sample included directors, advisers and managers responsible for implementation of KM strategies in their respective departments/organisations.

An important sample size issue in qualitative research involves saturation of information [25]. Saturation is a term used to describe the point when no new insights or range of ideas are generated through adding more data. In this study, data were collected until no new aspects of the CSFs were revealed. In this study, actual saturation of data occurred before the 40th interview. Therefore, 42 interviews were conducted. Content analysis was used followed by interpretive structural modelling (ISM) method.

\subsection{Interpretive structural modelling (ISM)}

According to Watson [26], ISM is a method involving a qualitative and interpretive approach (based on the judgement of the experts from the industry and academia) to resolve complex problems based on a structural mapping of interconnections of attributes, followed by transforming them into a multi-level structural model. The finding from content analysis was subjected to ISM method.

According to Raj et al. [27], ISM has several characteristics which make it suitable to be applied in the present study: experts' knowledge and experience is utilised to analyse the complex system and break it into different elements to build a clearer model; it is a modelling technique wherein relationships are depicted into a diagraph model; it is intended to be used for group and individual learning; and it improves the quality of communication within the context of the problem. Although ISM has several advantages, the methodology possesses a few limitations: a limited number of variables are used in the model development, leading, thus, to ignoring the least affecting variables or issues; and people's bias, which may impact the final result.

Malone [28] noted that ISM is an application of simple notations of graph theory used to explain the complex pattern of relationships. This methodology is widely used by researchers for exploring the direct and indirect association among the identified parameters of various disciplines in a simplified way. ISM is utilised to 
understand the relationships between the CSFs and to develop insights into a collective understanding of these relationships.

The eight steps involved in the ISM method are listed below [29-32].

Step 1: the CSFs for implementing KM strategies in the KSA public sector organisations context are identified through experts' opinion.

Step 2: a relationship is established between the CSFs determined in step 1.

Step 3: a structural self-interaction matrix (SSIM) of CSFs is developed, indicating a pair relationship between all CSFs.

Step 4: a reachability matrix is formed using the SSIM.

Step 5: the reachability matrix is put into different levels.

Step 6: a diagraph model is developed to illustrate the links.

Step 7: the developed diagraph is converted into a CSFs ISM model.

Step 8: ISM model is checked for consistencies.

\section{Interpretive structural modelling (ISM) development}

\subsection{Identification of the critical success factors for implementing KM in the KSA public sector organisations}

In this study, interviewees were asked to list and describe the CSFs for implementing KM strategies in their organisation through face-to-face interviews. Table 1 shows the nine CSFs for implementing KM strategies in the KSA public sector organisations. Each of these CSFs is discussed in detail below.

\subsubsection{Leadership}

Organisation leadership forms the foundation for successful KM implementation [33]. Ichijo and Nonaka [34] emphasise the role of leadership in building and managing knowledge in organisations. By reviewing the literature to provide a framework for assessing KM and KM success factors, Jennex and Olfman [35] note that leadership is one of the most important critical success factors.

In this study, overwhelmingly $95 \%$ (40 of the 42) said that the absence of active management involvement is likely to mean that the KM process will be handicapped by insufficient time, finance and human resources. Therefore, it is most important that knowledge workers perceive their leaders as being actively engaged

\begin{tabular}{lc}
\hline CSFs for effective implementation of KM strategies & Percentage of interviewees cited $(\mathbf{N}=\mathbf{4 2})$ \\
\hline Leadership & $95 \%(40 / 42)$ \\
\hline Organisational culture & $90 \%(38 / 42)$ \\
\hline Information and communication technology infrastructure & $83 \%(35 / 42)$ \\
\hline Reward and incentive system & $81 \%(34 / 42)$ \\
\hline KM strategy & $76 \%(32 / 42)$ \\
\hline Knowledge audit & $71 \%(30 / 42)$ \\
\hline Training and education & $69 \%(29 / 42)$ \\
\hline Knowledge sharing & $60 \%(25 / 42)$ \\
\hline Knowledge capture & $48 \%(20 / 42)$ \\
\hline
\end{tabular}

Table 1.

Critical success factors for implementing KM strategies in the KSA public sector organisations. 
and committed to supporting knowledge activities and they recognise and reward such attempts in their co-workers. Leadership is most important because this is the authority that shapes the organisation; they can build, create, gain and implement knowledge to achieve organisational goals. If the leaders focus on the knowledge sharing and implementation, the subordinates cannot hoard knowledge. Moreover, the leaders may include KM in the organisation's mission and vision.

For instance, one of the interviewees noted that:

\begin{abstract}
"Because of the recent recession, downsizing and cost-cutting initiatives taken by the KSA government, innovation is important for our sector in general and to my department in particular. Amount of knowledge loss because of retirement and downsizing becomes a crucial issue for us. Managing our internal knowledge assets is critical. Therefore, we have created a new position called Chief Knowledge Officer (CKO). The responsibility for developing and implementing KM strategies in our department often falls on the shoulders of a CKO. It becomes the CKO's responsibility to develop a strategy that dictates how a department handles its knowledge assets and to foster a culture that is constantly learning and growing. To meet the CKO's goals, we have created a new knowledge map, information and communication technology infrastructure and reward systems to promote knowledge capture and a sharing culture."
\end{abstract}

The aforementioned statement suggests that organisations are creating new leadership positions at the organisation or department levels to create culture for knowledge capture and sharing. Yu et al. [36] pointed out that both the support from high-ranking officers and the activities arranged by KM groups would influence the KM performance positively. Putting transformation and change in perspective helps people balance the fears and opportunities associated with change, and to make better choices about the way that they react. Leadership is everyone's job in an organisation, rather than the job of the leader, and it is hard to envision any degree of sustainability without it. Leadership is the essential ingredient in creating enthusiasm in an organisation, especially when the going gets tough. However, this factor is no different from that required in any other corporation driven by a strong vision [37].

In summary, leadership commitment to KM initiatives would assist in breaking down barriers in achieving KM goals-barriers such as tunnel vision, past practice, old ideas and cultural frameworks that, together, combine to discourage new visions of the future. The key to effective implementation of KM strategies in the KSA public sector organisations is for leadership to establish a culture that is proactive in formulating KM-related objectives, to pursue a strategy of continuous improvement and resource that strategy. In addition, leadership is about preparing organisations with a knowledge-based vision and values that resonate with the leadership team, all employees and key stakeholders. More importantly, top management and senior executives must demonstrate the sharing of their own knowledge, using others' knowledge in the actions they take and giving credit to accountants who share their knowledge [38]. Therefore, leadership is crucial for implementing KM initiatives. Leadership skills need to be reinforced by the corporate values, the funding of corporate change programmes and willingness to transform organisations towards a knowledge-based view of the firm.

\title{
3.1.2 Organisational culture
}

Of the interviewees, $90 \%$ (38 of the 42 ) asserted that organisational culture is one of the main critical success factors for successful implementation of KM-related 
initiatives in their organisations. These findings have also been supported by Al-Adaileh and Al-Atawi [58] as, in their study on the topic of significance of organisational culture in the context of Saudi Telecom; they concluded a positive direct relationship of organisational culture in the KM. The absence of active management involvement is likely to mean that the KM process will be handicapped by insufficient time, finance and human resources. Change in culture and individual behaviour must aim towards encouraging the use of knowledge, not for individual advantage, but for the benefits of the organisation as a whole [38].

Drawing on Tseng [39], organisational culture can either enable or disable the knowledge conversion process in an organisation. Liebowitz and Chen [40], for instance, found that it is more difficult to share knowledge in public sector organisations because most people associate knowledge with power, and their promotion opportunities. Tseng's [39] proposition is based on her study to identify the extent of correlation between different types of organisational culture and knowledge conversion and corporate performance.

Schein [41] defined organisational culture as a set of implied principles held by the people in a society which determines the behavioural implications. In the nutshell, cultures are the product of the tacit underlying beliefs and values that enforce the actions needed to achieve organisational goals [42]. Wang et al. [43], in their study, also supported the idea that organisational culture determines the observable norms and practices that prevail in an organisation which then results in laying down the foundation for rituals, expectations, routines, stories and myths. On the other hand, the norms set by the culture lead to the promotion of social context for the communication between people. Hislop [44] hinted at a link between organisational culture and KM through arguing that organisational culture lays down the social context which, in return, determines the source of knowledge in an organisation, such as who holds the knowledge and who is to share the knowledge.

\subsubsection{Effective information and communication technology}

In this study, $83 \%$ (35 of the 42 ) of the interviewees noted that the effective implementation of information and communication technology (ICT) tools to facilitate knowledge capture, mapping and sharing is another important critical success factor for their organisations. An ICT infrastructure provides a broad platform for mapping knowledge, exchanging knowledge, coordinating activities, sharing knowledge and supporting globalisation of commerce. Certain technologies can go a long way in making knowledge exchange easier and more efficient.

Quintas [45] stated that ICT has an unquestionable place in organisations. Information and communication technologies must work with, and not against, the key fundamentals that make human beings knowledgeable in social contexts. This emphasises the need for the transformation from tacit to explicit knowledge. Some of the advantages of ICTs are that they can lead to effective and efficient practices through the use and exploitation of knowledge and reduction in the number of mistakes being made.

\subsubsection{Reward and incentive system}

The role of a rewards and incentive system in managing knowledge is to motivate employees to map, capture and share their tacit and explicit knowledge. It is found that the motivation to contribute knowledge is an intangible critical success factor for any KM activity [46]. In this study, 81\% (32 of the 42) of the interviewees 
stated that a rewards and incentive system to promote KM initiatives is another important critical success factor. Wang et al. [43] also supported the adverse role of monetary reward for the KM, arguing that monetary rewards promote transactional behaviour in an organisation that, in the long-term, demotivates staff and could even lead to the destruction of a firm's financial position.

Knowledge workers are knowledge providers and value creators in an organisation [47]. As such, organisations will not be able to turn 'our people' into 'our most valuable assets' without addressing the real need of 'our people'. Therefore, it is important to encourage, motivate and reward employees who contribute to the organisation's knowledge and this culture-related issue remains a challenging task for most organisations [48]. However, relying solely on the monetary reward or incentive system to promote KM could prove to be a problematic task, hence, it is important for the management to keep a balance between monetary and nonmonetary reward as a basis for the promotion of KM [49].

\subsubsection{KM strategy}

In this study, 76\% (32 of 42) of the interviewees noted the need for having a robust KM strategy as one of the most important critical success factors. Many public sector organisations in the KSA suffer from the absence of a KM strategy and even those who do have one usually end up in facing resistance from upper level management to implement it [50]. In recent years, the concept of strategic management has shifted from the resource-based view to the knowledge-based view of the firm, as it enables organisations to increase their capacity and competitive advantage [51]. While the basic strategy of an organisation defines corporate direction through setting up its goals, objectives and strategic policies, when it comes to the $\mathrm{KM}$, strategy becomes the logical architecture that specifies critical elements in an organisation's strategy and serves as a tool for communicating and clarifying that strategy. Despite of the importance of the KM strategy for providing firms with competitive advantage in the marketplace, public sector organisations tend to have a lack in their ability to lay down a robust KM strategy. For instance, while studying the challenges faced by the public sector organisations for promoting open innovation, Mergel and Dsouza [52] found that even western public sector organisation's lack in their ability to promote innovation and the core reasons behind such inability is the lack of a robust KM strategy.

\subsubsection{Knowledge audit}

In this study, $71 \%$ (30 out of 42 ) of the interviewees also asserted that knowledge audit is an important tool for implementing and monitoring KM practices in the public sector organisations in Saudi Arabia. Alzeban and Sawan [53], in their study on the internal audit among public sector organisations in the Saudi Arabia, concluded a lack of focus of internal audit on the KM with focus instead given to more materialistic factors, such as financial issues and service quality. Generally, an audit is described as a process that investigates whether or not the goals of an organisation are met [54]. In the light of constant changes in the way organisations are run in the modern world, a knowledge audit has become a necessary part since it assists in identifying the extent of the efficiency by which one system has been replaced by another through comparing the resources consumed during the process and the new system, hence, helping in justifying the adoption of the new system. Similarly, while studying the process of knowledge audit in the implementation of $\mathrm{KM}$ in the public sector organisations in Malaysia, Zulkifli et al. [55] signified 
the importance of KM audit in public sector organisations through arguing that the work of public sector organisations involves both tacit and explicit knowledge; however, they insisted that there tends to be more tacit knowledge involved in the daily work of public sector organisations than explicit ones, due to the involvement of a hierarchical management structure.

Furthermore, hierarchical management structure has been found to negatively impact the process of knowledge capturing and the knowledge sharing process, hence, this further necessitates the conduct of a knowledge audit in the public sector firms [55]. While investigating the auditing concept within the information management field, Yatin et al. [54] provided a knowledge spectrum that emphasises on conducting a knowledge audit on the basis of four areas: wisdom, knowledge, information and data. By wisdom, Yatin et al. [54] meant wisdom of individuals over the overall purpose of the organisation. On the other hand, Yatin et al. [54] distinguished between data and information from knowledge by arguing that, while establishment of knowledge requires an extensive amount of experience with information on a subject, ultimately, information and data merely assist in the creation of knowledge and wisdom is usually reached after acquiring sufficient knowledge about the subject matter. Therefore, it would not be wrong to argue that a knowledge audit covers all other three elements of the knowledge spectrum, such a data audit, wisdom audit and information audit, and, hence, plays an important role in leveraging the knowledge in an organisation.

\subsubsection{Training and education}

In this study, 69\% (29 out of 42) interviewees noted that training and education is an important critical success factor for effective implementation of KM strategies. Drawing on the study by Abd-Rahman et al. [56], training and education cannot provide any material benefit to the organisation unless knowledge gained through training and education is shared, applied and documented for the purpose of organisational-wide use. To this end, Abd-Rahman et al. [56], in their study, concluded that it is important for the employees to apply and protect newly gained knowledge in the organisation so that improved organisational-wide results are achieved. However, while studying the main barriers to KM in the Saudi organisations, Al-Hussain et al. [50] found that the process used for training and educating employees is weak, as it is influenced by the cultural characteristics of collectivism. Collectivism has been defined as the cultural characteristics under which people tend to give preference to people to whom they know and has been recognised as a killer for merit. Therefore, Al-Hussain et al. [50] argued that, thanks to collectivism, a 'wastav' (bribing and connection) system prevails in the Saudi public sector organisations which, in turn, leads to the distribution of learning and development opportunities among those employees who are close to the management and, hence, directly impacts the KM process.

\subsubsection{Knowledge sharing}

In this study, $60 \%$ (25 out of 42 ) of the interviewees noted that sharing knowledge is the most impactful critical success factor for effective implementation of KM strategies. Among the many processes of the KM cycle, knowledge sharing has been identified as the most significant process as well as the cornerstone for effective KM [57]. Knowledge sharing has been associated with numerous positive outcomes in the past, such as organisational effectiveness, organisational innovation capability, 
improved productivity and team task performance. In their study on knowledge sharing, Wang and Wang [43] identified a direct relationship between knowledge sharing and organisational level innovation and performance. However, when it comes to the Saudi public sector organisations, such as Saudi Telecom Company (STC), Al-Adaileh and Al-Atawi [58] found cultural implications that prohibit the process required for the exchange of knowledge among employees in the organisation. This is despite the fact that effective KM cannot be attained unless knowledge is exchanged, distributed and shared among members of the organisation [59].

In relation to public service, knowledge sharing is able to improve the quality of a public service delivery system and enhance the productivity level of public service employees [57]. However, there is further need to identify whether the practice has been used effectively by the management or not.

\subsubsection{Knowledge capture}

In this study, only $48 \%$ (20 out of 42 ) interviewees noted that capturing knowledge is a key success factor for implementing KM strategies. Capturing tacit knowledge is the process through which the experience and expertise of an individual in an organisation is collected and made available to anyone who needs it [60]. Undoubtedly, capturing knowledge may be difficult, particularly in the case of tacit knowledge, but knowledge often only remains tacit until someone asks an appropriate question. At that point, tacit knowledge can become explicit, but, unless that knowledge is captured for someone else to use it again at a later date, learning, productivity and innovation are stifled. Knowledge work already represents $40 \%$ of the global economy. Unfortunately, over $50 \%$ of organisational knowledge is tacit and non-formalised. It is resident in the minds of its workers. Hence, the capture of knowledge is vital for any organisation, especially for key decisions made based on experience, which is usually shared informally.

Alamri and Abuaghayed [61] concluded that, while management in the Saudi organisations does recognise the importance of capturing knowledge for an effective KM, due to the problems at the structural level, such as public sector firms usually being run under a close rational and tightly controlled institutional mechanism, this results in the prohibition of the knowledge capturing practice.

\subsection{Development of a structural self-interaction matrix (SSIM) model}

In the present study, ISM method coupled with MICMAC (Matrix of CrossImpact Multiplications Applied to Classification) is applied to form the interrelationships between the identified critical factors for knowledge management and establish their driving and dependence power.

The interviews were analysed closely to identify any existing pair-wise relationships. The Structural Self-Interaction Matrix (SSIM) is formulated based on the interrelationship between the nine CSFs identified, as shown in Table 2. Four symbols were used to define the direction of the relationship between the CSFs.

\begin{tabular}{cl}
\hline $\mathrm{V}$ & CSF $\mathrm{i}$ will help achieve CSF $\mathrm{j}$ \\
\hline $\mathrm{A}$ & CSF $\mathrm{j}$ will help achieve CSF $\mathrm{i}$ \\
\hline $\mathrm{X}$ & CSF $\mathrm{i}$ and $\mathrm{j}$ will help achieve each other \\
\hline $\mathrm{O}$ & No relation between CSF $\mathrm{i}$ and $\mathrm{j}$ \\
\hline
\end{tabular}




\begin{tabular}{|c|c|c|c|c|c|c|c|c|c|c|}
\hline $\begin{array}{l}\text { Sl. } \\
\text { no }\end{array}$ & $\begin{array}{c}\text { Critical } \\
\text { success factors }\end{array}$ & CSF1 & CSF2 & CSF3 & CSF4 & CSF5 & CSF6 & CSF7 & CSF8 & CSF9 \\
\hline CSF1 & Leadership & - & $\mathrm{X}$ & V & V & V & $\mathrm{O}$ & V & V & V \\
\hline CSF2 & $\begin{array}{l}\text { Organisational } \\
\text { culture }\end{array}$ & - & - & $\mathrm{O}$ & V & V & $\mathrm{O}$ & V & V & V \\
\hline CSF3 & $\begin{array}{l}\text { Information } \\
\text { and } \\
\text { communication } \\
\text { technology } \\
\text { infrastructure }\end{array}$ & - & - & - & $\mathrm{O}$ & $\mathrm{X}$ & V & V & V & V \\
\hline CSF4 & $\begin{array}{l}\text { Reward and } \\
\text { incentive } \\
\text { system }\end{array}$ & - & - & - & - & A & $\mathrm{O}$ & V & V & V \\
\hline CSF5 & KM strategy & - & - & - & - & - & V & V & V & V \\
\hline CSF6 & $\begin{array}{c}\text { Knowledge } \\
\text { audit }\end{array}$ & & & & & & - & $\mathrm{X}$ & V & V \\
\hline CSF7 & $\begin{array}{l}\text { Training and } \\
\text { education }\end{array}$ & & & & & & & - & $\mathrm{X}$ & $\mathrm{X}$ \\
\hline CSF8 & $\begin{array}{l}\text { Knowledge } \\
\text { sharing }\end{array}$ & & & & & & & & & $\mathrm{X}$ \\
\hline CSF9 & $\begin{array}{l}\text { Knowledge } \\
\text { capture }\end{array}$ & & & & & & & & & \\
\hline
\end{tabular}

Table 2.

Structural self-interaction matrix (SSIM) of the critical success factors for implementing KM strategies in the KSA public sector organisations.

\subsection{Reachability matrix}

The initial reachability matrix (binary matrix) shown in Table 3 is developed from the SSIM. The reachability matrix shown in Table 4 is obtained by manually adding the transitivity property to the initial reachability matrix. For instance, if a $\mathrm{CSF} i$ is related to $\mathrm{j}$ and $\mathrm{j}$ is related to $\mathrm{n}$, then $\mathrm{i}$ is necessarily related to $\mathrm{n}$.

\subsection{Level partition}

CSFs in which the reachability and the intersection sets are similar would be allocated the top level in the ISM hierarchy. CSFs at this level do not have any other CSFs above them. Once CSFs within the top-level are identified, they are separated from the rest of the CSFs. The same process is repeated to identify CSFs within the next levels, until all CSFs fall in each level. This level partition helps with diagraph modelling. Table 5 shows the reachability set, antecedent set, intersection set, and the initial and final levels of all the CSFs. The level evaluation process of all the nine CSFs is completed in four iterations.

\subsection{Diagraph model}

A preliminary diagraph containing the transitive links shown in Figure 1 is obtained from the final reachability matrix. In the case of a relationship between CSF $i$ and $j$, an arrow points from $i$ to $j$. The final diagraph is developed after the removal of indirect links. The top-level CSFs are positioned at the top of the diagraph, followed by second level CSFs and so on. 
An ISM Approach to Evaluate Critical Success Factors for Knowledge Management... DOI: http://dx.doi.org/10.5772/intechopen.90069

\begin{tabular}{|c|c|c|c|c|c|c|c|c|c|c|}
\hline Sl. no & $\begin{array}{l}\text { Critical success } \\
\text { factors }\end{array}$ & CSF1 & CSF2 & CSF3 & CSF4 & CSF5 & CSF6 & CSF7 & CSF8 & CSF9 \\
\hline CSF1 & Leadership & 1 & 1 & 1 & 1 & 1 & 0 & 1 & 1 & 1 \\
\hline CSF2 & $\begin{array}{l}\text { Organisational } \\
\text { culture }\end{array}$ & 1 & 1 & 0 & 1 & 1 & 0 & 1 & 1 & 1 \\
\hline CSF3 & $\begin{array}{c}\text { Information and } \\
\text { communication } \\
\text { technology } \\
\text { infrastructure }\end{array}$ & 0 & 0 & 1 & 0 & 1 & 1 & 1 & 1 & 1 \\
\hline CSF4 & $\begin{array}{c}\text { Reward and } \\
\text { incentive system }\end{array}$ & 0 & 0 & 0 & 1 & 0 & 0 & 1 & 1 & 1 \\
\hline CSF5 & KM strategy & 0 & 0 & 1 & 1 & 1 & 1 & 1 & 1 & 1 \\
\hline CSF6 & $\begin{array}{l}\text { Knowledge } \\
\text { audit }\end{array}$ & 0 & 0 & 0 & 0 & 0 & 1 & 1 & 0 & 0 \\
\hline CSF7 & $\begin{array}{l}\text { Training and } \\
\text { education }\end{array}$ & 0 & 0 & 0 & 0 & 0 & 1 & 1 & 1 & 1 \\
\hline CSF8 & $\begin{array}{l}\text { Knowledge } \\
\text { sharing }\end{array}$ & 0 & 0 & 0 & 0 & 0 & 0 & 1 & 1 & 1 \\
\hline CSF9 & $\begin{array}{l}\text { Knowledge } \\
\text { capture }\end{array}$ & 0 & 0 & 0 & 0 & 0 & 0 & 1 & 1 & 1 \\
\hline
\end{tabular}

Table 3.

Initial reachability matrix of the of the critical success factors for implementing KM strategies in the KSA public sector organisations.

\subsection{ISM model}

The developed diagraph is converted into an ISM model by transforming the nodes by the CSFs' statements, as shown in Figure 2. From Table 5, it can be seen that CSFs knowledge audit, training and education, knowledge sharing, and knowledge capture were found at level one. Therefore, these CSFs were positioned at the top-level of the ISM hierarchy. The rest of the CSFs have been positioned in the hierarchy, reflecting their levels, as presented in Figure 2. The arrow direction indicates the relationship between the different CSFs. For example, the relationship between the organisational culture and leadership was a two-way relationship. Therefore, an arrow pointing in both directions was used to denote this relationship, whereas the relationship between the leadership and KM strategy was only one direction, in which the leadership influences the KM strategy. Therefore, an arrow pointing from the leadership to the KM strategy was used. It can be observed from Figure 2 that leadership and organisational culture were significant CSFs for implementing KM strategies in the KSA public sector organisations, as they came at the base level of the ISM model.

\subsection{Classifying CSFs for implementing KM strategies in the KSA public sector organisations: MICMAC analysis}

Based on the driver power and dependence power generated in Table 4, the CSFs for implementing KM strategies in the KSA organisations were classified into four clusters (namely autonomous, dependent, linkage and driving factors) as shown in Figure 3, which are explained below.

Autonomous clusters are the CSFs with a weak driving as well as dependency power and are relatively disconnected from the system. These CSFs do not have 


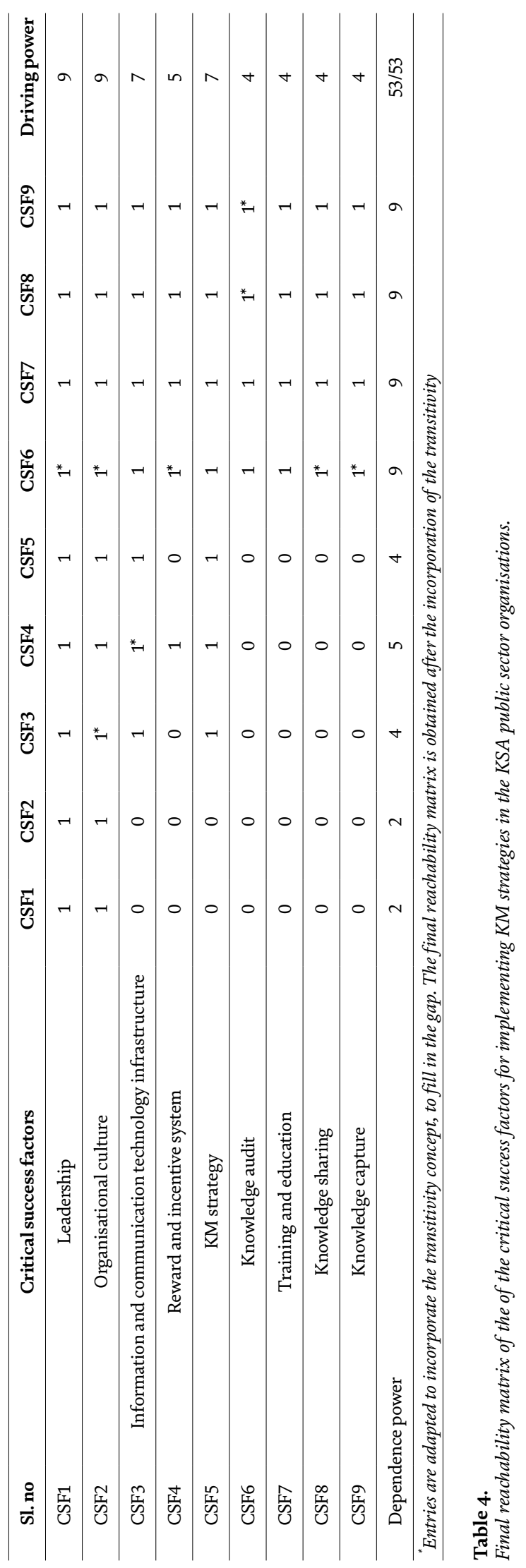


An ISM Approach to Evaluate Critical Success Factors for Knowledge Management... DOI: http://dx.doi.org/10.5772/intechopen.90069

\begin{tabular}{ccccc}
\hline Sl. no & Reachability set & Antecedent set & Intersection & Level \\
\hline CSF1 & $1,2,3,4,5,6,7,8,9$ & 1,2 & 1,2 & IV \\
\hline CSF2 & $1,2,3,4,5,6,7,8,9$ & 1,2 & 1,2 & IV \\
\hline CSF3 & $3,4,5,6,7,8,9$ & $1,2,3,5$ & 3,5 & III \\
\hline CSF4 & $4,6,7,8,9$ & $1,2,3,4,5$ & 4 & II \\
\hline CSF5 & $3,4,5,6,7,8,9$ & $1,2,3,5$ & 3,5 & III \\
\hline CSF6 & $6,7,8,9$ & $1,2,3,4,5,6,7,8,9$ & $6,7,8,9$ & I \\
\hline CSF7 & $6,7,8,9$ & $1,2,3,4,5,6,7,8,9$ & $6,7,8,9$ & I \\
\hline CSF8 & $6,7,8,9$ & $1,2,3,4,5,6,7,8,9$ & $6,7,8,9$ & I \\
\hline CSF9 & $6,7,8,9$ & $1,2,3,4,5,6,7,8,9$ & $6,7,8,9$ & I
\end{tabular}

Table 5.

Level partitions of the reachability matrix (iteration I to iteration IV).

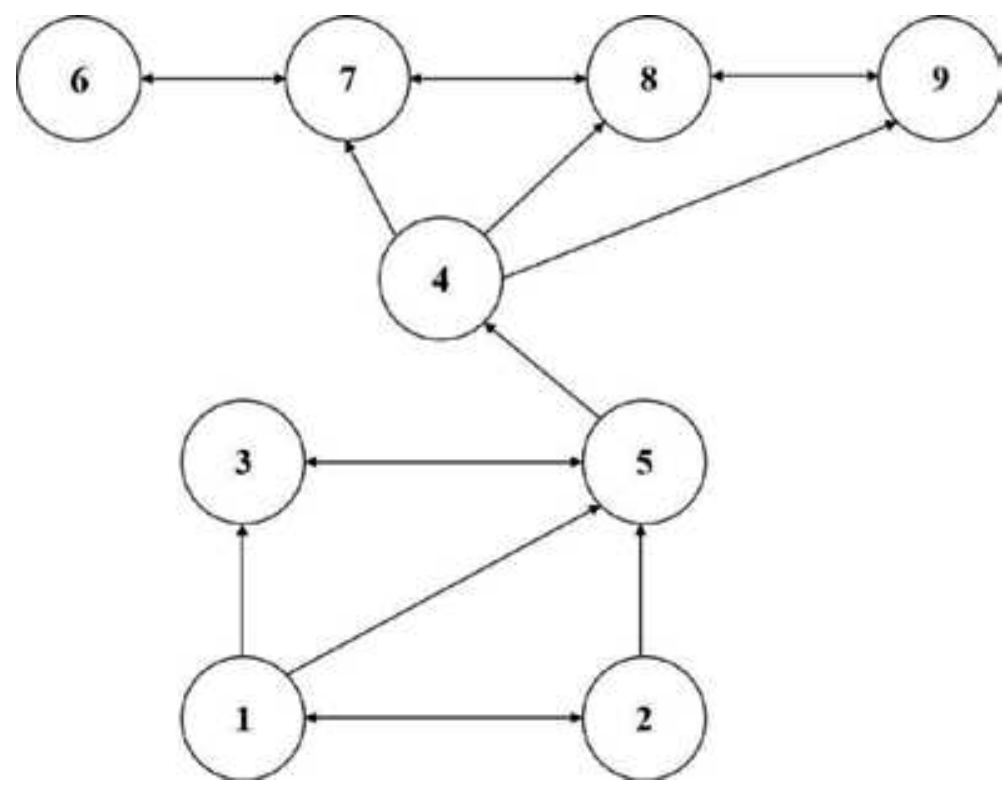

Figure 1.

Final diagraph showing the relationship between the CSFs.

much influence on the other CSFs of the system and are less significant to the policy and decision-makers. It is clear from Figure 3 that there no CSFs come under an autonomous cluster. The dependent cluster comprises of knowledge audit (CSF6), training and education (CSF7), knowledge sharing (CSF8), and knowledge capture (CSF9), having driving power value of 4 and high dependency power value of 9 . In the cluster of linking factors, there is one CSF, namely reward and incentives system (CSF4), having dependency and driving power value of 5 . In the driving factors cluster, there are four factors, namely leadership (CSF1) and organisational culture (CSF2), with the highest driving power of 9 and least dependency power value of 2. Two CSFs, namely information and communication technology infrastructure (CSF3) and KM strategy (CSF5), are found to have a driving power of 7 and dependency power of 4 . The factors of this cluster are very significant for the decision and policy makers as these CSFs have very high influential power and less dependency on the other CSFs. 


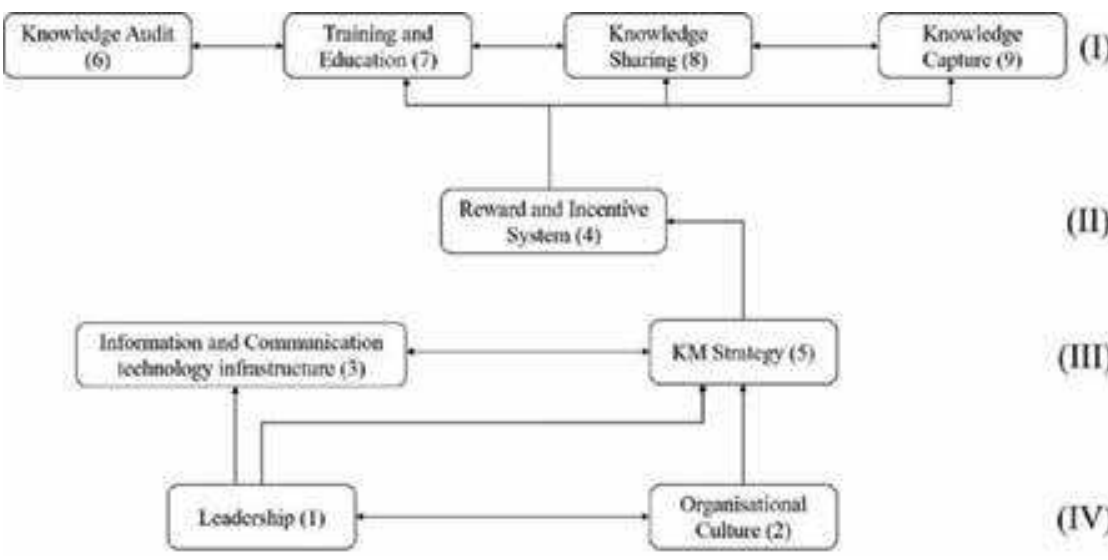

Figure 2.

ISM based model of CSFs.

Driving and Dependence Power Diagram

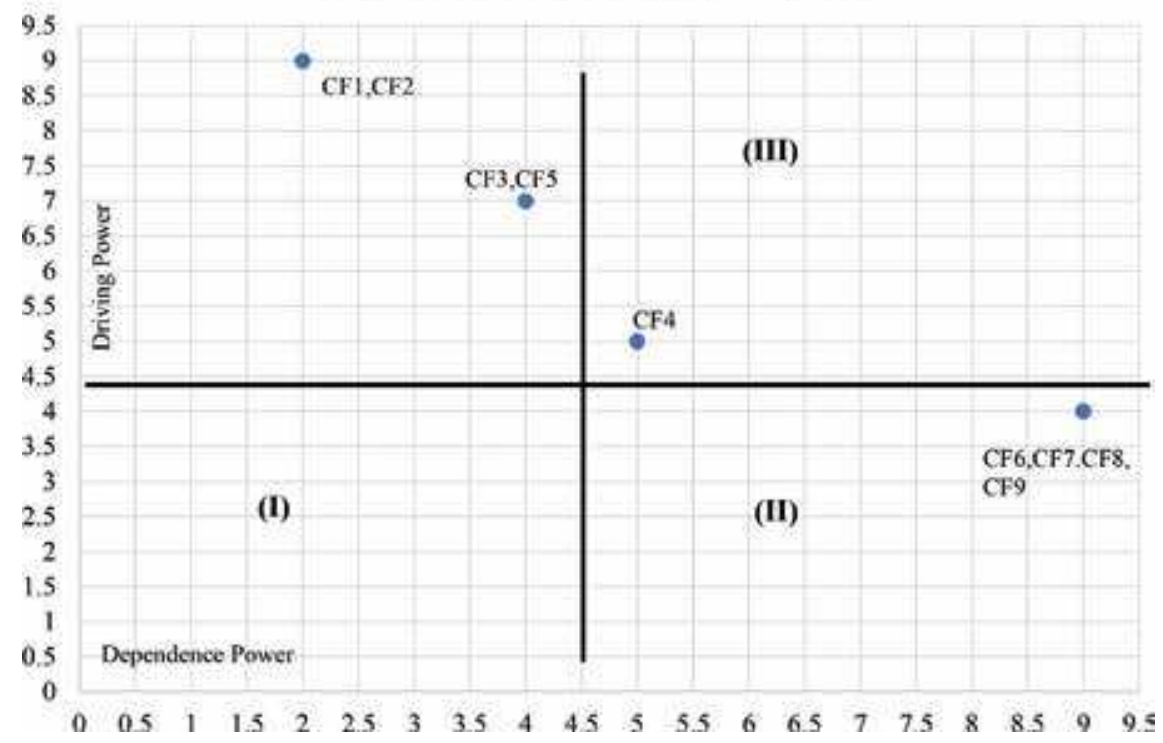

Figure 3.

The driving and dependence power diagram of CSFs.

In the current study, the CSFs for implementing KM strategies within the KSA public sector organisations are identified and modelled. The study findings suggest that leadership and organisational culture are very important CSFs for successful implementation of KM strategies.

Scholars have proposed that public sector decision-makers face unique challenges, which includes declining resources, frequent political influences, demands from external sources and, generally, the requirements to accomplish more with fewer resources [62]. Hence, there is a significant need in the public sector to deliver better value for money in services with increasing pressure to deliver more with less, the public sector needs to introduce more innovative and effective solutions and reduce decision-making time and the level of bureaucracy.

KM offers a perspective, principles, methods, practices and tools that can help KSA public sector organisations become more like intelligent and adaptive organisations. KM methods, practices and tools support better decisions and actions by enabling 
people to integrate (identify, capture and share) relevant existing knowledge and to produce new knowledge. However, there is a vast amount of knowledge within KSA public sector organisations. In KM the role of leadership has become a key operational component in the public sector due to the ever-changing and increasing demands from the public for government employees to do more with less [63]. The leadership must ensure that there is continuous personal development and lifelong learning for employees associated with KM in order to attract the right calibre of employees with career aspirations in KM. Furthermore, the leadership must ensure that a reward and recognition system is in place that promotes a joint sense of ownership of the KM programme.

\section{Conclusion}

This chapter has empirically investigated CSFs for successful implementation of KM strategies in the KSA public sector organisations. Semi-structured interviews were conducted with $42 \mathrm{KM}$ experts. By applying content analysis, the CSFs which emerged from the analysis were grouped into nine categories: leadership, organisational culture, information and communication technology infrastructure, reward and incentive system, KM strategy, knowledge audit, training and education, knowledge sharing, and knowledge capture. The CSFs have been then put into an ISM model to analyse the interaction between them. A hierarchical model of the CSFs was developed based on their significance by employing an ISM methodology. The developed model highlighted leadership (CSF1) and organisational culture (CSF2) as the most significant factors influencing the implementation of KM strategies in the KSA public sector organisations. The ISM-based model developed in this study provides decision-makers with a more realistic representation of the CSFs for implementing KM strategies in the KSA public sector organisations. The results demonstrated that leadership is the most important critical success factor for implementing KM strategies in the KSA public sector organisations.

Practical implication of this research would meet the Saudi Vision 2030, public sector organisations must show leadership. The scarcity of knowledge and expertise is, and will continue to be, a huge challenge for many organisations regardless of sector. The key to successful deployment of KM strategies lies in having a balance between the human, technological and process aspects of KM. It is imperative that public sector organisations view KM as a strategic tool and feel confident and positive about its impact on performance in the long term. It is essential to address the nine CSFs during the conceptualisation, design and implementation stages of KM programmes. This research has made significant original contributions, particularly on CSFs for implementing KM strategies in the KSA using an interpretive structural modelling (ISM) approach. It also gives valuable insight and guidance which will help the public sector decision-makers to accomplish KM strategies effectively.

Despite the novel insights provided by this study, it has some limitations. Given that the research reported in this chapter is largely exploratory by nature and participants were managers and directors only, the results presented are only tentative and of limited value for the purpose of generalisation. Furthermore, the findings of this chapter are limited to the KSA public sector organisations only; as such, the level of applicability outside this context may be very limited. However, we argue that the results obtained are useful to similar developed countries. Extending this study using a larger sample with more balanced representation across different public sector organisations will provide relevance of these findings to other countries' public sector organisations. Furthermore, attitudes and behaviours towards knowledge sharing vary across national cultures. Therefore, this may limit the applicability of the findings to other countries or regions. 


\section{Author details}

Suresh Renukappa*, Subashini Suresh, Saeed Al Nabt, Redouane Sarrakh and Khaled Algahtani

Faculty of Science and Engineering, University of Wolverhampton, Wolverhampton, England, United Kingdom

*Address all correspondence to: suresh.renukappa@wlv.ac.uk

\section{IntechOpen}

(C) 2020 The Author(s). Licensee IntechOpen. Distributed under the terms of the Creative Commons Attribution - NonCommercial 4.0 License (https://creativecommons.org/ licenses/by-nc/4.0/), which permits use, distribution and reproduction for non-commercial purposes, provided the original is properly cited. (cc) BY-NC 


\section{References}

[1] Chong SC, Salleh K, Ahmad SNS, Sharifuddin SISO. KM implementation in a public sector accounting organization: An empirical investigation. Journal of Knowledge Management. 2011;15(3):497-512

[2] Witherspoon CL, Bergner J, Cockrell C, Stone DN. Antecedents of organizational knowledge sharing: A meta-analysis and critique. Journal of Knowledge Management. 2013;17(2):250-277

[3] Lin H, Hwang Y. Do feelings matter? The effects of intrinsic benefits on individuals' commitment toward knowledge systems. Computers in Human Behavior. 2014;30(1):191-198

[4] Ragsdell G, Ortoll-Espinet E, Norris M. Knowledge management in the voluntary sector: A focus on project know-how and expertise. Knowledge Management Research and Practice. 2014;12(4):351-361

[5] Alavi M, Leidner DE. Knowledge management systems: Issues, challenges, and benefits. Communications of the Association for Information Systems. 1999;1(2):1-7

[6] Nonaka I, Takeuchi H. The Knowledge-Creating Company: How Japaneses Companies Create the Dynamics of Innovation. Oxford: Oxford University Press; 1995

[7] Madhoushi M, Sadati A.

Knowledge management, antecedent of organizational innovation and competitiveness. In: Proceedings of the European Conference on Intellectual Capital; Lisbon, Portugal. 2010. pp. 391-398

[8] Jashapara A. Knowledge Management. Harlow, Essex: Pearson/ Financial Times/Prentice Hall; 2011
[9] Wiig KM. Knowledge management: Where did it come from and where will it go? Expert Systems with Applications. 1997;13(1):1-14

[10] Egbu CO. Construction innovation through knowledge management. In: Akintoye A, Goulding J, Zawdie G, editors. Construction Innovation and Process Improvement. Oxford: WileyBlackwell; 2012. pp. 235-249

[11] Chase RL. Knowledge management benchmarks. Journal of Knowledge Management. 1997;1(1):83-92

[12] Alavi M, Leidner DE. Knowledge management and knowledge management systems: Conceptual foundations and research issues. MIS Quarterly. 2001;25(1):107-136

[13] Yahya K. Power-influence in decision making, competence, and organizational culture in public organizations. Journal of Public Administration Research and Theory. 2009;19(2):385-408

[14] Milner E. Managing Information and Knowledge in the Public Sector. London: Routledge; 2000

[15] Fattouh B, Sen A. Saudi Arabia's Vision 2030, Oil Policy and the Evolution of the Energy Sector, OIES Comment. Oxford: Oxford Institute for Energy Studies; 2016

[16] Ministry of Economy and Planning. (2017) Home-Ministry of Economy and Planning. Available from: http://www. mep.gov.sa/en/ [Accessed: 10 Apr. 2017].

[17] Digman JM. Personality structure: Emergence of the five-factor model. Annual Review of Psychology. 1990;41(1):417-440

[18] Gates LP. Strategic Planning with Critical Success Factors and Future 
Scenarios: An Integrated Strategic Planning Framework. Software Engineering Institute: Carnegie Melon University, USA; 2010

[19] Alazmi M, Zairi M. Knowledge management critical success factors. Total Quality Management \& Business Excellence. 2003;14(2):199-204

[20] Kvale S. InterViews-An Introduction to Qualitative Research Interviewing. Thousand Oaks, CA: Sage; 1996

[21] Ribbens J, Edwards R. Feminist Dilemmas in Qualitative Research: Public Knowledge and Private Lives. London: Sage; 1998

[22] Murry JW, Hammons JO. Delphi: A versatile methodology for conducting qualitative research. The Review of Higher Education. 1995;18:426-436

[23] Creswell JW. Research Design Qualitative, Quantitative, and Mixed Methods Approaches. Thousand Oaks, CA: Sage Publications; 2014

[24] Remenyi D, Williams B, Money A, Swartz E. Doing Research in Business Sand Management. London: Sage; 1998

[25] Strauss A, Corbin J. Basics of Qualitative Research: Techniques and Procedures for Developing Grounded Theory. Thousand Oaks, CA: Sage; 1998

[26] Watson RH. Interpretive structural modelling: A useful tool for technology assessment? Technological Forecasting and Social Change. 1978;11(2):165-185

[27] Raj T, Shankar R, Suhaib M. An ISM approach for modelling the enablers of flexible manufacturing system: The case for India. International Journal of Production Research. 2008;46(24):6883-6912

[28] Malone DW. An introduction to the application of interpretive structural modeling. Proceedings of the IEEE. 1975;63(3):397-404

[29] Beikkhakhian Y, Javanmardi M, Karbasian M, Khayambashi B. The application of ISM model in evaluating agile suppliers selection criteria and ranking suppliers using fuzzy TOPSIS-AHP methods. Expert Systems Applications. 2015;42(15):6224-6236

[30] Abuzeinab A, Arif M, Qadri MA. Barriers to MNEs green business models in the UK construction sector: An ISM analysis. Journal of Cleaner Production. 2017;160:27-37

[31] Lim MK, Tseng M-L, Tan KH, Bui TD. Knowledge management in sustainable supply chain management: Improving performance through an interpretive structural modelling approach. Journal of Cleaner Production. 2017;162(20):806-816

[32] Raut RD, Narkhede B, Gardas BB. To identify the critical success factors of sustainable supply chain management practices in the context of oil and gas industries: ISM approach. Renewable and Sustainable Energy Reviews. 2017;68:33-47

[33] Kim S, Suh E, Hwang H. Building the knowledge map: An industrial case study. Journal of Knowledge Management. 2003;7(2):34-45

[34] Ichijo K, Nonaka I. Knowledge Creation and Management: New Challenges for Managers. New York: Oxford University Press; 2007

[35] Jennex ME, Olfman L. Assessing knowledge management success. International Journal of Knowledge Management. 2005;1(2):33-49

[36] Yu SH, Kim YG, Kim MY. Linking organizational knowledge management drivers to knowledge management performance: An exploratory study. In: 37th Hawaii International Conference 
An ISM Approach to Evaluate Critical Success Factors for Knowledge Management... DOI: http://dx.doi.org/10.5772/intechopen.90069

on System Sciences, HICSS36. IEEE

Computer Society; 2004

[37] Collins JC, Porras JI. Built to Last: Successful Habits of Visionary Companies. New York: HarperCollins; 1997

[38] Barnes PC. A primer on knowledge management. Student Accountant (ACCA, UK). 2001;20(8):30-36

[39] Tseng SM. The correlation between organizational culture and knowledge conversion on corporate performance. Journal of Knowledge Management. 2010;14(2):269-284

[40] Liebowitz JY, Chen AH. Knowledge Sharing Proficiencies: The Key to Knowledge Management. Holsapple, C.W. Handbook on Knowledge Management Matters. Berlin: SpringerVerlag; 2003

[41] Schein EH. Organizational Culture and Leadership. San Francisco, CA: Jossey-Bass; 1985

[42] Hogan SJ, Coote LV. Organizational culture, innovation, and performance: A test of Schein's model. Journal of Business Research. 2014;67(8):1609-1621

[43] Wang S, Noe RA, Wang ZM. Motivating knowledge sharing in knowledge management systems: A quasi-field experiment. Journal of Management. 2014;40(4):978-1009

[44] Hislop D. Knowledge Management in Organizations: A Critical Introduction. Oxford University Press; 2013

[45] Quintas P. Knowledge Management in the 21st Century. New York: Springer Verlag; 2002

[46] Davenport T, Prusak L. Working Knowledge-How Organisations
Manage What they Know. Boston, MA: Harvard Business School Press; 1998

[47] Sveiby KE. The New Organizational Wealth: Managing and Measuring Knowledge Based Assets. New York: Berrett-Koehler Publishers; 1997

[48] Huang YH. Real life in virtual world: Online game addiction and its related factors (unpublished master's thesis). Taipei: Institute of Communication, Shih Hsih University; 2004

[49] Pandey SC, Dutta A. Role of knowledge infrastructure capabilities in knowledge management. Journal of Knowledge Management.

2013;17(3):435-453

[50] AL-Hussain AZ, Murphree EL Jr, Bixler CH. Barriers to knowledge management in Saudi Arabia. Journal of Knowledge Globalization. 2012;5(1):47-75

[51] Oluikpe P. Developing a corporate knowledge management strategy. Journal of Knowledge Management. 2012;16(6):862-878

[52] Mergel I, Desouza KC. Implementing open innovation in the public sector: The case of Challenge.gov. Public Administration Review. 2013;73(6):882-890

[53] Alzeban A, Sawan N. The role of internal audit function in the public sector context in Saudi Arabia. African Journal of Business Management. 2013;7(6):443-454

[54] Yatin SFM, Nawi NAMM, Nur'Ain Ismail SAA, Rahman SAMY, Ameri SNM. Audit on knowledge spectrum. Australian Journal of Basic and Applied Sciences. 2015;9(3):75-81

[55] Zulkifli H, Abdullah MF, Ibrahim M. Knowledge audit on the implementation of knowledge management in public sector research institute in Malaysia: 
A case study. In: 8th Knowledge Management International Conference KMICe 2016, Big Data to Knowledge Discovery, 29-30 August, 2016, Chiang Mai, Thailand. 2016

[56] Abd Rahman A, Imm Ng S, Sambasivan M, Wong F. Training and organizational effectiveness: Moderating role of knowledge management process. European Journal of Training and Development. 2013;37(5):472-488

[57] Yeşil S, Dereli S. An empirical investigation of the organisational justice, knowledge sharing and innovation capability. Procedia-Social and Behavioral Sciences. 2013;75:199-208

[58] Al-Adaileh RM, Al-Atawi MS. Organizational culture impact on knowledge exchange: Saudi Telecom context. Journal of Knowledge Management. 2011;15(2):212-230

[59] Massaro M, Dumay J, Garlatti A. Public sector knowledge management: A structured literature review. Journal of Knowledge Management. 2015;19(3):530-558

[60] Dalkir K. Knowledge Management in Theory and Practice. Boston, MA: Elsevier; 2005

[61] Alamri M, Abumaghayed Y. Rational or institutional intent? Knowledge management adoption in Saudi public organizations. International Public Management Review. 2016;17(2):36-58

[62] Lavigna RJ. Engaging Government Employees: Motivate and Inspire your People to Achieve Superior Performance. New York, NY: Amacom Publisher; 2013

[63] Jain AK, Jeppesen HJ. Knowledge management practices in a public sector organization: The role of leaders' cognitive style. Journal of Knowledge Management. 2013;17(3):347-362 


\title{
Importance of Social Networks for Knowledge Sharing and the Impact of Collaboration on Network Innovation in Online Communities
}

\author{
Stefan K. Behfar
}

\begin{abstract}
Innovation results from interactions between different sources of knowledge, where these sources aggregate into groups interacting within (intra) and between (inter) groups. Interaction among groups for innovation generation is defined as the process by which an innovation is communicated through certain channels over time among members of a social system. Apart from the discussion about knowledge management within organizations and the discussion about social network analysis of organizations on the topic of innovation and talks about various trade-offs between strength of ties and bridging ties between different organizational groups, within the topic of open source software (OSS) development researchers have used social network theories to investigate OSS phenomenon including communication among developers. It is already known that OSS groups are more networked than the most organizational communities; In OSS network, programmers can join, participate and leave a project at any time, and in fact developers can collaborate not only within the same project but also among different projects or teams. One distinguished feature of the open source software (OSS) development model is the cooperation and collaboration among the members, which will cause various social networks to emerge. In this chapter, the existing gap in the literature with regard to the analysis of cluster or group structure as an input and cluster or group innovation as an output will be addressed, where the focus is on "impact of network cluster structure on cluster innovation and growth" by Behfar et al., that is, how intra- and inter-cluster coupling, structural holes and tie strength impact cluster innovation and growth, and "knowledge management in OSS communities: relationship between dense and sparse network structures." by Behfar et al., that is, knowledge transfer in dense network (inside groups) impacts on knowledge transfer in sparse network (between groups).
\end{abstract}

Keywords: social networks, knowledge sharing, OSS development, collaboration, network innovation, online communities

\section{Introduction}

In organizational and information science, research topics related to network structure properties (e.g. degree distribution, network tie strength (weak-strong) and 
network cluster shape (dense-sparse)) have been studied in various articles because of their significant applications including (1) network generation, design and reproduction (e.g. "Emergence of scaling in random networks" by Barabási and Albert [1], "On power-law relationships of the internet topology" by Faloutsos et al. [2]), (2) social network analysis (e.g. "Creating social contagion through viral product design..." by Aral and Walker [3], "Optimal and scalable distribution of content updates over a mobile social network" by Ioannidis and Chaintreau [4]), (3) impact of network structure on network innovation (e.g. "Collaboration networks, structural holes, and innovation..." emphasizing the impact of direct and indirect ties on firm innovation by Ahuja [5], "Network structure of social capital” investigating the impact of sparse network structure on facilitating diffusion of ideas by Burt [6]) and (4) knowledge management among open-source-software (OSS) developers (e.g. "Location, location, location: how network embeddedness affects project success in open source systems" by Grewal et al. [7], "Knowledge transfer within information system development teams: examining the role of knowledge source attributes" by Joshi and Sarker [8]). However, to our best knowledge, there has been no study in the literature which explains impact of network structure on innovation and growth at group or cluster level. We will address this issue in this chapter, and explain the impact of group dynamics on OSS project group innovation (i.e. group intra- and inter-coupling as causal factors for group innovation and growth), also discuss knowledge management and intergroup diffusion of innovation (i.e. influence of knowledge diffusion within dense groups measured by intragroup density, degree centrality and betweenness onto knowledge diffusion between sparse groups measured by intergroup coupling).

We focus on clusters or groups rather than individuals as the level of analysis for both network structure as input and innovation diffusion as output, because (1) clusters represent collective impact on network output rather than individuals' impact, (2) impact of intra cluster couplings on cluster innovation and growth is different from the impact of inter cluster couplings on cluster innovation and growth and (3) trade-offs among dense and sparse network cluster structures are different from those associated with networks of individuals.

As the domain of interest, we have chosen open source software (OSS) collaboration network (or so-called OSS communities), where almost all prior works on OSS are concerned with project success measured by number of downloads or number of concurrent versions system (CVS) commits, and ignores group success measured by group growth and innovation. Group is referred to one including small or big number of developers who work on some or many project tasks. In addition, OSS developer is the unit of analysis, where two developers working on the same project task builds a tie in the network.

\section{What is a network?}

A network is a set of interlinked nodes, which can be simple, such as a lattice, random network or a complex network (a graph with non-trivial topological features that are not found in simple networks). However, most complex structures can be realized by networks with a medium number of interactions [9]. What is in fact a complex network?

\subsection{Complex networks}

A complex network is composed of nodes and links, or modules and dependencies, where a module is a component whose structural elements are strongly 
intra-connected and relatively weakly inter-connected to other modules [10]. A complex network is used to model complex systems, where a complex system is "one made up of a large number of parts that interact in a non-simple way; in such systems the whole is more than the sum of parts, at least in the important pragmatic sense that given the properties of the parts and the laws of the interaction, it is not a trivial matter to infer the properties of the whole" ([11], p. 195). Simon viewed firms as hierarchical systems made of subsystems that are loosely coupled vertically and horizontally, and interact based on input and output. Loose coupling implies that interactions among subsystems are much weaker than interactions within subsystems.

\subsection{Network clusters}

In the context of organizational science, a cluster is defined as an ensemble of various firms and institutions that interact formally and informally via agreements and transactions or informal occasional meetings that collectively contribute to innovation within a given industry. An innovation cluster includes an ensemble of various organizations and institutions "(a) that are defined by respective geographic locations occurring at variable spatial scales, (b) that interact formally and/or informally through inter-organizational and/or interpersonal regular or more occasional relationships and networks (c) that contribute collectively to the achievement of all kinds of innovations within a given industry or domain of activity, i.e. within a domain defined by specific fields of knowledge, competences and technologies" ([12], p. 18). Innovative interaction among clusters is defined as "the process by which an innovation is communicated through certain channels over time among members of a social system" [13].

There are also definitions of industrial clusters: industrial clusters are "geographically proximate firms in vertical and horizontal relationships involving a localized enterprise support infrastructure with shared developmental vision for business growth, based on competition and cooperation in a specific market field" [14]. Clusters and industrial districts are synonymous, whereas the concept of a network is more general, and it does not necessarily entail local embedding, a shared objective, or a specific market ([15], p. 4).

In information systems, the notion of cluster cannot be precisely defined (see [16]); however, a group of data objects is a common definition. The notion of a cluster is determined by different cluster models which themselves vary significantly in their properties. In social networks, Watts and Strogatz [17] have shown that nodes tend to be made of tightly knitted groups identified by a relatively high density of ties with likelihood greater than the average probability of a randomly established tie. Clustering in social network analysis has been discussed by Wasserman and Faust [18] and Opsahl and Panzarasa [19].

\subsection{Network structural properties}

In network theory, graphs could be classified according to two independent structural features: clustering coefficient and average shortest path length (average node-to-node distance). Purely random graphs, according to the Erdős-Rényi (ER) [20] and Watts and Strogatz [17], feature a small average shortest path length along with a small clustering coefficient, this varies in terms of the logarithm of the number of nodes. According to Watts and Strogatz [17], many real-world networks have a small average shortest path length and high clustering coefficient; they proposed 
small-world network with the properties (i) a small average shortest path length and (ii) a large clustering coefficient [21].

Using network structure models, one can simulate complex network structure based on analyzing link formation or predict network structure based on link prediction models. There have been primary contributions in the area of network models; Erdős-Rényi [20] presented non-growing randomly connected network model (ER); Watts and Strogatz [17] presented non-growing randomly re-connected network model (so-called small world) (WS) and Barabási-Albert [1] presented a network grow model, so-called preferential attachment model or rich-get-richer (BA). In this model, probability of adding new nodes is proportional to the number of incoming links. According to ER and WS models, the number of nodes in the network is fixed, where the linkages among existing link formation nodes are built. On the other hand, BA model assumes time-homogeneous network growth with a mechanism for preferential attachment link formation. We use this cluster/group concept throughout this chapter.

In the paper "Directed networks' different link formation mechanisms causing degree distribution distinction" by Behfar et al. [22], we discussed the network structural property of degree distribution distinction in different network levels of decomposition from dependency in a cluster of open-source-software (OSS) projects down to software project corpus dependency. We emphasized the importance of the study of in/out degree distribution distinction, and discussed why the type of distribution is significant in terms of (a) structural property of complex networks, (b) statistical property of complex networks, (c) selforganizing property of complex networks and (d) decomposability property of complex networks.

We distinguished between in and out degree distributions, and claimed link formation mechanisms as a causal factor for this distinction. First, we discussed the importance of directed networks, and why outlinks are important, which have been often neglected in the previous studies. Second, we identified the causal factors for distinction between in and outdegree for the sample network of OSS projects as well as the Java software corpus as a network. Third, we analyzed whether this distinction holds for different levels of decomposition from projectproject dependency to package-package dependency and down to class-class dependency. We proved our hypotheses both analytically and empirically and concluded that in/outdegree dependencies do not follow similar types of degree distributions, where indegree dependencies follow power-law distribution, in some cases power-law with flat-top or exponential cut-off, while outdegree dependencies do not follow power-law/heavy-tailed distribution, in most cases they follow exponential distribution.

\section{What is innovation in a network perspective?}

Innovation is shown to be interactive, cooperative and cumulative [5] and it emerges through a combination of many sources of knowledge connected through a network. Innovation could be (1) incremental (creative accumulation), which is always based on already existing innovation or (2) radical (creative destruction), which is created by combining all new skill sets [23]. For new product development as products become modular, collaboration becomes essential, since individuals do not possess all the required knowledge to accomplish innovation [24] and knowledge is distributed among individuals within a complex system.

Rogers [13] defined "innovation diffusion as the process by which an innovation is communicated through certain channels over time among members of a social 
system". There have been papers in the literature in various topics e.g. diffusion of innovation in manufacturing and service industries, healthcare and education [25]. Rogers also gave the first typology of innovation diffusion covering innovation, diffusion networks and rate of adoption in different social systems. Generally, the study of innovation, see Rogers [13], covers new product, process or market generation, adoption and implementation.

Inside organizations, units can learn from each other and knowledge diffusion can provide new mutual opportunities for units as well as the whole organization. Huber [26] suggested that organizational units transfer knowledge and learn from other units, in case those units have the capacity to access to new knowledge, which can be obtained and improved by networking. Other authors such as Hansen [27] attempted to model an organization as a complex network where units are inter-connected; knowledge transfer within this organization can be investigated by analyzing this complex network. Kogut and Zander [28] and Tsai [29] also modeled organizations as a social network and suggested that social networks facilitate the creation of new knowledge within organizations. Moreover, Tsai [30] also discussed how organizational units can gain useful knowledge from other units to improve its innovation and performance, also emphasized the role of strong ties in intra-corporate and strategic alliances. Apart from strong ties within organizations, Hansen [27] investigated transfer and sharing of knowledge and emphasized the role of weak ties in organizations.

In the field of knowledge sharing, for example, Ma and Agarwal [31] discussed the role of perceived identity in augmenting knowledge sharing and Ren et al. [32] investigated the role of similarities in direct reciprocity and design of online communities. As an alternative approach, DiMaggio and Powell [33] argued that under conditions of doubt or uncertainty, innovation occurs through inter-organizational imitation because organizations learn from similar organizations or from industry leaders. Researchers have investigated the importance of networks for knowledge sharing and the impact of collaboration on overall network performance. Knowledge-sharing network model elements are represented in Table 1.

\subsection{Open source software (OSS) communities}

OSS projects are accounted as a significant economic, social and cultural phenomenon [34]. Initially there were doubts over the quality of OSS products, which software industry was struggling to find innovative methods to develop quality products; at the same time, Linux and the Apache server attained a big success and demonstrated a new approach to produce reliable and high-quality products that are also inexpensive [35]. Due to these advantages, OSS development claimed to have the potential to compete with traditionally produced software, also to replace traditional development methods [36].

In fact, OSS communities provide alternative strategies for knowledge creation and growth, implement innovations and new product development [34, 37]. Nevertheless, software developers are now facing new labor market, where participation in OSS

\begin{tabular}{ll}
\hline Network node & Organization (SMEs) \\
\hline Tie & Knowledge-sharing activity \\
\hline Tie strength & Frequency of activity \\
\hline Tie diversity & Type of activity (joint team, project collaboration) \\
\hline Tie content & Knowledge (know-how, information, asset) \\
\hline
\end{tabular}

Table 1.

Details of knowledge-sharing network model. 
projects could lead to increased salaries and improved job security. In fact, three forms of competitive advantage have emerged: verifiable technical skills, peer-certified competencies and positional power, as stated by Riehle [38].

Considering the significance of this phenomenon, researchers have widely used social network analysis (SNA) to model behavior of communication intra and inter groups in OSS communities. According to Jackson [39], the positions and relationships among developers in a social network are significant in the efficiency of the network, where they use different tools and techniques such as SNA. Grewal et al. [7] and Singh et al. [40] also state that success of many OSS projects is closely related to the communication structure in OSS network. Also, according to Grewal et al. [7], the distinguished feature of the OSS development is that cooperation and collaboration among members cause various social networks to emerge.

Many companies such as IBM, Google, Sun Microsystem and Oracle have decided to integrate OSS projects into their business operation. Other firms are also looking for business opportunities associated with OSS projects [37]. Moreover, public or private institutions also attempt to incorporate open source software in their business model. On the other hand, reliance on open software systems increases concerns over software security, and whether we can trust different platforms. OSS success should also help policy makers to better understand and implement their strategies considering different opportunities and threats [41].

\subsection{Network ties and coupling}

Granovetter [42] proposed a network theory which links micro and macro levels of sociological theory through analysis of weak ties bridging groups otherwise connected by strong ties. In a simple definition, strong ties are relationships with individuals whom we know very well, on the other hand, weak ties provide bridges over which innovations cross over boundaries of social groups, which are in fact strongly tied.

Weick [43] initially defined the concept of loose coupling; Orton and Weick [43] made a literature review on loose coupling, continued research on the topic, mentioned more and useful interpretations. Based on Granovetter definition of weak-vs.-strong ties and Weick definition of loose coupling, Girvan and Newman [44] defined the concept of "community structure" as a new property of sociological and biological networks, where nodes join together in tightly knit groups which are loosely connected to each other.

Granovetter [42] argued that we can separate our relationship networks into a circle of close friends with strong ties and a circle of acquaintances with weak ties. Strong ties lead to clusters of communities, while weak ties connect those communities. Weak ties are significant for content dissemination due to the graph-theoretic effect of edge expansion. Weak ties could accelerate diffusion of job information [42], adoption of new technology [13] and coordination of collective action. The concept of strong and weak ties has been extensively used in organization systems, for example, Hansen [27], Kogut and Zander [28] and Tsai [29, 30].

\subsection{Network ties and innovation}

Some studies in the literature attempted to link network structure and innovation output by analyzing the impact of tie strength on innovation [27, 29, 42]. In addition, Hansen [27] thoroughly discussed the impact of weak versus strong ties, and investigated moderating effect of knowledge complexity on project time completion. Hansen concluded that weak ties reduce project time completion, but this effect is moderated by knowledge complexity. Ahuja [5] investigated the impact of direct and 
indirect ties on firm innovation, and concluded that the more direct ties that a firm possess, the greater would be the firm's subsequent innovation output, on the other hand the more indirect ties, the greater the innovation output. Shane [45] investigated network relationship among firms which could impact on the rate of innovation; this permits knowledge sharing and information flow. There are also other studies in the network literature focusing within topic of knowledge sharing and innovation adoption; in these studies, importance has been rendered to the number of firm linkages and geographical proximity impacting rate of adoption [46, 47].

Some studies have shown that innovation generation benefits from network structural holes, moderated by type of innovation and type of firm. Some types of new technology diffusion require trust and cooperation between firms, which corresponds to fewer structural holes. For some other types of firms where information brokerage is the primary business, more structural holes are necessary for knowledge sharing $[5,48]$; other scientists have investigated the distinction between sparse and dense network structure to promote network innovation. Walker et al. [49] argued that strong ties are required for the exchange of complex knowledge, while a dense network structure impacts on the implementation of ideas within each group. Burt [48] stressed that a sparse network structure facilitates diffusion of ideas and argued that strong ties within a dense network due to lack of diversity in resources are inefficient to acquire external knowledge.

Moreover, Cowan et al. [50] wrote that many empirical studies investigating creation of knowledge demonstrate that innovation to a large extent is obtained via recombination of existing knowledge. They examined the evolution of networks when innovation is resulted from agents accumulating their knowledge endowments, based on the assumption that agents freely form pairs in a globally stable balance, and that paired agents combine their existing knowledge to create new knowledge.

By now, we have discussed definition of innovation in a network perspective, OSS communities, network ties and coupling and network ties and innovation in order to investigate impact of network structure on group innovation within domain of open source software. While prior researches have given insights into performance of OSS projects, they usually ignore impact of network structure on group innovation. Therefore, we claim that there is a need for a new conceptualization composing of different factors influencing on innovation and growth at group level. These factors include network embeddedness or structure parameters, for example, intra- and inter-cluster coupling, structural holes and tie strength impact group innovation, which we have addressed in the paper "Network tie structure causing OSS group innovation and growth" by Behfar et al. [51].

Open Source Software (OSS) project collaboration constitutes a new means of producing goods and services by self-organizing groups within worldwide virtual networks, and represents a new form of partnership between businesses and customers. More companies are now attempting to establish relationships to benefit from these potential value-creating groups. This makes it essential to investigate these communities further and see how to improve their success rate. Hahn et al. [52] investigated the personal factors causing a new developer to join a project, whereas in this study we are only concerned about network structural factors that influence developers to join existing projects or initiate new projects within a group. In other words, we investigated network structure as causal factor influencing both new project initiation within a group (representing group innovation) as well as new developers joining existing projects within a group (representing group growth).

We discussed three aspects of network structure-tie strength, group coupling and structural hole-as impacting innovation output. At the same time, we provided four hypotheses: (1) intra-group coupling has a positive impact on group 
growth, (2) inter-group coupling has positive impact on group innovation, (3) inter-group structural hole has a positive impact on group innovation and (4) there is a trade-off between the effects of inter-group structural hole and inter-group coupling on group innovation. We discussed the logic and provided empirical analysis to validate these hypotheses. Developers contributing to project tasks in groups other than their own can access novel ideas for new project creation, whereas developers contributing to project tasks inside their group exploit ideas to improve those existing projects with better inside-group search possibility. This demands more developers to existing projects.

Project managers could target different goals within software development teams including increasing project success rate, bolstering innovation within teams or attracting more developers to join existing projects. Targeting task contribution between groups or intergroup structural hole make achieve more group innovation, whereas targeting number of task contributions inside a group or number of users per task makes achieve more group growth. The number of developers contributing to each task indicates how popular each project task is; and the more popular each task is the higher the number of developers contributing to the task, which indicates group coupling, and this could lead to group innovation.

\section{What is knowledge management in a network perspective?}

Baer et al. $[53,54]$ performed a meta-analysis of literature on innovation and social networks and presented various trade-offs between strength of ties and bridging ties among other things. Tsai $[29,30]$ stated that social networks facilitate creation of new knowledge within organizations, also discussed how organizational units gain useful knowledge from other units to enhance its innovation and performance. Huber [26] investigated knowledge transfer among organizational units, and concluded that not all units have access and capacity to learn knowledge and apply it; they require external access and internal capacity [26]. Moreover, Ahuja [5] discussed firm's network relationship impacting the rate of innovation, where network allows for knowledge sharing and information flow.

\subsection{Knowledge diffusion within open source software communities}

Cooperation and collaboration among OSS community members is the distinguished feature of any development model, which explores OSS as a social network. It is interesting to know that OSS groups are more networked than the most organizational communities; in OSS network, programmers can join, participate and leave a project groups at any time, and in fact developers can collaborate not only within the same project but also among different projects or teams. One distinguished feature of the open source software (OSS) development model is the cooperation and collaboration among the members, which will cause various social networks to emerge.

Some studies investigated social network structure of open source software, and used long-term popularity as a measure to conclude that previous ties are generally an indicator of past success which would lead to future success [55]. Crowston et al. $[50,56]$ based on their analysis of social structure of open source software development teams and the interactions among 122 large and active projects, and found out that some projects are highly centralized, and others are not. Other authors also discussed knowledge sharing between team members based on similarity-attraction paradigm; where it was proposed that knowledge sharing more likely happen between same demographic team members [57]. 


\subsection{Network innovation trade-offs}

There are different studies in the literature which attempted to link network structure and innovation; where they mention some ambiguities:

1. One ambiguity in studies of the impact of tie strength on innovation concerns the distinction between strong and weak ties [27, 29, 42]. Granovetter [42] initially proposed a theory of weak versus strong ties, which link micro and macro levels of sociological theory through an analysis of various types of weak ties bridging groups otherwise connected by strong ties. Strong ties are relationships with individuals whom we know very well, but weak ties provide bridges which allow innovations to cross boundaries between social groups, which themselves are strongly tied.

2. Ahuja [5] investigated the impact of direct and indirect ties on firm innovation, and reported that more direct ties lead to greater firm's innovation output; and more indirect ties also leads to greater innovation output of the firm. Finally, there is a trade-off between impact of indirect ties and direct ties level on a firm's innovation output.

3. There is also ambiguity regarding the benefit of structural hole which promotes innovation generation moderated by types of firms, and even types of innovation. For some new technology diffusion, trust and cooperation between firms is required, which corresponds to fewer structural holes, whereas for firms where brokerage of information is the primary business, more structural holes are needed (see Burt [48], Ahuja [5]).

4. Lastly, there is also ambiguity concerning the impact of sparse and dense network structure to promote network innovation. Walker et al. [49] stated that dense network structure impacts implementation of idea within each group, and argued that strong ties within dense networks are required for exchange of complex knowledge; on the other side, Burt [48] stressed that a sparse network structure facilitates diffusion of ideas where strong ties within dense network are inefficient to obtain external knowledge because they do not bring diversity in resources.

After discussion over knowledge management in a network perspective, knowledge sharing in OSS communities and network innovation trade-offs concept, we investigate network innovation trade-offs further in order to explore impact of knowledge sharing within dense network structures on knowledge sharing between sparse network structures. Although we focus on the domain of open source software, but the scope is not constrained to OSS, and could generally encompass all group-like structures.

In the paper "Knowledge management in OSS communities: Relationship between dense and sparse network structures" by Behfar et al. [58], we discussed whether knowledge transfer in dense network (inside groups) has an influence on knowledge transfer in sparse network (between groups). For this purpose, we distinguished mechanisms influencing on knowledge transfer within groups as opposed to between groups.

To investigate how intragroup density affects intergroup coupling, we used utility function for each project based on benefit and cost of new link formation. We showed that when initial link is formed between two groups, subsequent link formation is always cost-wise beneficial to be formed, which indicates that 
intragroup density leads to subsequent intergroup coupling. The reason includes awareness or common neighborhood, which makes this link formation cost-wise beneficial.

In addition, we conducted an empirical analysis to validate the relationship between intragroup density and intergroup coupling using regression model on the OSS data. The results concluded that intragroup density has a positive and significant influence on intergroup coupling. This implies that betweenness has an insignificant influence on intergroup coupling; and degree centrality has a significant but negative influence on intergroup coupling, which indicates that users with high degree centrality do not participate in inter group projects, rather collaborate more with other developers for projects within a group. Our results demonstrate that when users in a group have a lot of in-group tasks to contribute to, given number of users as a constant, the users would be more likely to contribute to tasks in other groups.

The results of this paper could have significant implications for project managers in open source environment, such as IBM and Sun Microsystems actively working in open source projects with decision to sponsor project tasks to promote knowledge transfer between groups. This indicates that to achieve more knowledge transfer between groups, one needs to target number of developers within each group. Consider that the number of developers contributing to project tasks implies how popular each project task is, attracting more developers who can contribute to project tasks which corresponds to more intragroup coupling, leads to more knowledge transfer between groups.

\section{Conclusion}

This chapter in general was focused on the impact of network structural factors as a proxy for collaboration inside online communities (OSS groups in particular) onto network group innovation and growth. We have already published three papers in this topic, to which we hanged on in order to explain very different subjects in this limited number of pages. We aimed to answer questions (1) how social network of OSS projects influence on new users joining existing projects, or new project initiation within a group, and what kind of strategies should be used to improve it and (2) how knowledge sharing inside dense groups affects knowledge sharing between sparse groups.

We briefly discussed degree distribution distinction as a network structural property, then explained the impact of group dynamics on OSS project group innovation (i.e. group intra- and inter-coupling as causal factors for group innovation). Finally, we reported how knowledge transfer within and between groups are related, in that we explored how network tie density, centrality and betweenness inside groups influence on intergroup coupling. We also mentioned the practical implications, where companies adapt to the threats and opportunities of OSS movements, and exploit those specific strategies to take advantage of OSS projects. 
Importance of Social Networks for Knowledge Sharing and the Impact of Collaboration... DOI: http://dx.doi.org/10.5772/intechopen.89605

\section{Author details}

Stefan K. Behfar ${ }^{1,2}$

1 Digital Lab, CGI Consulting, Stuttgart, Germany

2 Audencia Business School, Nantes, France

*Address all correspondence to: stefankambiz.behfar@gmail.com

IntechOpen

(C) 2020 The Author(s). Licensee IntechOpen. Distributed under the terms of the Creative Commons Attribution - NonCommercial 4.0 License (https://creativecommons.org/ licenses/by-nc/4.0/), which permits use, distribution and reproduction for non-commercial purposes, provided the original is properly cited. (cc) BY-NC 


\section{References}

[1] Barabási AL, Albert R. Emergence of scaling in random networks. Science. 1999;286:509-512

[2] Faloutsos M, Faloutsos P, Faloutsos C. On Power-Law Relationships of the Internet Topology. SIGCOMM 99; Cambridge, USA; 1999

[3] Aral S, Walker D. Creating social contagion through viral product design: A randomized trial of peer influence in networks. Management Science. 2011;57(9):1623-1639

[4] Ioannidis S, Chaintreau A. On the strength of weak ties in mobile social networks. In: Proceedings of the Second ACM EuroSys Workshop on Social Network Systems. 2009. pp. 19-25

[5] Ahuja G. Collaboration networks, structural holes, and innovation: A longitudinal study. Administrative Science Quarterly. 2000;45:425-455

[6] Burt RS. The network structure of social capital. In: Sutton RI, Staw BM, editors. Research in Organizational Behavior. Greenwich, Conn.: JAI Press; 2000. pp. 345-423

[7] Grewal R, Lilien GL, Mallapragada G. Location, location, location: How network embeddedness affects project success in open source systems. Management Science. 2006;52(7):1043-1056

[8] Joshi KD, Sarker S. Knowledge transfer within information system development teams: Examining the role of knowledge source attributes. Decision Support Systems. 2006;43(2):322-335

[9] Wilhelm T, Kim J. What is a complex graph? Physica A: Statistical Mechanics and its Applications. 2008;387:2637-2652

[10] Newman MEJ. Modularity and community structure in networks.
Proceedings of the National Academy of Sciences. 2006;103(23):8577-8582

[11] Simon HA. The architecture of complexity. Proceedings of the American Philosophical Society. 1994;106(6):462-482

[12] Hamdouch A. Innovation clusters and networks: A critical review of the recent literature. In: Proceedings of the 19th EAEPE Conference; Universidade do Porto. 2007

[13] Rogers EM. Diffusion of Innovations. New York: Free Press; 1999. p. 367

[14] Cooke P, Huggins R. Hightechnology clustering in Cambridge. In: Sforzi F, editor. The Institutions of Local Development. Aldershot: Ashgate; 2003. pp. $51-74$

[15] Nooteboom B. Innovation, learning and cluster dynamics. In: Asheim BT, Cooke P, Martin R, editors. Clusters and Regional Development: Critical Reflections and Explorations. London: Routledge; 2006

[16] Estivill-Castro V. Why so many clustering algorithms-A position paper. ACM SIGKDD Explorations Newsletter. 2002;4(1):65-75

[17] Watts DJ, Strogatz SH. Collective dynamics of 'small-world' networks. Nature. 1998;393:440-442

[18] Wasserman S, Faust K. Social Network Analysis: Methods and Applications. Cambridge University Press; 1994. ISBN: 9780511815478

[19] Opsahl T, Panzarasa P. Clustering in weighted networks. Social Networks. 2009;31(2):155-163

[20] Erdős P, Rényi A. On the evolution of random graphs. In: Publications of the Mathematical Institute of the 
Hungarian Academy of Sciences. Vol. 5. pp. 17-61

[21] Barmpoutis D, Murray RM. Networks with the smallest average distance and the largest average clustering; Cornell University Library. 2010; arXiv:1007.4031

[22] Behfar SK, Turkina E, Cohendet $P$, Burger-Helmchen T. Directed networks' different link formation mechanisms causing degree distribution distinction. Physica A: Statistical Mechanics and its Applications. 2016;462:479-491

[23] Morone P, Taylor R. Knowledge Diffusion and Innovation Modelling Complex Entrepreneurial Behaviors. UK: Edward Elgar; 2010

[24] Baldwin CY, Clark KB. Managing in an age of modularity. Harvard Business Review. 1997;75(5):84-93

[25] Davies H, Nutley S, Mannion R. Organisational culture and quality of health care. Quality in Health Care. 2000;9(2):111-119

[26] Huber GP. Organizational learning: The contributing processes and the literatures. Organization Science. 1991;2:88-115

[27] Hansen MT. The search-transfer problem: The role of weak ties in sharing knowledge across organization units. Administrative Science Quarterly. 1999;44:82-111

[28] Kogut B, Zander U. Knowledge of the firm, combinative capabilities, and the replication of technology. Organization Science. 1992;3(3):383-397

[29] Tsai W. Social capital, strategic relatedness and the formation of intraorganizational linkages. Strategic Management Journal. 2000;21(9):925-939
[30] Tsai W. Knowledge transfer in intra-organizational networks: Effects of network position and absorptive capacity on business unit innovation and performance. Academy of Management Journal. 2001;44(5):996-1004

[31] Ma M, Agarwal R. Through a glass darkly: Information technology design, identity verification, and knowledge contribution in online communities. Information Systems Research. 2007;18(1):42-67

[32] Ren Y, Kraut R, Kiesler S. Applying common identity and bond theory to design of online communities. Organization Studies. 2007;28: 377-408

[33] DiMaggio P, Powell W. The New Institutionalism in Organizational Analysis. The University of Chicago Press; 1991. ISBN: 9780226185941

[34] Von Hippel E, Von Krogh G. Open source software and the privatecollective innovation model: Issues for organization science. Organization Science. 2003;14(2):209-223

[35] Von Hippel E. Innovation by user communities: Learning from open-source software. MIT Sloan Management Review. 2001; 42(4):82-86

[36] Mockus A, Fielding RT, Herbsleb JS. Two case studies of open source software development: Apache and Mozilla. ACM Transactions on Software Engineering and Methodology. 2002;11(3):309-346

[37] Von Krogh G. Research briefOpen-source software develop-ment. MIT Sloan Management Review. 2003;44(3):14-18

[38] Riehle D. The Open Source Software Developer Career and its Benefits. IEEE Computer; 2015 
[39] Jackson MO. A survey of models of network formation: Stability and efficiency. In: Demange G, Wooders M, editors. Group Formation in Economics: Networks, Clubs and Coalitions. Cambridge: Cambridge University Press; 1996. pp. 1-62

[40] Singh PV, Tan Y, Mookerjee V. Network effects: The influence of social capital on open source project success. MIS Quarterly. 2011;35(4):813-829

[41] Wang J. The role of social networks in the success of open-source-software systems: a theoretical framework and an empirical investigation [PhD thesis]. Kent State University Graduate School of Management; 2007

[42] Granovetter M. The strength of weak ties. The American Journal of Sociology. 1973;78:1360-1380

[43] Weick K. Educational organizations as loosely coupled systems.

Administrative Science Quarterly. 1976;21(1):18

[44] Girvan M, Newman MEJ. Community structure in social and biological networks. Proceedings of the National Academy of Sciences of the United States of America. 2001;99(12):7821-7826

[45] Shane S. Are champions different from non-champions. Journal of Business Venturing. 1994;9(5):397-421

[46] Florida R. Towards the learning regions. Futures. 1995;27:527-536

[47] Van Oort FG, Atzema OALC. On the conceptualization of agglomeration economies: The case of new firm formation in the Dutch ICT sector. The Annals of Regional Science. 2004;38(2):263-290

[48] Burt RS. Structural Holes. Cambridge, Mass: Harvard University Press; 1992
[49] Walker G, Kogut B, Shan WJ. Social capital, structural holes and the formation of an industry network. Organization Science. 1997;8(2):109-125

[50] Cowan R, Jonard N, Zimmermann JB. On the creation of networks and knowledge. In: Gallegati M, Kirman AP, Marsili M, editors. The Complex Dynamics of Economic Interaction. Essays in Economics and Econophysics. Berlin: Springer; 2004. pp. 337-354

[51] Behfar SK, Turkina E, Burger-Helmchen T. Network tie structure causing OSS group innovation and growth. Problems and Perspectives in Management. 2017;15(1):7-18

[52] Hahn J, Moonm JY, Zhang C. Emergence of new project teams from open source software developer networks: Impact of prior collaboration ties. Information Systems Research. 2008;19:369-391

[53] Baer M. The strength-of-weakties perspective on creativity: A comprehensive examination and extension. The Journal of Applied Psychology. 2010;95(3):592-601

[54] Baer M, Evan K, Oldham GR, Boasso A. The social network side of individual innovation. A metaanalysis and path-analytic integration. Organizational Psychology Review. 2015;5(3):191-223

[55] Antwerp MV, Madey G. The importance of social network structure in the open source software developer community. In: Proceeding of the 43rd Hawaii Int. Conf. on System Sciences. 2010

[56] Crowston K, Annabi H, Howison J. Defining open source software project success. In: Proceeding of the International Conference on Information Systems (ICIS). 2003. pp. 1-14 
Importance of Social Networks for Knowledge Sharing and the Impact of Collaboration... DOI: http://dx.doi.org/10.5772/intechopen.89605

[57] Ojha AK. Impact of team demography on knowledge sharing in software project teams. South Asian Journal of Management. 2005;12(3):67-78

[58] Behfar SK, Turkina E, BurgerHelmchen T. Knowledge management in OSS communities: Relationship between dense and sparse network structures. International Journal of Information Management. 2018;38(1):167-174 

Section 3

\section{KM, Mission Critical Applications}





\title{
Knowledge Redundancy Cycles in Complex Mission-Critical Systems
}

\author{
Darrell Mann
}

\begin{abstract}
Based on a 20-year, 10-million case study programme of research, $98 \%$ of all innovation attempts end in failure. The main aim of the research has been to decode the underpinning, first-principle-driven 'DNA' of the $2 \%$ of successful attempts. Sitting right at the centre of this DNA is a triad of fundamentals: the need to embrace the dynamics of complex adaptive systems, the need to actively seek out and eliminate compromises and contradictions, and the need for industry domains to periodically unlearn knowledge that has become redundant. The chapter discusses all three of these pillars. Particular attention is paid to the knowledge redundancy topic, where the fact that the life-cycle of knowledge follows distinct, repeating patterns of evolution at meta, macro and micro- hierarchical levels is demonstrated. The research further demonstrates how organizations can use these patterns to objectively identify redundancy 'pulse-rates' and thus objectively manage both the acquisition of required new knowledge and the disposal of knowledge that is no longer fit for purpose. The research shows too that a key aspect of this 'unlearning' activity demands that organizational leaders acknowledge and accommodate the very human emotions that accompany change initiatives where the things that define a person's competence become a hazard to the future success of the enterprise.
\end{abstract}

Keywords: complex-systems, S-curves, innovation, redundant knowledge, embedded knowledge, emotional design

\section{Introduction}

Across the evolutionary history of mankind, technology has generally evolved through trial and error. Luck, happenstance and the occasional random 'Eureka' moment appear to have been the dominant mechanisms of progress, more often than not, appearing against the prevailing 'common sense' of the day [1]. Johnson [2] does not take the story much further with his seven principles of progress, the majority of which also seem to feature a strong bias in the direction of randomness - serendipity, error, exaptation, 'the adjacent possible' and 'slow hunches' being five of the seven-leaving just 'liquid networks' and 'platforms' as the two that offer even a glimmer of hope that scientific progress might have any underpinning repeatable 'theory' upon which future engineers and scientists might seek to design the future. If Wolpert and Johnson-and the myriad other authors sharing the same basic views-are to be believed, the future progress of mankind is little more than a game of roulette. Except with somewhat worse odds of success. If this is in any way true then things do not seem to bode well in a world of globalization, digitalization 
and exponentially increasing interdependencies. If we cannot fathom the mechanics of new knowledge creation, what hope is there that engineers, scientists and business leaders can know when existing knowledge has become redundant?

The question is not a trivial one. Especially when viewed through the mission critical lens provided by the recent pair of crashes of Boeing's new 737 Max aircraft, the first, Lion Air flight 610 on 29 October 2018, and then the second, Ethiopian Airlines flight 302 on 10 March 2019. The first generation 737 entered service in 1968, and the various evolutions have collectively made it the best-selling commercial aircraft of all time. This in an industry that sets the global standard when it comes to safety.

In 1946, meanwhile, as is the case with the large majority of discoveries reported by Wolpert, Johnson and their ilk, an apparently random research question sparked another major discovery. Albeit one that, to date, still has not been recognized by most. The recipient of the question was Soviet engineer, Genrich Altshuller, when he was sent to the Patent Office to determine the differences, if any, between 'good' and 'bad' inventions [3]. The research-still ongoing today, and now able to take advantage of computerized search techniques that permit several thousand new case studies to be analyzed per week (not coincidentally, the same rate that new patents and patent applications are published) — has, through largely empirical means revealed much of what might be described as the 'DNA' of the $2 \%$ of innovation attempts that end up achieving success. In examining, at the time of writing, over 10 million case studies have been built into a series of 'first principles' focused databases that together reveal:

a. 'good' solutions deliver the customer-desired functions better than previous incumbent solutions, where 'better' means an ever-increasing ratio of benefits to negatives (cost, waiting time, harmful side-effects, etc.).

b. 'good' solutions do not make the trade-offs and compromises associated with 'optimization'-based design strategies taught in schools and colleges, but rather progress by eliminating said compromises and contradictions.

c. 'good' solutions follow clear trajectories of successive contradiction emergences and eliminations.

Sitting right at the heart of the Soviet-originated discoveries is the so-called S-curve of system evolution. S-curves are visible enough that many authors have been able to spot their basic characteristics. Indeed, most engineers and scientists will claim some kind of passing awareness of the dynamics associated with S-curves, albeit few can be observed making meaningful use of the knowledge when it comes to the curves' relevance to the generation of new knowledge, or the redundancy of old.

The vertical axis on any S-curve picture may be plotted to show any and all of the attributes of a system that might wish to be improved. At a management level, the axis might be plotting customer adoption, or profit, or ROI. At more granular engineering levels, the axis might be plotting performance parameters like speed, range, payload, or, closer to manufacturing operations, quality, waste-reduction or cost-reduction. Oftentimes, all of these attributes can be integrated together so that the curve plots 'value'. The horizontal axis is usually plotted as time, or, in more enlightened environments, improvement effort expended (Figure 1).

The shallow gradient start of the S-curve is usually associated with the inevitable struggle that occurs when a new technology appears. Eventually, assuming a critical mass of 'early-adopter' customers are willing to pay enough for the 'poor' 


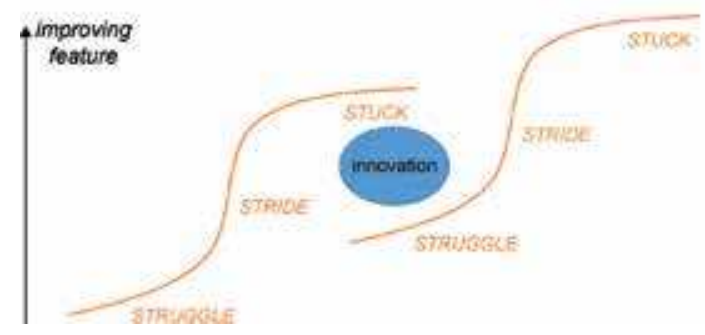

Figure 1.

S-curves and the dynamics of discontinuous change.

initial manifestations of the technology, this early revenue will pay for the continuing development of the technology. At some point, there will be some form of internally-controlled production-related Eureka moment-a new manufacturing technology, for example, or a new pricing model-that will allow the curve to follow a much steeper upward trajectory. This 'stride' portion of the curve is the joyous stage of an enterprise when life is easy-easy sales, easy improvements and easy knowledge creation and sharing. But then, sooner rather than later, comes the law of diminishing returns top part of the curve; the 'stuck' portion. This is where contradictions begin to emerge: whatever it is that the enterprise is trying to improve, 'something' increasingly comes to prevent the achievement of those improvements. Then finally-some smart individual or team solves the contradiction and in so doing permits the jump to a new S-curve. And, assuming the 'right' new solution is selected, the struggle-stride-stuck dynamics of the S-curve will repeat again.

The process by which systems advance up their S-Curve and the process through which the discovery that permits the discontinuous shift from one S-Curve to the next can be seen to be polar opposites. The majority of the tools, processes and management strategies (Lean, Six Sigma, Agile, etc.) found in modern enterprises have evolved to assist in the process of optimizing systems and thus allowing them to climb their S-curve. As the top of the curve is approached, however, a fundamental law of diminishing returns kicks in, whereby as these tools, methods and strategies are adopted by greater and greater numbers of people tasked with 'continuously improving' the system, their efforts produce fewer and lesser benefits. If the tools being used enable optimization, they, by definition, prohibit the real job from taking place. Optimization is the nice word for making trade-offs. Innovation-i.e. the successful jump to the next S-curve-is all about not making those trade-offs and solving the contradictions instead. Alas, the number of engineers, scientists and leaders that even recognize the existence of contradiction-solving tools is still very much in the minority. And consequently, the majority of organizations find themselves stuck at the top of their current S-curve deploying tools that are no longer relevant. In many ways, all that the currently fashionable 'Agile' movement has shown is how deploying the wrong tools faster does not equate to faster progress, it merely means improvement teams spin their same trade-off wheels faster and go around and around in ever tightening circles which deliver no tangible progress.

A big part of the task of climbing the current S-curve is about eliminating the complexity of a situation. By understanding how the system works and by 'standardizing' as much of it as possible, enterprise leaders have been taught for the last 100 years, that is how the greatest efficiencies are obtained. Standard work makes it much easier to train workers. Making every worker focus on a narrower and narrower area of specialization, on the other hand, also creates enormous knowledge silos. Silos make for high efficiency, but become a serious hindrance when the need to innovate arises. 
Innovating - the job of leaving the current S-curve and finding the next onemeans embracing the inherent complexities of the world. In the world of standardization there are clear rules and protocols, everything is controllable, mistakes are bad, failure is worse. If there's a problem, root-cause analysts will find it. In the world of innovation, there are no clear rules-the job is in fact to break the current rules in order to find better ones-seemingly nothing is controllable, there is no such thing as a root cause anymore, and mistakes and failure are one of the primary mechanisms of progress. Failure, in the complex and often chaotic world of innovation, is learning. And in a complex world, the teams that learn the fastest are the ones most likely to prevail.

In the S-curve climbing world of optimization, chaos is to be avoided at all costs, whereas those tasked with working through the fog of uncertainty inherent to the innovation process know that chaos often plays a pivotal role. Some authors, most notably Hurst [4], would say that chaos was an essential component.

The Cynefin Framework [5] offers a pioneering means of displaying the different kinds of operating regime found in the world of business. Originating from work in the knowledge management domain, Cynefin's starting premise is that unless managers understand which of these regimes they are currently withinobvious, complicated, complex or chaotic —it is highly likely they find themselves using the wrong sorts of methods at the wrong time and for the wrong reasons. More recently the Complexity Landscape Model [6] has extended the Cynefin framework to incorporate a second dimension that now maps not just the system being managed, but also that of the surrounding environment.

Figure 2 takes the ideas of Hurst regarding the importance of chaos in the innovation process and plots a typical S-Curve-to-S-Curve discontinuous change process onto the Complexity Landscape Model. 'Creative destruction' and 'ethical anarchy' are expressions used by Hurst to describe the thinking necessary to successfully navigate the chaotic 'no man's land' between the prevailing and emerging new S-curves. They are also the engine behind the un-learning that needs to take place during the transition process. In many ways this 'unlearning of the old' is as critical to success as the discovery of the new.

If the descent into chaos provides the necessary 'permission' to unlearn the current knowledge, the surrounding complex domain demands a shift in the way innovators see the world. The links between cause and effect become highly tenuous and consequently there are no root-causes in the complex domain. Repeatability largely disappears. And all of the optimization-related knowledge acquired during

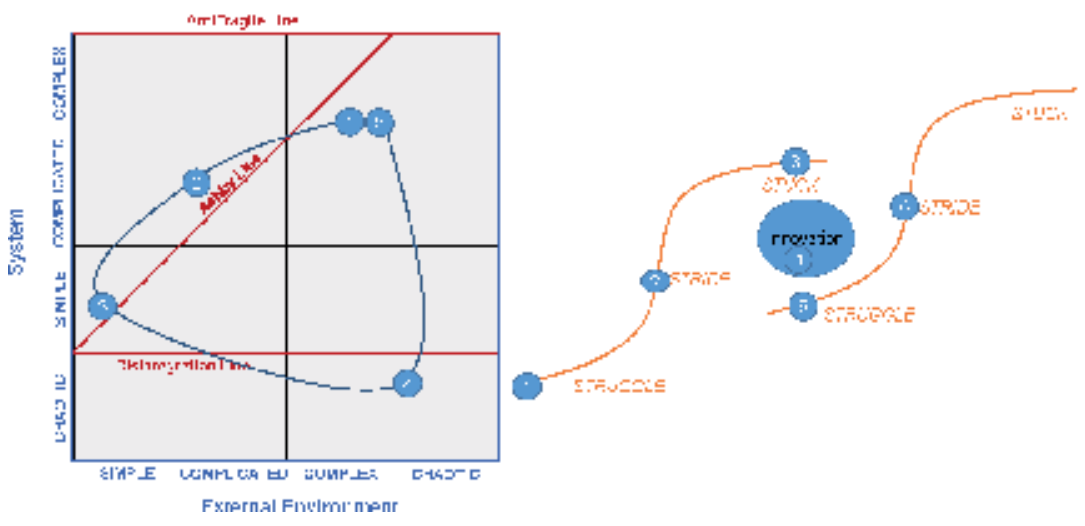

Figure 2.

Complexity landscape model and discontinuous change. 
the rise from 'stride' to 'stuck' very clearly becomes redundant. The only knowledge, in fact, that does not become redundant is that relating to the first principles from which the system behavior emerges.

The discontinuous shift from one system S-Curve to another may thus be seen to have potentially profound implications for the management and flow of knowledge. With this in mind, an important knowledge management metric for any enterprise relates to the frequency with which such discontinuities occur. For the most part, these discontinuity 'pulse-rates' are typically not understood or are not managed well in most enterprises. Rather it has been the 10-million case-study research started in the former Soviet Union in 1946 that has done most to reveal this kind of pulse rate information. And specifically, how it varies considerably from one industry domain to another. In high capital investment, slow-changing industries like mining or oil and gas, for example, the discontinuity pulse rate is typically over 30 years. Contrast this with the digital world, especially the 'innovation cauldron' that is China, where significant changes are likely to occur every few months, thanks in no small part due to a working culture in which intellectual property is not respected and hence in order for an enterprise to stay ahead of the game, they need to be innovating on an almost continuous basis [7]. Old knowledge in the digital world can become redundant in a matter of months, meaning that workers in the field need to devote a significant proportion of their time to learning new ways of achieving the functions customers wish to have delivered. Contrast this with a typical mining engineer, who might, if they are unfortunate enough to join the profession at the wrong time, might never see a discontinuous change during their entire working career.

One other aspect of the Soviet-instigated research that also features heavily on the knowledge redundancy story involves another revealed pattern associated with the S-Curve. That pattern is reproduced in Figure 3.

This graph shows how, despite attempts to reduce system complexity, the actual complexity of a system follows an increasing-decreasing characteristic. The firstincreasing complexity-portion of this curve is all about the inherent need to add elements to a system in order to improve performance and functionality. A classic example of this pattern in action in today's world can be seen with the evolution of the mobile phone-which has progressively added cameras, e-cash, alarm-clock, torch, music-player, and an app-store full of other functional capabilities over the course of the past decade. Sooner or later, however, and probably sooner as far as

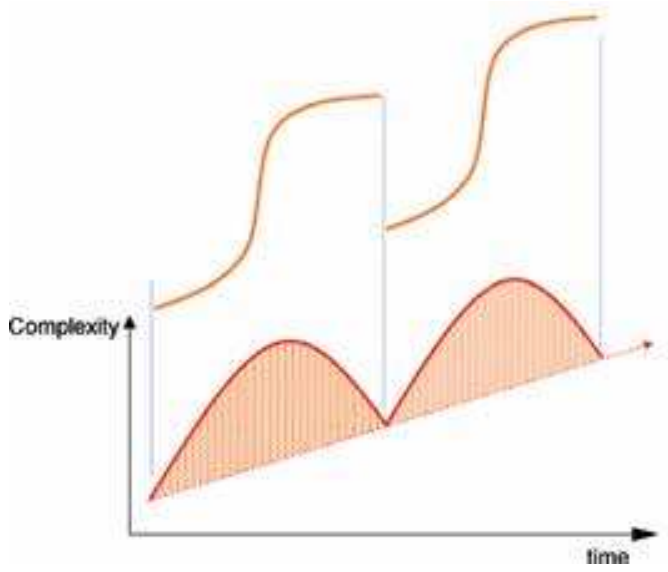

Figure 3.

S-curves and complexity. 
our phones are concerned, customers begin to complain that the phone is overserving their needs. Or that they are having to be continually re-charging it. Or that durability is impaired. Something tells the providers of the handsets that the system has reached a maximum viable level of complexity. Once this point has been reached, the motivation of the designers tasked with continuing the evolution story makes the shift towards simplification. The need during this second phase of the curve is to maintain the required functionality of the system but to achieve it with fewer components and lower cost. Complexity, in other words, head in a downward trajectory, in part through cunning engineering design, and also by embedding the complexity so that it is no longer visible to the customer.

The increasing-decreasing complexity curve describes an important aspect of the knowledge story. In effect the shaded area under the curve describes the 'excess knowledge' generated during the S-curve evolution journey. Complexity of systems over the course of multiple S-curve jumps tends to head in an upward direction, but in effect during each individual S-curve there is an 'over-shoot' that happens because designers aren't smart enough (or there is not enough incentive to become smarter) during the early evolution of the system to make functional improvements without adding new elements into the system. If designers were smarter, or at least understood the complexity curve pattern, it ought to be possible to avoid much of this complexity over-shoot and the consequent surplus or redundant knowledge that is attributable to it.

A more subtle characteristic of the transition from one S-curve to the next is that, traditionally, when further improvement of the current system becomes difficult, engineers and scientists make many attempts to try and find the new S-curve. Thomas Edison famously tried over a thousand different materials before he found one suitable for the filament in his lightbulb. Almost as famously in more recent times, James Dyson built over 5000 prototypes of his cyclone vacuum cleaner before he found something worthy of release onto the market. In many ways this trial-and-error experimentation-Figure 4-is what sits behind the $98 \%$ failure rate of innovation attempts.

This work, too, has considerable relevance to the knowledge creation story. Finding several thousand solutions that do not work represents a considerable amount of redundant knowledge being generated. True, a failed experiment provides a modicum of new knowledge ('don't bother doing this again'), but when the modus operandi is trial and error, it inherently means that a significant amount of 'non-knowledge' is generated. Traditionally, the generation of new knowledge has been somewhat inefficient. Perhaps because there has been an implicit assumption by engineers and scientists that this is the way the world works.

Initially, of course, it very likely was the way the world had to work. But today, having benefited from millions of trial and error S-curve shifting experiments,

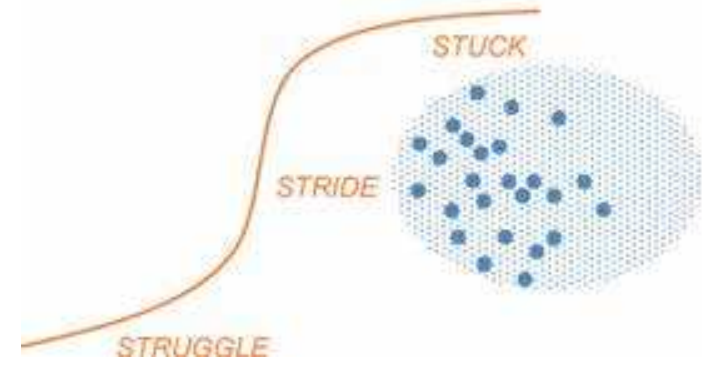

Figure 4.

Finding the new S-curve. 
the Soviet-sparked innovation-DNA research has revealed a number of patterns that now show how engineers can do something far more efficient than trial and error. Ninety-eight percent of innovation attempts end in failure. If the $98 \%$ failed attempts ('noise') are removed from the analysis and the remaining 2\% ('signal') are analyzed, a clear roadmap of successful design strategy begins to emerge. The next section examines two important elements of this roadmap. Just before heading into that story, it is worth summarizing the knowledge flow story in relation to the S-curve pattern described in this section:

1. When systems make jumps from one S-curve to the next, much of the knowledge associated with the old system is likely to become redundant.

2. The pace of knowledge redundancy-the 'half-life' of knowledge-is determined by the rate at which discontinuous S-curve shifts occur.

3. During the search for the 'right' new S-curve start-point, significant amounts of new knowledge are generated; much of this knowledge will never result in meaningful progress and is thus 'noise'.

4. Once the right new S-curve solution emerges from this noise, designers tend to overshoot the complexity of the solutions they design, and thus find themselves generating yet more knowledge that also becomes redundant.

Historically, this process of random knowledge creation and redundancy was deemed to be 'the way the world works'. It was inefficient but there was no alternative. Innovation in today's world increasingly cannot afford the $98 \%$ 'waste' and, like all other aspects of life, needs to begin climbing its own S-curve. The world has experienced the 'struggle' portion of the innovation capability S-curve, now it needs to hit its stride ... and, thanks to a random cluster of Soviet engineers working on a fortuitously posed question in 1946, perhaps it can ...

\section{Patterns of system evolution}

The trick to identifying and removing the $98 \%$ noise present in the innovation world involves, first, recognizing the need to examine the world in terms of function. In the words of the cliché, customers want a hole not a drill. The implication of this cliché is that rather than looking at the evolution of drills, it is more sensible to examine the evolution in terms of how holes get made. Figure 5 examines an evolution journey relating to the function, 'protection':

Shields were one of the first solutions by which humans sought to protect themselves against an aggressive threat from others. As time progressed, the design of shields improved, but no matter how light they became, or how much their productions were reduced, shields suffer a pair of fundamental problems. Number one, they have to be held and this causes a severe impairment to the parallel attacking function. Secondly, the bigger the shield becomes, the more of a person it is able to protect, but, unfortunately, this extra size results in extra weight and less maneuverability. There are, in other words, two contradictions-one relating to attack-versus-defense and the other to area-versus-weight. The emergence of these two contradictions effectively saw the shield stuck at the top of its evolutionary S-curve.

Necessity being the mother of invention, eventually the inventors of the day devised the first armor solutions. Now the wearer had two arms free and, although 



Figure 5.

Early evolution of the 'protection' function.

they were still heavy, at least the weight was better distributed and allowed a certain freedom of movement. The new S-curve had arrived. Importantly, like almost every innovation when it first appears, the new system is likely to be inferior in multiple ways to the much-optimized previous solution. The armor manufacture technology barely existed and so, if nothing else, the armor solution was much more expensive to produce than the shield. The armor was also difficult to get on and off, and so on. The new armor S-curve finds itself lower than the top of the shield S-curve for the majority of prospective 'customers'. At the same time, crucially, a person fortunate enough to be wearing armor is much more likely to be the victor in a fight against someone carrying only a shield. And because of this advantage, more 'customers' demand suits of armor and that interest causes the design of the armor to become progressively improved. Armor producers struggled for a while, but eventually hit their stride, and armor became the dominant protection solution and armor was a better solution than the best shield.

The suit of armor, of course, never gets to be the perfect protection solution. Armor technology is also subject to the 'stuck' law of diminishing returns found at the top of the S-curve. In this case, the limiting contradiction was about lack of mobility. If the wearer was attacked from the side, it would take several seconds to turn and face the opponent. Necessity being again the mother of invention, eventually some smart designer conceives the idea of chain-mail, and a new protect S-curve begins.

Repeat this story for tens of thousands of innovation step-changes and a very clear pattern of evolution occurs. The most popular version of the pattern is reproduced in Figure 6. It is usually related to the evolution of movement or 'dynamization' within systems:

At the first stage of evolution, like the shield, designers typically create artifacts that are 'immobile'. Then, for various reasons, they find it beneficial to add joints to enable greater freedom of movement. Sometimes this might mean adding a single joint (think about the evolution of the clamshell or flip-up mobile phones that followed in the wake of the original mono-block handsets), and sometimes-in the case of the armor-multiple joints. Eventually, the jointed solutions evolve to become 'completely flexible'. From there, there is a likely fluidic stage, which 


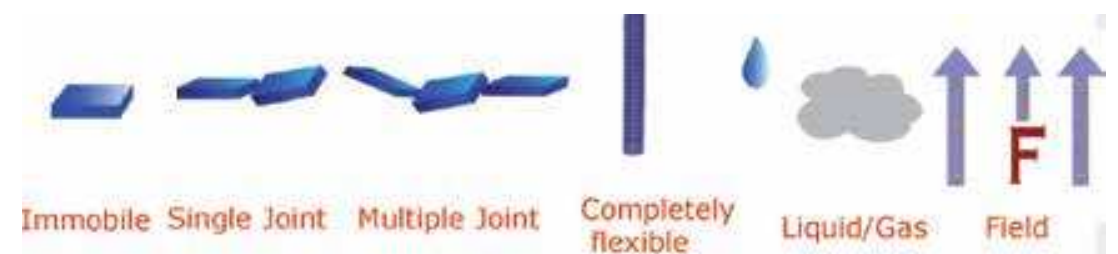

Figure 6.

Dynamization trend pattern.

ultimately finds itself replaced by solutions making use of 'fields'. It is usually not possible to specifically pin down what kind of field this will be in a given domainit could be an electrical field, magnetic, digital, or anywhere along the electromagnetic spectrum-but it can be said with certainty that field solutions will eventually supplant the earlier mechanical or fluidic solutions. It is more effective, ultimately, to move electrons rather than atoms. Think laser-drills, digital user-interfaces on smartphones, 'drive-by-wire' vehicle control systems, electric vehicles, maglev trains, etc.

The Dynamization trend pattern in effect offers designers a roadmap of future solutions. Thus, staying with the protection function for a moment or two longer, if the designer of Kevlar bullet-proof vests was looking to explore likely future technologies, the Dynamization trend firstly asks them to place the current Kevlar solution on the trend (if we are being generous to the Kevlar scientists, we might call it 'flexible'). Once we have found the current position, the roadmap then tells us the places that others in a similar position have successfully evolved their own solutions. The future of armor, according to this trend is, next, some form of 'liquid', and will ultimately become some kind of field. To date, it does not appear that a field-based bullet stopper is possible, but the future of armor does indeed look like a fluidic solution-specifically a non-Newtonian fluid-offers a highly effective and commercially viable solution to the main contradictions present in today's 'flexible' Kevlar vests [8].

From a knowledge redundancy perspective, the Dynamization trend pattern holds a number of important clues. Mechanical solutions will sooner or later be superseded by fluidic ones; fluidic ones will be superseded by field-based solutions. Mechanical engineers and mechanical engineering knowledge is useful when physical artifacts are being produced for a period of time, but ultimately that knowledge will become redundant as the 'field'-based solutions begin to emerge. The ability to design scalpels, for example, is an important design skill only so long as clinicians decide that lumps of sharpened metal or composite are a better way to conduct invasive surgery than a laser.

To date, 37 other patterns have been identified relevant to the evolution of technical systems [9], 31 patterns have been found pertaining to the evolution of business systems [10], and 26 patterns found relevant to the evolution of IT systems [11]. Figure 7 illustrates one of the other technical evolution patterns, one with particular relevance to the exploitation of knowledge in the design of mission critical systems:

Mission critical means achieving high levels of reliability, availability and system resilience. Such parameters are typically measured in terms of the number of 'nines' a given design is able to deliver. A 'two-nines' solution, for example, will be available $99 \%$ of the time; three-nines will be available $99.9 \%$ of the time, and so on. State of the art automotive design will aim to achieve four- or five- nines levels of performance. Commercial aircraft will typically be at ten- or eleven-nines levels of performance. The Resilient Design trend pattern reproduced in Figure 7 


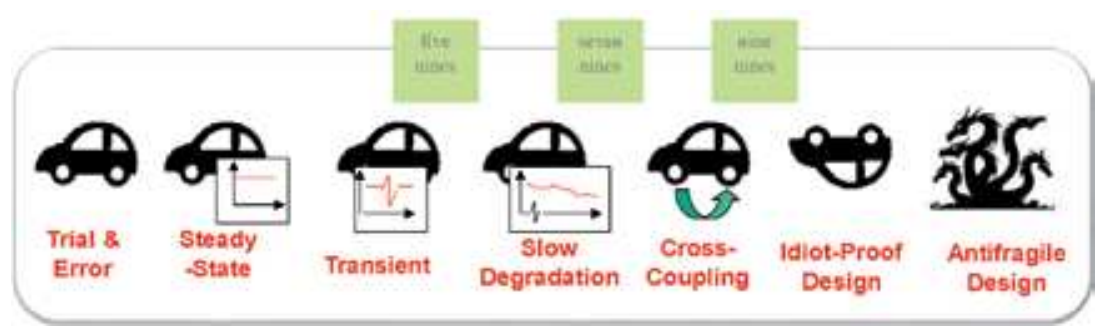

Figure 7.

Resilient design trend pattern.

illustrates the various step-change different design methodologies (i.e. as with the Dynamization pattern, each stage may be viewed as a distinctly separate S-curve to the one that precedes it). The first stage of the pattern is the 'trial and error' methodology that essentially exists within the innovation world today. The average $98 \%$ failure rate of the innovation world-i.e. slightly below two-nines-is typical of what's achievable when designers essentially make guesses about how to design the systems they are responsible for.

The next stage beyond 'trial and error' sees the adoption of some form of steadystate prediction model. Typically, this means defining an 'optimum' condition for the system-a production-line, for example, or an internal combustion engine 'cruise' state-and modeling the desired interactions between the various components of that system. Such a model permits each of the variables in the system to be 'optimized' to deliver the most efficient performance, and then, from an operational perspective, the aim becomes to operate the system at that optimal condition for as much of the time as possible.

The next evolution stage then sees system designers coming to recognize that while 'steady-state' might be a target, there will be inevitable 'transient' conditions where the system may well be expected to operate far from its optimal state. A cold engine, for example, is not the same as one that has reached its cruise operating temperature; a production-line at a shift handover is likewise non-optimal. Building a transient model of the system permits 'optimal' performance to be extended to a broader and broader spectrum of transient conditions.

Next up comes the 'slow degradation' design capability stage. This is the stage that recognizes that systems-particularly physical ones-wear out over time. A new engine is not the same as one that has been driven $100,000 \mathrm{~km}$. A slow-degradation design capability thus enables designs that are able to operate optimally (and safely) as aging takes place.

A slow-degradation capable design capability, depending somewhat on the level of complexity of the system under consideration, will enable up to seven-nines levels of reliability. Going beyond this level demands another step-change in capability. This time one that in effect creates a 'whole-system' analysis capability in which elements that one might think aren't connected to one another in actual fact are. In theory the behavior of the jet engine mounted on the wing of an aircraft should have no impact on the design of the nose landing gear, but in a cross-coupling level design capability, potential interactions between the two are incorporated into the design process.

The next S-curve jump in design capability builds on the need to mitigate for the dangerous user. In this way of thinking, no matter how big a mistake a user makes, the system ought to be able to survive.

Finally—so far_comes the 'AntiFragile' evolution stage [12]. This is a level of system design capability that not only sees the system able to survive abusive 
treatment, but also to become stronger as a result of that abuse. As in the Hydra from Greek mythology, or, in less metaphorical terms, the growing number of software systems that 'learn' from attempted attacks such that those attacks will be automatically dealt with in the future.

If the previous Dynamization evolution pattern was about the knowledge acquired at each new stage to make previous stage knowledge largely redundant, with the Resilient Design pattern, the knowledge acquired from each previous stage tends to become embedded within the next stage. It might thus become essentially invisible to the user, but it still has a role to play in the successful design of future systems. An example of this form of embedded knowledge can be seen in the design of aircraft control systems. When a pilot in an early generation was coming in to land, they would be expected to manually set the flap-angles on the aircraft's control surfaces. It is very unlikely that a modern day commercial pilot would have anything beyond a passing awareness of their flap-angles, the aircraft's control systems now effectively having evolved to the point whereby, under normal landing conditions, the pilots will do little more than programme the desired runway location and let the aircraft take over all the functions necessary to land safely.

\section{Emotions and intangibles}

Considered from purely rational perspectives, the knowledge acquisition/ disposal story appears straightforward: where a system is on its S-curve journey informs us when there is a need for new knowledge, and conversely, when there is a need to dispose of redundant knowledge or embed still useful knowledge. Of course, when the discussion centres around human beings, 'purely rational' is rarely a possibility.

An engineer or scientist that has devoted the best part of their career designing mechanical systems is highly unlikely to welcome the advent of a disruptive 'field'-based successor technology. That same engineer is not likely to be much more welcoming of a new 'idiot-proofing' design methodology that forces them to double or triple the amount of time they have to devote to conceiving unlikely failure scenarios.

Take the case of physician, Barry Marshall, an Australian internist that resorted to drinking an infectious broth of Helicobacter pyloria in order to demonstrate that stomach ulcers were caused by a bacterial infection that could be treated with anti-biotics. The prevailing medical advice of the time was that ulcers were caused by stress and could only be cured by removal of said stress, or, rather more drastically, removal of the stomach [13]. For an industry supposedly built on the premise of clinical evidence, long after Marshall had demonstrated that ulcers were caused by bacteria, the large majority of ulcer specialists were still looking in the direction of stress and gastrectomy for their patients. Humans, it seems, do not like being wrong [14].

It is often said in academic circles that redundant old knowledge only truly disappears with the death of its originator. If this is the case, it brings a whole new dimension to the S-curve pulse rate story.

In industry terms, the equivalent of this phenomenon comes from the average tenure within a job role. Over the course of the last 50 years, tenure pulse rates have risen considerably. Go back three generations from today, and most workers would spend their whole career in the same basic job. Today, many will expect to be shifting every 2-3 years. Faster still in the management domain.

This rising pulse rate is likely a good thing from the perspective of removing redundant knowledge, but it sees the emergence of another, perhaps more 
pernicious problem: the unintended removal of knowledge that continues to be relevant.

If the average tenure period of personnel is greater than the knowledge pulse rate, then there is a possibility that acquired knowledge will be preserved. If, on the other hand, average tenure is less than the knowledge pulse-rate then valuable knowledge will inevitably be lost. This is especially true of the tacit knowledge that is almost impossible to meaningfully record. Unless that tacit knowledge is transferred person-to-person while 'on the job' the likelihood is that it does not get transferred at all.

\section{Mission critical systems}

When thinking about 'mission critical' systems, the benchmark for safety and resilience is set largely by the aerospace sector. Safety is everything, the factor that unites the whole industry. When planes fall out of the sky it is not good news for anyone. Therefore, the moment an incident occurs, it is investigated rigorously and objectively and the findings spread across the industry to ensure that a repeat will never happen. This is the way to build the world's safest industry.

But then, of course, the innate human desire for 'more' and the inevitability of the S-curve dynamics sooner or later pushes systems towards dangerous cliff edges. The full story of the two Boeing 737 Max accidents are not yet known, but it is nevertheless possible to see that something significant has shifted.

The aerospace industry in general, and Boeing in particular have a long and successful track record of evolving their products in order to offer customers better performance, economy and reliability, and so, over the years, there have been several versions of the 737 .

In order to ensure safety, the industry takes very complicated systems (' 600,000 components flying in close proximity') and makes them 'simple' for operators by imposing strict constraints on what is and is not allowable for pilots to do. In terms of our Complexity Landscape Model (CLM), for the early evolution from the 100to the 200-Series 737, the aim is to constrain the operating complexity such that the aircraft sits in the simple-simple domain, with sufficient variability to operate above the Ashby Line [15] (Figure 8):

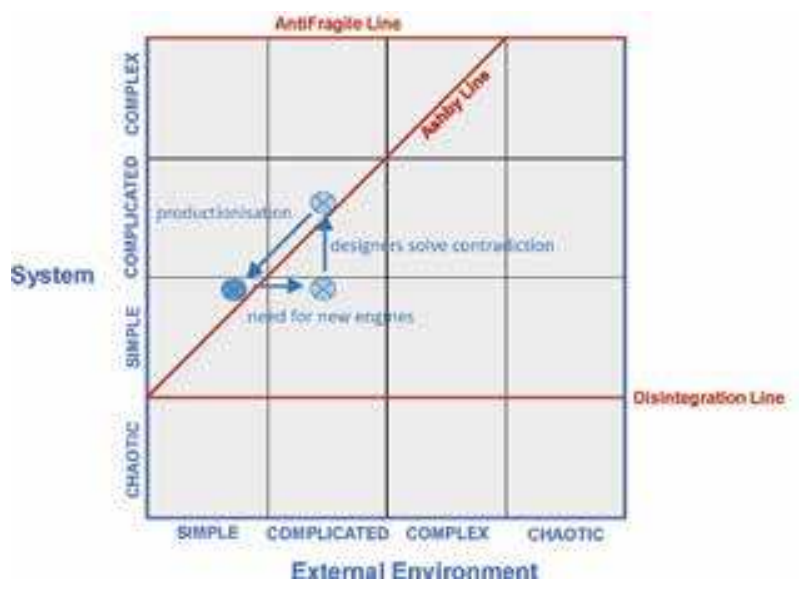

Figure 8.

Complexity landscape model_Boeing 737,100-200 series. 
One of the 100- to 200 Series evolutions arrived with the advent of much more fuel efficient high-bypass-ratio turbofan engines. This new generation of engines offered the potential to save a substantial amount of fuel, but at the expense of having a bigger overall size than the pencil-like low-bypass-ratio engines they replaced-Figure 9. These bigger diameter engines created a complicated problem for the 737 design team: how to fit them in the space under the wing without having to re-design the wing or the undercarriage. Here was a classic engineering contradiction. The answer, now widely familiar as an illustration of another of the Sovietresearch discovered contradiction-solving strategies, Asymmetry, was to design the 'squashed' engine nacelle.

As shown in Figure 9, the need for the new, higher diameter, engines created a complicated problem. When the designers successfully solved the contradiction associated with this problem they made use of complicated design tools and methods. And then, once the problem had been solved and validated through a series of qualification trials, the productionised solution would be effectively no different from the operator perspective.

The latest, Max, evolutions of the 737, in theory at least, created a similar CLM development programme trajectory. Firstly, a desire to improve performance triggering a series of complicated engineering challenges: even bigger diameter, heavier engines, stretched and strengthened fuselage and new dual-feather winglets.

Yet again, the desire for increased fuel efficiency saw the creation of bigger, heavier engines, and yet again there was a desire to not make big changes to the undercarriage or wing design. This time the solution involved moving the engines forward and upward slightly, and an increase in the height of the nose landing-gear. One of the consequences of these moves was to alter the balance of the aircraft. Another complicated problem, but one that the engineers were able to solve using changes to the control software of the aircraft.

So far so good. Simple, resilient, well understood system, has complicated changes imposed on it, which get solved, and validated ... and, hey presto, the new aircraft design returns back to 'simple' from the operator perspective.

Except. Not quite. This time around the business imperative was much greater than in the past. Airbus were winning lots of orders thanks to their new, fuel efficient A320neo, and Boeing were forced to offer airlines a more competitive 737. Costs are always important, but now they became critical to securing future business. One constraint put on the engineers was to ensure the flyability of the Max was as near as possible the same as for the 'classic' $737 \mathrm{~s}$. This would mean

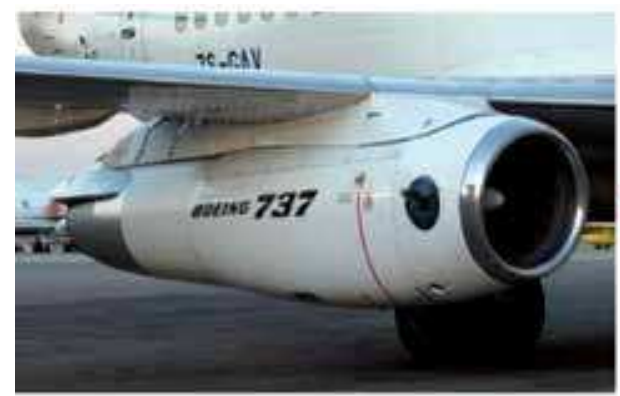

$100 / 200$ Series

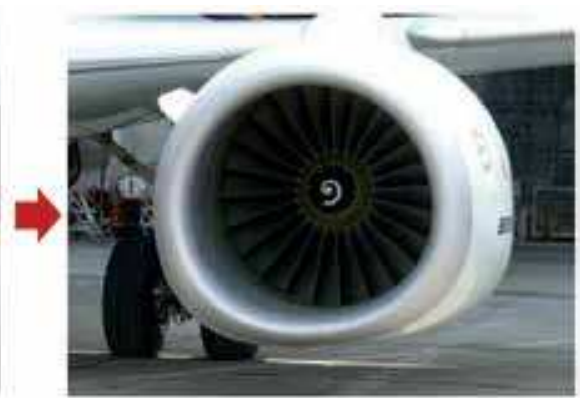

300 Series

Figure 9.

Shift from low to high bypass ratio engines on Boeing 737. 
that pilots could be re-trained very easily. Again, a complicated problem that the engineers seemed to have found a fix for. Another cost constraint then starts to appear: on-time delivery of the new aircraft. As is the way in the airline industry these days, if aircraft are delivered late, airlines benefit from substantial compensation fees.

This time pressure now hits the programme managers. And specifically the costschedule-quality iron-triangle. Which two did the Boeing senior managers want? On budget, on time, or to the right quality?

No-one can as yet know for sure how the programme managers and their managers chose to tackle this iron-triangle problem. But what we can say for sure is that the problem is no longer a purely technical one. Crucially, the moment we bring humans - most project managers count as humans-into the equation, a previously complicated problem has now become complex ...

The problem context (environment) having transitioned into the Complex domain, now demands a system capable of dealing with that complexity. The fact that two 737 Max aircraft have fallen out of the sky and killed 346 people tells us that the system did not possess that requisite level of capability. Nothing had changed about the project management iron-triangle-i.e. this knowledge was still relevant-and so almost inevitably, given the average tenure of the project management community, important (tacit) knowledge had been lost from the management system. Including, it thus far seems, the essential 'first principles' knowledge essential to the management of any complex system.

In the same way that it is very possible to push a technical system across a boundary (from Simple-to-Complicated, for example, or Complicated-to-Complex), it is also very possible that the business and social systems surrounding that technical system can also see similar boundaries being crossed. The premise for building the Complexity Landscape Model was to help organizations to know where and when such boundaries do get crossed. And the reason that premise arose in the first place was the observation that almost none of the world's enterprises or those tasked with leading them had the first clue that such boundaries existed, never mind that they might be being crossed (Figure 10).

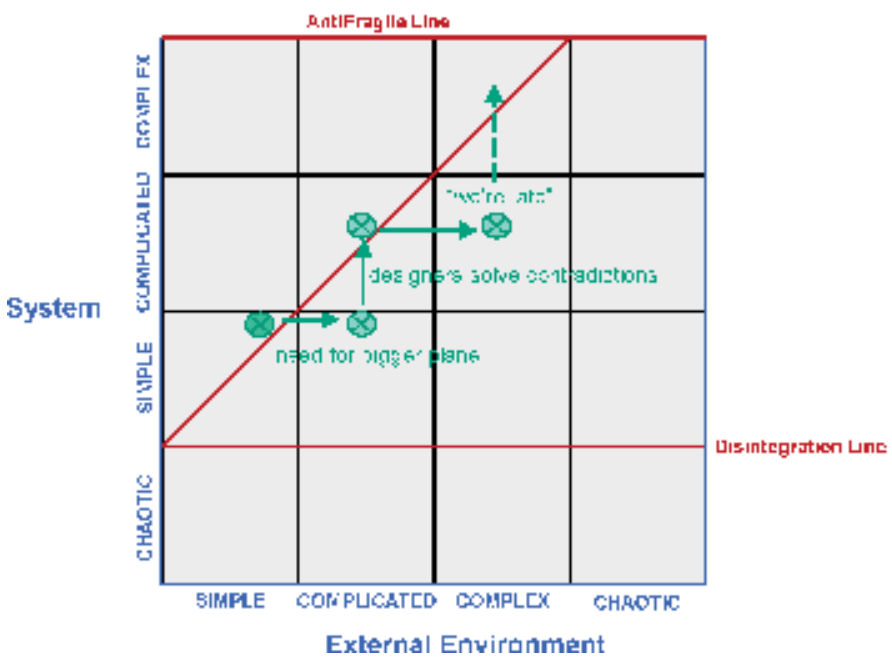

Figure 10.

Complexity landscape model_Boeing 737,300-max series. 


\section{Conclusions}

In order to establish the validity or otherwise of the prevailing knowledge existing within a given domain, it is incumbent upon those responsible for the effective functioning of systems to understand:

- What the domain S-curve pulse-rate is, and whereabouts on the S-curve cycle they are

- Where in the CLM the system is operating, and, if complexity is involved, what the 'first principles' from which the overall system behavior emerges are.

- Whether the intangible and emotion related human factors regarding knowledge are consistent with the retention of requisite levels of knowledge.

Experience working with large numbers of organizations over the course of the last 20 years has revealed that very few are able to answer these questions. For the most part this is due to widespread ignorance regarding the Soviet-sparked research to reveal the 'DNA' of innovation.

This DNA reveals:

- The future of successful system designs is highly predictable, at least in terms of where systems will evolve in the future.

- If domain (S-curve) pulse-rates can be determined, the ability to foresee knowledge redundancy cycles is increased to the point of meaningful science.

- A multitude of Trend Patterns (like the Dynamization and Resilient Design patterns used as illustrations in Section 2) assist knowledge managers to determine what the 'next' knowledge will be.

- Domains tend to 'overshoot' on the knowledge generated during the advance through the S-curve. Much of this overshoot comes as the result of working on optimization tasks. When S-curve discontinuities occur, all of that optimization knowledge becomes redundant.

- During some S-curve shifts (e.g. advances on the Dynamization Trend) significant proportions of the previously relevant knowledge become redundant.

- During other shifts (e.g. the Resilient Design Trend) some of the knowledge from the previous S-curve becomes embedded within the new.

- When the prevailing environment is or transitions to being complex (as when human beings become involved directly in a system), the only knowledge that is meaningful is that which pertains to the first principles upon which system behavior emerges.

- This 'first principle' knowledge falls into two main categories: one relating to function, and one related to strategies for resolving contradictions.

The ongoing Boeing 737 Max story demonstrates that the technical aspects of the two lost aircraft problems were complicated rather than complex, and 
that the appropriate (contradiction-solving) knowledge was in all probability brought to bear to provide appropriately resilient technical solutions. In the case of the surrounding 'business' issues, however, challenges that were inherently complex, the requisite management knowledge was either lost or missing. The required first-principle-based knowledge (e.g. the project management irontriangle) had not pulsed since the initial launch of the 737 in 1968, but between 1968 and the present day, several generations of managers had followed one another, and, in so doing, it appears likely that a critical mass of tacit project management knowledge has been lost.

The advent of the Internet is frequently described as the engine that has caused the generation of new knowledge to expand exponentially. If the data scientists are to be believed, knowledge doubles in periods now less than a year. What the Innovation DNA research has revealed, however, is that the large majority of this apparent new knowledge is merely noise (Figure 11).

First Principles knowledge is remarkably stable. The laws of physics are essentially just that: laws. As mankind's understanding of these laws evolves, the 'first principles' will evolve too, but their half-life generally speaking is measurable in decades or centuries. More subtle, but the Soviet innovation-DNA research has also revealed the relative stability of knowledge pertaining to the emergence and resolution of contradictions. Innovation-the successful transition from one S-curve to another-is in effect driven by this contradiction story. Innovation, to all intents and purposes, is contradiction solving. Knowledge pertaining to how contradictions are solved thus becomes one of the critical factors in the knowledge management story. If organizations are not managing the contradictions in their business, they are placing their future on a $98 \%$ likelihood of failure.

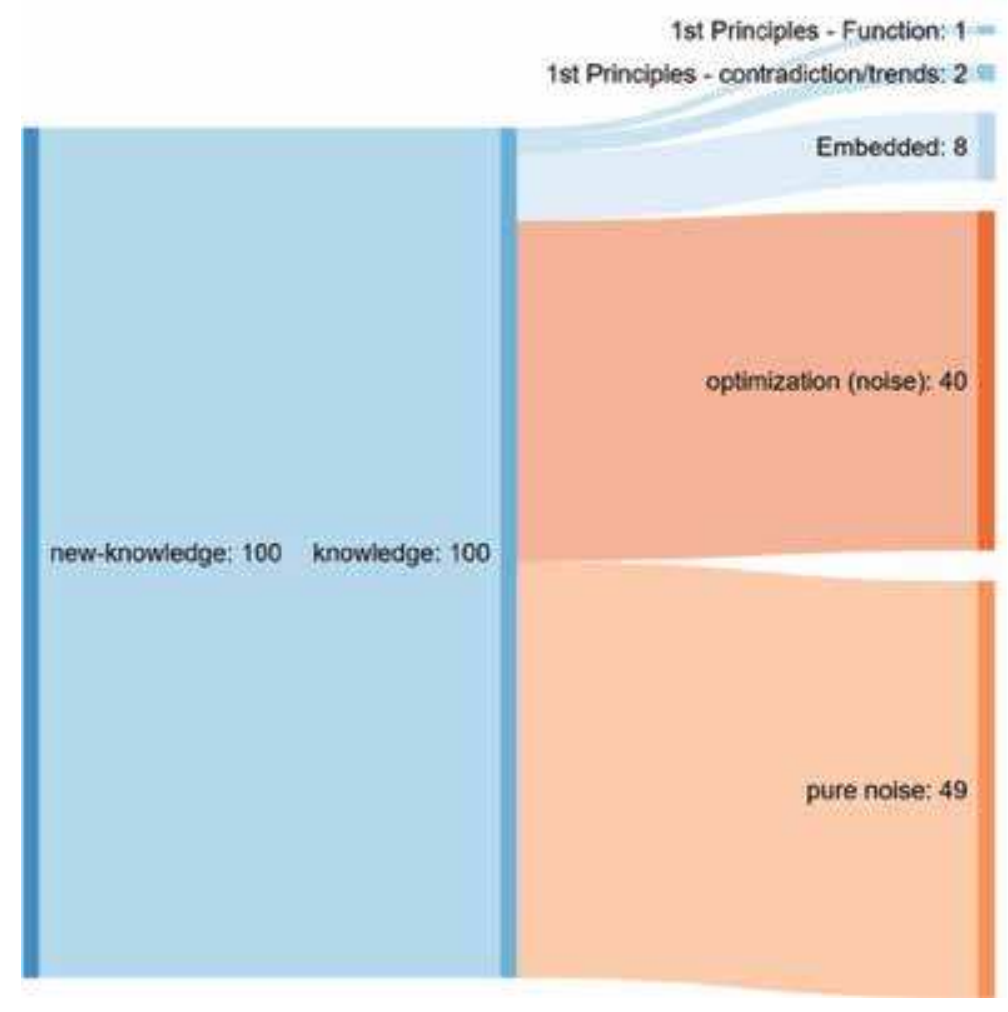

Figure 11.

Knowledge redundancy in mission critical systems. 
Knowledge Redundancy Cycles in Complex Mission-Critical Systems

DOI: http://dx.doi.org/10.5772/intechopen.90138

\section{Author details}

Darrell Mann

Systematic Innovation Network, Bideford, UK

*Address all correspondence to: darrell.mann@systematic-innovation.com

IntechOpen

(C) 2020 The Author(s). Licensee IntechOpen. Distributed under the terms of the Creative Commons Attribution - NonCommercial 4.0 License (https://creativecommons.org/ licenses/by-nc/4.0/), which permits use, distribution and reproduction for non-commercial purposes, provided the original is properly cited. (cc) BY-NC 


\section{References}

[1] Wolpert L. The Unnatural Nature of Science. London: Faber and Faber; 1992

[2] Johnson S. Where Good Ideas Come from: The Natural History of Innovation. London: Allen Lane; 2010

[3] Altshuller GS. Creativity As an Exact Science: The Theory of the Solution of Inventive Problems, Translated into English. London: Gordon and Breach; 1984

[4] Hurst DK. Crisis and Renewal: Meeting the Challenge of Organizational Change. Boston: Harvard Business School Press; 1995

[5] Snowden DJ. Boone MEA. Leader's Framework For Decision Making. Harvard Business Review; 2007

[6] Mann DL. If all you Have Is a Hammer: TRIZ and Complexity, Paper Presented at ETRIA TRIZ Future Conference. Marrakech; 2019

[7] Lee KF. AI Superpowers: China, Silicon Valley and the New World Order. Boston: Houghton Mifflin Harcourt; 2019

[8] Teel R. Army explores futuristic uniform for SOCOM, US Army Research, Development and Engineering Command Public Affairs bulletin. 28; 2013

[9] Mann DL. Hands-on Systematic Innovation. 2nd ed. UK: IFR Press; 2009

[10] Mann DL. Hands-on Systematic Innovation for Business and Management. UK: IFR Press; 2007

[11] Mann DL. Systematic (Software) Innovation. UK: IFR Press; 2008

[12] Taleb NN. Anti Fragile: Things that Gain from Disorder. London: Penguin Random House; 2012
[13] Weintraub, P. The Doctor Who Drank Infectious Broth, Gave himself an Ulcer, and Solved a Medical Mystery. Waukesha, WI: Discover Magazine; 2010

[14] Schulz K. Being Wrong: Adventures In the Margin of Error. New York: Ecco Press; 2010

[15] Ashby WR. An Introduction to Cybernetics. London: Chapman and Hall; 1957. Available at: http://pespmc1. vub.ac.be/books/IntroCyb.pdf 


\title{
Simplexity: A Hybrid Framework for Managing System Complexity
}

\author{
Michael Reiss
}

\begin{abstract}
Knowledge management, management of mission critical systems, and complexity management rely on a triangular support connection. Knowledge management provides ways of creating, corroborating, collecting, combining, storing, transferring, and sharing the know-why and know-how for reactively and proactively handling the challenges of mission critical systems. Complexity management, operating on "complexity" as an umbrella term for size, mass, diversity, ambiguity, fuzziness, randomness, risk, change, chaos, instability, and disruption, delivers support to both knowledge and systems management: on the one hand, support for dealing with the complexity of managing knowledge, i.e., furnishing criteria for a common and operationalized terminology, for dealing with mediating and moderating concepts, paradoxes, and controversial validity, and, on the other hand, support for systems managers coping with risks, lack of transparence, ambiguity, fuzziness, pooled and reciprocal interdependencies (e.g., for attaining interoperability), instability (e.g., downtime, oscillations, disruption), and even disasters and catastrophes. This support results from the evident intersection of complexity management and systems management, e.g., in the shape of complex adaptive systems, deploying slack, establishing security standards, and utilizing hybrid concepts (e.g., hybrid clouds, hybrid procedures for project management). The complexity-focused manager of mission critical systems should deploy an ambidextrous strategy of both reducing complexity, e.g., in terms of avoiding risks, and of establishing a potential to handle complexity, i.e., investing in high availability, business continuity, slack, optimal coupling, characteristics of high reliability organizations, and agile systems. This complexity-focused hybrid approach is labeled "simplexity." It constitutes a blend of complexity reduction and complexity augmentation, relying on the generic logic of hybrids: the strengths of complexity reduction are capable of compensating the weaknesses of complexity augmentation and vice versa. The deficiencies of prevalent simplexity models signal that this blended approach requires a sophisticated architecture. In order to provide a sound base for coping with the meta-complexity of both complexity and its management, this architecture comprises interconnected components, domains, and dimensions as building blocks of simplexity as well as paradigms, patterns, and parameters for managing simplexity. The need for a balanced paradigm for complexity management, capable of overcoming not only the prevalent bias of complexity reduction but also weaknesses of prevalent concepts of simplexity, serves as the starting point of the argumentation in this chapter. To provide a practical guideline to meet this demand, an innovative model of simplexity is conceived. This model creates awareness for differentiating components, dimensions, and domains of complexity management as well as for various species of interconnectedness, such as the
\end{abstract}


aligned upsizing and downsizing of capacities, the relevance of diversity management (e.g., in terms of deviations and errors), and the scope of risk management instruments. Strategies (e.g., heuristics, step-by-step procedures) and tools for managing simplexity-guided projects are outlined.

Keywords: complexity, complexity sciences, edge of chaos, emergence, heuristics, management patterns, simplexity, simplicity

\section{Introduction}

For several decades [1] complexity management represents a standard constituent of the generic management body of knowledge. This signals that complexity management is far from being a hype or a management fad [2]. Across numerous disciplines of natural, social, and systems sciences, the complexity approach serves as a holistic framework for various types of formal modeling [3-7]. It utilizes complexity as a key unit of analysis. The spectrum of approaches includes, for instance, mass production, risk management, international management, the design of hybrids (vehicles, learning methods, plants, materials, strategies, etc.), dynamic nonlinear systems, change management, descriptive statistics, conflict management, probability theory, catastrophe theory, chaos theory, dissipative structures, as well as fuzzy set theory and management.

Not all variants of "complex" or "simple" are denoted by exactly these terms. Quite often, terms like "sophisticated," "diverse," "maxi," "big," “mega” (e.g., megaproject management), "multi," "poly," "distant," “nontransparent," "full” (e.g., full service, full or fat clients), or "fuzzy" are used to delineate complexity. The "weak versus strong" wording, for instance, has an (ambiguous) connection to the complex-simple distinction: weak signals are in fact complex due to their hidden, ambiguous, conjectural, unclear, or fuzzy character. In contrast, there is no affinity between the so-called weak or strong ties and complex or simple ties. Likewise, "light" does not always mean "simple": "Light" versions in terms of minimal requirements for equity of start-ups are in fact simple. In contrast, "light" signaling a reduced amount of detrimental ingredients (tar in cigarettes, sugar in sodas, etc.) does not imply simplicity.

The management of complexity follows two antithetic paradigms: on the one hand, simplification, i.e., the reduction of complexity, and, on the other hand, complexification, i.e., the augmentation of complexity. Among scientists and practitioners, there is a manifest bias for the simplification paradigm, in terms of "taming," "cutting through," "killing," "overcoming," or "fighting" complexity. The mantra of complexity reduction $[8,9]$ is reflected in philosophical and methodological concepts like Occam's razor, ceteris paribus assumptions, austerity, dogmatism, order, parsimony or amnesty, and "one in, one (or two or three) out" rules for fighting red tape (bureaucracy), in management concepts such as concentration on core competencies, freezing specifications of products, averaging, summarizing, standardizing, off-the-peg products, eliminating items, filtering noise, streamlining, 0CX (zero complexity), closed innovation, closed shops, simple rules, less-is-more effect, preprocessing rules, reduction rules (e.g., "kernelization"), damping of oscillatory systems, churn management, funnels, stabilizing, homeostasis, equilibria, linearization, lean management, 80:20 rule, focusing, establishing regularities (e.g., on the timeline: rhythmic intervention and equidistant check-ups [10]), normal distribution, abstraction, practices following "simplify your life" guidelines or "Keep It Short and Simple" (KISS) slogans, as well as everyday phenomena such as 
using abbreviations, concise and brief descriptions "in a nutshell," or halo, primacy, and recency effects.

Nevertheless, a comparatively long list of complexity-friendly approaches such as mixes, product variants, customer segmentation, portfolios, open innovation [11], management by exception, double-loop learning, deutero learning, borderless organization, wisdom of crowds and swarm intelligence ("the many"), black swans [12], chance [13], multiplex relationships, informal relationships, creative destruction, 360-degree feedbacks, models of embeddedness, paradoxes (inventor's paradox, Icarus' paradox, anti-patterns, Red Queen effect, etc.), incomplete contracts, hybrid concepts like mass customization [14], coopetition [15], co-production, organized anarchy or hybrid clouds, production detours, triangulation as a measurement principle, intermittent reinforcement schedules, power law tails (e.g., the "long tail"), divide et impera strategies, blended learning, leagility, it takes three to tango-constellations [16], extended (mixed and augmented) reality, arborescent structures (binary, bifurcate, treelike, etc.), prosumers, frenemies, customized, personalized, turnkey or bespoke problem solutions, "thinking outside the box" slogans, and "breaking down silos" mentality, documents a plea for "embracing" complexity. In the same vein, complexity serves as the core of business models, e.g., in the shape of full service, diversification, mass personalization, derivatives, blue ocean strategies, or hyper-competition [17].

Both paradigms have evident drawbacks, partly owing to the superficiality of the implicitly underlying distinction between "bad" complexity and "good" complexity. Against the background of their respective strengths-weaknesses profiles, a mix or hybrid blend of the two approaches serves as a promising heuristic: Following the generic best-of-both-worlds logic of hybrids, the strengths of one second-best approach are capable of compensating the weaknesses of the opposite second-best approach to some extent-without just neutralizing "minus-operations" by "plusoperations." An optimistic blending scenario even allows for the accumulation of strengths. The term "simplexity" has been proposed to capture the essence of this simple-complex-hybrid [18-22]. Within the scope of patterns for handling complexity in conflicts, simplexity represents the opposite of tit-for-tat patterns which rely on "more-more" or "less-less" procedures.

Existing simplexity models [23-26] advocate, for example, simple infrastructures, rules, and heuristics [27-30] for optimizing complex systems. In addition to the explicit simplexity approaches, some models like divergent-convergent problem solving or sedimented change [31] implicitly deploy simplexity, e.g., in terms of less volatility obtained via more ambiguity. Along the lines of simplexity, the punctuated equilibrium concept [32, 33] mixes phases of continuous change (or even stasis) and discontinuous change in the evolution of social systems. In models of path dependence, episodes of minimal variance (diversity) follow episodes of high variance [34].

The underlying blending approach is not just delineating the coexistence of simplicity and complexity. Moreover, simplexity stands for connections between the two paradigms, both cause-effect relationships (e.g., simplicity causing complexity), and means-end relationships like simplicity mastering complexity. In mathematical or sciences models (chaos theory, catastrophe theory, bifurcation theory, etc. $[35,36])$, research on "order out of chaos" and "chaos out of order" [37] characterizes specific linkages between complexity and simplicity.

At first glance, some hybrid concepts like glocalization (characterized by the slogan "Think global, act local") also belong to the cluster of complex-simple models. However, glocalization factually represents a predominantly complex approach since the underlying formula correctly reads "Think global, act multi-local." 


\section{Simplexity: state-of-the-art review}

Unfortunately, prevalent models of simplexity not only suffer from common infancy problems typical of all innovative and particularly of paradoxical approaches. Their utility is deeply impaired by fundamental misconceptions. Existing models of simplexity mainly recommend the solution of "complex" problems by simple means. Yet, the underlying creed "simple rules for complex organizations" goes along with several inconsistencies.

A coherent notion of complexity or simplicity is missing. Whereas simplicity is specified in terms of numbers of rules, hierarchical levels and specialists, semistructures, clarity, unambiguity, and persistence, the complexity of decisions or organizations is only vaguely specified (big business? high-tech business? diversified portfolios? global players?), quite often not relying on the same unit of analysis as simplicity.

A distinction between formal and content-specific ways of modeling problems and solutions is not stringently deployed. For the modeling of companies and their environment, primarily system theory has made us familiar with the distinction between formal modeling (elements, relations) on the one hand and contentspecific modeling (brands, employees, computers, compensation, corporate culture, etc.) on the other hand. However, existing simplexity approaches do not differentiate between "complex tasks" (formal modeling) and "difficult tasks" [38] (content-specific modeling) nor between "simple" and "easy". "Difficulty" denotes the overall challenge of solving problems, e.g., bootstrapping is difficult due to a restricted availability of money, skills, and knowledge. For levels of extreme difficulty, terms like intractability, dilemmas, wicked problems $[39,40]$, super wicked problems [41], mission impossible, or death spirals have been proposed.

In contrast, "complexity" only captures the formal aspects of a challenge, such as ill-structured problems, multitude, instability, unpredictability, ambiguity, and uncertainty. Difficulty, e.g., as a feature of matrix structures, normally implies complexity. However, formal modeling has to make complexity explicit, in matrix organizations, for instance, in terms of the number of matrix managers required, two-line system, or conflicts. This also applies to priority sequencing rules (e.g., random selection or longest processing time). Likewise, the concept of antifragility [42], also a mix of difficulty and complexity, is based on specific stressors, mistakes, or shocks that cause better performance. Within a formal complexity-focused modeling, this concept is labeled "complex" since the achieved improvement is counter-inductive or paradox. In the same vein, "feasible," "viable," "intangible," "cheap," "disproportionate," and other notions cognate to simple (or complex) require some refinement as for their implicit complexity. Thus, the performance of a plan B depends on its content. Through the lens of complexity management, it depends on alternatively relying on two different plans A and B. In analogy, organizational "tents and palaces" differ with respect to their missions, from a complexity angle with regard to their respective stability.

The complexity-focused versus difficulty-focused modeling also applies for mindfulness, a concept that foremost serves as a potential to handle difficulty [43]. Coping mindfully is accomplished by focusing on the essentials such as the bottomline problem(s). However, complexity approaches per se do not provide guidelines for prioritizing or ranking according to relevance.

Along these lines, the specific threats spotted in a SWOT analysis of strengths, weaknesses, opportunities, and threats (e.g., new entrants, substitutes, bargaining power of customers, bargaining power of suppliers, competitive rivalry) are difficult whenever appropriate strengths to cope with these threats do not exist. 
In this case, a complexity-based modeling informs about the number of threats, level of imbalance of power, surprise, misleading signaling of competitors, and further complexity aspects.

Likewise, single-loop, double-loop and triple-loop learning differ with respect to the learning content (actions, rules, learning method). The wording signals that they also differ from a complexity point of view with respect to the diversity of learning modes.

Conversely, focusing on the one, i.e., most restricting bottleneck, may be considered as simple. Yet, spotting this critical bottleneck in a sea of bottlenecks, covering, for instance, possible political, economic, social, technological, environmental, and legal constraints diagnosed via a PESTEL analysis, is truly difficult. In the same vein, decomposing a problem into subproblems makes problem solving easier but simultaneously also more complex given the additional task of integrating the partial solutions.

Finally, as a nonacademic exemplification, "living in summertime" is easy ("fish jumping," "cotton high"). Whether it is simple (transparent, unambiguous, predictable, non-chaotic, etc.) has to be clarified via some formal modeling. In analogy, the frequently addressed "writing of a short letter" is primarily difficult because elaborating and focusing the content takes time. In addition, it is "complex" since a complex input (lot of time spent on writing) goes along with an ostensibly simple output (short letter).

The lesson learned from these examples reads: The lack of differentiation between complexity-focused modeling and content-specific modeling, typical of prevalent simplexity models, most likely turns any model into some complexity reasoning and concurrently "complexity" into a platitude.

In existing models of simplexity, there is no stringent differentiation between complexity load and complexity potential, i.e., resources deployable to cope with the respective complexity load. Actually, organizations may be (as well) considered as complex owing to the scope of their resources, their versatility, technical capacities, and dynamic capabilities (ambidexterity, change readiness, etc.). Including potential into the notion of complexity explains, for instance, that in times of Big Data capabilities [44], the complexity-triggered risks of information overload or paralysis by analysis may have to be reconsidered. The extension of complexitybased modeling also makes clear that so-called small worlds are not genuine "simple" worlds: even though one node "simply" needs a handful of immediate egocentered connections, its worldwide connectedness requires a complex relationship potential provided by the totality of all nodes.

The ample evidence of high performance (when working with simple rules, semi-structures, or fast and frugal heuristics) provided in prevalent models signals optimism bias and meliorism. Failure due to following simple rules is hardly ever addressed. Consequently, groupthink (e.g., self-censorship) which is simple but not high performing is disregarded. This also holds for activities following, for instance, the arm's-length principle or the forward-backward scheduling in project management which are complex but performing.

The trade-off between effectiveness and efficiency is underestimated when arguing that simple rules "work." Complex "detours" in management like the "divide and rule strategy," step-by-step implementation, decomposition of tasks, decomposition of time series, or the involvement of third parties (impartial conflict managers, bartering, clearing houses, election monitors, etc.) are effective although not necessarily efficient.

Effectiveness is frequently cut down to adaptability, flexibility, fluidity, adjustment, or agility. This bias results in neglecting "compatibility," "interoperability," 
"standardization" (e.g., the company language, non-discrimination policies), as well as "economies of scale and scope" as relevant performance criteria.

The focus on structure in prevalent simplexity models goes along with a rudimentary notion of infrastructure. In addition to structure and routines (i.e., the traditional core of governance), infrastructure comprises human capabilities (e.g., empowered "complex practitioners," "comps"), self-organization, information technology, and trust. Furthermore, structure or infrastructure do not necessarily constitute disabling and restricting constraints, e.g., of repertoire and options, but may serve as enablers (e.g., of more latitude, degrees of freedom).

Hybrid entities (apart from complex-simple hybrids such as organic-mechanistic mixes), like public private partnerships, mixed top-down and bottom-up coordination, prosuming, coopetition (e.g., generic and brand-name drugs in the same corporate portfolio), chaordic systems, leagility, or the mixed push-pull control of supply chains, represent—despite their effectiveness—alien elements in the majority of prevalent simplexity models, most likely due to their complex genes.

Finally, the focus on opportunities leads to neglecting risks and the infrastructure for risk management. However, the inherent plea for self-organization requires underpinning infrastructures to cope with some downsides of self-organization such as non-compliance, discrimination, shadow economy, plagiarism, corruption, managerial entrenchment, moral hazard, bootlegging, and reactance.

\section{Architecture of simplexity}

\subsection{Meta-complexity}

In addition to the inherent inconsistencies delineated above, prevalent models of simplexity underestimate or even ignore the meta-complexity of their core basic concepts: management and complexity. As a consequence, the handling of complexity degenerates into a truism, a pseudo-guideline, or a misleading compass. The following sections contour the implicit meta-complexity of the architecture.

In addition to the complexity of complexity management, a closer look at the complexity concept reveals several architectural features of meta-complexity. Actually, there is no such thing as "the" monolithic complexity. The following sections deal with the variety of building blocks (components, domains, and dimensions) and their connectedness. Strictly speaking, any reference to "complexity" should be specified by three coordinates, i.e., component, domain, and dimension.

\subsection{Complexity of managing complexity}

Simplexity approaches have to accommodate themselves to the generic complexity of managing complexity. Across the board, the three generic building blocks of management processes, i.e., objectives, context, and instruments, are marked by complexity in terms of multitude, diversity, ambiguity, and instability. The scope of performance measures, i.e., effectiveness and efficiency, is not just a matter of multitude, i.e., a complex multi-criterion system, but also of trade-offs between criteria. Furthermore, objectives are subject to changes: Levels of aspiration vary in accordance with success or failure (e.g., from maximizing to satisficing). Moreover, factors like the installed base effect or the volatile weighing of performance criteria cause instability of pursued performance levels.

The complexity of the context, particularly the environment of an organizational entity, is a constituting feature of prevalent management models. Standard models of environmental analysis screen various domains of the context. As a rule, 
the screening discovers divergent trends in different domains, e.g., imbalances of power on procurement markets may differ from those on sales markets. Portfolio analysis, for instance, is marked by ambiguity with respect to the supposed differential controllability of the two portfolio dimensions, e.g., market growth versus market share. Instability in the shape of turbulent environments is commonly considered the touchstone of professional management.

Last but not least, meta-complexity also characterizes the instruments of complexity management, as a rule hallmarked by multitude, diversification, and hybrid mixes. A core challenge for managing complexity is ambiguity due to an overlap of emergent and engineered variants of complexity. For the understanding and the handling of this overlay, generic hybrid or mixed management concepts like rational heuristics [45], bounded rationality, ecological rationality, logical incrementalism, guided evolution, bricolage, patching, or controlled chaos have been conceived. They combine the "reconstruction" of emergent complexity phenomena (evolution, behavior) and the purposeful "construction" of "optimal" complexityfocused concepts (development, action).

Reconstruction relies on understanding emergent complexity-related patterns such as coevolution, ecological rationality, path dependence, the transitivity principle ("enemies of my friends are my enemies"), regression toward the mean, central tendency bias (in survey-based data collection), viral dissemination, rules of thumb, frozen accidents, percolation, ripple effects, heuristics out of the "adaptive toolbox" of individuals (e.g., recognition heuristic, representativeness heuristic, naïve allocation), chunking, framing, stereotypes, antifragility, Brooks' law, the simplicity paradox, and other unintended consequences or paradoxes as well as trends and hypes. In fact, models of emergent simplexity quite often deal with irrationality, dysfunctionalities, misfits, and paradoxes, e.g., handling of cognitive dissonance, amnesia, neurotic defense mechanisms, bipolar disorders, or adverse selection. The Darwinian model of evolution composed of complexity augmenting "variation and reproduction" and complexity reducing "selection and retention" represents a seminal emergent simplexity pattern.

The construction of (optimal) complexity is based on means-end models of standardization, commoditization, industrialization of services business models, carryover parts, elimination (e.g., of negative aspects), smoothing, averaging, linearization, accelerating or decelerating of change [46], hiding, or camouflage. Thus, some complexity-driven cyberattacks like email bombing aim at overwhelming the capacity of servers. In pricing, more transparency (i.e., less complexity) can be obtained by partitioned pricing and less transparency (i.e., more complexity) by drip pricing.

To sum up, the resulting hybrid management models of simplexity management consist of a fusion of emergent building blocks (i.e., context and unintended effects or side effects such as collateral damage and externalities) and engineered building blocks (i.e., means and ends): The winner-take-all phenomenon-creating, for instance, the so-called GAFA world, i.e., dominated by players like Google, Apple, Facebook, and Amazon-perfectly illustrates the hybridity of simplexity management; it combines emergent complex processes (e.g., by facilitating network effects) on the (multi-sided) demand sector (i.e., more customers) with simplifying the supply sector (i.e., fewer vendors, quasi-monopoly). Likewise, congestion models (such as traffic or network congestions) combine emergent building blocks (e.g., queueing delays) and engineered ones, e.g., congestion avoidance.

\subsection{Multicomponent architecture}

Unlike prevalent approaches which consider complexity solely as a load, stress, hardship, or evil, an unbiased approach differentiates between two components of 
complexity [47]: A straining complexity load and a valuable complexity potential that can be used for handling this load. The spectrum of complexity potential comprises both hard factors (e.g., Big Data analytics, warehouse management software for chaotic storage, data highways, memory capacity, network capacity with a different reach of wide area networks and local area networks, facilities, transmission capacity, Internet infrastructure, built-in flexibility, delay-tolerant networking, upward compatibility, slack, float, buffers, space, safety stocks, commons, complex adaptive systems, traffic system capacity, capital, project budget, patents, claims, etc.) and soft factors such as complexity competencies [48]; open culture (shared values and beliefs); self-organization; intelligence; entrepreneurship; conflict tolerance; forbearance; patience; role flexibility; versatility; ambiguity tolerance; single-loop, double-loop, and triple-loop learning; mindfulness; trust; "loopholing" (finding and exploiting loopholes); meta-competences; and dynamic capabilities [49].

One has to keep in mind that a complexity potential captures merely formal features of the resources in question (e.g., available worktime, high availability of servers), not all aspects of the asset, e.g., not skill or will factors of individuals.

All interactive systems, i.e., communication, exchange, supply chains, value nets, competition, conflict, or teams, entail domains for each player involved, e.g., each stakeholder of a company. From a complexity point of view, every domain comprises two components attributed to the respective actor. As a consequence, concepts that look similar through the complexity lens, e.g., "second sourcing" and "dual sourcing", have to be distinguished as "customer-driven risk management" versus "manufacturer-driven risk management," respectively.

Without an attribution to actors, the differentiation between load and potential is factually impossible since the complexity potential of one party may constitute a complexity load for the other party: Hence, a plan B represents a potential for the respective planning player but a load other players have to cope with. Likewise, in distributive conflict constellations, claims and negotiating faculties of one party constitute a load for the opposite party. In the same way, customer lock-in represents a potential for the vendors but a latitude-narrowing load for the customers.

In integrative conflict management, neutral third parties are characterized by a specific profile of components: On the one hand, their complexity load consists of the diverging interests of the conflicting parties. The complexity potential on the other hand contains skills for detecting and emphasizing communalities, e.g., shared superordinate goals.

The component architecture requires the clarification of some fuzzy basic concepts: in the case of "diversity," this clarification identifies this notion either as a complexity load (e.g., different standards, lack of communalities, tension, Babylonian confusion) or a complexity potential (e.g., scope, interdisciplinarity, source of creativity) depending on the respective context.

The two-component model goes along with several patterns of simplexity (Section 4.3). Many of them rely on a blend of reducing load (simplification) and augmenting potential (complexification). Thus, in simplexity-oriented conflict management, models combine de-escalation strategies, i.e., the investment in reducing discrepancies between involved parties or decoupling parties on the one hand with establishing conflict tolerance as well as promoting integrative strategies of negotiating (for win-win situations) on the other hand. In the same vein, post-merger integration combines dismantling of discrepancies and establishing of more commonalities.

\subsection{Multidimension architecture}

An in-depth analysis reveals that complexity itself constitutes a multi-facet construct covering several dimensions [50]. One-dimensional concepts which 
alternatively focus on either size (e.g., number of stakeholders or iterations, mass production) or uncertainty (e.g., randomness, discontinuity) are incapable of capturing all relevant aspects. Even two-dimensional models like the Duncan matrix (complexity and dynamics) [51], Stacey matrix [52], and the Cynefin model or three-dimensional approaches like the diversity-ambiguity-turbulence model do not embrace all facets of complexity. More useful are four-dimensional models like the so-called VUCA-world model (volatility, uncertainty, complexity, ambiguity), IBM's four Vs of Big Data (volume, variety, velocity, and veracity), or the four-dimensional model of multitude, diversity, ambiguity, and dynamics [47]. Examples of high complexity illustrate both complexity load (lists on the left sides) and complexity potential (lists on the right side) in Figure 1.

Quite often, each of the four categories covers several complexity aspects as sub-dimensions. So, in time series analysis (e.g., of climate data), it is assumed that dynamics consist of one or several systematic patterns (global warming trend, seasonal fluctuations, long term cycles, etc.) and of random noise (e.g., extreme and erratic weather). As outlined in Figure 1, the whole spectrum of exemplifications of complexity can be construed and explained by a combination of four dimensions of complexity. This umbrella concept unifies the prevalently separated modeling in terms of complicatedness, multitude, dynamics, uncertainty, and complexity. Consequently, when applying the four-dimensional terminology, the terms "complex adaptive system" or "complex dynamical systems" [53, 54] have to be paraphrased by referring to two dimensions of complexity, e.g., by "diverse and adaptive/dynamic systems."

For a better comprehension of the meta-complexity challenge, the four dimensions are consolidated in Figure 1 to two "archetypes": The two dimensions of the "both-and" or "conjunctive" or "additive" complexity can be consolidated to

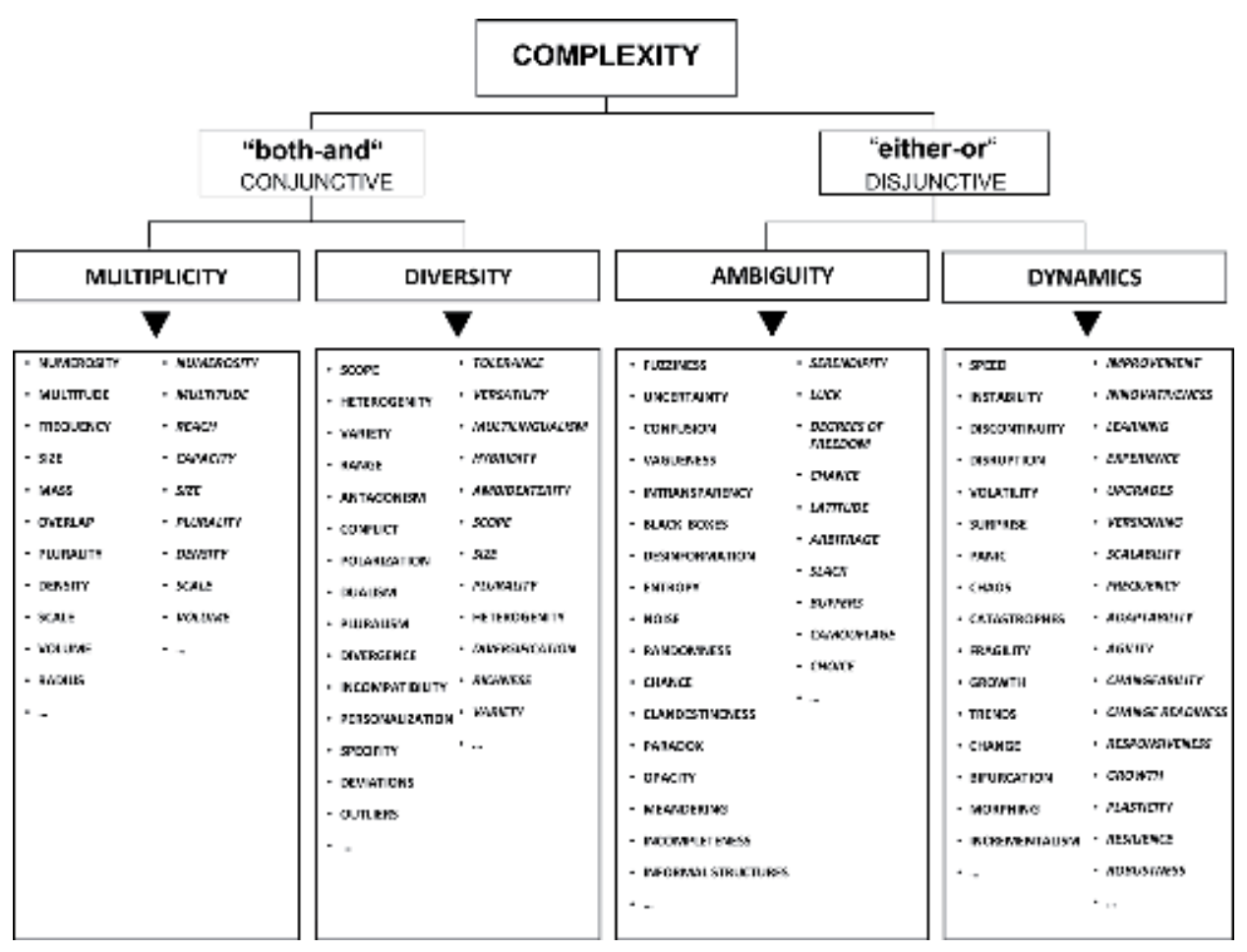

Figure 1.

Dimensions of complexity. 
diversity, since diversity implies at least two items (i.e., numerosity), likewise the two dimensions of the "either-or" or "disjunctive" or "alternative" complexity to dynamics, since dynamics_like ambiguity_also diminishes the identity of an entity over time. In analogy, complexity potentials to handle big numbers or heterogeneity can be packed to an integration potential, correspondingly the capabilities to handle fuzziness and volatility to a flexibility potential [55-59].

This compact two-dimensional approach allows a specific differentiation between "simple" and "complex" complexity: An extremely complex complexity load results from an accumulation of diversity and dynamics. The simultaneous coexistence of additive complexity (short: diversity) and alternative complexity (short: dynamics) characterizes hyper-complexity $[55,60]$. This challenge transcends the mere propagation of complexity across the four dimensions, e.g., the propagation of volume into variety, diversity into ambiguity, or ambiguity into volatility.

Consequently, one should consider that the umbrella term "complexity" houses two significantly different species of complexity: So, one variant of complex organizational structures is characterized by many and fine-grained regulations, typical of hierarchies. Another variant relies on few and ambiguous regulations (e.g., opening clauses, incomplete contracts, delegation). However, against the background of manifold interconnections between the dimensions (Section 3.6), complexity does not consist of two strictly separated islands. In fact, the connections, e.g., in the shape of complexity propagation across dimensions, serve as bridges between these islands. For example, due to inter-dimensional connections, hybrids are usually characterized by two rather different categories of complexity features: diversity ("fusion of two worlds") and ambiguity ("lack of identity").

In contrast to this complementary accumulation on the load component of complexity, there is a considerable risk of a conflict between the concurrent availability of an integration potential (for handling diversity) and a flexibility potential (for handling turbulence). Awareness for this imminent conflict comes, for instance, from the so-called organizational dilemma according to which diverse team configurations facilitate flexibility (e.g., creative problem solving) but inhibit integration in terms of reaching consensus. In the same vein, unrelated diversification (i.e., a high level of diversity in the shape of conglomerate diversification) supports flexibility (e.g., risk management) but does not generate synergy (i.e., integration). In contrast, related diversification serves as a source of synergy, though not being capable to support risk management.

Nevertheless the resolution of this conflict seems feasible, for instance, by deploying simplexity concepts. Thus, some sophisticated pricing systems like twopart tariffs [61] manage to mix integration (by means of a fixed price component reflecting ordinary average costs or consumption) and flexibility by a variable price component for deviations. Likewise, mass customization delivers both integration (cost-efficient manufacturing of standard modules) and flexibility (customized configuration of modules).

\subsection{Multi-domain architecture}

Meta-complexity requires a holistic approach covering several domains of complex phenomena. Domains are defined in the shape of specific actors (stakeholders in value adding networks, individual and collective actors such as teams or coalitions, etc.), populations (swarms, crowds, customer segments, etc.), temporal units (periods, episodes), spatial units (terrains, countries, geographical regions, etc.), levels in hierarchical systems such as product-trees and organizations, knowledge domains (e.g., know-that, know-why, know-how), organizational units 
(companies, departments, divisions, projects, committees, etc.), and domains of diversity such as gender, age, language, and ethnicities as well as performance domains (e.g., the perspectives in a balanced scorecard). Unfortunately, standards for domain demarcation, either horizontal or vertical, are missing. This gap is responsible for another facet of meta-complexity. Anyhow, the common reference to "the" (turbulent) environment as "one" domain lacks differentiation since different domains of environment show different complexity aspects, e.g., the upstream domain versus the downstream domain of a supply chain.

In general, inter-domain simplexity is the result of the increasing complexity load in one domain in conjunction with a compensatory decrease in a separate domain in order to avoid an increase of the overall complexity load. Thus, standardization in procurement and production (simplicity) is frequently fused with personalization (complexity) in marketing.

\subsection{Interconnectedness}

Meta-complexity is not just a matter of multicomponent, multidimension, or multi-domain constellations. In addition to this coexistence of the building blocks, the architecture also encompasses various connections between them [62]: Just like light creates shadow, mass and diversity (frequently labeled "complicatedness") constitute a driver of the significantly different features of complexity, i.e., ambiguity and dynamics, traditionally viewed as complexity in the narrower sense. Prevalent approaches like matrix-based concepts of complexity ignore these varieties of derivative complexity by assuming an orthogonal configuration of the respective dimensions (e.g., diversity and turbulence).

Connections between the building blocks of complexity are logical or empirical as well as emergent or engineered. Logical connections between dimensions arise from the fact that alternative complexity logically implies additive complexity: So, ambiguity as well as change is based on a heterogeneous set of items. Likewise, flexibility requires multiplicity and diversity, e.g., in the case of dual sourcing, hedging, or plan B. Finally, all complexity dimensions imply multiplicity.

The landscape of interconnections encompasses connections within one component, one dimension, or one domain and between two or more components, dimensions, or domains. In addition to two-stage connections, there are typical multistage inter-dimension as well as inter-domain connections. Multidimension connections result from a multistage proliferation, e.g., reduced group size logically going along with less diversity, more identity, and less fluctuation. Multistage inter-domain connections are characteristic of conflict management, e.g., in the shape escalating or de-escalating, of several sequential tit-for-tat interactions or of the triggering of follow-up conflicts possibly involving additional parties. Bidirectional connections (e.g., feedback loops) may yield spiraling effects such as death spirals or the spiral of trust evolution.

Intra-component connections (across domains) deal with interconnected complexity loads (e.g., jobs and follow-up jobs) or complexity potentials (e.g., automation, outsourcing). Exemplifications of intra-dimension connections are (1) dynamics relying on multiple patterns of change, in the case of climate change, for instance, trends, i.e., global warming, and random erratic weather, (2) the linkage between the numerosity of nodes and of edges, and (3) multiple diversity, e.g., the endeavor to reach a simultaneous balance with respect to gender, age, ethnicities, and nationality in committees. Conflicts and follow-up conflicts as well as cost overruns and delays in managing projects illustrate the essence of intra-domain connectedness.

Some inter-component connections warrant a congruence of complexity load and potential. Thus, Say's law of markets assumes that supply volume creates its 
demand volume, whereas Keynes' law states that demand creates its own supply. In contrast, the so-called pig cycle model is characterized by the imbalance of demand volume (load) and supply volume (potential) caused by lags in the adjustment process. Remanence constitutes another example of an unbalanced constellation caused by latency: Even though jobs or projects (load) have been finished, extant human resources, facilities, and machinery (potential) cause (remanent) costs. Learning or experience curves deal with another load-potential connection, i.e., the improvement of skills and knowledge (potential) as a result of learning by doing or repetitive execution of jobs (load).

Fragility constitutes an emergent simplexity pattern between load and potential: An increasing complexity load, e.g., in the shape of ruinous competition, stress, or avoidance-avoidance conflicts, impairs coping capabilities due to the degeneration of muscle, disabling of capabilities, or panicking.

Inter-dimension connections occur predominantly as simplification or complexification patterns. Thus, the number of members in social networks triggers diversity, possibly yielding both positive and negative network effects. Likewise, ambiguity may cause volatility or oscillations.

As is generally known, systems management emphasizes the inter-domain connections between two formal domains: the number and scope of elements (e.g., companies in a supply chain or supply network) and the multiplicity or diversity of relations (e.g., flows of information, of merchandise, and of money). Against this background, the focused dealing with the complexity of a single enterprise, market, business unit, department, period or episode, etc., detached from other systems or subsystems, is necessarily bound to underestimate the actual scope of the respective complexity challenge or potential since it neglects the inter-domain connections.

Moral hazard in complexity parlance assumes a complex nontransparent situation regarding the attribution of outcomes to activities of an individual as member of a collective (team, community, insurance entity). The lack of transparence motivates and enables an individual member to exploit the complexity of a system to increase his individual utility at the cost of the other members which creates inequality (diversity) among the members.

The following examples illustrate the simplexity-based variants of connections between domains:

- The law of large numbers implies simplexity: numerosity (e.g., many trials) creates less uncertainty, i.e., better estimations.

- In adverse selection, a nontransparent situation, i.e., a factually skewed diversity of clientele against the background of an assumed balanced diversity, paradoxically creates the homogeneity of the clientele: the selection process reduces the diversity of factual customers, unfortunately adversely to the intentions of the provider of the service in question.

- Information flow analysis with a complexity focus captures diversity like media breaks (e.g., digital to print media) and dynamics in the shape of error propagation across domains, both across departments and along supply chains (e.g., bullwhip effect). In the same manner, complexity-focused material flow analysis deals with delays, inventories, just-in-time sourcing (complexity load), and diversity of multimodal and intermodal transportation systems (e.g., last mile delivery, railroad combined transport) as complexity potential.

- Inter-level connections within multilevel systems (e.g., organizational hierarchies, product trees, global, regional, and national standards systems) concern 
top-down dissemination (e.g., control and command, compliance) and bottom-up dissemination (suggestions, good practices, benchmarks, etc.).

- In business relationship management (e.g., supplier relationship management), a balance is required between the domains of interdependency (e.g., reciprocal exchange, sharing, distribution of property rights) and integration (e.g., standards, solidarity, trust).

- Border management, i.e., relocating borders between two (or more) domains as well as merging or splitting existing domains, aims to achieve more interdependency and integration inside certain domains than between different domains. Border management is accomplished, for instance, via mergers and acquisitions, joint venturing, spin-offs, carve-outs, sourcing (insourcingoutsourcing), customer segmentation, decoupling the push-domain and the pull-domain of a supply chain, regulating access to information, and radically switching from closed to open innovation. In multilevel entities, e.g., corporations comprising the domain of a holding company and the domain of subsidiaries, the relocation of borders frequently results in centralization or decentralization.

- From a simplexity angle, insourcing, at first glance a pattern of simplification by means of reducing dependence on suppliers, constitutes in fact a simplexity pattern: the reduction of interdependence with external suppliers goes hand in hand with a higher demand for proprietary resources and internal coordination.

\section{Multilevel architecture of simplexity management}

\subsection{Spectrum}

The building blocks of simplexity-focused management originate from a management architecture composed of an abstract-generic paradigm level, a pattern level, and a concrete-palpable parameter level. Paradigms of simplification, complexification, or simplexity have an ample extent combined with a poor specification, whereas parameters (e.g., processes and tools of diagnosing, planning, implementing, measurement) have a narrow extension coupled with high specification. In between, patterns (e.g., punctuated equilibrium, sedimented change, transitivity principle, priority rules for modifying complexity load or potential, attractors) are marked by a medium range of application as well as a mean precision. Paradigms and patterns serve as frameworks for the application of parameters.

\subsection{Paradigm of simplexity management}

The two-component model serves as a guideline for a balanced handling of complexity: Neither merely reducing nor solely augmenting complexity but aligning complexity load and complexity potential represents the suitable heuristics for handling complexity.

According to the generic fit-performance model, the fit, match, balance, congruity, or congruence of complexity load and complexity potential helps approximating the optimal system performance. This also includes temporal congruence, i.e., the synchronization of load and potential. The congruence approach comprises both the notions of requisite complexity (e.g., Ashby's law) and requisite simplicity. 


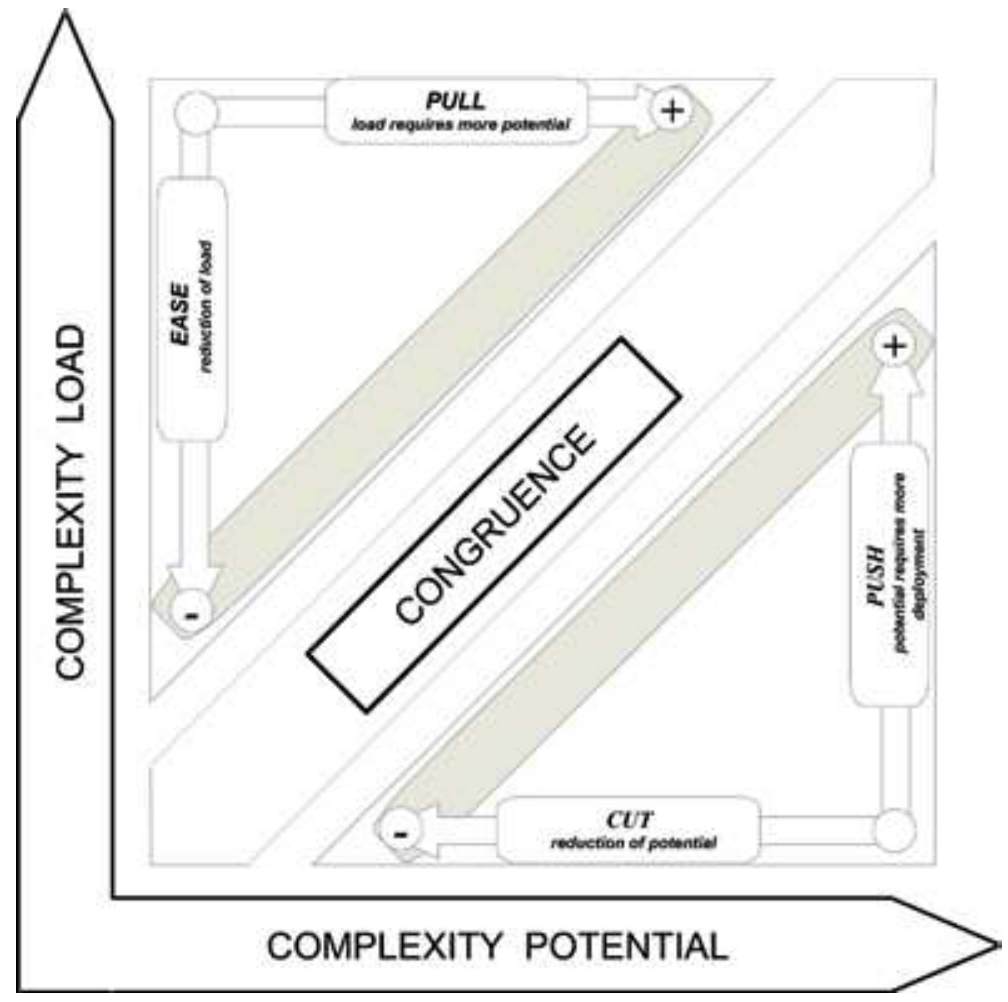

Figure 2.

Alignment of complexity load and complexity potential.

The underlying idea of congruence bears a specific ambiguity: As illustrated in Figure 2, congruence represents a corridor, not just a line. The corridor concept partially intersects with the Ashby space [63]. The corridor encompasses slack constellations, i.e., slightly more potential than load, as well as stretch constellations, i.e., slightly more load than potential. As a consequence, this tolerance approach deviates from the stringent (temporal) alignment applied in just-in-time strategies. The corridor implies the existence of tolerable imbalances in terms of slight overload ("stretch" to mobilize potential), as well as slight surplus, e.g., "slack" to respond to unexpected increases in complexity load as well as so-called tit-for-two-tats strategies in conflict management, allowing the opponent to defect from the agreed upon strategy twice which requires a tolerance potential on the side of the "forgiving" party. Finally, the corridor leaves space for contradictions and paradoxes like escalating commitment [64].

The idea of load-potential congruence is elucidated by the following examples:

- In dealing with systems of (linear) equations, congruence (warranting solution) is reached if the number of unknowns (complexity load) equals the number of equations (complexity potential).

- The paradigm of sensemaking [65] fosters a congruence by reducing the complexity load (primarily in the shape of the unknown) to a level that makes sense, i.e., is comprehensible with available knowledge (potential).

- Several hybrid concepts of organization are capable of furnishing a hypercomplex congruence, i.e., both an integration and flexibility potential as response to a blended load of diversity and dynamics. Thus, in strategic 
management holdings, the corporate center (shared services) is in charge of integration, whereas the subsidiaries (business units) are in charge of flexibility. In a similar way, "decentralized centralization," i.e., centers of competence installed in units or nodes of decentralized organizational entities (corporations, networks, etc.), delivers both integration and flexibility. Likewise, franchise systems or a cooperation between a big (pharmaceutical) corporation and a small (biotechnology) start-up yields integration and flexibility. Finally, the slogan "small within big is beautiful" conveys the conjunction of integration and flexibility.

- Congruence-focused simplexity management is efficient since it eliminates excess complexity both in the load component (e.g., an overlap of self-organization and intervention, overlapping of competences) and in the potential component ("waste").

- As for effectiveness, e.g., in terms of creativity and adaptability, the congruency between high levels of load and of potential delineates the notorious "edge of chaos" which actually constitutes a "region of chaos."

- Conversely, incongruence causes the risk of complexity-driven failure: Thus, a lack of synchronization of load and availability of potential may engender delays, inventories, or unpunctuality. In the same vein, so-called super wicked problems are characterized by the fact that the time (load) available for solving the respective problem (e.g., damping the greenhouse effect) is shorter than the time needed to develop countervailing strategies of problem solving, e.g., reaching a consensus on climate laws or proactive measures like a carbon tax [41].

- In interactive contexts, the inherent existence of two loads and two potentials requires differentiated investigating into congruence or incongruence. So, a complexity view of so-called asymmetrical information between two actors (e.g., principal and agent) is characterized by a discrepancy of two complexity potentials: The actor having an informational advantage (agent) augments his potential by disinformation, e.g., hiding, camouflage, faking, misleading signaling, and creating ambiguity. This increases the incongruence with the principal's potential.

- Competition goes hand in hand with typical interrelationships between the complexity components of the two actors involved. Thus, in a two-competitor constellation, the complexity potential of competitor I (e.g., surprising) most likely creates a complexity load ("threat") for competitor II which causes incongruence. In contrast, cooperative interactions merge the respective resources and equally the complexity potentials.

Whenever the relationship between the actors is unclear which economically corresponds to the hybrid constellation of coopetition, load-potential relationships are also ambiguous, like in the case of so-called good competitors.

\subsection{Patterns of simplexity management}

\subsubsection{Patterns of blending and assignment}

Simplexity management operates on two categories of patterns: (1) blending patterns which answer the question: "How can simplicity and complexity be 
mixed?" and (2) assignment patterns that clarify which component, domain, or dimension serves as an arena for simplification and which for complexification.

For blending simplicity and complexity, a scope of several patterns of blending is available. Awareness for this scope comes, for example, from blending exploitation and exploration according to the pattern of contextual ambidexterity or the pattern of structural ambidexterity. Again, this spectrum of amalgam, multilevel, sequential, sectoral, subsidiary, and situated patterns of blending options [66] illustrates how meta-complexity is underestimated in existing simplexity approaches that normally assume a "one and only" blending pattern.

Within amalgam mixes the blending is performed in a "total" fashion, yielding new genuinely hybrid frameworks that incorporate both genes of their parent paradigms. For instance, two-part tariff pricing operates with prices simultaneously composed of a fixed (simple) and a variable (complex) component. The multilevel blending pattern combines, for instance, a simple (stable) macro-level with complex (dynamic) microlevels. In a similar fashion, the blended Water-Scrum-Fall model [67] relies on a disciplined (simplified) handling of project specification and release, which serves as a framework for (complex) agile scrum processes in the design phase of the project.

In the case of sectoral and sequential blending, complexity managers pick different paradigms to apply them in distinct sectors, i.e., dimensions, components, and domains (areas, episodes, etc.) of the entire problem solving process: Along these lines, mass customizing is based upon standard modules (simplicity) in conjunction with creating a customized configuration of these modules (complexity) [14]. In the same vein, the unfreeze-move-refreeze pattern of attitude change relies on a sequential blending of complexification episodes (unfreeze, move) and simplification episodes (refreeze). So-called hybrid systems are capable of mixing continuous incremental changes ("flowing") and discrete dynamic behavior ("jumping"). By means of the outlined blending patterns, simple and complex strategies can be contingently assigned to different segments of the context, e.g., the intra-company context versus external targets.

Subsidiary blending, another blending pattern familiar from management by exception, combines a default (standard) approach (e.g., simplification) and a fallback approach (e.g., complexification). Thus, time pacing may serve as a default, event pacing as an exception. Finally, blended menus offer simplification and complexification as alternative options for ad hoc choices. As for problem solving tactics, the situated choice is between simple straight procedures (e.g., immediate performing) and complex detour procedures (e.g., rest before performing, problem decomposition). Likewise, path constitution comprises a "complex" path breaking option or a "simple" path dependence option [34].

\subsubsection{Component-focused simplexity patterns}

The cluster of assignment patterns locates simplicity and complexity in the load or the potential component. In unison with the simplexity paradigm, simplexity pattern clarifies ways of obtaining a congruence of complexity load and complexity potential via appropriate assignment strategies as portrayed in Figure 2.

Some of the patterns rely on strategies of complexity reduction, i.e., ease strategies reducing the complexity load and cut strategies reducing (idle) potential. Along these lines, more (less) slack represents the appropriate response to more (less) turbulence.

Inversely, strategies of complexity augmentation cover pull strategies ("complexity load requires more potential") and push strategies ("complexity potential requires more deployment"). Thus, in team development, norming, i.e., consensus, 
cohesion and commitment to rules (pulling potential), serves as a response to conflicts in the storming stage (pushing load). Likewise, practicing high-frequency trading requires sophisticated algorithms as technical infrastructure.

Blended pull ease - as well as push cut-strategies constitute the simplexity patterns, operating on two diametrical modifications of complexity load and complexity potential in the pursuit of load-potential congruence.

Thus, strategies of conflict management for developing more potential (tolerance, third party involvement, etc.) in conjunction with less load (decoupling of parties, providing proprietary assets, reduced claims, etc.) follow this pattern. In the same vein, flexi-time models usually rely on a compromise between three stakeholders of worktime, i.e., customers, employers, and employees. The divergence of interests, i.e., extended availability, avoidance of overtime payments, and work-family balance, is mitigated by deploying potential-enhancing devices (e.g., customer self-service, working remote) and sophisticated compromises like glide time.

Also in a pull-ease mode, so-called blue ocean strategies rely on designing innovative business models (pulling potential) that avoid competition (easing load).

In contrast, outsourcing relies on cut-pull strategies: In comparison to insourcing, outsourcing requires less investment in production activities but more investment in transaction activities.

\subsubsection{Dimension-focused simplexity patterns}

The landscape of patterns contains various proliferation patterns, i.e., moremore or less-less strategies. According to this logic, multitude and diversity trigger major changes in response (dynamics), e.g., when red lines are crossed, quota fulfilled, or critical values (e.g., break-even points) reached. Similarly, according to Gresham's law, the multiplicity of currency generates diversity in terms of a differentiation of functions ("store of value" versus "medium of exchange") between "good money" and "bad money." In the same vein, democracy combines the majority rule (multitude) with the protection of minority rights (diversity). In addition, the landscape is characterized by several simplexity patterns.

Thus, so-called incomplete contracts require only a modest investment of time for conclusion (simplification) but go along with frequent renegotiations (complexification). Optimal lot sizing (achieved by balancing ordering costs and inventory costs) through the lens of complexity relies on choosing between many small quantities and few big quantities. Likewise, the optimal dosage of change relies on choosing between many small steps (incrementalism) and few big jumps (low multiplicity in conjunction with high rates of change), at the extreme, a single "big bang."

Sedimented change, i.e., the overlay of an old and a new regime, combines less volatility obtained via more ambiguity. Likewise, backward compatibility of software versions as well as transition periods (e.g., for the redesign of the energy portfolio) helps avoid abrupt change at the cost of more concomitant ambiguity. Standardization (simplification) constitutes the backlash to an increasing number of elements (complexification). Amalgam hybrids such as intrapreneurs or prosumers are marked by a high diversity in just one single domain.

\subsubsection{Domain-focused simplexity patterns}

Complexity-oriented managers are more familiar with handling inter-domain complexity or simplicity patterns than simplexity patterns: Thus, the handling of errors (deviations) such as the increasing complexity load caused by the bullwhip 
effect requires more complexity potential, e.g., integrative supply chain cooperation or hybrid push-pull strategies for controlling value adding processes. Another complexification pattern results from the fact that the respective requirements of vendors and customers concerning the duration of the "fuzziness or nontransparency phase" in the life cycle of a product or service normally diverge. This discrepancy goes along with various complexity patterns. So, manufacturers want to freeze product specification as soon as possible (in order to avoid costs of parallel developments), in contrast customers as late as possible, i.e., just-in-time for use. Compromises are based on postponement $[68,69]$, modularization, or prosuming, i.e., product finalization by the customer, for instance, by finishing a vanilla box. Likewise, late cancelations (risk of no shows) can be handled by overbooking in conjunction with cancelations fees. Some travel agencies want to keep, for instance, their hotel accommodation services or carriers opaque, i.e., prefer late specification, whereas some customers want transparent specified offers as soon as possible. Price discrimination, i.e., a price reduction for partly transparent services (so-called opaque pricing), constitutes an appropriate strategy to find a compromise.

In addition to the sketched complexity patterns, the following examples illustrate the logic of domain-focused simplexity patterns:

In organizational design we encounter various simplexity patterns covering two domains: Thus, the dismantling of hierarchies (reduced vertical span of hierarchy levels) is accompanied by an increase of the horizontal span of management. Furthermore, simplexity patterns support the optimal dosage of change: In change management projects, simplexity patterns help obtain an optimal dosage of change pacing by combining "complex" event pacing and "simple" time pacing of change initiatives [10].

Multilateralization implies the propagation of the number of nodes ( $n$ ) into the number of edges (e.g., $\mathrm{n}(\mathrm{n}-1)$ ). However, this complexification pattern is not universal: There are various strategies to damp the numerical increase of edges; hub-and-spoke networks, for instance, are characterized by an increase of nodes (due to logistics on a global scale) but harness the number of connections between these nodes. Likewise, simplexity-focused negotiating between multiple parties (e.g., players in value nets) operates on selected multi-bilateral interactions in lieu of multilateral network-shaped interactions.

Complex overreactions (in the form of panic, actionism, "law and order" attitudes, bureaucratization, etc.) to "simple" stimuli like stress of competition or weak signals of disorder represent a complexity escalation comparable to the "butterfly effect" or bifurcation in chaos theory. In the same vein, complex (chaotic) bifurcations in the shape of disorientation may also be the paradoxical consequence of ample but contradictory information such as contradicting first and second opinions or suspicion of fake information. In contrast to prevalent models of decisionmaking such as the attention, interest, desire, action (AIDA) formula that convert more knowledge into focused action, action is inhibited by a confusing knowledge base, a paradox commonly labeled as "paralysis by analysis."

In managing mergers and acquisitions, a merger (i.e., upsizing) is frequently accompanied by a demerger (downsizing), e.g., whenever the upsizing violates a ceiling (critical value) like market power. Subsequent episodes (temporal domains) are sometimes characterized by simplexity patterns in contrast to proliferation patterns. This holds for path dependence, i.e., episodes of randomness followed by episodes of regularity and stability. In analogy, the escalation of conflicts with external parties (increased diversity) is capable of de-escalating internal conflicts (reduced diversity) via increasing solidarity.

The development of more competence for self-organizing accompanied by less formal organization (intervention, planning, controlling, etc.) constitutes the 
simplexity logic behind empowerment, agile management, and various leadership approaches.

Collusion, i.e., a species of cooperation among competitors in terms of a reduction of the intensity of conflict (simplification), provokes various conflicts (complexification) in other affected domains, i.e., with antitrust authorities, with competitors that are not members of the cartel, and with (negatively) affected customers.

Likewise, the so-called freemium pricing models apply standard low prices for basic products (simple diversity) and price discrimination for premium products (complex diversity).

Patterns of harmonizing capacities (e.g., airline capacities and airport capacities, power generation and power transmission capacities) frequently use simplexity patterns, first and foremost a combined upsizing and downsizing of capacities. Short-term optimization efforts align capacities to the bottleneck domain by dismantling idle capacities. Long-term optimization involves investment in the upsizing of bottleneck sectors.

The determination of the so-called customer order decoupling point (demand penetration point) between the push and the pull control domains of a value chain relies on simplexity patterns: A switchover from make-to-stock to make-to-order strategies, for instance, goes along with curtailing the push domain in favor of expanding the pull domain.

Change in management quite often relies on a mix of learning (enrichment of the behavioral repertoire) and unlearning (simplification of the behavioral repertoire) [70].

In conflict management an empowerment of the conflicting parties reduces the need to involve third parties or to practice organizational escalation.

The so-called rolling planning deploys a sophisticated simplexity pattern that combines detailed short-term plans with aggregate (rough-cut) long-term planning.

\subsection{Parameters of simplexity management}

Within the outlined framework, i.e., the congruence paradigm and the component-, dimension-, and domain-focused patterns, parameters provide a more palpable orientation for deploying simplexity, primarily by further specifying blending patterns and assignment patterns. On this level, each blending pattern is quantitatively specified by fixing the proportions of blending: In sequential blending the duration of the simplification and complexification episodes substantiates the qualitative blending. 50:50 proportions stand for a balanced blending, while an 80:20 ratio indicates the dominance of one category, typical of subsidiary blending. The same logic applies to push and pull proportions in value chain management, make and buy proportions in blended procurement, and the contractual fixing of shares by mutual agreements in managing conflicts. The specification of assignment patterns delivers numerical change rates, appropriate levels of decomposition (for instance, sentences, words, syllables, and letters in linguistic parsing), and optimal numbers of reinforcements.

The parameter level of simplexity management comprises (a) processes (measuring, representation, diagnosing, planning, implementing) and (b) corresponding methods, tools, skills, hardware, and software to support these activities.

Measurement provides some metrics of complexity. The spectrum comprises counting (numerosity), N/K ratios (number of elements/number of connections per element) [36], statistics of central tendency (mean, median, mode), variance, range, standard deviation (variety), probabilities and entropy (fuzziness), and volatility (dynamics). Yet, as a rule, complexity can only be measured on ordinal 
scales, differentiating "more" and "less" complexity. This also holds for the underlying concepts of "congruence" and "incongruence."

The representation of simplexity patterns relies on several media of verbal representation (papers, narratives, storytelling, parables featuring Icarus, Red Queen, David and Goliath, etc.), numerical representation (median, variance, homogeneity indices, sensitivity indices, number of factors extracted in factor analysis, data mining, etc.), and visual representation, e.g., metaphors (e.g., chameleons, Janus head, organizational tents and palaces, icebergs), maps (mind-mapping, road maps, heat maps, canvases, etc.), and charts (e.g., matrices, arborescent structures, diagrams, graphs, fitness landscapes).

Diagnosing the antecedents, varieties, and consequences (e.g., in-congruence) of simplexity strategies requires collecting weak signals (for proactive complexity management), screening (supported by gamification in the shape of signaling games and screening games), target-performance comparisons, benchmarks, radars, scenario analysis, gap analysis, and forecasting methods.

Planning, i.e., searching for or approximating optimal size, optimal conflict intensity, or optimal change rates, is based on operational heuristics [71]. The spectrum covers qualitative rules of thumb, intuition, educated guesses, best practices, plausibility, trial and error, as well as some quantitative methods, e.g., computational heuristics based on simulation. Holistic planning across several domains requires meta-heuristics rather than local search heuristics. Thus, so-called tabu search improves efficiency by avoiding coming back to previously visited solutions that already turned out to be blind alleys.

Implementing the hybrid concept of simplexity into a context consisting of the communities of simplifiers and complexifiers requires a communication-based "selling," going through unfreeze-move-freeze-processes, training, as well as stepwise procedures, e.g., piloting [66].

\section{Conclusions}

A major lesson learned of this introduction to simplexity is the need of a holistic (i.e., complex) handling of complexity. Against the background of the multicomponent, multi-domain, and multidimension architecture of complexity, any characterization of an entity as "(very) complex" or "simple" is inadequate. Hence, the prevalent piecemeal approaches are incapable of capturing the essence of the complexity construct. So, it remains unclear whether "complex organization" refers to complexity load, complexity potential (or the connection of the two components), additive complexity or alternative complexity, or an entire system versus just certain areas (domains) of the respective system. In other words, a holistic characterization of complexity must be based on (at least) three coordinates.

Unlike several complexity-focused heuristics, simplexity does not primarily constitute an iterative heuristics on the parameter level that supports some fine-tuning in search of the optimal degree of complexity, for instance, iterative downsizingupsizing in search of the right size of a business unit or resource management that develops from insourcing via outsourcing to backsourcing. In fact, simplexity consists of an idiosyncratic paradigm that clarifies not only the denotation but also the connotation of complexity beyond the crude antipodes of "bad complexity" (mess, disorder, etc.) and "good complexity" (latitude, momentum, etc.). Moreover, the simplexity framework contains manifold patterns that are helpful in dealing with the varieties of complexity.

The heuristic power of this framework is not exhausted by just remodeling implicit approaches like moral hazard and push-pull control in terms of complexity. 
In fact, the approach furnishes a better understanding and better design than prevalent modeling. The paradigm enables compensating the weaknesses of simplification and complexification beyond merely coping with taming or exploiting complexity.

Despite these strengths, inherent deficiencies of the simplexity framework propose various lessons that have still to be learned. The lack of appropriate metrics is a major drawback of simplexity reasoning, especially when it comes to "estimating" congruence or incongruence. Moreover, the different alleys to obtain congruence in Figure 2 have to be evaluated to answer the following question: What determines whether contractionary strategies (ease, cut) or expansionary strategies (push, pull) represent the optimal pathway to congruence? In different contexts these strategies will go along with different costs or time lags, e.g., reducing load in comparison to strengthening potential or downsizing potential.

Another critical drawback has already been repeatedly addressed: Unfortunately, complexity management in general and simplexity in particular go along with a substantial meta-complexity. Hence, the manual for the simplexity-product is quite extent and may impair practicality. The well-known ambivalence of being fascinated and confused by complexity might turn into perplexity given the metacomplexity of the simplexity framework.

This leads to a generic dilemma between an approach effective, but complex on the one hand and acceptable on the other hand. Any attempt to implement simplexity will have to find a compromise between these oppositional objectives. It can be achieved by a mixed effort to (a) improve the meta-potential in the context, i.e., awareness, capacities, and skills for handling simplexity and (b) assimilate the paradigm to available capabilities and readiness. Fortunately, the concept entails several built-in options of developing a "simplexity light" version to further acceptance without questioning the essence of the model. To accomplish such a simplification of simplexity, the congruence corridor can be widened, i.e., by accepting varieties of minor misfit of complexity load and complexity potential or even prioritizing efficiency of complexity management: This would justify the situated deploying of non-hybrid models of complexity handling, most likely focused on the simplification of complexity load. All the strengths and weaknesses considered, adopting the simplexity framework realistically means relying on a "perpetual beta."

\section{Author details}

Michael Reiss

Stuttgart University, Stuttgart, Germany

*Address all correspondence to: michael.reiss@bwi.uni-stuttgart.de

IntechOpen

(C) 2020 The Author(s). Licensee IntechOpen. Distributed under the terms of the Creative Commons Attribution - NonCommercial 4.0 License (https://creativecommons.org/ licenses/by-nc/4.0/), which permits use, distribution and reproduction for non-commercial purposes, provided the original is properly cited. (cc) BY-NC 


\section{References}

[1] Simon HA. The architecture of complexity. Proceedings of the American Philosophical Society. 1962;106:467-482

[2] Maguire S, McKelvey B. Complexity and management: Moving from fad to firm foundations. Emergence. 1999;1:19-61

[3] Cooksey RW. What is complexity science? A contextually grounded tapestry of systemic dynamism, paradigm diversity, theoretical eclecticism. Emergence. 2001;3:77-103

[4] Lewin R, Parker T, Regine B. Complexity Theory and the organization: Beyond the metaphor. Complexity. 1998;1998(4):36-40

[5] Thietart R-A, Forgues B. Complexity science and organization. In: Allen $P$, Maguire S, McKelvey B, editors. The Sage Handbook of Complexity and Management. London: SAGE Publications; 2011. pp. 53-64

[6] Stacey RD, Griffin D, Shaw P. Complexity and Management: Fad or Radical Challenge to Systems Thinking? London/New York: Routledge; 2000

[7] Anderson P. Complexity theory and organization science. Organization Science. 1999;10:216-232

[8] Miller D. The architecture of simplicity. Academy of Management Review. 1993;18:116-138

[9] Ashkenas R. Simplicity-minded management. Harvard Business Review. 2007;85(12):101-109

[10] Klarner P, Raisch S. Move to the beat. Academy of Management Journal. 2013;56:160-184

[11] Hautz J, Seidl D, Whittington R. Open strategy: Dimensions, dilemmas, dynamics. Long Range Planning. 2017;50:298-309

[12] Hajikazemi S, Ekambaram A, Andersen B, Zidane YJT. The black swan-knowing the unknown in projects. Procedia - Social and Behavioral Sciences. 2016;226:184-192

[13] Denrell J, Fang C, Liu C.

Perspective-chance explanations in the management sciences. Organization Science. 2015;26:923-940

[14] Barman S, Canizares AE. A Survey of mass customization in practice.

International Journal of Supply Chain Management. 2015;4:65-72

[15] Bouncken RB, Gast J, Kraus S, Bogers M. Coopetition. Review of Managerial Science. 2015;9:577-601

[16] El Sawy OA, Malhotra A, YoungKi P, Pavlou PA. Seeking the configurations of digital ecodynamics: It takes three to tango. Information Systems Research. 2010;21:835-848

[17] Zohar A, Morgan G. Refining our understanding of hypercompetition and hyperturbulence. Organization Science. 1996;7:460-464

[18] Pina e Cunha M, Rego A. Complexity, simplicity, simplexity. European Management Journal. 2010;28:85-94

[19] Kluger J. Simplexity: Why Simple Things Become Complex (and How Complex Things Can Be Made Simple). New York: Hachette Books; 2008

[20] Berthoz A. Simplexity: Simplifying Principles for a Complex World. New Haven: Yale University Press; 2012

[21] Collinson S, Jay M. From Complexity to Simplicity: Unleash your Organization's Potential. Basingstoke: Palgrave Macmillan; 2012 
[22] Colville I, Brown AD, Pye A. Simplexity: Sensemaking, organizing and storytelling for our time. Human Relations. 2012;65:5-15

[23] Davis JP, Eisenhardt KM, Bingham CB. Optimal structure, market dynamism, and the strategy of simple rules. Administrative Science Quarterly. 2009;54:413-452

[24] Eisenhardt KM, Piezunka. Complexity theory and corporate strategy. In: Allen P, Maguire S, McKelvey B, editors. The Sage Handbook of Complexity and Management. London: SAGE Publications; 2011. pp. 506-523

[25] Sull D, Eisenhardt KM. Simple rules for a complex world. Harvard Business Review. 2012;90(9):68-74

[26] Sull D, Eisenhardt KM. Simple Rules. How to Thrive in a Complex World. Boston/New York: Mariner Books; 2016

[27] Giregenzer G, Todd PM, ABC Research Group. Simple Heuristics that Make us Smart. New York: Oxford University Press; 1999

[28] Hertwig R, Hoffrage U, ABC Research Group. Simple Heuristics in a Social World. New York/Oxford, UK: Oxford University Press; 2013

[29] Gigerenzer G, Hertwig R, Pachur T. Heuristics: The Foundations of Adaptive Behavior. Oxford, UK: Oxford University Press; 2011

[30] Mousavi S, Gigerenzer G. Risk, uncertainty, and heuristics. Journal of Business Research. 2014;67:1671-1678

[31] Cooper D, Hinings B, Royston Greenwood R. Sedimentation and transformation in organizational change: The case of Canadian law firms. Organization Studies. 1996;17:623-648

[32] Gersick C. Revolutionary change theories: A multilevel exploration of the punctuated equilibrium paradigm. Academy of Management Review. 1991;16:10-36

[33] Romanelli E, Tushman ML. Organizational transformation as punctuated equilibrium: An empirical test. Academy of Management Journal. 1994;37:1141-1166

[34] Sydow J, Windeler A, Müller-Seitz G, Lange K. Path constitution analysis: A methodology for understanding path dependence and path creation. Business Research. 2012;5:155-176

[35] Kauffman SA. The Origins of Order. New York: Oxford University Press; 1993

[36] Vidgen R, Bull L. Applications of Kauffman's coevolutionary NKCS model to management and organization studies. In: Allen P, Maguire S, McKelvey B, editors. The Sage Handbook of Complexity and Management. London: SAGE Publications; 2011. pp. 200-219

[37] Gribbin J. Deep Simplicity: Chaos, Complexity and the Emergence of Life. London: Penguin Books; 2004

[38] Campbell DJ. Task complexity: A review and analysis. Academy of Management Review. 1988;13:40-52

[39] Daviter F. Coping, taming or solving: Alternative approaches to the governance of wicked problems. Policy Studies. 2017;38:571-588

[40] Ritchey TT. Wicked problems: Modelling social messes with morphological analysis. Acta Morphologica Generalis. 2005;2:1-8

[41] Levin K, Cashore B, Bernstein S, Auld G. Overcoming the tragedy of super wicked problems: Constraining our future selves to ameliorate global climate change. Policy Sciences. 2012;45:123-152 
[42] Aven T. The concept of antifragility and its implications for the practice of risk analysis. Risk Analysis. 2015;35:476-483

[43] Weick KE, Sutcliffe KM. Managing the Unexpected: Assuring High Performance in an Age of Complexity. San Francisco: Jossey-Bass; 2001

[44] Grover P, Kar AK. Big data analytics: A review on theoretical contributions and tools used in literature. Global Journal of Flexible Systems Management. 2017;18:203-229

[45] Bingham C, Eisenhardt KM. Rational heuristics: The 'simple rules' that strategists learn from process experience. Strategic Management Journal. 2011;32:1437-1464

[46] Ross AM, Rhodes DH, Hastings DE. Defining changeability. Systems Engineering. 2008;11:246-262

[47] Reiss MA. Complexitybased approach to production management in the new economy. In: Fandel G, Backes-Gellner U, Schlüter M, Staufenbiel JE, editors. Modern Concepts of the Theory of the Firm. Berlin/ Heidelberg: Springer; 2004. pp. 264-284

[48] Joachim Funke J, Andreas Fischer A, Holt DV. Competencies for complexity: Problem solving in the twenty-first century. In: Care E, Griffin P, Wilson M, editors. Assessment and Teaching of 21st Century Skills. Research and Applications. Berlin/Heidelberg: Springer; 2018. pp. 41-53

[49] Teece DJ. Dynamic capabilities. Routines versus entrepreneurial action. Journal of Management Studies. 2012;49:1395-1401

[50] Nedopil C, Steger U, Amann W. Managing Complexity in Organizations: Text and Cases. Houndmills, Basingstoke, Hampshire/New York: Palgrave Macmillan; 2011
[51] Duncan RB. Characteristics of organizational environments and perceived environmental uncertainty. Administrative Science Quarterly. 1972;17:313-327

[52] Stacey RD. Strategic Management and Organizational Dynamics: The Challenge of Complexity. 7th ed. Harlow: Pearson; 2011

[53] McDaniel RR Jr. Management strategies for complex adaptive systems. Performance Improvement Quarterly. 2007;20:21-42

[54] Schneider M, Somers M. Organizations as complex adaptive systems: Implications of complexity theory for leadership research. The Leadership Quarterly. 2006;17:351-365

[55] Reiss M. Change managementsupport for operations management: Mastering the hyper-complexity challenge. In: Nelson WD, editor. Advances in Business and Management. Vol. 13. Hauppauge, NY: Nova Publishers; 2017. pp. 77-115

[56] Bernardes ES, Hanna MD. A theoretical review of flexibility, agility and responsiveness in the operations management literature. International Journal of Operations \& Production Management. 2009;29:30-53

[57] Pérez Pérez M, Serrano Bedia AS, López Fernández MC. A review of manufacturing flexibility: Systematising the concept. International Journal of Production Research. 2016;54:3133-3148

[58] Kapoor R, Klueter T. Decoding the adaptability-rigidity puzzle. Academy of Management Journal. 2015;58:1180-1207

[59] Farjoun M. Beyond dualism: Stability and change as a duality. Academy of Management Review. 2010;35:202-225 
[60] Hildebrandt M, Jehle L, Meister S. Leading in HyperComplexity: A Practical Guide for Leaders. Faringdon: Libri Publishing; 2016

[61] Schlereth C, Stepanchuk T, Skiera B. Optimization and analysis of profitability of tariff structures with different number of two-part tariffs. European Journal of Operational Research. 2019;206:691-701

[62] Ritter T. A framework for analyzing interconnectedness of relationships. Industrial Marketing Management. 2000;29:317-326

[63] Boisot M, McKelvey B. Complexity and organization-environment relations: Revisiting Ashby's law of requisite variety. In: Allen $P$, Maguire S, McKelvey B, editors. The Sage Handbook of Complexity and Management. London: SAGE Publications; 2011. pp. 278-298

[64] Schad J, Lewis MW, Raisch S, Smith WK. Paradox research in management science. Academy of Management Annals. 2016;10:5-64

[65] Ancona D. Sensemaking. Framing and acting in the unknown. In: Snook S, Nohria N, Khurana R, editors. The Handbook for Teaching Leadership: Knowing, Doing, and Being. Los Angeles: SAGE Publications; 2012. pp. 3-19

[66] Reiss M. Change Management. Norderstedt: BoD; 2012

[67] Theocharis G, Kuhrmann M, Münch J, Diebold P. Is Water-ScrumFall Reality? On the Use of Agile and Traditional Development Practices. Available from: https:// www.researchgate.net/ publication/281546858_Is_WaterScrum-Fall_Reality_On_the_Use_of_ Agile_and_Traditional_Development_ Practices
[68] Yang B, Burns N, Backhouse C. Management of uncertainty through postponement. International Journal of Production Research. 2004;42:1049-1064

[69] Zinn W. A historical review of postponement research. Journal of Business Logistics. 2019;40:66-72

[70] Starbuck WH. Organizational learning and unlearning. The Learning Organization. 2017;24:30-38

[71] Loock M, Hinnen G. Heuristics in organizations: A review and a research agenda. Journal of Business Research. 2015;68:2027-2036 



\title{
Redundancy and Synchronisation Management in Mission- and Time-Critical Wireless Sensor Networks
}

\author{
Davide Scazzoli, Maurizio Magarini and Giacomo Verticale
}

\begin{abstract}
Wireless sensor networks (WSNs) are a technology that has been increasingly adopted thanks to their ability to inexpensively and safely gather information in difficult-to-access environments. Because of this they are an invaluable tool to gather knowledge about health, usage, and performance parameters of products in any environment as well as identify the onset of, and avoid or mitigate, catastrophic failures. This chapter will introduce the benefits that WSNs can bring to the process of knowledge management for the development and maintenance of products as well as discuss emerging research trends regarding two prominent concerns inherent to WSNs: redundancy management and synchronisation. After reviewing these results, their impact and applicability to mission-critical applications will be discussed, as well as the interaction between the solutions.
\end{abstract}

Keywords: wireless sensor networks (WSNs), mission-critical, redundancy management, synchronisation

\section{Introduction}

Volatile requirements and mutating operating scenarios have moved industries towards engineering approaches that rely on knowledge-based systems (KBS) [1]. To help engineers with removing ambiguity in requirements and monitoring operational parameters after deployment through prognostics and health management systems, wireless sensor networks can offer invaluable aid [2]. WSNs comprise a set of interacting devices, called nodes, which are often used to sense information from the environment and wirelessly transmit it back to a data collector. They are often deployed in environments that are difficult to reach for maintenance personnel. For example, a WSN could be deployed to monitor seismic activity from an active volcano [3], enemy activity in a military conflict area [4], or radiation levels in areas with radioactive contamination [5]. Due to this, one or more nodes can be damaged or even compromised by intelligent attacks. Even in less extreme conditions, WSN nodes may fail due to energy reserves depleting over time. In order to contrast this behaviour, WSNs are often deployed with much greater number of nodes than strictly needed and with much denser spatial distances. This inevitably introduces great amounts of redundancy, which negatively impacts the lifetime of the WSN. 
While the redundancy allows for the network to continue functioning in spite of some node failures, reducing the lifetime of the network as a whole is a heavy price to pay. Because of this, many works in the literature have focused on managing redundancy and exploiting redundancy for increasing the lifetime of the network as well as detect malicious attacks or other node faults [6]. The second part of this chapter will deal with the synchronisation of individual sensor nodes inside WSNs, which is another prominent aspect of research. Synchronisation is necessary not only for application-specific requirements but also to properly manage sleep cycles and to avoid waste of energy in redundancy management. Lastly, synchronisation is a fundamental aspect of health monitoring and disaster mitigation; a failure in one system or part of a system can often lead to cascading effects impacting many other systems. It is therefore imperative to establish a correct timeline for the gathered sensor data in order to establish a timeline that allows the engineer to recognise the root cause of a failure and mitigate its effects [2].

\section{Redundancy and its management in WSN}

Node redundancy management has the goal of improving sensor lifetime and, at the same time, guaranteeing that the sensing area is covered. This second requirement is especially important for mission-critical applications, where temporal or spatial holes in sensed information can lead to disastrous effects. In general, the process for achieving this goal can be broken down in two main phases:

1. Node discovery: During this phase, the nodes in the network identify sensing and communication neighbours. Sensor nodes localise one another either by means of localisation equipment (e.g. GPS) or, more commonly, by employing localisation techniques such as received signal strength indicator (RSSI) ranging, time difference of arrival (TDoA), or angle of arrival [7]. Such information is then used to identify which nodes can be deemed redundant and thus switched off and which ones should remain active.

2. Sleep cycle management: While redundant sensors are switched off or enter deep sleep cycles to save energy, they still need to occasionally exchange information with neighbours. This is done with the purpose of identifying failures of other nodes and determining whether they need to become active and take the place of other failed or failing nodes. Thus, it is common that inactive nodes alternate between sleep and checking states. Nodes can switch to an active role under various conditions such as the failure of a neighbour node or when the residual energy levels of neighbour active nodes fall below a certain threshold (see, for example, [7-12]).

\subsection{Strategies for redundancy management}

Node redundancy provides benefits with respect to fault tolerance and reliability. However, it also introduces undesired effects such as faster depletion of resources due to the measuring of unnecessary, redundant data, and its associated higher communication overhead [6].

When sensors are deployed in random positions over an area, which is a common deployment strategy, node redundancy is unavoidable. There are several strategies to address redundancy, which we can broadly divide into the following categories: 
- Spatial redundancy: Multiple sensor nodes are able to gather information about the same spatial area.

- Physical redundancy: The same physical quantity is measured by different independent sensor nodes.

- Analytical redundancy: A certain node's measured variable can be estimated by analytical models from the variables measured by other nodes.

- Temporal redundancy: Multiple measures of the same quantity by the same node are taken over a period of time.

- Temporal communication redundancy: The same data sampled by a specific node is recurrently transmitted over a period of time.

- Information redundancy: Redundant data are transmitted along normal data in order to reconstruct lost information.

Spatial, physical, and analytical redundancy have been used to deal with node failures, while temporal and information redundancy have been used in a variety of applications such as ensuring correct data delivery in data link layer protocols [6], improving the precision of the measured data, and identification of malicious sensor attacks [5].

\subsection{Failures in WSNs}

Failures can be classified in terms of type and scope as depicted in Figure 1. Node failures are broadly distinguished between single node failures and multiple node failures. A single node failure may interest an end node, a router, or the sink, while multiple node failures may result in bridged, isolated, or lost areas. Communication failures can be characterised based on their duration, temporary or permanent, and their scope: single link, localised area or entire network.

The most common case of WSN nodes failure is exhaustion of energy resources, which is widely investigated in the literature $[5,6,13]$. A less common failure scenario is the failure of the sink node, which can be managed by employing redundancy of the sink node itself in order to mitigate the onset of failures [14]. Even in this case redundancy needs to be efficiently managed in order to avoid wasting resources.

A particular class, called common mode failures, involve problems that manifest on all redundant devices simultaneously, causing a collapse even in the presence of redundancy. This class can be managed using diversity redundancy techniques.
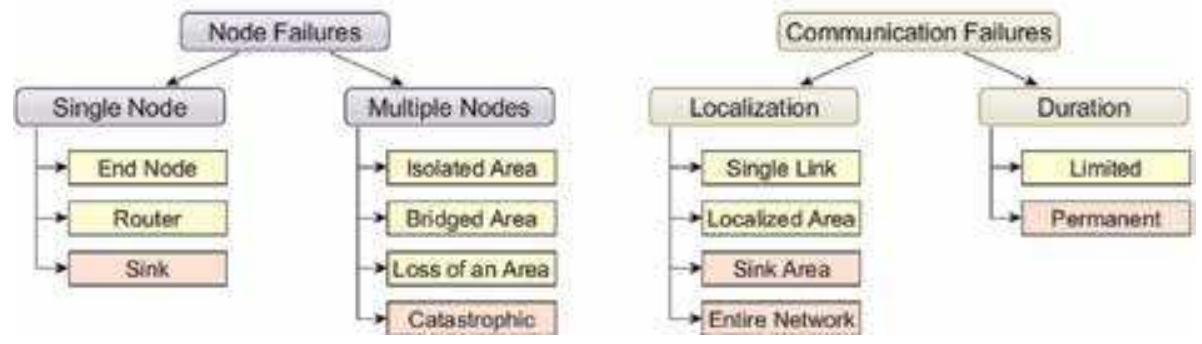

Figure 1.

Type and scope of node failures and communication failures. 
That means using redundancy options which involve different types of hardware rather than replicating the same device a number of times. One example is using different communication technologies where one technology may be subject to a common mode failure as in the case of electromagnetic wireless communication in areas where there is heavy radioactivity [5].

\subsection{Redundancy estimation techniques}

It is generally assumed that the sensing area of a sensor node can be described as a circle of a certain radius. Consequently, redundancy management can be reduced to the problem of providing the optimal coverage of a certain area or of a number of test points using the smallest amount of sensor nodes. While in reality sensing areas often assume different shapes according various factors, such as the environment they are deployed in, the usage of circular sensing areas greatly simplifies calculations.

\subsubsection{Redundancy estimation via Voronoi diagrams}

One approach presented in [15] is to use Voronoi diagrams to identify redundant sensors as shown in Figure 2. Given a set of sensors $S_{1}, S_{2}, \ldots, S_{n}$, it is possible to subdivide the $x, y$ plane in cells according to Eq. (1), where dist $(a, b)$ denotes the Euclidean distance between points $a$ and $b$ :

$$
\operatorname{cell}\left(\mathbf{S}_{i}\right)=\bigcap_{j=1, j \neq i}^{n}\left\{\mathbf{x} \mid \operatorname{dist}\left(\mathbf{S}_{i}, \mathbf{x}\right) \leq \operatorname{dist}\left(\mathbf{S}_{j}, \mathbf{x}\right)\right\}
$$

In Figure 3, a sensor is called Voronoi generator of another if the Voronoi cells of the two sensors share an edge with one another. In this kind of graph, two types of points are of interest:

1. Voronoi vertices (VVs), which are the points where 3 Voronoi edges intersect

2. Voronoi intersection points (VIPs), which are the intersection points between Voronoi edges and the circumference describing the sensing radius of a particular sensor

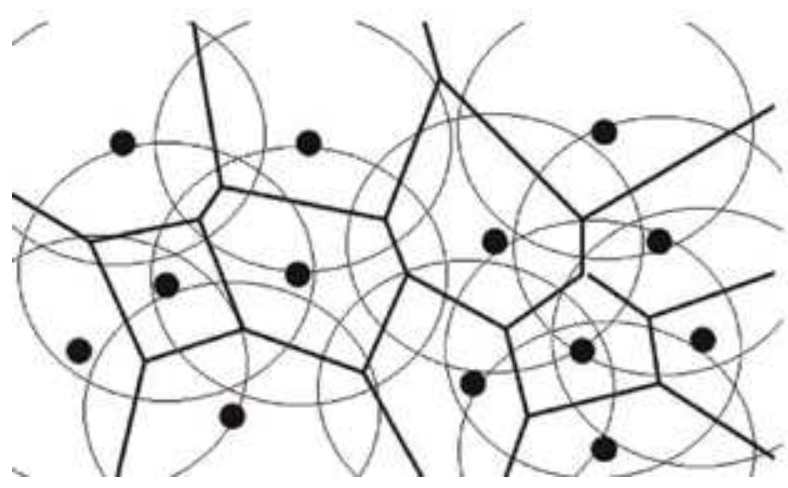

Figure 2.

Example of subdivision of the $x, y$ plane in Voronoi cells. 


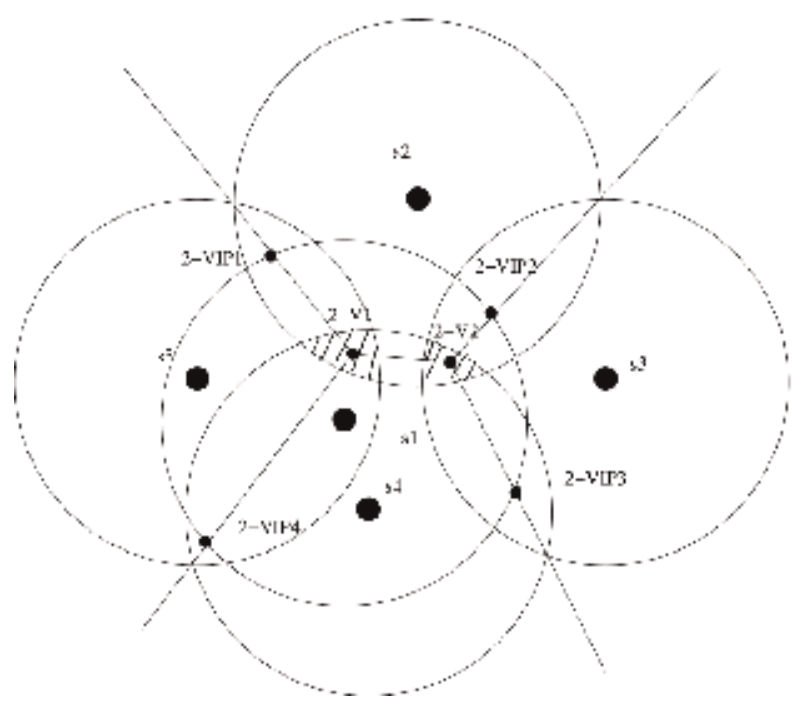

Figure 3.

Example showing the relationship between the VVs and VIPs with sensing area. All the 2-VV and 2-VIPs are covered by the sensing area of at least two neighbours.

In order to evaluate the redundancy of a node, we must first construct the 2Voronoi diagram which is simply the Voronoi diagram when that particular sensor is not considered. Inside this diagram we will consider the VVs of the diagram and VIPs of the excluded sensor which will be respectively labelled 2-VV and 2-VIP. If all of the 2-VV and 2-VIP are covered by at least two generators, then the entire sensing area of the node is covered by at least one other node as can be seen in the example shown in Figure 3.

\subsubsection{Redundancy estimation via analytical methods}

Another approach, shown in [16], is to analytically determine redundancy based on a set of test points. The problem is to determine whether a node's sensing area is completely covered by other sensor nodes. We can describe it analytically as

$$
K_{i} \subseteq \bigcup_{j \in N\left(s_{i}\right)}\left(K_{j} \cap K_{i}\right),
$$

where $K_{i}$ indicates $i$-th node's sensing area, which in this case is a set of test points such as $\left\{q_{i_{0}}, q_{i_{1}}, \ldots, q_{i_{n}}\right\}$, and $N\left(s_{i}\right)$ indicates the set of neighbouring nodes with respect to node $i$.

The set of all test points, $Q=\left\{q_{1}, q_{2}, \ldots, q_{m}\right\}$, is called the sensor field. Considering $S$ as the sensor set, then the problem becomes finding the minimal subset of nodes $S^{\prime} \subseteq S$ such that the sensor field is completely covered. We can define for each point a binary variable, $\beta_{i}$, which defines whether test point $q_{i}$ is redundantly covered. In order to determine whether a sensor is redundantly covered, all of its test points must be redundantly covered. Therefore, redundancy is identified by the binary product of the variables $\beta_{i}$, which is true if all the $\beta_{i}$ are true and false otherwise. Each sensor can calculate its own redundancy $\alpha_{i}$ according to Eq. (3):

$$
\alpha_{i}=\prod_{K_{i}} \beta_{i}
$$


The simplicity of this algorithm makes it ideal for an analytical study with typical sensor distributions such as uniform randomly distributed and Poisson distribution. The limitation of this algorithm is that it does not give an exact result but a probabilistic one. Indeed when applying this algorithm, it is possible to envision scenarios where the algorithm identifies sensors as redundant when they should not be. Imagine, for example, two sensors placed in the exact same place for simplicity; they will both cover the same points and thus will both identify themselves as redundant due to the other sensor's presence. Should they both turn off, however, all the point would become uncovered. Careful consideration must be therefore applied when using this algorithm, especially for mission-critical applications. One way to avoid this problem is to recalculate the $\alpha_{i}$ after every single change in state from one of the neighbouring nodes.

\subsection{Sleep cycle management techniques}

Managing redundancy also requires the ability to handle redundant nodes in an energy-efficient manner so that they do not waste resources while the nonredundant nodes are working [7-12]. The simplest sleep cycle management can be done via a watchdog timer that periodically wakes up the sensor to check the situation of neighbouring nodes; check if any nodes have failed or are close to failing, and, if so, switch to active status to replace them. A simplified scheme of the typical protocol states is shown in Figure 4. The node wakes up and checks for neighbouring node conditions with different methods based on the specific protocol. It can broadcast a HELLO message to check for active nodes in the vicinity [8] or check residual energy levels for neighbouring nodes [7]. If a change in state from the checking state to the active state is triggered, most protocols include reiterations of the redundancy estimation algorithm to verify that coverage is maintained and there are no redundant sensors.

One of the most critical aspects of this is how to choose the duration of the sleep cycle. Four different strategies are shown in Figure 5 and are detailed below:

- The Random Back-off Sleep Protocol (RBSP) [10] uses a random back-off approach in order to determine the sleep cycle duration. Every time the redundant node wakes up, it checks the energy levels of the active nodes. Then, it selects a random sleep duration, which is influenced by the level of energy of the active nodes. In this strategy, wakeups are more frequent when



Figure 4.

Example of state machine diagram of the sleep cycle management within redundancy management protocols. When sleeping nodes wake up, they check the condition of neighbouring nodes in different ways such as failure to reply to HELLO messages or energy levels below a certain threshold. 




Figure 5.

Different strategies for the management of sleep cycles [12].

active nodes are running out of energy. As a consequence, this strategy has the effect of saving energy during the normal operation and decrease the time needed to discover a node failure.

- The coverage and energy strategy for wireless sensor networks method introduced in [9] adopts simple periodic wakeups rather than complex timing techniques. It however focuses on the interactions between the nodes once they wake up, defining DUTY and HELP messages that active nodes can share with sleeping nodes once they wake up. HELP message indicates they have spare energy but wish to exchange roles with nodes that have higher energy levels, while DUTY message indicates their energy is almost depleted and another node must take their place.

- In the Probing Environment and Collaborating Adaptive Sleeping (PECAS) [11] protocol, two different sleep management approaches are proposed: Prescheduled independent sleeping (PIS) and neighbourhood cooperative sleeping (NCS). The former implements a random independent sleeping delay for each node, while the latter makes active nodes decide a next_sleep_time value based on energy consumption and advertises it to other sleeping nodes when they wake up. Thus, other nodes in the range of the active node will be warned of the exact time when the active node will begin sleeping, enabling the application to control the frequency of when wakeups happen.

- Lastly, the Optimised Discharge-Curve-Based Coverage Protocol (ODCP) [12] introduces an optimised sleep time calculation. This sleep time is optimised in terms of energy efficiency and is derived from the discharge curve and failure probability of active nodes.

\subsubsection{Sleep management in mission-critical applications}

Sleep management protocols mainly focus on the aspect of saving energy. However, they present new issues should they be employed in mission-critical domains 
where downtime must be avoided. In particular, some protocols can be adapted to minimise downtime, such as PECAS or the protocol used in [7], by using high wakeup frequency or frequent role changes. This however introduces energy consumption which negates the benefits of the protocols. Particularly worse is the ODCP since it is optimised for energy and probabilistic in nature. It is entirely possible that, in the middle of the long optimised sleep cycle, a failure happens and no redundant sensor wakes up to prevent downtime. This problem stems from the main limitation of the transceivers which are shut down during sleep cycle and unable to receive information. Some solutions can be adopted for this problem. One solution is to maintain some redundancy so that random failures are unlikely to leave blind spots before a sleeping node wakes up to cover the failed one. The protocol shown in Section 2.3.2 can be easily modified to check that the points are covered by at least $N$ sensors rather than just one. Another approach is to overcome this limitation entirely by employing crude passive telecommunication transceivers, which do not consume as much as the main transceiver and are used only for the purpose of waking up the sensor [17]. Regardless of the adopted solution, the flexibility of WSNs makes them an ideal candidate for scenarios where requirements are not fixed and deployment environment is not static. WSNs are highly flexible and can adapt to meet changing requirements even in the post-production phase. Their intrinsic ability to acquire data in the most hostile of environments allows engineers to collect information on the health and usage of products in any scenario.

\section{Synchronisation for mission-critical WSNs}

Another critical aspect of managing WSNs is how to properly synchronise each node to a common time frame. Traditionally time synchronisation across network has been carried out by means of protocols such as the Network Timing Protocol [18], but these protocols are unsuitable for WSNs as the typical node presents heavy constraints on the protocols in terms of complexity and energy efficiency. Another strategy widely used for synchronisation is the usage of a global time scale, such as GPS to synchronise all nodes. In some applications it is required that the nodes are as inexpensive as possible due to the very large number of nodes that have to be deployed, rendering the option of installing GPS receiver on each node prohibitively expensive. Because of these reasons a multitude of synchronisation protocols which rely on the exchange of timing information between nodes have been proposed in the literature [19-24]. Synchronisation offers great benefits towards managing redundancy in mission-critical applications. While some of the protocols for managing redundancy previously mentioned attempt to solve the issue in a probabilistic manner [10, 12], for such applications a deterministic approach might be better. Having all nodes synchronised to a common time frame has the advantage of bringing notable gains. It is common, for example, to use heartbeat protocols for mission-critical applications [14], and thus sleeping nodes can wake up at the exact time when such heartbeat should be transmitted and confirm the active node status without having to transmit a request themselves and wait for the replies. This section will first give an overview of the main aspects of synchronisation, in particular the characterisation of the error, and then will illustrate both basic and advanced methods used to achieve synchronisation in WSNs.

\subsection{Synchronisation error characterisation}

Synchronisation error is caused by a difference between two clock counters and is often divided in the following components: 
- Clock offset: the instantaneous difference at a given time

- Clock skew: the clock frequency difference at a given time

- Clock drift: the clock offset caused by the accumulation of clock skew over time

In a WSN scenario, offset may be caused by different turn-on times for the sensors but also by the accumulation of clock skew error over time. Skew is caused by difference in the clock signal generators, which in WSNs are often quartz or ceramic resonators, which arise from the fabrication process but also due to environmental conditions such as different temperature, humidity, and pressure. Clock offset is directly linked to clock skew; it is therefore necessary to estimate clock skew in order to limit the synchronisation overhead and maintain a low offset between nodes for the longest period of time possible [25]. Synchronisation protocols rely on the exchange of timing information between nodes. Because of this they are susceptible to random delays in the delivery of the information which can impact on the synchronisation accuracy. The following nondeterministic factors are responsible for the degradation in the accuracy of synchronisation protocols:

- Sender uncertainty: It covers all the variable delays attributed to the sender of a packet. It can be subdivided in:

$\circ$ Send time: It is the time required to send a packet to the medium-access control (MAC) layer. The uncertainty of this time is mainly influenced by interruptions that could happen during the operation of constructing a packet and calling the functions to send it once the sending time stamp has been recorded.

- Access time: It indicates the time the packet must wait in queue at the MAC layer before being actually transmitted. It is highly variable, and it depends heavily on network traffic.

- Transmission time: This delay is the result of the transmission speed of the connection at the physical layer. If the connection speed does not change and there are no interruptions during transmission, then it can be considered deterministic.

- Propagation delay: This delay is introduced by the transmission medium and covers the physical propagation of the information from sender to receiver. Given that the distance between nodes of a WSN is often very small and static, this component often assumed negligible.

- Receiver uncertainty: It covers the variable delays attributed to the receiver. It can be further subdivided in:

- Reception time: Analogous to the transmission time, it is the time taken to receive the individual bits and pass them to the MAC layer.

- Receive time: The time taken to construct a packet from the received bits and pass it to the upper layers. Just like in the send time, the uncertainty stems from the variable delays introduced by the operating system. 


\subsection{Synchronisation protocols}

As mentioned before, synchronisation protocols achieve their objective by exchanging timing information in the form of packets. In the following subsections, we will briefly describe the different approaches adopted in the literature. Many of the current state-of-the-art protocols are variations of one of these architectures.

\subsubsection{Sender-receiver synchronisation}

The sender-receiver approach is one of the first ever adopted in the scope of network synchronisation. It is used by both NTP [18] and more recent protocols specific to WSNs such as TPSN [19] or FTSP [26]. In this case a sender is synchronised to a receiver as shown in Figure 6.

\subsubsection{Receiver-receiver synchronisation}

A more recent approach first introduced by RBS [20] is the usage of a reference broadcast to synchronise all the nodes which have received this broadcast as shown in Figure 7. This approach has the benefit of negating the impact of all the uncertainty components relative to the sender: Given a particular broadcast, send time, access time, and transmission time will be the same for all receivers. This allows the protocol to average out these contributions and achieve better performance. It is interesting to note that the broadcast node is not synchronised and that no synchronisation information is contained in the reference broadcast. The receiver

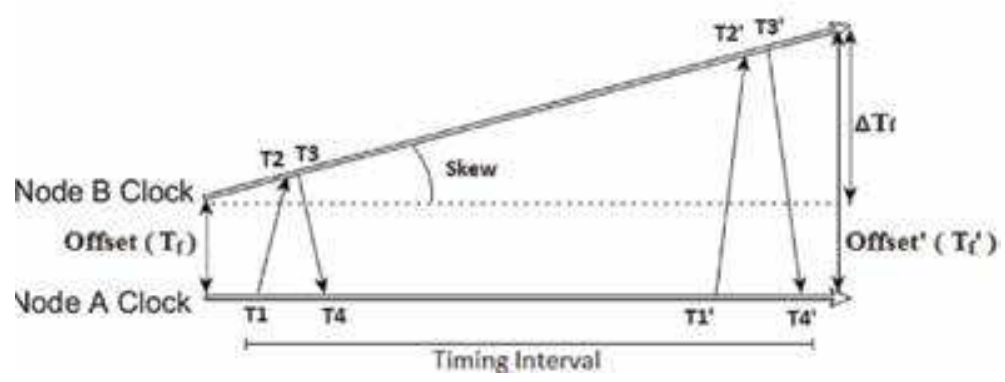

Figure 6.

Illustration of the sender-receiver exchange of packets.

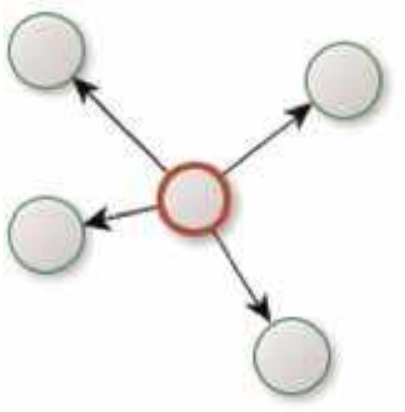

(a)

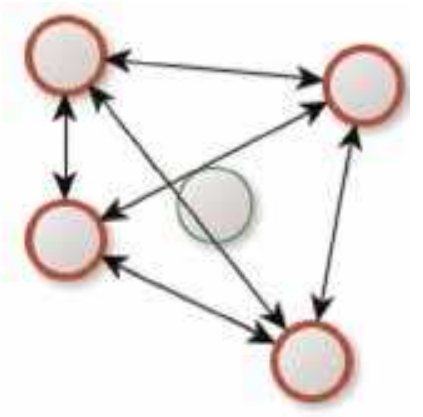

(b)

Figure 7.

Illustration of the reference broadcast synchronisation procedure. (a) Reference Broadcast, and (b) Exchange of reception time. 
Redundancy and Synchronisation Management in Mission-and Time-Critical Wireless Sensor... DOI: http://dx.doi.org/10.5772/intechopen.90133

nodes will note down all the reception time stamps of the other nodes and reach a common consensus. This protocol has been shown to achieve good performance in terms of synchronisation accuracy; however, the large amount of packets that need to be exchanged between nodes make this protocol much more energy consuming than other protocols such as TPSN or FTSP [27].

\subsubsection{Receiver-only synchronisation}

One of the main constraints of WSNs is the limited energy, and thus energy efficiency is of the highest importance even in synchronisation protocols. For this reason the receiver-only paradigm began to emerge. This approach was first introduced by PBS [23] which, as shown in Figure 8, synchronises a pair of nodes via the sender-receiver paradigm and then synchronises all overhearing nodes through receiver-only synchronisation. As WSNs are often densely packed, the probability of having a large number of overhearing nodes is high; this translates to large efficiency gains with respect to other approaches.

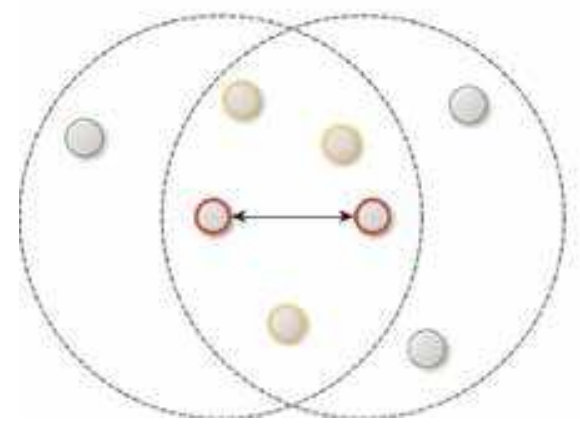

Active Node

Overhearing Node

Inactive Node

Figure 8.

An example of pairwise broadcast synchronisation where two nodes actively synchronise and three nodes overhear this exchange.

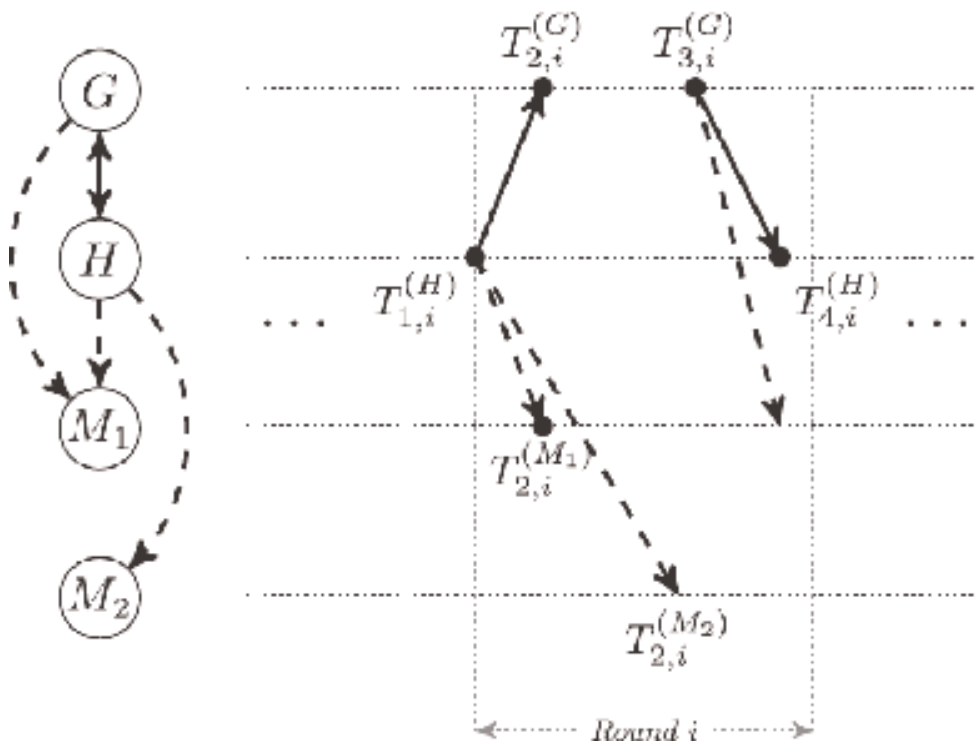

Figure 9.

Message exchange for the SPiRT protocol, node $H$ is a cluster head which is synchronising to node G. node M1 overhears the entire exchange, while M2 only overhears the messages sent by the cluster head [21]. 


\title{
3.2.4 E-SPiRT
}

Synchronisation through Piggybacked Reference Timestamps (SPiRT) exploits the popularity of two-tier network architectures in WSN, where nodes are grouped into disjoint clusters [21]. Each cluster has a cluster head which synchronises its clock to that of a reference node in the network through message exchange. Since cluster members can overhear the cluster-head transmissions, SPiRT, much like PBS, takes advantages of such synchronisation traffic to adjust the clock of the cluster members. SPiRT, however, takes this principle one step further with respect to PBS and synchronises even the nodes that only partially hear the exchange. By appending the reference time stamps in the cluster-head messages, SPiRT allows all cluster members to estimate their clock offset, as shown in Figure 9. This protocol has been recently refined into E-SPiRT, which is an extension that operates over multi-hop links in order to achieve network-wide (global) synchronisation [22].

\section{Conclusion}

In this chapter we have introduced wireless sensor networks and how they can help engineers with their unprecedented information gathering capabilities in both design and operation phases. We then introduced the requirements for missioncritical wireless sensor networks, a way to achieve them through redundancy, and the main aspects of their management broken down into the two phases of redundancy estimation and sleep cycle management. Our focus then switched to the introduction of time synchronisation, motivating its importance for the analysis of gathered information and covering its intrinsic link with sleep cycle management. We explained both basic and advanced protocols for obtaining synchronisation as well as how to characterise their error. We have reviewed recent advances regarding all these aspects, highlighting both their intended advantages and possible problems when applied in the particular scope of mission-critical applications.

\section{Author details}

\author{
Davide Scazzoli*, Maurizio Magarini and Giacomo Verticale \\ Dipartimento di Elettronica, Informazione e Bioingegneria, Politecnico di Milano, \\ Milan, Italy
}

*Address all correspondence to: davide.scazzoli@polimi.it

\section{IntechOpen}

(C) 2020 The Author(s). Licensee IntechOpen. Distributed under the terms of the Creative Commons Attribution - NonCommercial 4.0 License (https://creativecommons.org/ licenses/by-nc/4.0/), which permits use, distribution and reproduction for non-commercial purposes, provided the original is properly cited. (cc) BY-NC 


\section{References}

[1] Ciancarini P, Messina A, Poggi F, Russo D. Agile knowledge engineering for mission critical software requirements. In: Synergies Between Knowledge Engineering and Software Engineering. Springer; 2018.

pp. 151-171. Available at: https://www. springer.com/shop

[2] Gao S, Dai X, Hang Y, Guo Y, Ji Q. Airborne wireless sensor networks for airplane monitoring system. Wireless Communications and Mobile Computing. 2018:1-18

[3] Lara R, Bentez D, Caamano A, Zennaro M, Rojo-Alvarez JL. On realtime performance evaluation of volcano-monitoring systems with wireless sensor networks. IEEE Sensors Journal. 2015;15(6):3514-3523

[4] Ahmad I, Shah K, Ullah S. Military applications using wireless sensor networks: A survey. International Journal of Engineering Science. 2016; 6(6):7039

[5] Dhanoriya S, Pandey M. A survey on wireless sensor networks: Faults, misbehaviour and protection against them. In: Computing, Communication and Networking Technologies (ICCCNT), 2017 8th International Conference on. IEEE; 2017. pp. 1-7

[6] Curiac D-I, Volosencu C, Pescaru D, Jurca L, Doboli A. Redundancy and its applications in wireless sensor networks: A survey. WSEAS Transactions on Computers. 2009;8(4):705-714

[7] Islam MN, Jang YM, Choi S, Park S, Park H. Redundancy reduction protocol with sensing coverage assurance in distributed wireless sensor networks. In: Communications and Information Technology, 2009. ISCIT2009. 9th International Symposium on. IEEE; 2009. pp. 631-636
[8] More A. Residual energy based distributed coverage protocol for wireless sensor networks. In: Communications (MICC), 2017 IEEE 13th Malaysia International Conference on. IEEE; 2017. pp. 12-17

[9] Le N-T, Jang YM. Energy-efficient coverage guarantees scheduling and routing strategy for wireless sensor networks. International Journal of Distributed Sensor Networks. 2015; 11(8):612383

[10] More A, Raisinghani V. Random backoff sleep protocol for energy efficient coverage in wireless sensor networks. In: Advanced Computing, Networking and Informatics-Volume 2. Springer; 2014. pp. 123-131. Available at: https://www.springer.com/shop

[11] Gui C, Mohapatra P. Power conservation and quality of surveillance in target tracking sensor networks. In: Proceedings of the 10th Annual International Conference on Mobile Computing and Networking. ACM; 2004. pp. 129-143

[12] More A, Raisinghani V. A node failure and battery-aware coverage protocol for wireless sensor networks. Computers and Electrical Engineering. 2017;64:200-219

[13] Younis M, Senturk IF, Akkaya K, Lee S, Senel F. Topology management techniques for tolerating node failures in wireless sensor networks: A survey. Computer Networks. 2014;58: 254-283

[14] Scazzoli D, Mola A, Silverajan B, Magarini M, Verticale G. A redundant gateway prototype for wireless avionic sensor networks. In: 2017 IEEE 28th Annual International Symposium on Personal, Indoor, and Mobile Radio Communications (PIMRC). IEEE; 2017. pp. 1-7 
[15] Carbunar B, Grama A, Vitek J, Carbunar O. Coverage preserving redundancy elimination in sensor networks. In: Sensor and Ad Hoc Communications and Networks, 2004. IEEE SECON 2004. 2004 First Annual IEEE Communications Society Conference on. IEEE; 2004. pp. 377-386

[16] Sakib K, Tari Z, Bertok P. Ar analytical framework for identifying redundant sensor nodes from a dense sensor network. In: Computer and Information Technology (ICCIT), 2010 13th International Conference on. IEEE; 2010. pp. 187-192

[17] Spenza D, Magno M, Basagni S, Benini L, Paoli M, Petrioli C. Beyond duty cycling: Wake-up radio with selective awakenings for long-lived wireless sensing systems. In: 2015 IEEE Conference on Computer Communications (INFOCOM). IEEE; 2015. pp. 522-530

[18] Mills DL. Internet time synchronization: The network time protocol. IEEE Transactions on Communications. 1991;39(10): 1482-1493

[19] Ganeriwal S, Kumar R, Srivastava MB. Timing-sync protocol for sensor networks. In: Proceedings of the 1st International Conference on Embedded Networked Sensor Systems. ACM; 2003. pp. 138-149

[20] Elson J, Girod L, Estrin D. Finegrained network time synchronization using reference broadcasts. ACM SIGOPS Operating Systems Review. 2002;36(SI):147-163

[21] Benzaid C, Bagaa M, Younis M. An efficient clock synchronization protocol for wireless sensor networks. In: Wireless Communications and Mobile Computing Conference (IWCMC), 2014 International. IEEE; 2014.

pp. $718-723$
[22] Benzaid C, Bagaa M, Younis M. Efficient clock synchronization for clustered wireless sensor networks. Ad Hoc Networks. 2017;56:13-27

[23] Noh K-1, Serpedin E, Qaraqe K. A new approach for time synchronization in wireless sensor networks: Pairwise broadcast synchronization. IEEE Transactions on Wireless Communications. 2008;7(9):3318-3322

[24] Elsharief M, El-Gawad MAA, Kim H. Density table-based synchronization for multi-hop wireless sensor networks. IEEE Access. 2018;6: 1940-1953

[25] Djenouri D, Bagaa M. Synchronization protocols and implementation issues in wireless sensor networks: A review. IEEE Systems Journal. 2016;10(2):617-627

[26] Maroti M, Kusy B, Simon G, Ledeczi A. The flooding time synchronization protocol. In: Proceedings of the 2nd International Conference on Embedded Networked Sensor Systems. ACM; 2004. pp. 39-49

[27] Bae S-K. Power consumption analysis of prominent time synchronization protocols for wireless sensor networks. Journal of Information Processing Systems. 2014;10:300-313 


\title{
Harnessing IoT Data and Knowledge in Smart Manufacturing
}

\author{
Joseph Shun Ming Yuen, King Lun Choy, Yung Po Tsang and \\ Hoi Yan Lam
}

\begin{abstract}
In the modern digitalized era, the use of electronic devices is a necessity in daily life, with most end users requiring high product quality of these devices. During the electronics manufacturing process, environmental control, for monitoring ambient temperature and relative humidity, is one of the critical elements affecting product quality. However, the manufacturing process is complicated and involves numerous sections, such as processing workshops and storage facilities. Each section has its own specific requirements for environmental conditions, which are checked regularly and manually, such that the whole environmental control process becomes time-consuming and inefficient. In addition, the reporting mechanism when conditions are out of specification is done manually at regular intervals, resulting in a certain likelihood of serious quality deviation. There is a substantial need for improving knowledge management under smart manufacturing for full integration of Internet of Things (IoT) data and manufacturing knowledge. In this chapter, an Internet-of-Things Quality Prediction System (IQPS), which is a mission critical system in electronics manufacturing, is proposed in adopting the advanced IoT technologies to develop a real-time environmental monitoring scheme in electronics manufacturing. By deploying IQPS, the total intelligent environmental monitoring is achieved, while product quality is predicted in a systematic manner.
\end{abstract}

Keywords: smart manufacturing, Internet of Things, knowledge management, quality prediction, fuzzy logic

\section{Introduction}

In recent years, the demand on consumer electronics has dramatically increased due to the numerous advanced inventions, such as smartphones and smart city devices. Product quality, which is assessed by the products' features and characteristics, is one of the determinant factors in the sale of consumer electronics [1]. In order to maintain and improve product quality, it's essential that the manufacturing process is under tight control with monitoring of environmental conditions so as to produce electronic devices with high levels of product quality. This area has drawn considerable research interest regarding effective approaches for managing manufacturing conditions, for example, industrial Internet of Things (IoT) applications. However, the electronic manufacturing process is different and more complicated than other general manufacturing processes, including design, development, fabrication, assembly, and testing approaches $[2,3]$. Therefore, an effective 


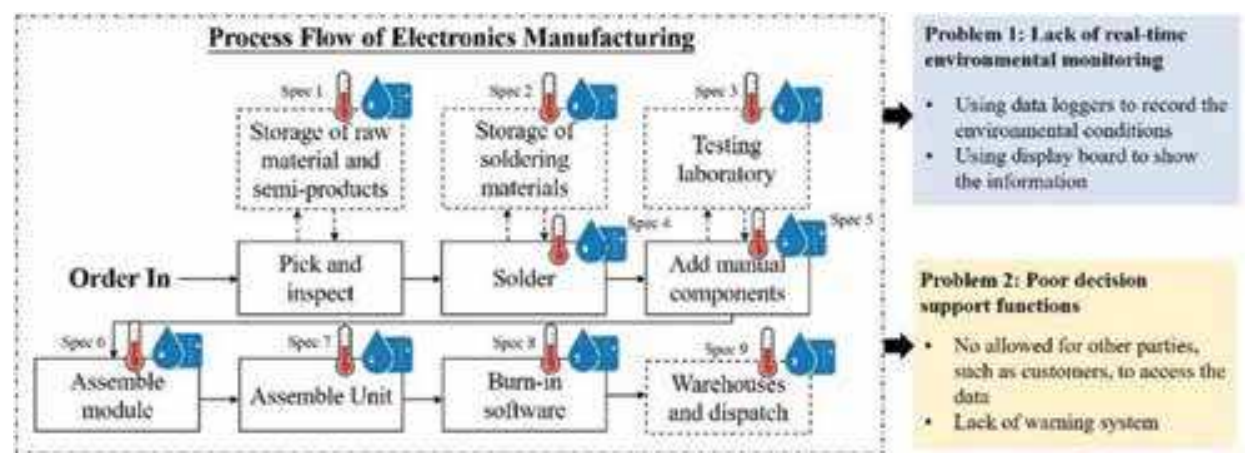

Figure 1.

Process flow of electronic manufacturing and its problems.

environmental monitoring and quality prediction system that fits various manufacturing requirements in the production lines is needed. In electronic manufacturing sites, the arrival of production orders affects the entire manufacturing process, namely, picking, inspecting, soldering, assembling, software burning-in, and dispatching, as shown in Figure 1. However, there are two major problems regarding environmental monitoring in manufacturing sites. Firstly, various sections in the manufacturing process have their own requirements on environmental conditions, and data loggers are used to record the environmental conditions, i.e., ambient temperature and humidity, for each section or workshop. On-site supervisors are required to memorize all this information and check it regularly. However, it is time-consuming to record all the data and act accordingly if the conditions do not meet to the requirements. Secondly, traditional environmental control does not allow other parties, such as customers or auditors, to access the data externally, and there is an inefficient warning system when violation of specific environmental conditions occurs. Therefore, the performance of environmental control and monitoring in existing electronic manufacturing is poor, resulting in negative impact on product quality. In order to address the above problems, the development of IoT system in smart manufacturing requires the integration of certain level of domain knowledge, such as the relationship between environmental conditions and quality prediction. In addition, the intelligent environmental monitoring and quality prediction align the business missions and policies of most electronic manufacturing companies. Without such systems, the companies may not be able to formulate operational and business strategies in a proactive manner.

In this chapter, a research methodology for problem identification and knowledge goal definition is presented to connect the academic research and real-world applications with anticipated results in knowledge management. For electronic manufacturing companies, in order to survive in the fiercely competitive business environment, quality management, including quality control and quality assurance, is one of the essential objectives. In the past, the quality problems were identified after production by inspection and testing. By using such a reactive approach in quality management, certain amount of waste in raw materials and company resources are incurred. Therefore, there is room to integrate knowledge from quality management and state-of-the-art technologies, such as IoT technologies and artificial intelligence techniques. An Internet of Things quality prediction system (IQPS) is proposed through making use of the advanced Internet of Things (IoT) technologies and artificial intelligence technique, i.e., fuzzy logic, for monitoring the environmental conditions in a real-time manner and predicting the quality of manufacturing process. Wireless sensor nodes are adopted to collect the environmental data in a specific manufacturing site and transmit the data to local 
devices via wireless communication technologies, such as Wi-Fi and Bluetooth. Consequently, the messaging protocol is then applied to publish the data to a specific IoT platform and cloud database for further system development and data management. Under the IoT environment, the sensing devices are interconnected efficiently and effectively such that the various requirements regarding environmental monitoring can be fulfilled. This enables the environmental conditions to be ensured within the specifications, and it can reduce one of the crucial factors which may cause the deviation on product quality. With using the collected monitoring data, the decision support on quality prediction can be established by means of fuzzy logic, and relationship between product quality and some indirect factors can be constructed. Adopting fuzzy logic in real-world application adds the intelligence in learning the knowledge from domain expert in the form of membership functions and fuzzy rules. The resultant knowledge can be managed and stored in the knowledge repository for generating meaningful results, namely, quality prediction, in this chapter. The membership functions can define the fuzziness of input and output parameters, while fuzzy rules are used to connect input and output to generate appropriate adjustments and evaluations in specific circumstances.

This chapter is organized as follows. Section 1 is the introduction. In Section 2, the related work and literature in the aspects of electronic manufacturing, Internet of Things (IoT), and its applications are described. Section 3 presents the system architecture of IQPS. A case study in implementing the proposed system is illustrated in Section 4. Section 5 gives the results and discussion related to the benefits and limitations of the proposed system. Conclusions are drawn in Section 6.

\section{Related works}

Electronic manufacturing is a series of activities for designing, developing, fabricating, assembling, and testing of electronic parts, tools, products, and systems [4]. There are three epochs in the evolution of electronic manufacturing, namely, the vacuum tube era, the transistor era, and the integrated circuit era. Current electronic manufacturing falls under the integrated circuit era, focusing on producing small and reliable electronic devices and components at low cost. However, the complexity and dynamics in electronic manufacturing processes have rapidly increased in recent years due to short product life cycle and efficient new product development $[5,6]$. Since the initial investment for manufacturing technologies is high and talented professionals in process engineering and quality are required, there is a great barrier for most start-up electronic manufacturers to enter the fiercely competitive market. In addition, effective and comprehensive control on the production environment, without which product quality deviation, occupational injuries, and low productivity may occur, should consider four major elements, i.e., equipment, process, ambient factors, and job procedures [7]. Most studies have covered the elements of equipment, process, and job procedures, such as advanced inkjet printing equipment, process optimization, job shop scheduling, and lean manufacturing [8-11]. Moreover, in order to manage the manufacturing process effectively, some new manufacturing systems have been developed. For example, an advanced concept of cyber-physical system (CPS) architecture where the information from all related perspectives in the manufacturing process are closely monitored and synchronized was proposed so as to standardize the development process for Industry 4.0 [12]. However, the ambient factors in electronic manufacturing are a less-touched research area due to the technology barriers in the past. The control and monitoring of the ambient factors, for example, lighting, relative humidity, and temperature, can be completed under the environment 
and paradigm of Internet of Things (IoT). In addition, the concept of knowledge management can be integrated in the system development process so as to improve the machine learning process and the expected results from the system.

The ontology of knowledge management (KM) has drawn huge attention in the modern research and business sectors, with the aim of creating value for stakeholders [13]. In recent years, KM is well-defined as the processes and practices in an organization with the aim of enhancing the effectiveness and efficiency in managing its knowledge resources [14]. To facilitate the development of knowledge management, technology adoption is a crucial element to provide functionalities of knowledge sharing and process innovation, such as business process reengineering. An et al. [15] presented a KM framework to drive collaboration, communication, and connectivity in three directions, namely, (i) rearrangement of KM roles by people, (ii) reengineering of KM activities by processes, and (iii) reconfiguration of KM artifacts by technology. In other words, the effective KM approach requires the integration of people, process, and technology in a systematic manner. Dehghani and Ramsin [16] summarized several methodologies used in the development of knowledge management systems, which should cover the stages of identification, assessment, classification, and knowledge goals. Also, the development of KM needs to focus on adaptability, analysis, and maintenance so as to develop a practical and beneficial application for the industry. In the world of smart manufacturing, it refers to adopting pervasive applications and ubiquitous computing, in which traditional facilities are transformed to knowledge-embedded facilities, enabling functions of predictive approach, incident prevention, performance enhancement, and decision-making capabilities [17]. Thus, the role of KM for knowledgeembedded facilities in smart manufacturing is inevitable. Papazoglou et al. [18, 19] proposed a knowledge-based model for smart manufacturing with integrating advanced technologies, including IoT, to establish manufacturing analytics and resource integration. Its knowledge structures covered partner, product, process orchestration, and quality assurance blueprint controlled by various knowledge repositories. Therefore, the value of quality assurance in smart manufacturing by means of KM is proven, and the integration of state-of-the-art technologies and KM is the preferred approach.

IoT $\mathrm{a}$ is an emerging concept in which objects equipped with certain sensors, actuators, and mobile devices are able to interact with each other so as to achieve a specific goal $[20,21]$. IoT technologies are developed from the extension of radio-frequency identification (RFID) technologies. In recent years, the IoTrelated solutions and applications have dramatically increased in many industries, such as smart health, smart home, and smart manufacturing. The IoT solutions are basically developed with three technology stacks, namely, thin layer, connectivity layer, and IoT cloud layer [22]. The above three stacks clearly describe the requirements on the sensor nodes, the process of using protocols to connect the sensor nodes and cloud services, and the system development in the IoT cloud platform. In view of the detailed IoT elements, IoT consists of six major elements to create various functionalities in the applications and solutions, i.e., identification, sensing, communication, computation, services, and semantics. Da et al. [23] presented six key considerations in building a new IoT solution, i.e., energy consumption, data latency, throughput rate, scalability, topology, and security. For evaluating the industrial IoT applications, the aforementioned factors are used to establish the key performance indicators (KPIs) to ensure designated level in quality of service (QoS) and appropriate structure of service-oriented architecture (SOA). With appropriate system configuration and deployment, IoT applications can be developed which are applied into numerous application areas, including the healthcare service industry, food supply chain, safer mining production, and 
logistics [24-27]. The above applications show that IoT technologies have sufficient capability in monitoring the conditions of an indoor environment. Therefore, there is room to extend the advanced IoT concepts, methods, and technologies for building an environmental monitoring system in electronic manufacturing. After IoT monitoring application is established, the data analytics by means of artificial intelligence can be followed. To achieve the goals of quality assurance and quality prediction, fuzzy logic, which is able to process linguistic variables and terms and mimicking human thinking process, is selected [28]. The knowledge from domain experts is managed in the knowledge repository in the form of if-then rules, and it can connect input and output attributes which may be subjective and uncertain to provide decision support in quality assurance.

With the above study, it is concluded that electronic manufacturing plays an essential role in our society for producing the latest electronic devices. Since the end users require a high level of product quality, control and monitoring in the electronic manufacturing process are one of the key elements for improving product quality and productivity. In order to achieve the above objective, IoT technology is feasible for developing a real-time and automatic monitoring system in electronic manufacturing and formulating an intelligent quality prediction for manufacturing process. Therefore, an intelligent environmental monitoring and quality prediction system is proposed, and a knowledge-based approach is used to design the framework of entire system development and implementation in this chapter.

\section{Integrating $\mathrm{KM}$ and IoT data in smart manufacturing}

To achieve the goals of quality assurance and prediction in smart manufacturing, a knowledge-based approach is used to formulate the practical system with three phases, as shown in Figure 1. They are (i) problem identification and knowledge goal definition, (ii) design of IQPS, and (iii) performance measurement. It takes advantage of KM approach in developing and deploying the IoT systems in the real-world situations [29]. Apart from merely collecting the IoT data, the fusion between IoT data and human knowledge from domain experts is then exploited to generate decision support in smart manufacturing. With the systematic way to manage such knowledge, the effectiveness and efficiency of an organization can be further improved. Consequently, the projection of expected quality defects can be quantified in a systematical manner (Figure 2).

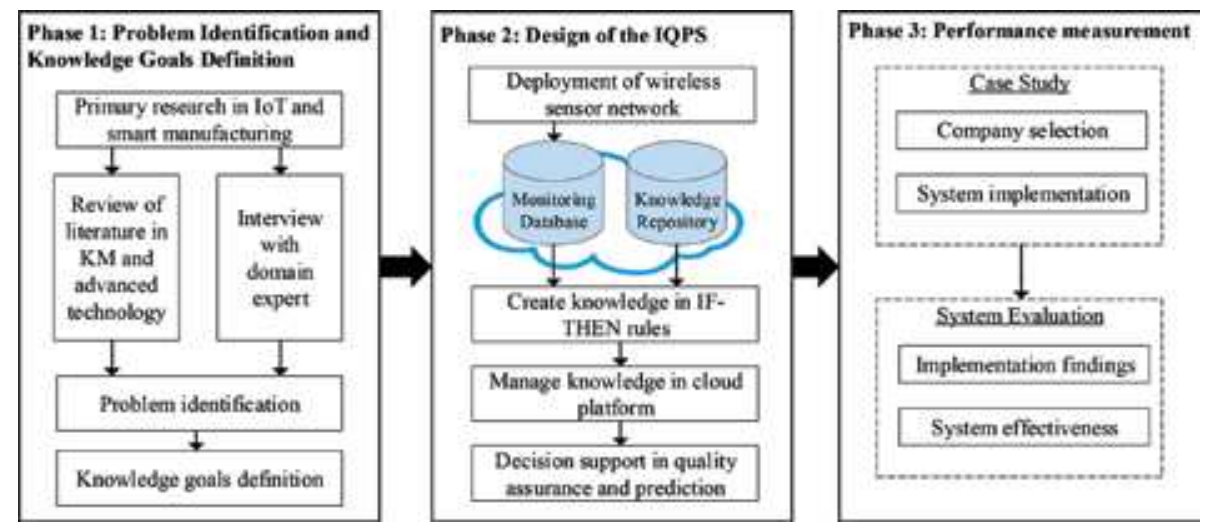

Figure 2.

Process flow of electronic manufacturing and its problems. 


\subsection{Phase 1: problem identification and knowledge goal definition}

To harness IoT data and knowledge in the environment of smart manufacturing, the primary research in the fields of IoT and smart manufacturing is required to select the appropriate IoT technologies and techniques. However, merely deploying systematic solutions is insufficient for success, and KM approaches are needed to consider other angles in the organization. The literature related to KM and interviews with the industrial experts are then conducted to explore research gaps in the real-world situations. The interview and even site visits can truly reflect the existing situations in the organization, by investigating the workflow and discussing with the frontline operators. This generates the information for identifying the practical problems for manufacturing companies. Once the problem scenarios are built, the knowledge goals can be defined for effectively managing the knowledge in the entire system environment.

\subsection{Phase 2: design of IQPS}

This section describes an Internet-of-Things (IoT) quality prediction system (IQPS) to automatically collect ambient factors, namely, ambient temperature and relative humidity in production lines, and to predict in-process quality by using fuzzy logic. Figure 3 shows the system architecture of the proposed system, IQPS, which consists of three modules, namely, the sensor node deployment module, the cloud connectivity module, and the quality prediction module. It aims at developing an automatic and real-time environmental monitoring system so that it can assist the regular recording and checking process for the indoor ambient factors. As a result, the collected data are analyzed to formulate decision support in quality prediction regarding manufacturing quality defects.

\subsubsection{Sensor node deployment module}

The SensorTag CC2650 is selected for the use in the sensor nodes in the proposed system due to low cost, capability of using multiple communication protocols, and low energy consumption. It is placed in various workshop environments so as to collect, at most, 10 different types of data, including ambient temperature and relative humidity. In order to deploy the sensor nodes effectively, target coverage and sensor node connectivity are two key elements, which are achieved by using the deterministic approach [30]. Firstly, the target coverage, which implies that sensor nodes at the target point get the optimal coverage level, is done by a binary coverage model and coverage algorithm. It ensures that the deployed sensor nodes are able to reach all the target nodes within the sensing reading range. In addition to controlling the number of sensor nodes, sensor $s_{i}$ which covers the most target points is selected in a specific grid $m$, as in Eq. (1). When considering multiple grids simultaneously in a Cartesian coordinate system, the grid $n$ is selected where the distance to the farthest target node $d_{i, t}$ is minimized among all the considered grids, as in Eq. (2). P denotes the grid set with the same number of target nodes, and $Q$ denotes the set of target nodes covered by the sensor nodes:

$$
\begin{gathered}
m=\arg \max \left(s_{i}\right) \\
n=\arg \min _{i \in P} \max _{t \in Q}\left(d_{i, t}\right)
\end{gathered}
$$




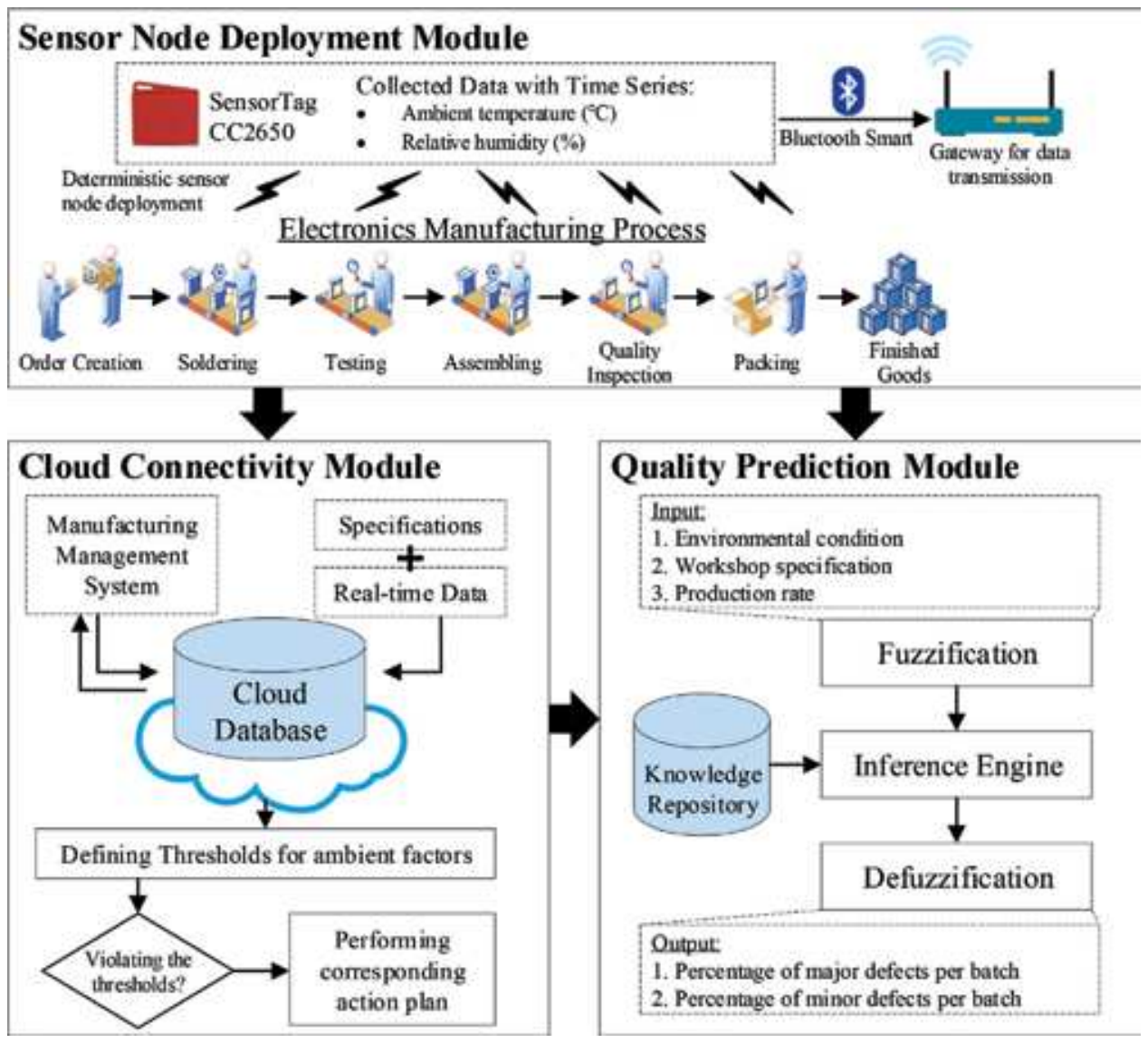

Figure 3.

System architecture of IQPS.

Secondly, for the sensor node connectivity, relay nodes should be placed in the indoor environment so as to transmit the collected data to specific host computers. Sensor node grouping and group connectivity are two major factors for placing the relay nodes. Firstly, relay nodes are required when there are some unconnected groups of sensor nodes, and the relay nodes are used as the node neighbor in each unconnected group. In addition, the number of relay nodes should be controlled through minimizing the relay node $r_{i}$ and sensor node $s_{k}$ in group $j$ in a specific grid, as in Eq. (3). When considering more than one grid, the relay nodes $r \in R$ should connect the various groups of sensor nodes $t \in P$ as far as possible, as in Eq. (4):

$$
\begin{array}{r}
d_{r j}=\min \left[d\left(r_{i}, s_{k}\right)\right] \\
f_{n}=\arg \max \min \left[d\left(r_{i}, t\right)\right]
\end{array}
$$

\subsubsection{Cloud connectivity module}

In this module, all the collected data are then transmitted to the cloud services or host computers through the transmission protocols, for example, Message Queuing Telemetry Transport (MQTT). In order to effectively create the IoT applications, the data are stored in the cloud database under an IoT development platform, such as 
IBM Cloud. The sensor nodes have to be registered in advance for configuring and authenticating data queries and messaging to the pointed web services. In the cloud platform, the real-time data and specifications for ambient factors are integrated to formulate a monitoring application. In addition, the collected data stored in the cloud database can be linked to the existing manufacturing management system so as to enable suppliers and customers to view the reports on indoor ambient factors. If the collected ambient environmental conditions are violated, corresponding action will be taken to maintain stable and appropriate environmental conditions.

\subsubsection{Quality prediction module}

In the IBM Cloud, some development tools are well-designed for creating a customized IoT application, for example, Node-RED. They embed the major programming environment and capability of using multiple programming languages. It offers the advantage to freely design an appropriate solution for meeting a specific goal. The proposed system, apart from real-time monitoring and alert management, is also able to generate a report with time series data and to build customized user interfaces for displaying the collected data to the suppliers and customers. Last but not least, the proposed system is also able to record the number of quality deviations under the controlled indoor environment in order to access the system performance.

On the other hand, the fuzzy logic approach is used to evaluate the quality in the manufacturing process by making use of the real-time data and other static data, namely, workshop specification and production rate. In the fuzzy logic approach, the percentage of major and minor defects per batch can be evaluated by the environmental information, i.e., ambient temperature and relative humidity; workshop specification, i.e., workshop area; and production rate. In order to formulate the relationship between input and output attributes, there are three generic steps in fuzzy logic approach, namely, fuzzification, inference engine, and defuzzification. In the step of fuzzification, the linguistic input attributes are converted into fuzzy sets, where the fuzzy set $F$ is defined by membership function $\mu \mathrm{F}(\mathrm{x})$ with element $\mathrm{x}$ as shown in Eq. (5):

$$
F=\sum_{i=1}^{n} \frac{\mu_{F}\left(x_{i}\right)}{x_{i}}
$$

The fuzzy sets are then processed to the inference engine in which Mamdani's method is used to integrate the fuzzy-rule-based knowledge stored in the knowledge repository. Therefore, the crisp input values are estimated and aggregated to be an appropriate adjustment of output values. The fuzzy rules used in this process are stated in the format of if-then rule which contains antecedent and consequent statements. The rules in the fuzzy logic are the knowledge which is collected from domain experts intuitively to express the relationship between input and output attributes. The inference engine is connected with the knowledge repository to facilitate the computation and conversion. Thus, the inference engine can be customized according to the extracted knowledge related to input and output attributes in different manufacturing environments. After aggregating the membership values in consequent membership functions, the OR operator is used for handling multiple attributes, and thus the bounded area can be formed, and the defuzzification process can be used consequently so as to obtain estimated output values. In the step of defuzzification, the centroid method which measures the center of gravity of the bounded area is applied to obtain the crisp output value y as shown in Eq. (6). Therefore, the average number of major and minor defects per batch can be predicted and estimated: 


$$
y=\frac{\int \mu_{F}(y) \cdot y d x}{\int \mu_{F}(y) d x}
$$

\subsection{Phase 3: performance measurement}

To measure the performance of the proposed method, a case study and performance evaluation are two major approaches. To conduct a case study, two major steps are involved, i.e., company selection and system implementation. In the case study, the company should be the active practitioner in the electronic manufacturing industry, and the quality assurance is one of its business objectives. The selection criteria cover the company size, capability on quality management, and product variety. Thus, operators and staff at management level can be actively engaged in the quality assurance to provide high level of knowledge quality, and the value of decision support by using expert knowledge can be guaranteed. After implementing the system, the results need to be analyzed, and the effectiveness and satisfaction should be evaluated through conducting a survey. The results can be used to formulate the strategic quality planning in future production schedule to adjust the controllable factors for maximizing yield rate. Also, the proposed system advocates the domain experts to input their own expertise and knowledge for the inference engine to improve the quality of results.

\section{Case study in an electronic manufacturing company}

In order to validate the proposed system, a case study was conducted in an electronic manufacturing company, called Innovation Sound Technology Co. Ltd., which mainly produces headsets, headphones, and earphones. The company has 10 working and storage areas with various requirements on ambient temperature and relative humidity. The areas, with specifications as shown in the bracket, are the mold workshop $\left(21-28^{\circ} \mathrm{C} ; 40-60 \%\right)$, laboratory $\left(21-28^{\circ} \mathrm{C} ; 40-60 \%\right)$, processing workshop $\left(21-28^{\circ} \mathrm{C} ; 40-70 \%\right)$, dust-free workshop $\left(21-28^{\circ} \mathrm{C} ; 40-70 \%\right)$, packaging workshop $\left(21-28^{\circ} \mathrm{C} ; 40-70 \%\right)$, assembly workshop $\left(21-28^{\circ} \mathrm{C} ; 40-65 \%\right)$, chemical warehouse $\left(10-25^{\circ} \mathrm{C} ; 40-80 \%\right)$, electronic warehouse $\left(15-28^{\circ} \mathrm{C} ; 40-60 \%\right)$, glue warehouse $\left(5-21^{\circ} \mathrm{C} ; 40-60 \%\right)$, and general warehouse $\left(15-32^{\circ} \mathrm{C} ; 40-70 \%\right)$. The section supervisors and managers are required to remember all the above specifications and to check it regularly, but this manual approach is not effective in monitoring the ambient factors and in providing alert management. Due to growing technologies and solutions under the IoT environment, a real-time environmental monitoring system can be used to address the above challenges in electronic manufacturing sites. In order to implement the proposed system in the case company, there are three milestones in the entire implementation process, namely, (i) sensor node deployment, (ii) IoT system deployment, and (iii) quality prediction development.

In the first milestone, the sensor nodes, i.e., the SensorTag CC2650, are deployed according to the consideration of the target coverage and sensor node connectivity. The sensing radius for the sensor nodes is around $50 \mathrm{~m}$ in using Bluetooth Smart for data transmission. In the workshop environment, the sensor nodes are placed in the corners to collect temperature and humidity data at specific points, and the relay nodes have to be placed within sensor nodes' sensing radius so as to transmit the data to the cloud services. This method not only collects the data at the specific locations but also computes an average value to express the entire environmental conditions in the workshop environment. After placing the sensor nodes and relay nodes correctly, the sensor nodes and relay nodes are registered in the IoT development platform, i.e., IBM Cloud, in the second milestone. In this milestone, the service "Internet of Things Platform 


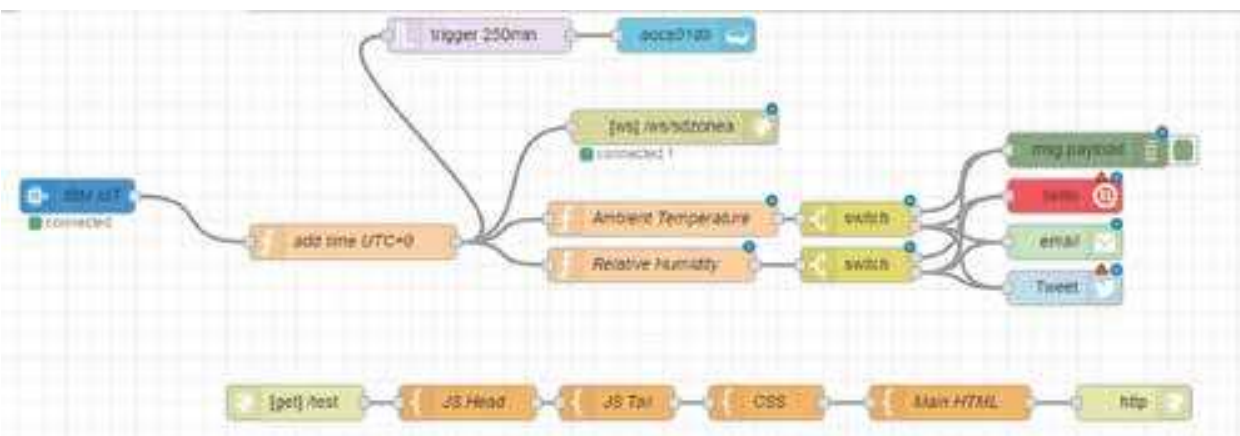

Figure 4.

System development in IBM Cloud.

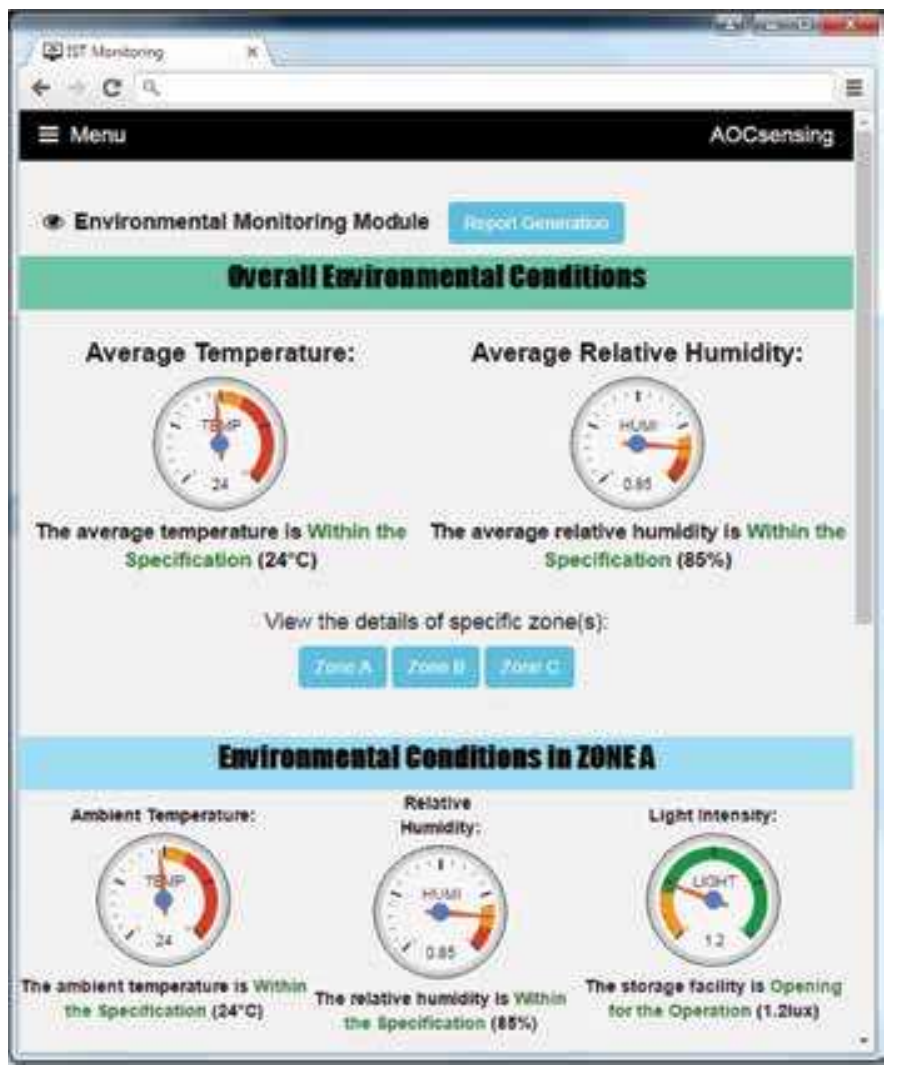

Figure 5.

User interface of IQPS.

Starter," which consists of a standard development kit (SDK) for Node.js, Cloudant NoSQL database, and Internet of Things platform, is used. First and foremost, the sensor nodes are required to register in the Internet of Things platform with returning the authentication and configuration information. The sensor nodes can be connected to the Internet of Things platform by setting the configuration information in the relay nodes using IoT-registered services. After successfully connecting the sensor nodes, the system development is done in the Node-RED platform, including environmental monitoring, alert management, reporting, user interface development, and quality deviation analysis. Figure 4 shows the entire system development to achieve all the 
above functionalities. The node IBM IoT is the input from the sensor nodes where the data is transmitted in the format of JavaScript Object Notation (JSON). The data can be stored in the Cloudant NoSQL database effectively for further messaging and querying functions. In addition, a rule-based mechanism can be set to detect any violation of the collected data by comparing with the specifications. If there is a violation in either temperature or humidity, it will activate the services of Twilio, email, and tweet to alert supervisors and managers via SMS, email, and Twitter. Therefore, such alerts are transparent to all the corresponding parties. These functions are limited to a certain number of stakeholders with controlling security settings and system environment variables in the Node-RED platform, and therefore the leakage of personal information can be prevented. In addition, an add-on system monitoring plug-in is used to keep track of the IPs of access and usage of Internet traffic.

On the other hand, the collected data can be sent to a web application by using WebSocket, i.e., /ws/sdzonea in the proposed system. Figure 5 shows the user interface for displaying the collected data in a user-friendly manner. All the stakeholders, including supervisors, managers, and customers, can gain access right to the web application for checking the environmental conditions at specific zones.

In the third milestone, the fuzzy logic approach is implemented in the case company so as to predict the product quality in the electronic manufacturing process. Under the Python programming environment, skfuzzy 0.2, which is the Python module of fuzzy logic approach, is applied where the fuzzification, Mamdani's inference, and defuzzification are included. First of all, the maximum and minimum values of attributes are defined in advance. The membership function of input and output attributes in the triangular shape are presented by fuzz.trimf(attribute name, $[\mathrm{x} 1, \mathrm{x} 2, \mathrm{x} 3])$, where $[\mathrm{x} 1, \mathrm{x} 2, \mathrm{x} 3]$ represents the

\begin{tabular}{|c|c|c|c|}
\hline Attributes & Range & Fuzzy class & $\begin{array}{l}\text { Membership } \\
\text { function }\end{array}$ \\
\hline \multicolumn{4}{|l|}{ Input attributes [Abbr.] (Unit) } \\
\hline \multirow[t]{3}{*}{ Ambient temperature $[\mathrm{AT}]\left({ }^{\circ} \mathrm{C}\right)$} & \multirow[t]{3}{*}[10,35]{} & Low & {$[10,15,20]$} \\
\hline & & Medium & {$[15,20,25,30]$} \\
\hline & & High & {$[25,30,35]$} \\
\hline \multirow[t]{3}{*}{ Relative humidity $[\mathrm{RH}](\%)$} & \multirow[t]{3}{*}[0,1]{} & Low & {$[0,0.1,0.2]$} \\
\hline & & Medium & {$[0.1,0.4,0.7]$} \\
\hline & & High & {$[0.4,0.7,1.0]$} \\
\hline \multirow[t]{3}{*}{ Workshop area $[\mathrm{WA}]\left(\mathrm{m}^{2}\right)$} & \multirow{3}{*}{$\begin{array}{l}{[100,} \\
5000]\end{array}$} & Small & {$[100,400,500]$} \\
\hline & & Medium & $\begin{array}{l}{[400,500,1500,} \\
2000]\end{array}$ \\
\hline & & Large & {$[1500,2000,5000]$} \\
\hline \multirow[t]{3}{*}{ Production rate [PR] (unit/hour) } & \multirow[t]{3}{*}[50,500]{} & Slow & {$[50,70,100]$} \\
\hline & & Medium & {$[70,100,270,300]$} \\
\hline & & Fast & {$[270,300,500]$} \\
\hline \multicolumn{4}{|l|}{ Output attributes } \\
\hline \multirow{2}{*}{$\begin{array}{l}\text { Percentage of major defects per batch } \\
{\left[\mathrm{MD}_{1}\right](\%)}\end{array}$} & \multirow[t]{4}{*}[0,1]{} & Low & {$[0,0.2,0.4]$} \\
\hline & & Medium & {$[0.2,0.4,0.6]$} \\
\hline \multirow{2}{*}{$\begin{array}{l}\text { Percentage of minor defects per batch } \\
{\left[\mathrm{MD}_{2}\right](\%)}\end{array}$} & & High & {$[0.4,0.6,0.8]$} \\
\hline & & Significantly high & {$[0.6,0.8,1]$} \\
\hline
\end{tabular}

Table 1.

Fuzzy logic specifications for input and output attributes. 


\begin{tabular}{llllll}
\hline Fuzzy inputs & & & \multicolumn{3}{l}{ Fuzzy outputs } \\
\hline AT & RH & WA & PR & MD1 & MD2 \\
\hline Low & Low & Small & Low & Low & Low \\
\hline Low & Low & Small & Medium & Low & Low \\
\hline$\vdots$ & $\vdots$ & $\vdots$ & $\vdots$ & $\vdots$ & $\vdots$ \\
\hline Low & Low & Medium & Medium & Low & Medium \\
\hline$\vdots$ & $\vdots$ & $\vdots$ & $\vdots$ & $\vdots$ & $\vdots$ \\
\hline Medium & Low & Medium & Medium & Medium & Medium \\
\hline Medium & Medium & Medium & Medium & Medium & Medium \\
\hline$\vdots$ & $\vdots$ & $\vdots$ & $\vdots$ & $\vdots$ & $\vdots$ \\
\hline High & Medium & Medium & Medium & Medium & High \\
\hline High & High & Large & Medium & High & Significantly high \\
\hline
\end{tabular}

Table 2.

Knowledge of fuzzy rules for manufacturing quality prediction.

vertexes of the triangular membership function. For the trapezoidal membership function, fuzz.trapmf(attribute name, $[\mathrm{x} 1, \mathrm{x} 2, \mathrm{x} 3, \mathrm{x} 4]$ ) is used, where $[\mathrm{x} 1, \mathrm{x} 2, \mathrm{x} 3, \mathrm{x} 4]$ represents the vertexes of the trapezoidal shape. After that, the fuzzy rules stored in the knowledge repository is controlled by using ctrl. Rule(antecedent, consequence) and ctrl.ControlSystem([rule1, rule2 ... rulen]). Consequently, when the values of the input attributes are input properly, the fuzzy logic engine is then able to estimate the values of the output attributes. Table 1 shows the range and membership function of the attributes for the fuzzy logic approach.

Moreover, the fuzzy rules for the Mamdani's inference is collected from domain experts and summarized as Table 2. The fuzzy rules, or core knowledge in the proposed system, are expressed by using the defined fuzzy classes in Table 1 . They are stored in knowledge repository and activated when the input parameters match the antecedents of the rules. The quality and quantity of stored knowledge determine the quality and accuracy of the results in quality prediction.

\section{Results and discussion}

This chapter presents IQPS for formulating a real-time environmental monitoring and quality prediction system for managing the environmental conditions and manufacturing process in electronic manufacturing sites with the adoption of advanced IoT technologies. According to the implementation of IQPS in Innovation Sound Technology Co. Ltd., routine work regarding regularly recording and checking the environmental conditions by using data loggers can be eliminated. All the relevant parties can access and view the environmental conditions for all the zones in a web application, and the site supervisors and managers can receive an alert message via either SMS, email, or Twitter, when any violation of environmental specifications occur. Besides, all the collected data is stored in a cloud database such that this can be used to generate a report about the workshop's environmental condition with a defined timeframe. On the other hand, the results of the quality prediction in manufacturing process by means of fuzzy logic approach are shown in Table 3. Five processing workshops are 
Harnessing IoT Data and Knowledge in Smart Manufacturing

DOI: http://dx.doi.org/10.5772/intechopen.86293

\begin{tabular}{lcccccc}
\hline Workshop & AT & RH & WA & PR & MD1 & MD2 \\
\hline 1 & 25 & 0.55 & 1000 & 210 & 0.06 & 0.11 \\
\hline 2 & 23 & 0.58 & 850 & 180 & 0.01 & 0.05 \\
\hline 3 & 29 & 0.66 & 1650 & 480 & 0.12 & 0.20 \\
\hline 4 & 26 & 0.49 & 600 & 200 & 0.01 & 0.03 \\
\hline 5 & 26 & 0.52 & 1500 & 480 & 0.09 & 0.31 \\
\hline
\end{tabular}

Table 3.

Results of fuzzy logic approach.

\begin{tabular}{lcc}
\hline Parameters & Before implementing IQPS & After implementing IQPS \\
\hline Average \% of quality defects & & \\
\hline • Major quality defects & 0.11 & 0.07 \\
\hline - Minor quality defects & 0.19 & 0.12 \\
\hline QM staff satisfaction (scale of 1-10) & 6.8 & 7.9 \\
\hline Average production yield rate & $98.5 \%$ & $99.1 \%$ \\
\hline Time for environmental monitoring & 1 hr./day & Real-time \\
\hline
\end{tabular}

Table 4.

Comparative analysis before and after implementing IQPS.

selected to conduct the inspection to investigate the quality performance during the manufacturing process. Through the proposed system, the environmental conditions and quality performance can be visualized for all the staff involved in the electronic manufacturing process. The high percentage of estimated defects can be an indicator to the line supervisors and manager to adjust the operations and other manufacturing processes.

Through implementing the IQPS, the expert knowledge is constructed in the form of the if-then rules to generate expected quality defects in electronic manufacturing operations. The results can be used to evaluate the system effectiveness, and a survey is conducted to compare the performance and satisfaction before and after implementing the proposed system in the case company. Table 4 shows the findings of the comparative analysis for implementing IQPS in the case company. It demonstrates a positive impact on reduction of average quality defects and improvements in quality management staff satisfaction and average production yield rate. Also, the environmental monitoring is done by IoT technologies instead of the manual recording approach. Thus, the time for recording environmental conditions manually can be minimized.

As a consequence, two advantages can be gained after implementing the proposed system, namely, (i) better visibility of environmental conditions in the manufacturing sites and (ii) systematic approach to analyze the relationship between quality deviation and ambient factors. Firstly, since the regular recording and checking of environmental conditions are not the core business in electronic manufacturing sites, the time taken for these tasks is regarded as wasteful and redundant. Through adopting the IQPS, the operators don't need to keep recording and checking data regularly, such that they pay more attention to the electronic production. In addition, the proposed system also gives a better visibility regarding environmental conditions for all the stakeholders as the data can be accessed in a simple web application. Secondly, as a report on environmental factors in various 
workshops can be generated, managers are able to conduct an analysis to investigate the relationship between quality deviation and ambient environmental factors. Incidents on quality deviation, including major and minor defects in production, are of great concern, and management aims at minimizing all possible causes of product defects. The above analysis is helpful to the management level to predict future quality deviation and to improve the existing manufacturing facilities.

\section{Conclusions}

Due to increasing demand and higher-quality level of electronic products all over the world, attention on quality improvement and monitoring has attracted considerable attention in the research field of electronic manufacturing. In manufacturing sites, there are numerous workshops and facilities for producing the electronic products, such as laboratory and assembly lines, but the requirements for environmental conditions in workshops vary according to the technical specifications. In order to ensure that the environmental conditions inside the manufacturing site are met, an environmental monitoring system is needed, but the traditional approach, which relies on data loggers and manual recording, is ineffective. With the rapid growth of IoT in recent years, the environmental monitoring system can be integrated with advanced IoT technologies. However, only replying on advanced technologies cannot develop and deploy the practical and mission-critical systems for the companies. Knowledge-based approach is considered in providing the systematic framework for the system development and performance measurement. Apart from that, the knowledge and information from the companies can be managed in the knowledge repository to enhance the computing systems by mimicking human thinking and logic. This chapter proposes an Internet of Things quality prediction system (IQPS) where SensorTag CC2650 is used to collect the environmental data and to transmit the data through wireless communication protocols to the cloud services. The sensor nodes and relay nodes are deployed by satisfying the target coverage and sensor node connectivity and are registered in the IBM Cloud so as to develop a customized system in the Node-RED platform. All the collected data is stored in the Cloudant NoSQL database with complete messaging and querying functions. With the adoption of IQPS, the manual recording and checking work can be eliminated, and automatic environmental monitoring and alert management can be provided. In view of the managerial perspectives, IQPS not only provides the real-time environmental monitoring inside manufacturing sites but also can be applied to investigate relationships between quality deviation and ambient environmental conditions. The fuzzy logic is thus applied in this situation for predicting the product quality along the entire manufacturing process. The expert knowledge stored in knowledge repository is extracted for the use of inference engine, and thus the proposed system can reflect the on-site relationship between input and output attributes in quality assurance. The possibility of major and minor defects per order batch can be estimated and visualized, and the workshop supervisors and managers are able to take any control actions to maintain the product quality at an appropriate level. Therefore, the visibility of environmental conditions inside manufacturing sites can be enhanced, while the quality deviation can be predicted and reduced.

\section{Acknowledgements}

The authors would like to thank the Faculty of Engineering of the Hong Kong Polytechnic University through the engineering doctorate program for supporting this project. 


\section{Author details}

Joseph Shun Ming Yuen, King Lun Choy*, Yung Po Tsang and Hoi Yan Lam Department of Industrial and Systems Engineering, The Hong Kong Polytechnic University, Hung Hom, Hong Kong

*Address all correspondence to: kl.choy@polyu.edu.hk

\section{IntechOpen}

(C) 2020 The Author(s). Licensee IntechOpen. Distributed under the terms of the Creative Commons Attribution - NonCommercial 4.0 License (https://creativecommons.org/ licenses/by-nc/4.0/), which permits use, distribution and reproduction for non-commercial purposes, provided the original is properly cited. (cc) BY-NC 


\section{References}

[1] Holbrook MB. Product quality, attributes, and brand name as determinants of price: The case of consumer electronics. Marketing Letters. 1992;3(1):71-83

[2] Mason SJ, Cole MH, Ulrey BT, Yan L. Improving electronics manufacturing supply chain agility through outsourcing. International Journal of Physical Distribution and Logistics Management. 2002;32(7):610-620

[3] Lau JH, Wong CP, Lee NC, Lee SR. Electronics Manufacturing: With LeadFree, Halogen-Free, and ConductiveAdhesive Materials. New York: McGraw-Hill, Inc; 2003

[4] Landers TL, Brown WD, Fant E, Malstrom EM, Schmitt NM. Electronics Manufacturing Processes. New Jersey: Prentice Hall; 1994

[5] Stark J. Product lifecycle management. In: Product Lifecycle Management. Vol.

1. Cham: Springer; 2015. pp. 1-29

[6] Salgado EG, Salomon VA, Mello CH. Analytic hierarchy prioritisation of new product development activities for electronics manufacturing. International Journal of Production Research. 2012;50(17):4860-4866

[7] Helander MG, Burri GJ. Cost effectiveness of ergonomics and quality improvements in electronics manufacturing. International Journal of Industrial Ergonomics. 1995;15(2):137-151

[8] Abbel R, Teunissen P, Rubingh E, van Lammeren T, Cauchois R, Everaars $M$, et al. Industrial-scale inkjet printed electronics manufacturing-Production up-scaling from concept tools to a rollto-roll pilot line. Translational Materials Research. 2014;1(1):015002

[9] Doniavi A, Mileham AR, Newnes LB. A systems approach to photolithography process optimization in an electronics manufacturing environment. International Journal of Production Research. 2000;38(11):2515-2528

[10] Gupta AK, Sivakumar AI. Job shop scheduling techniques in semiconductor manufacturing. The International Journal of Advanced Manufacturing Technology. 2006;27(11-12):1163-1169

[11] Abdulmalek FA, Rajgopal J. Analyzing the benefits of lean manufacturing and value stream mapping via simulation: A process sector case study. International Journal of Production Economics. 2007;107(1):223-236

[12] Lee J, Bagheri B, Kao HA. A cyberphysical systems architecture for industry 4.0-based manufacturing systems. Manufacturing Letters. 2015;3:18-23

[13] Rubenstein-Montano B, Liebowitz J, Buchwalter J, McCaw D, Newman B, Rebeck K, et al. A systems thinking framework for knowledge management. Decision Support Systems.

2001;31(1):5-16

[14] Inkinen H. Review of empirical research on knowledge management practices and firm performance. Journal of Knowledge Management. 2016;20(2):230-257

[15] An X, Bai W, Deng H, Sun S, Zhong W, Dong Y. A knowledge management framework for effective integration of national archives resources in China. Journal of Documentation. 2017;73(1):18-34

[16] Dehghani R, Ramsin R. Methodologies for developing knowledge management systems: An evaluation framework. Journal of Knowledge Management. 2015;19(4):682-710 
[17] Davis J, Edgar T, Porter J, Bernaden J, Sarli M. Smart manufacturing, manufacturing intelligence and demand-dynamic performance. Computers and Chemical Engineering. 2012;47:145-156

[18] Papazoglou MP, Elgammal A. The manufacturing blueprint environment: Bringing intelligence into manufacturing. In: International Conference on Engineering, Technology and Innovation, ICE/ITMC. 27-29 June 2017. Madeira: IEEE; 2017

[19] Papazoglou M, van den Heuvel WJ, Mascolo J. Reference architecture and knowledge-based structures for smart manufacturing networks. IEEE Software. 2015. DOI: 10.1109/ MS.2015.57

[20] Wortmann F, Flüchter K. Internet of Things. Business and Information Systems Engineering. 2015;57(3):221-224

[21] Al-Fuqaha A, Guizani M, Mohammadi M, Aledhari M, Ayyash M. Internet of Things: A survey on enabling technologies, protocols, and applications. IEEE Communications Surveys and Tutorials. 2015;17(4):2347-2376

[22] Porter ME, Heppelmann JE. How smart, connected products are transforming competition. Harvard Business Review. 2014;92(11):64-88

[23] Da Xu L, He W, Li S. Internet of Things in industries: A survey. IEEE Transactions on Industrial Informatics. 2014;10(4):2233-2243

[24] Pang Z, Chen Q, Tian J, Zheng L, Dubrova E. Ecosystem analysis in the design of open platform-based in-home healthcare terminals towards the internet-of-things. In: 2013 15th International Conference on Advanced Communication Technology (ICACT). IEEE; 2013. pp. 529-534
[25] Tsang YP, Choy KL, Wu CH, Ho GTS, Lam HY, Tang V. An intelligent model for assuring food quality in managing a multi-temperature food distribution centre. Food Control. 2018;90:81-97

[26] Qiuping W, Shunbing Z, Chunquan D. Study on key technologies of Internet of Things perceiving mine. Procedia Engineering. 2011;26:2326-2333

[27] Tsang YP, Choy KL, Wu CH, Ho GTS, Lam HY, Koo PS. An IoT-based cargo monitoring system for enhancing operational effectiveness under a cold chain environment. International Journal of Engineering Business Management. 2017;9:1-13

[28] Klir GJ, Yuan B. Fuzzy Sets and Fuzzy Logic: Theory and Applications. New Jersey: Prentice Hall PTR; 1995

[29] Choy KLT, Siu KYP, Ho TSG, Wu CH, Lam HY, Tang V, et al. An intelligent case-based knowledge management system for quality improvement in nursing homes. VINE Journal of Information and Knowledge Management Systems. 2018;48(1):103-121

[30] Guo XM, Zhao CJ, Yang XT, Sun C, Li M, Li W, et al. A deterministic sensor node deployment method with target coverage based on grid scan. Chinese Journal of Sensors and Actuators. 2012;25(1):104-109 


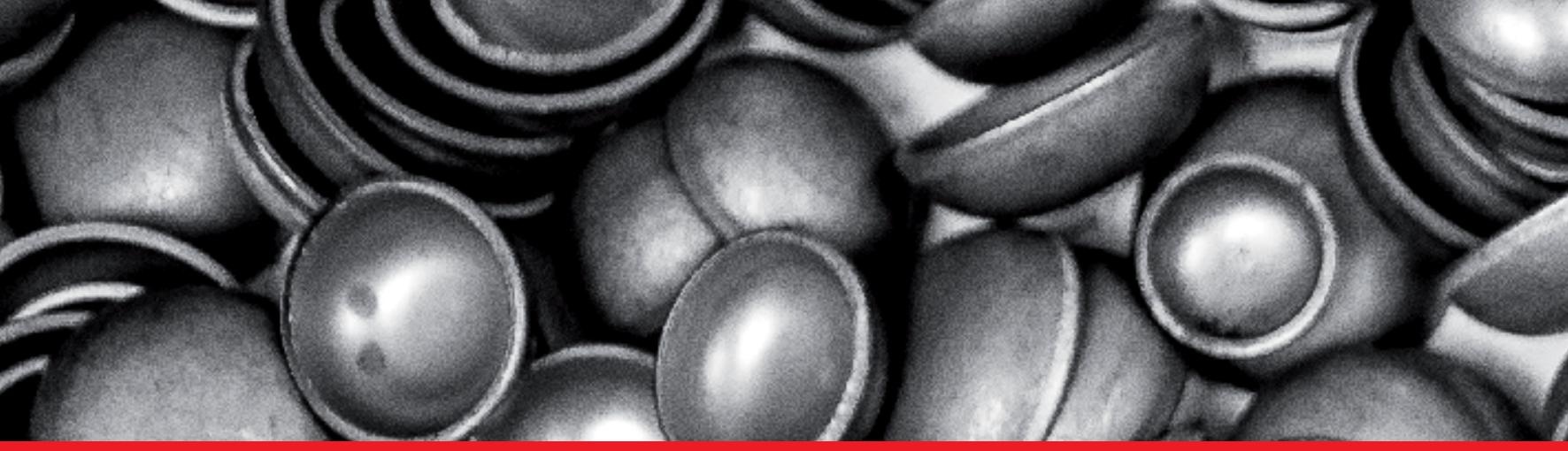

\section{Edited by Ali G. Hessami}

This book explores the critical role of acquisition, application, enhancement, and management of knowledge and human competence in the context of the largely digital and data/information dominated modern world. Whilst humanity owes much of its achievements to the distinct capability to learn from observation, analyse data, gain insights, and perceive beyond original realities, the systematic treatment of knowledge as a core capability and driver of success has largely remained the forte of pedagogy. In an increasingly intertwined global community faced with existential challenges and risks, the significance of knowledge creation, innovation, and systematic understanding and treatment of human competence is likely to be humanity's greatest weapon against adversity. This book was conceived to inform the decision makers and practitioners about the best practice pertinent to many disciplines and sectors. The chapters fall into three broad categories to guide the readers to gain insight from generic fundamentals to discipline-specific case studies and of the latest practice in knowledge and competence management.

Published in London, UK

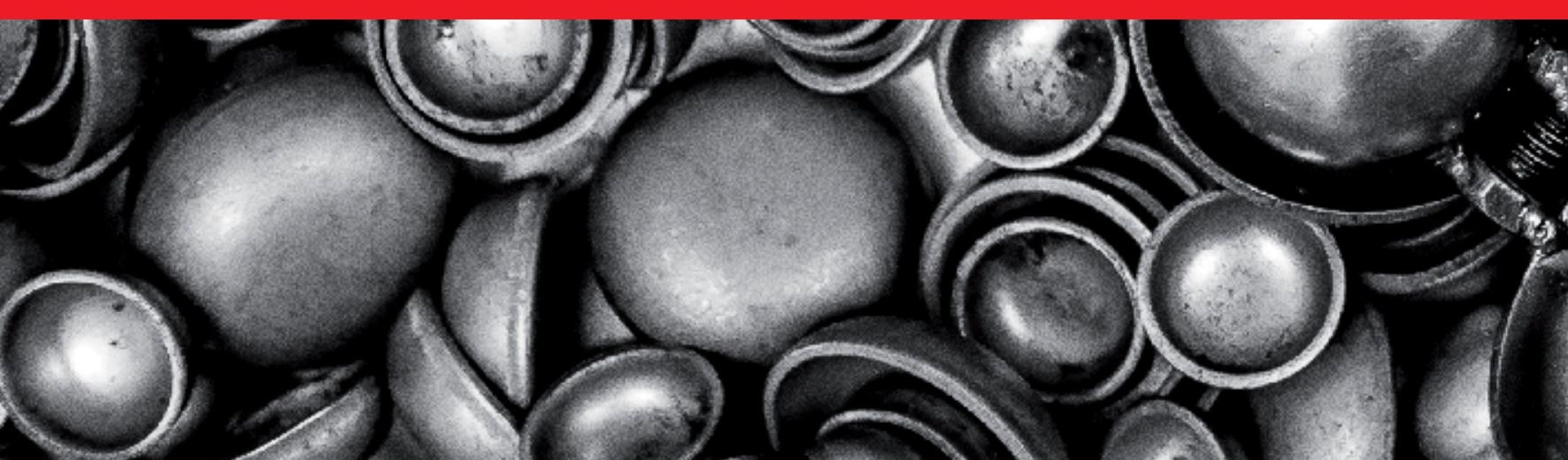

